Portland State University

PDXScholar

3-10-2021

\title{
An Analysis of Suspended Sediment Dynamics in a Partially Mixed Estuary
}

Riyadh Hamad Muttaleb

Portland State University

Follow this and additional works at: https://pdxscholar.library.pdx.edu/open_access_etds

Part of the Civil and Environmental Engineering Commons, and the Sedimentology Commons Let us know how access to this document benefits you.

\section{Recommended Citation}

Muttaleb, Riyadh Hamad, "An Analysis of Suspended Sediment Dynamics in a Partially Mixed Estuary" (2021). Dissertations and Theses. Paper 5656.

https://doi.org/10.15760/etd.7528

This Dissertation is brought to you for free and open access. It has been accepted for inclusion in Dissertations and Theses by an authorized administrator of PDXScholar. Please contact us if we can make this document more accessible: pdxscholar@pdx.edu. 
An Analysis of Suspended Sediment Dynamics in a

Partially Mixed Estuary

by

Riyadh Hamad Muttaleb

A dissertation submitted in partial fulfillment of the requirements for the degree of

\author{
Doctor of Philosophy \\ in \\ Civil and Environmental Engineering
}

\author{
Dissertation Committee: \\ David Jay, Chair \\ David Schoellhamer \\ Annette Dietz \\ Stefan Talke \\ Gerald Recktenwald
}

Portland State University

2021 


\begin{abstract}
The purpose of this work is to investigate via data analysis and numerical modeling the SPM (suspended particulate matter) dynamics of a heavily contaminated partially urban estuary, the Lower Passaic River estuary (LPR), NJ. Accordingly, I investigate the quantity and mechanics of variation of fine and coarse SPM in the LPR via data analysis. Data analysis focuses on the parameters that affect SPM dynamics at six moored stations occupied during the Fall and Spring seasons, from near the estuary mouth to tidal freshwater. A 3D hydrodynamic model (Delft3D-FM) is used to analyze the effects of estuary topography on the dynamic distribution of bed shear stress, $\tau_{b}$, and to interpret the observations. Moored data from a station seaward of the LPR are used to for model calibration.
\end{abstract}

This work will address three primary issues. The first is to determine bulk settling velocity $\left(w_{s b}\right)$ values and the factors that affect $w_{s b}$ along the estuarine salinity gradient. The second is to determine the quantity of fine and coarse SPM throughout the water column distributed in Rouse-like and Modified-Rouse profiles, and to (a): investigate the dynamical importance of advection in influencing SPM profile structure for fine and coarse SPM, and (b) determine how the SPM concentration varies with particle size, river flow, and tidal range. These two issues are analyzed using acoustic Doppler current profiler (ADCP) data. An ADCP provides simultaneous profiles of velocity and acoustic backscatter (ABS); the ABS signal can be converted to SPM concentration using appropriate calibration data. Finally, Delft3D-FM was set up on a grid of a generic, 
convergent estuary similar to the LPR. This grid was used to investigate how oceanographic factors (e.g., channel curvature and tidal range to depth ratio), natural and man-made roughness elements (e.g., grains, meanders, and bridge pilings), and external forcing by river inflow influence the distribution of bed shear stress in a stratified estuary similar to the LPR.

To investigate the behavior of bulk settling velocity $w_{s b}$ (the first question), friction velocity $\left(\mathrm{u}_{*}\right)$ estimated from the ADCP velocity profile taking into consideration the effect of density stratification due to salinity intrusion. A log-linear velocity equation used when the water column stratified, and a logarithmic velocity profile used to estimate shear velocities, $\mathrm{u}_{*}$ for unstratified conditions. Suspended sediment concentration, SSC, was estimated from ADCP acoustic backscatter (ABS) and calibrated against gravimetric SSC samples. Time series of profiles of flow velocity and SSC, and shear velocities used to calculate time series of $w_{s b}$ via a least-squares analysis that fit a theoretical SSC profile to the ADCP-derived SSC values. Analysis of the resulting time and space distributions of $w_{s b}$ shows that the mean $w_{s b}$ decreases landward. In addition, $w_{s b}$ mainly correlated with Simpson Number (Si, defined in Section 4) in brackish waters, while it primarily correlated with flow velocity in tidal freshwater. Greater diurnal tidal range, $T R$, and river flow, $Q_{R}$, were secondary factors throughout the system.

Investigating the second question (the different behaviors of fine and coarse material) involves making use of defined settling velocity values, the $w_{s i}$, to fit observed SPM profiles. These following values were chosen: $0.05 \mathrm{~mm} / \mathrm{s}$ to represent the fines (wash 
load to medium silt) at all stations, and $10 \mathrm{~mm} / \mathrm{s}$ for River Mile (RM) 1.4 and 4.2 and 7 $\mathrm{mm} / \mathrm{s}$ for $\mathrm{RM}$ 6.7, 10.2, and 13.5 to represent the coarser load (fine sand above salinity intrusion and aggregate in the salinity intruded part of the system). A Rouse profile is then assumed for each of the two SSC components, and a non-negative least square regression is applied to calculate the profiles of fine and coarse components in terms of a reference concentration for each component at the base of the profile.

The results show a significant ability to describe observed SSC profiles, especially when the profiles are Rouse-like. For other periods, the results showed a good match to the observed SSC profiles when modified Rouse profiles have used that account for the effects of advection on the SSC profiles during periods of strong currents. Also, $Q_{R}, T R$, and horizontal advection are the dominant hydrodynamic factors controlling the variability of fine and coarse SSC, though settling-resuspension processes (not quantified here) are also likely important. The percentage of coarse suspended particles near the estuary mouth is greater than in low-salinity areas and freshwater by $\sim 60 \%$ in Fall and $\sim 80 \%$ in Spring. This is likely related to aggregation of fines in the moderate salinity waters near the LPR mouth. Furthermore, SSC responded directly to change in velocity; thus, the variation of fine and coarse particles is largely in phase with velocity.

The third question, the question of the effects of channel topography and oceanographic factors like stratification and $\frac{\partial \rho}{\partial x}$ on shear bed stress, will be addressed using a 3D (three-dimensional) grid with the hydrodynamic model Delft3D-FM. The model runs will represent plausible projections of the effect of the roughness elements (from grains 
roughness, meanders, and bridge pilings) together with tidal range to depth ratio, vertical density gradients, and river flow on the distribution of bed shear stress.

The LPR is an urban estuary with many bridges -25 below the head of the tide. Not surprisingly, model results have shown a significant influence of these bridge piers (acting as large roughness elements) on $\tau_{b}$, stratification and salinity intrusion. Model results show that $\tau_{b}$ is highest around the bridge's piers and outer sides of the curvatures. Modeled $\tau_{b}$ is higher upstream near the head of the tide for high flows than low flows, and with rough bed (Chezy 50-30) than the smoother bed (Chezy 70-50). Moreover, more erosion (as inferred from $\tau_{b}$ distributions) took place on spring-tide ebbs during high flow periods, but on spring-tide floods during low flow periods. Modeled salinity contours move farther landward without bridge piers and lower bed roughness (higher Chezy number) due to reduced vertical mixing. Also, vertical salinity stratification is affected by bridge piers and river flow. The modeled occurrence of stable stratification was reduced during lowflows in the LPR model with piers, while stable stratification occurred prominently near the estuary with/without piers and with high flow. Unstable stratification occurred farther landward direction. 


\section{Acknowledgments}

I would like to thank the Ministry of Higher Education and Scientific Research (MOHESR) in Iraq for funding this research. Also, I wish to express my sincere appreciation and gratitude to my advisor, Professor David Jay, for his continuous guidance and support. I would like to thank you very much for your support and understanding over these past five years.

I would also like to show gratitude to my committee, Dr. David Schoellhamer, Dr. Annette Dietz, Dr. Stefan Talke, and Dr. Gerald Recktenwald. Special thanks to the staff of the Civil and Environmental Engineering Department at Portland State University for their kindness and assistance. Also, I would thank my friend, Aqeel Al Bahadily, for his outstanding support. Finally, I wish to acknowledge the support and great love of my family, my wife, my two lovely daughters, and my lovely son. 


\section{Table of Contents}

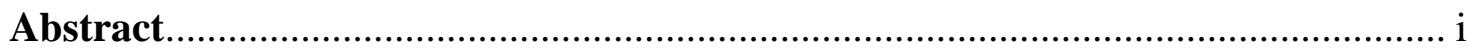

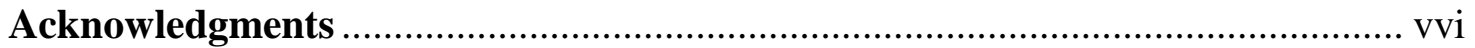

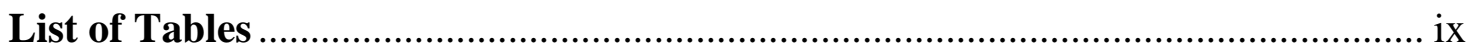

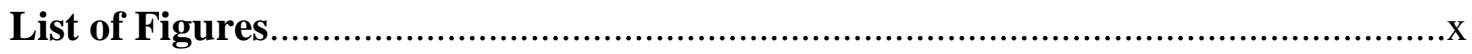

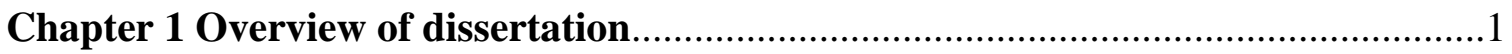

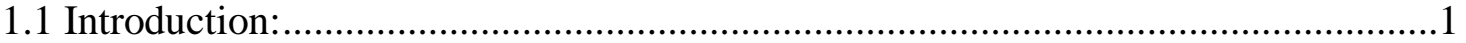

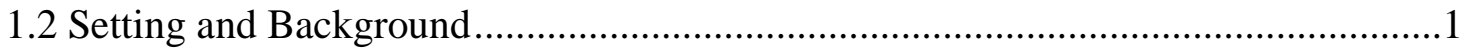

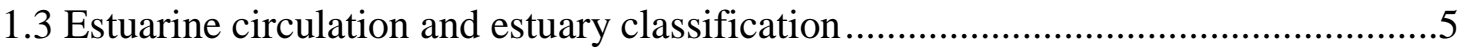

1.4 Salinity intrusion and stratification ...............................................................

1.5 Suspended particular matter dynamic and settling velocity ...............................11

1.6 SPM measurement methods (acoustical and optical) ........................................15

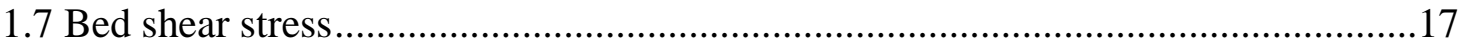

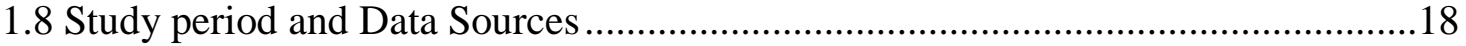

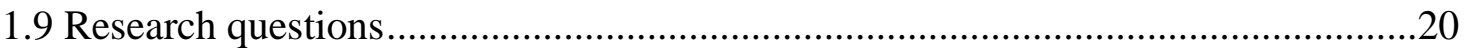

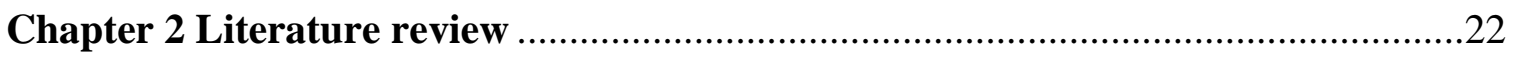

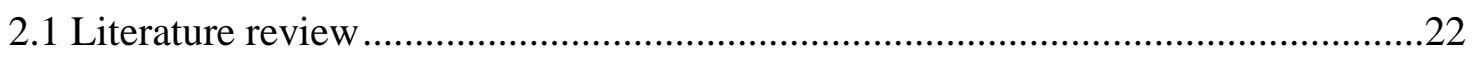

2.2 Suspended sediment transport and turbidity maxima in estuaries .........................22

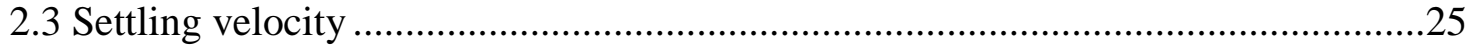

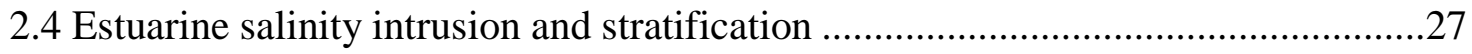

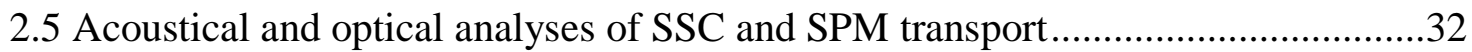

2.6 Bed shear stress variability with the oceanographic factors ................................34

Chapter 3 Settling Velocity variation into the Lower Passaic River Estuary ............37

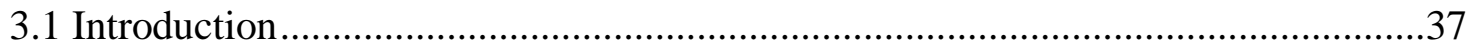

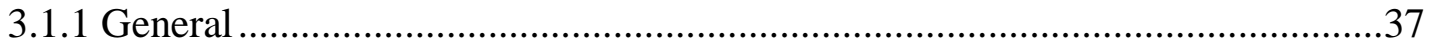

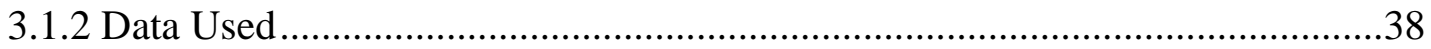

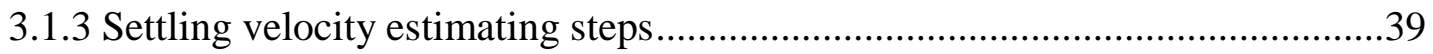

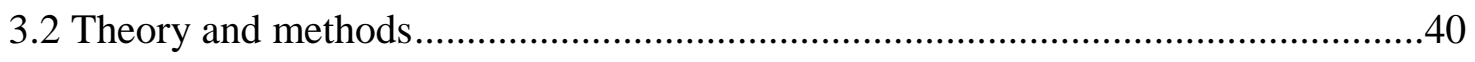

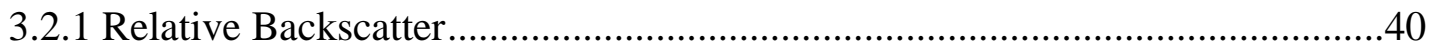

3.2.2 Bed stress and stratification effects on bed stress ........................................45 


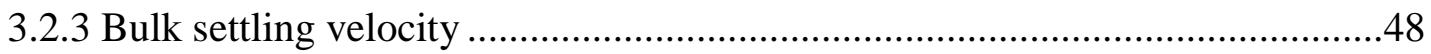

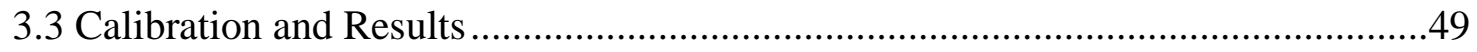

3.3.1 Importance of parameters in controlling settling velocity .................................55

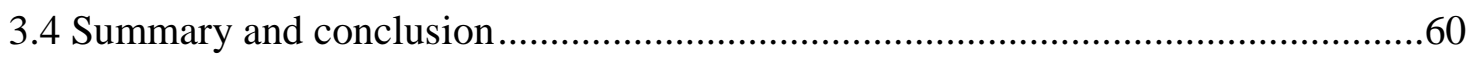

Chapter 4 Suspended sediment variation in the Lower Passaic River .......................63

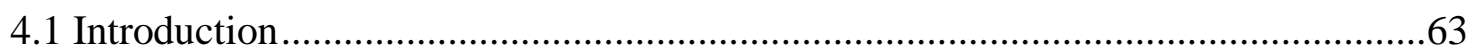

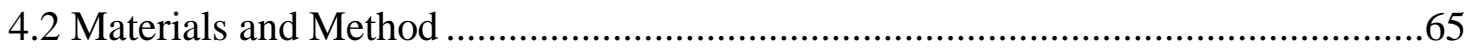

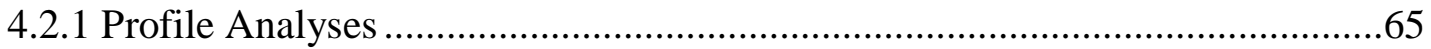

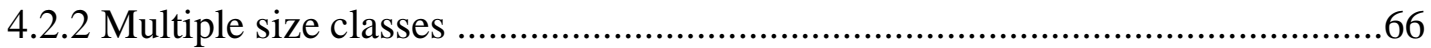

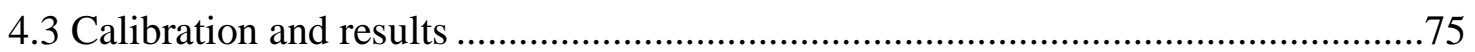

4.3.1 Importance of advection in controlling Rouse profiles....................................75

4.3.2 Importance of advection in controlling the variability of surface/bottom SSC 78

4.4 Control SSC by advection and erosion/deposition ................................................87

4.5 Dynamical variations of SSC and sediment transport ........................................90

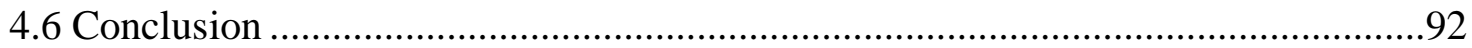

Chapter 5 Bed shear stress variation around bridge piers …………………….......94

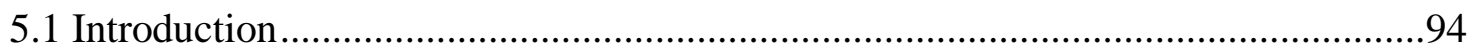

5.2 Bed shear stress modeling ..........................................................................98

5.3 Boundary conditions and model validation ………................................................100

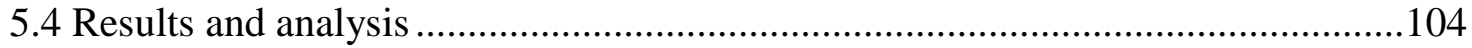

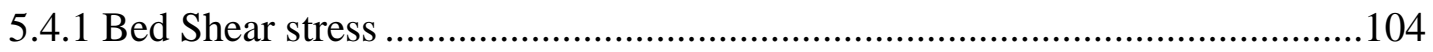

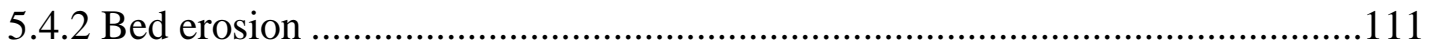

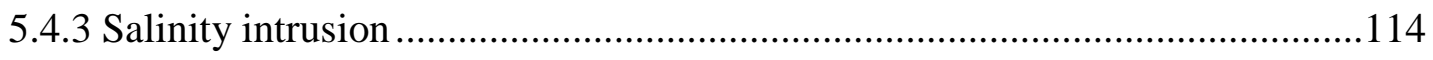

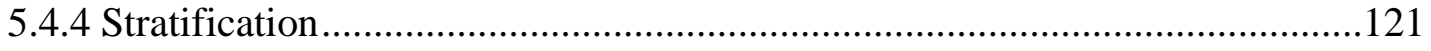

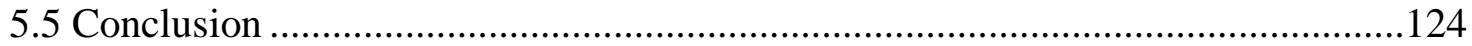

Chapter 6 Summary and Conclusion ...................................................................127

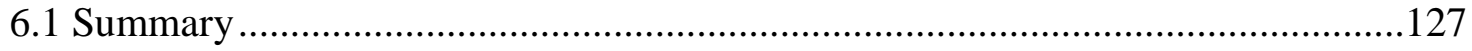

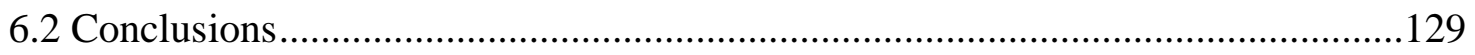

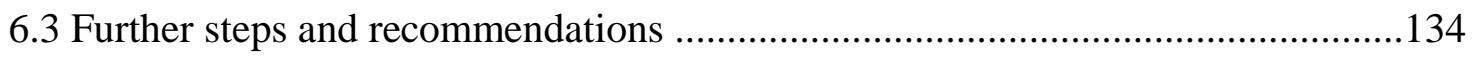

6.4 The implications on other systems.....................................................................134 


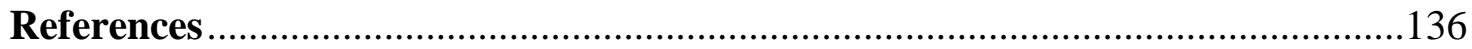

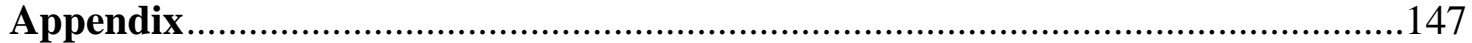




\section{List of Tables}

Table 1-1. First bin distance from the face of the transducer ....................................... 19

Table 3-1. Correlation coefficients $\mathrm{R}^{2}$ and the constants of the multiple linear regression

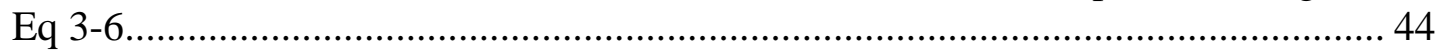

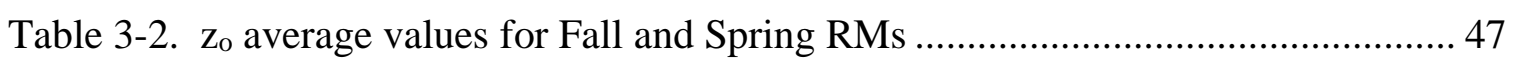

Table 3-3. Mean, median, $25^{\text {th }}$, and $75^{\text {th }}$ settling velocity in $\mathrm{m} / \mathrm{s}$ for Fall and Spring RMs

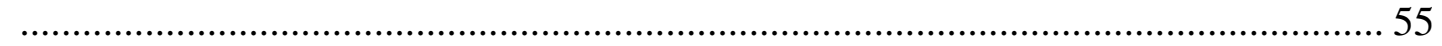

Table 3-4. Correlation coefficients and $\mathrm{n}$ values for fall and spring RM ..................... 57

Table 4-1. The percentage of Modified-Rouse Profiles............................................... 76

Table 4-2. R2 between A vs. N_u, N_TR, and N_f.................................................... 86

Table 4-3. mean fine and coarse classes near the surface and bottom.......................... 91

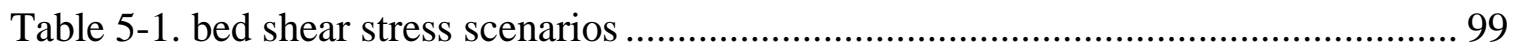

Table 5-2. R $\mathrm{R}^{2}$ of WL and Salinity (Top-Bottom) at LPR .......................................... 104

Table 5-3. The fraction of the erosion points between RKm 5.75 and 9 ...................... 112

Table 5-4.The maximum $\tau$ b around bridge 7 and at RKm 7.7 without bridges ............ 113

Table 5-5: $\mathrm{n}$ values at low and high flow, and with/without bridges piers ................... 115

Table 5-6. 2-psu (X2) for salinity intrusion in the LPR at a- low flow b- High flow.... 116 


\section{List of Figures}

Figure 1-1: Site Map of the In-Situ ADCP instruments (Environmental Protection Agency, 2014) 3

Figure 1-2. Estuarine classification, Coastal plain estuaries are formed via sea-level rise, A Fjord has a deep channel with a sill, and a Bar-Built estuary has a break-point bar between ocean and estuary. A Salt wedge has a well-defined near-bed salty layer separated from the upper freshwater layer by a sharp pycnocline. A highly stratified estuary is associated with high river flow and may have strong tides, while a Partially Mixed estuary occurs with a smaller river flow to tidal prism ratio. A weakly stratified estuary is associated with strong tides and/or a weak river prism ratio. Adapted from Dyer (1973) 7

Figure 1-3. Along-Estuary distribution of stratification with 1-psu salinity contour intervals; a-Neap tide, b-Spring tide, Hudson River Estuary (Ralston \& Geyer, 2019)

Figure 1-4(a,b). a-Typical distributions of SPM for diverse values of Rs: $1.2<$ coarse sand $<2.5,0.8<$ fine sand $<1.2$, and fine silt $<0.8$, coarse sand is concentrated near the bed and reduces with depth as faster as than do fine sand and fine silt, b- Similarly, the grain size distribution shows that coarser particles display more vertical variation than do the vertical distribution of grain size of fine sand and silt, (Hickin, 1995). 13

Figure 1-5. daily mean flow and water level of the LPR (Aug, 2009-July, 2010); the shadow

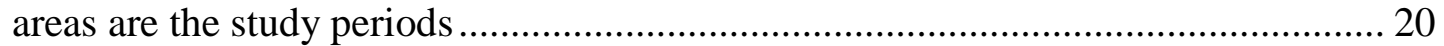

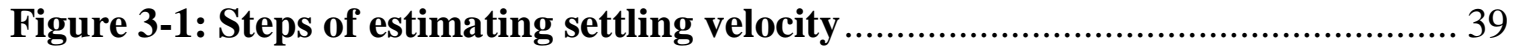

Figure 3-2. Time series of depth-resolved RB for fall and spring RM.......................... 42

Figure 3-3(a,b). Distribution of SSC in LPR a-Fall and b-Spring, the concentration close

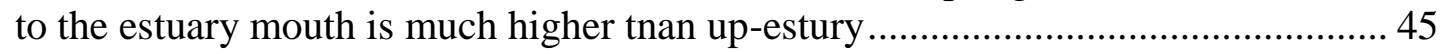

Figure 3-4 (a-b). time-series of Shear velocity distribution in Fall and Spring .............. 48

Figure 3-5. Distribution of Settling velocity in space and time ..................................... 52

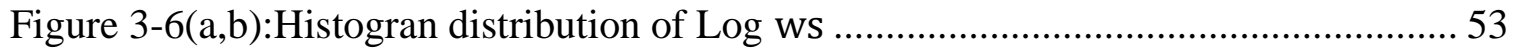

Figure $3-7.25^{\text {th }}, 50^{\text {th }}$, and $75^{\text {th }}$ of the time-series settling velocity .................................. 54

Figure 3-8(a, b). Examples of the variations of ws with flow and Si (near mouth; 1.4- 4.2), and with tidal velocity and river flow at upriver stations $(6.7,10.2$, and 13.5$) \ldots \ldots \ldots .59$

Figure 4-1 $(a, b)$. Histogram of $\mathrm{R}^{2}$ values for fitting of SSC for the Rouse-like profiles . 68

Figure 4-2(a,b). Examples of "Rouse-like" profilers of SSC distribution for each station

Figure 4-3(a,b). $\varepsilon$ ranges for fine and coarse SSC in Fall and Spring ......................... 71

Figure 4-4(a,b). R2 between Fitted and SSC for Modified-Rouse profiles .................... 72 
Figure 4-5(a,b). Examples of "Modified-Rous" profilers of SSC distribution for each RM 73

Figure 4-6 (a, b). Modified-Rouse profile periods with (green dots) due to the effect of the

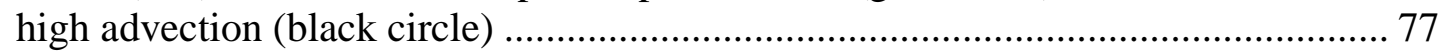

Figure 4-7 $(\mathrm{a}, \mathrm{b})$. Variation of fine and coarse particles near the surface and bottom with

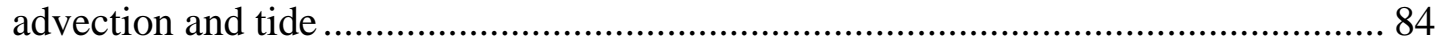

Figure 4-8. Average variation of fine and coarse particles with advection ..................... 89

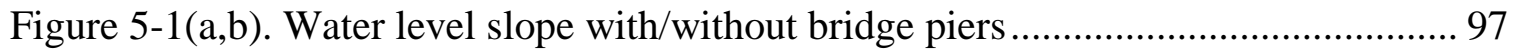

Figure 5-2. The plan view of the Newark Bay and LPR grid ..................................... 102

Figure 5-3 (a,b,c,d,e,f). Observed - Modeled water level; the blue the blue plot is the error

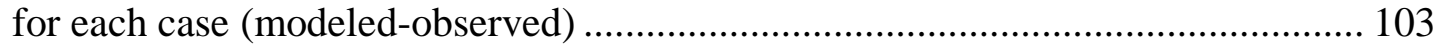

Figure 5-4 (a, b). Constituent analysis of observed vs. modeled, a-M4/M2 b-M2 ........ 103

Figure 5-5. Top and Bottom actual vs. modeled Salinity at NNB and RM 10.2 ........... 103

Figure 5-6. Velocity, salinity, and stratification development around bridges piers at downtown Newark. Flow is from right to left ...................................................... 105

Figure 5-7. Bed shear stress up/downstream bridges piers a- rough bed b- smooth bed 107

Figure 5-8. Variations of $\tau \mathrm{b}$ and the ratio of tidal range to the depth. ......................... 108

Figure 5-9. Times of spring- ebb plots in color maps ................................................. 109

Figure 5-10. Bed stress color map for five bridges piers in downtown Newark and the bend for different bed roughness a- Chezy (50 at Bay-River at 30) b- Chezy (70 at BayRiver at 50)

Figure 5-11. Bed stress color map without bridges piers for different bed roughness aChezy (50 at Bay-30 at River) b- Chezy (70 at Bay-50 at River) ........................ 111

Figure 5-12. Erosion color map showing the ratiotbtcr with bridges piers for different bed roughness a- Chezy (50 at Bay-River at 30) b- Chezy (70 at Bay-River at 50) ...... 114

Figure 5-13(a,b). Vertical salinity section for low flow, spring tide for ebb and flood conditions, with two different bed roughness; the white contour line refer to the $2 \mathrm{psu}$ isohaline. X-2 is the position of the 2 PSU contour near the bed. The red circles refer to the bridge's location, and the blue lines refer to the curvature location. ............. 120

Figure 5-14. The effect of the flow and piers on the stratification along LPR, stratification is the density differential between two riverine layers due to salinity and temperature differences or a combination of both. 123 


\section{Chapter 1 Overview of dissertation}

\subsection{Introduction:}

This chapter focuses on the system background for the Lower Passaic River (LPR) and general information about river estuaries and their importance. It begins with a brief description of the LPR and a history of the accumulation of contaminants in the system. Then important concepts necessary for understanding the research questions are explained. These include settling velocity, sediment transport, density stratification, bed shear stress, and the use of an acoustic backscatter sensor (ABS) to represent SPM concentration. The role of these concepts in motivating the research questions is discussed. Finally, the study period and data sources are described.

\subsection{Setting and Background}

The Passaic River and its estuary are located in northern New Jersey Figure 1-1. The Passaic River is approximately $128 \mathrm{~km}$ in length, with an average discharge of $40 \mathrm{~m} 3 / \mathrm{s}$. The Lower Passaic River estuary (LPR) extends $27.5 \mathrm{~km}$ from Dundee Dam in Garfield to Newark Bay, NJ. It has been severely degraded since the late 1700s because of industrial development and pollution (Iannuzzi \& Ludwig, 2004). The LPR is the site of a complex Superfund cleanup, and the contaminants found in the water column are mostly attached to fine suspended sediment and aggregates. Accordingly, it is important to distinguish the different behaviors of fines, aggregates, and other coarse materials. For this study, the LPR is divided into three zones (The Louis Berger Group \& Battelle, 2014): a) RM 0-8 is mesohaline with mostly mud sediments; b) RM 8-13 has low salinities and mixed fine and 
coarse sediment and is fresh during high flows, and c) RM 13-17.5 is micro-tidal with zero or near-zero salinity.

The United States Environmental Protection Agency has defined Eight Contaminants of Concerns (CoCs) in the LPR: lead, mercury, PCBs, PAHs, pesticides, Chlordane, copper, and 2,3,7,8- Tetrachlorodibenzo-p-dioxin (TCDD) (The Louis Berger Group \& Battelle, 2014). Due to the accumulation of sediment in the LPR by these contaminants, the United States Environmental Protection Agency announced their plan to remediate this area in April of 2014, focusing on "the lower eight miles," RM 0-8.3 (Newark Bay to Belleville Township), as the most contaminated part of the system. Because of the role of SPM in bringing contaminants into the water column, this dissertation focuses on SPM concentration and SPM transport and the relationship of these variables to salinity intrusion and stratification, to system topography, and to external forcing by river flow and tides. 


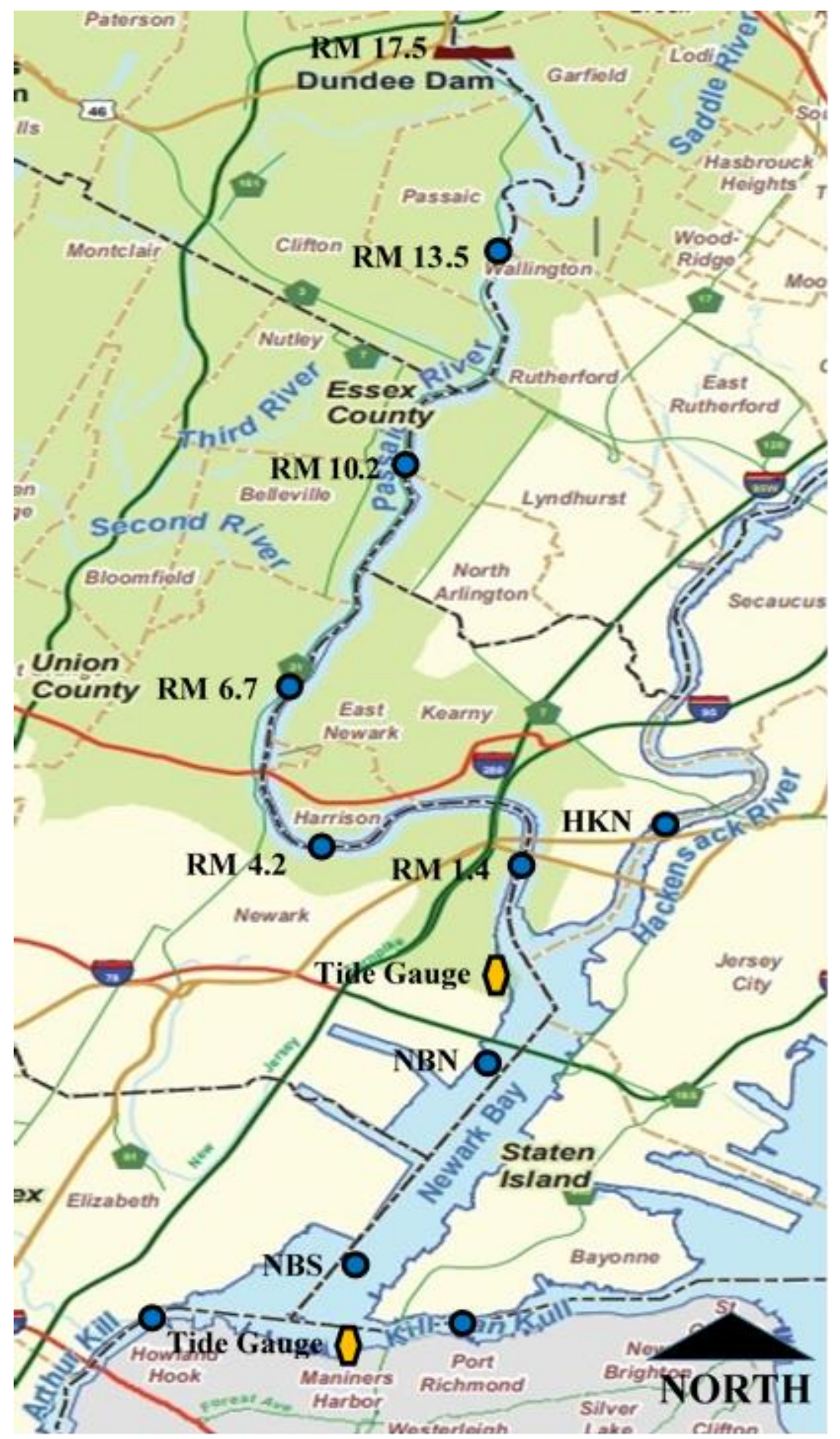

Figure 1-1: Site Map of the In-Situ ADCP instruments (Environmental Protection Agency, 2014) 
The LPR has been industrialized since ca. 1800, and it has suffered severe deleterious effects of industrialization and urbanization. Bathymetric changes in the Passaic River over the last 140 years altered the ability of the river to trap sediments (Chant et al., 2011). The major changes in the bathymetry have been due to: a) dredging to obtain a deep navigation channel; b) filling of shoreline and adjacent wetland areas that have narrowed the channel and reduced tidal prism, and c) the construction of 25 bridges in the $28.5 \mathrm{~km}$ long LPR that have constricted the channel laterally and caused scour around bridge piers. While dredging in the LPR began ca. 1800 (Iannuzzi \& Ludwig, 2004), major dredging of the system began about 1910. According to (Chant et al., 2011), the lowest 3-4 km of Passaic River had been deepened to 8-10 m, and to 6-7 $\mathrm{m}$ up to $\mathrm{km} 10$ by 1940. System scale dredging ceased in the 1980s, when the degree of pollution of the dredged material was discovered. Also, as ship sizes increased, the LPR largely ceased to be useful for shipping. By 2010, the mean low water depths of LPR had decreased to $4 \mathrm{~m}$, and the deeper holes were approximately $8 \mathrm{~m}$.

Sediment supply is an important consideration in understanding LPR sedimentation processes and contaminant transport. The net sedimentation rate in the LPR was 5-10 cm/year (Huntley et al., 1996) after dredging ceased but appears to have decreased since that time. Chant et al. (2011) argued that a geomorphological equilibrium is being approached, i.e., that SPM moves landward during the low flow but seaward during the moderate and high river flow, so that the long-term average LPR export sediment to Newark Bay is approximately equal to the annual input load. However, sea level is rising at 4-5 $\mathrm{mm} \mathrm{yr}^{-1}$ (Talke et al., 2014), requiring net sedimentation of $5-10 \mathrm{~cm} / \mathrm{year}$ due to 
increasing the erosion (Chant et al., 2011) to maintain present depths, and large storms (>10 yr return internal) likely play a role in disturbing the system in ways that have not been investigated. Moreover, sea-level rise affects tide mainly through altering frictional, depth changes, and other geometric factors, like changes in basin length and width (Talke \& Jay, 2020).

\subsection{Estuarine circulation and estuary classification}

Estuaries are complex systems, transition areas in which freshwater from river flow mixes with saltwater from the ocean (Geyer \& MacCready, 2014). In positive estuaries, the fresh river water flows out to the sea, and the sea saltwater moves along the bottom of the estuary. Through mixing and advection processes, saltwater becomes distributed throughout the estuary (Hela et al., 1957). The baroclinic pressure gradient causes water near the seabed to move landward, compensated near the surface by water that moves seaward; this circulation pattern is called gravitational circulation. The surface outflow is larger than the inflow near the bed due to river inflow, which creates the baroclinic pressure gradient driving this circulation. This circulation plays an important role in estuarine dynamics because it is related to the transport of salt, suspended sediment, and nutrients (Becherer et al., 2015 and Wang et al., 2017). However, internal tidal asymmetry can also cause estuarine circulation (Jay \& Musiak, 1994, 1996), which is induced by the horizontal density gradient. Here, asymmetry refers to the differences in vertical density stratification between flood and ebb, leading to tidal differences in vertical mixing. These systematic variations tidal variations in vertical mixing then lead to two-layer flow. 
Estuaries are affected by factors such as river flow, tidal forcing, and turbulent mixing (Geyer \& MacCready, 2014). The results of this forcing can be represented by variables such as SSC, salinity intrusion length, stratification, circulation, and mixing. The mixing is approximately given by $S_{\text {in }} S_{\text {out }} Q_{r}=S_{\text {in }} \Delta S$ Q $Q_{\text {in }}$, in $\left(\mathrm{g} \mathrm{kg}^{-1}\right)^{2} \mathrm{~m}^{3} \mathrm{~s}^{-1}$, MacCready et al., 2018) in steady-state (e.g., averaging over the spring-neap cycle ), where $S_{\text {in }}$ and $S_{\text {out }}$ are the salinities of in-and outflowing layers at the mouth; $\Delta \mathrm{S}=\mathrm{S}_{\mathrm{in}}-\mathrm{S}_{\text {out }} ; Q_{r}$ is the river flow; and $\mathrm{Q}_{\text {in }}$ is the exchange flow. Exchange flow increases with mixing with fixed $\Delta \mathrm{S}$ while the more mixing will decrease $\Delta \mathrm{S}$. Furthermore, the circulation in the narrow estuaries can be classified by the type of mixing. Jay \& Smith (1990) divided narrow estuaries into three types based on mixing: highly stratified, weakly stratified, and partially stratified. The weakly stratified estuaries may be modeled as a whole of weak interactions found in baroclinic and barotropic modes (Jay \& Smith, 1990). However, estuaries can also be classified based on topography, salinity structure, and hydrodynamics according to (Dyer, 1973) as shown in Figure 1-2. The LPR is classified as a partially mixed estuary under most conditions, with moderate river inflow and an intermediate level of density stratification. During high flows, salt is expelled from the system. 


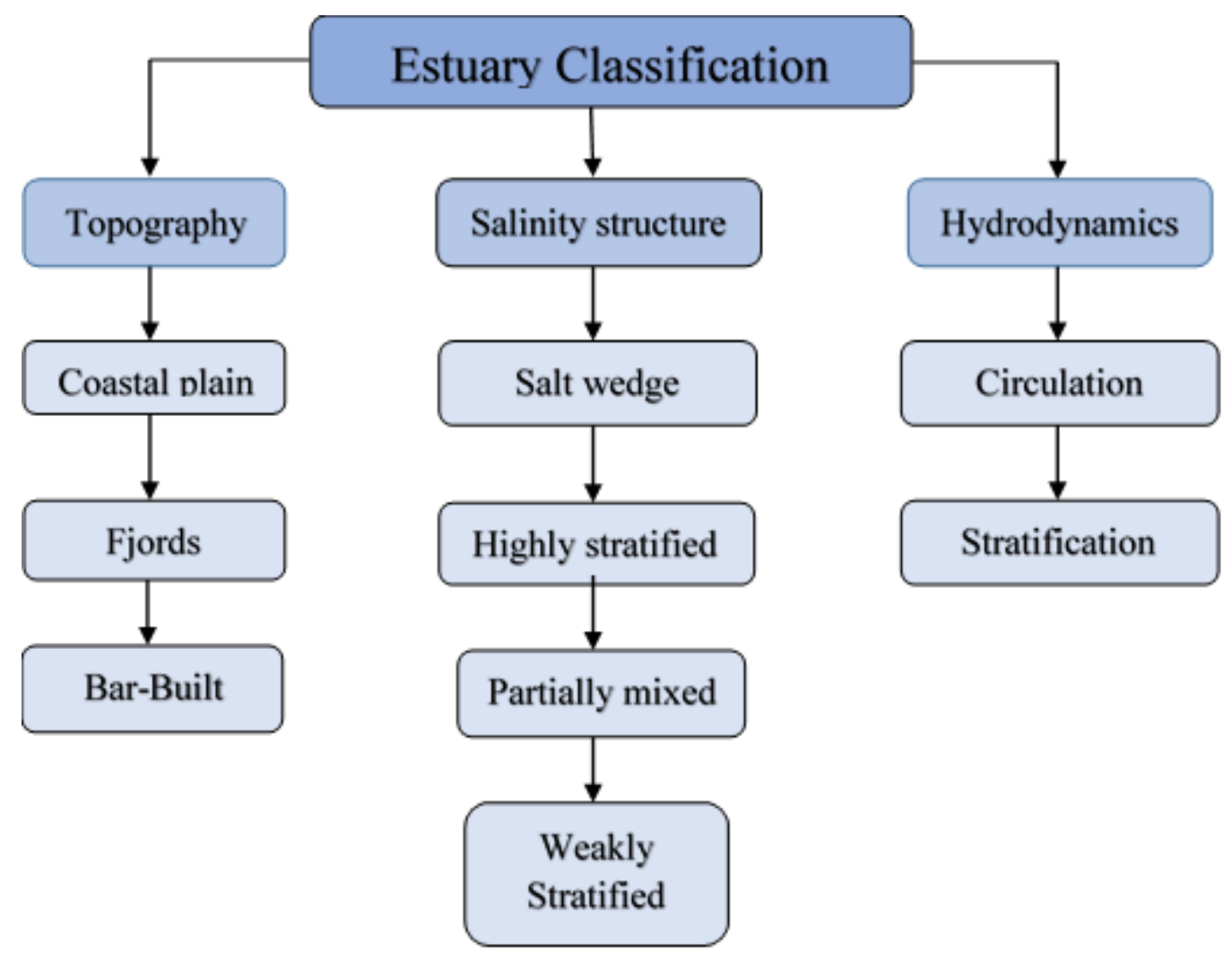

Figure 1-2. Estuarine classification, Coastal plain estuaries are formed via sea-level rise, A Fjord has a deep channel with a sill, and a Bar-Built estuary has a break-point bar between ocean and estuary. A Salt wedge has a well-defined near-bed salty layer separated from the upper freshwater layer by a sharp pycnocline. A highly stratified estuary is associated with high river flow and may have strong tides, while a Partially Mixed estuary occurs with a smaller river flow to tidal prism ratio. A weakly stratified estuary is associated with strong tides and/or a weak river prism ratio. Adapted from Dyer (1973)

The river flow directly affects salinity intrusion, and high flow is linked with reduced salinity intrusion. More recently, (Geyer \& MacCready, 2014) explained the salt content in the estuary and the associated salinity gradient $\partial_{s} / \partial_{x}$ varies because of the river outflow variation, tidally induced salinity intrusion processes, and the exchange flow. The river flow has a relatively significant impact on the salinity intrusion, where increased river flow pushes the salinity intrusion seaward, but increases $\partial_{s} / \partial_{x}$, increasing the two layer 
flow to maintain salt in the estuary. Moreover, the subtidal salt balance formulation by Hansen \& Rattray (1965) divided the salt transport into a seaward component via river outflow and two landwards components due to estuation circulation and tidal dispersion. This formulation has been written by Lerczak et al. (2006) as:

$$
\frac{d}{d t}\left\langle\int s d V\right\rangle=\left\langle\int u s d V\right\rangle=u_{0} s_{0} A_{0}+\int u_{1} s_{1} d A_{0}+\left\langle\int u_{2} s_{2} d A\right\rangle \quad \text { Equation 1-1 }
$$

where the subscript 0 refers to quantities that are averaged tidally average and over the cross-section. Subscript 1 refers tidally average quantities that vary over the cross-section, while subscript 2 refers to the tidally and sectionally varying quantities. The first term is associated with river flow-export of salt, the second with the estuarine exchange flow (which typically imports salt), and the third with tidal salt transport (which is variable but usually imports salt when averaged over a long period).

\subsection{Salinity intrusion and stratification}

Salinity is the concentration of salt dissolved in water. When freshwater from a river meets saline ocean water, the freshwater tends to freshen the mixture and reduce the salinity, especially in the more landward parts of an estuary. On the other hand, the tidal movement tends to drive the salt landward by dispersion and advection because of the density difference between the salty water and freshwater. Thus, higher levels of salinity intrusions were observed by Xu et al. (2018) on larger tides; furthermore, the mean salinity increases when river flow decreases. Storms can drive salt into or out of an estuary, depending on wind direction and salinity intrusion. Therefore, they vary on multiple time scales, daily tidal, tidal monthly, seasonal river flow, and storm-event (MacCready \& 
Geyer, 2010). However, systems like the LPR respond sluggishly, and the salinity may lag behind the tidal and river flow forcing.

The 2 psu salinity contour (known as $\mathrm{X} 2$ ) is often used to describe estuarine salinity intrusion length (Monismith et al., 2002). The maximum intrusion distance of $X 2$ into the LPR is about $20 \mathrm{~km}$ during spring-low periods, while in the high flow $\mathrm{X} 2$ is pushed out into Newark Bay (Chant et al., 2011). Also, the surface-to-bed vertical salinity difference approached 10 PSU during high-flow neap tides, while during low-flow spring tides, the water column is weakly stratified. This type of spring-neap variability is usually observed in a partially mixed estuary (Geyer et al., 2000).

As an example, Figure 1-3(a,b) shows the stratification distribution in a partially mixed estuary, the Hudson River Estuary (Ralston \& Geyer, 2019), which is similar to the LPR estuary.
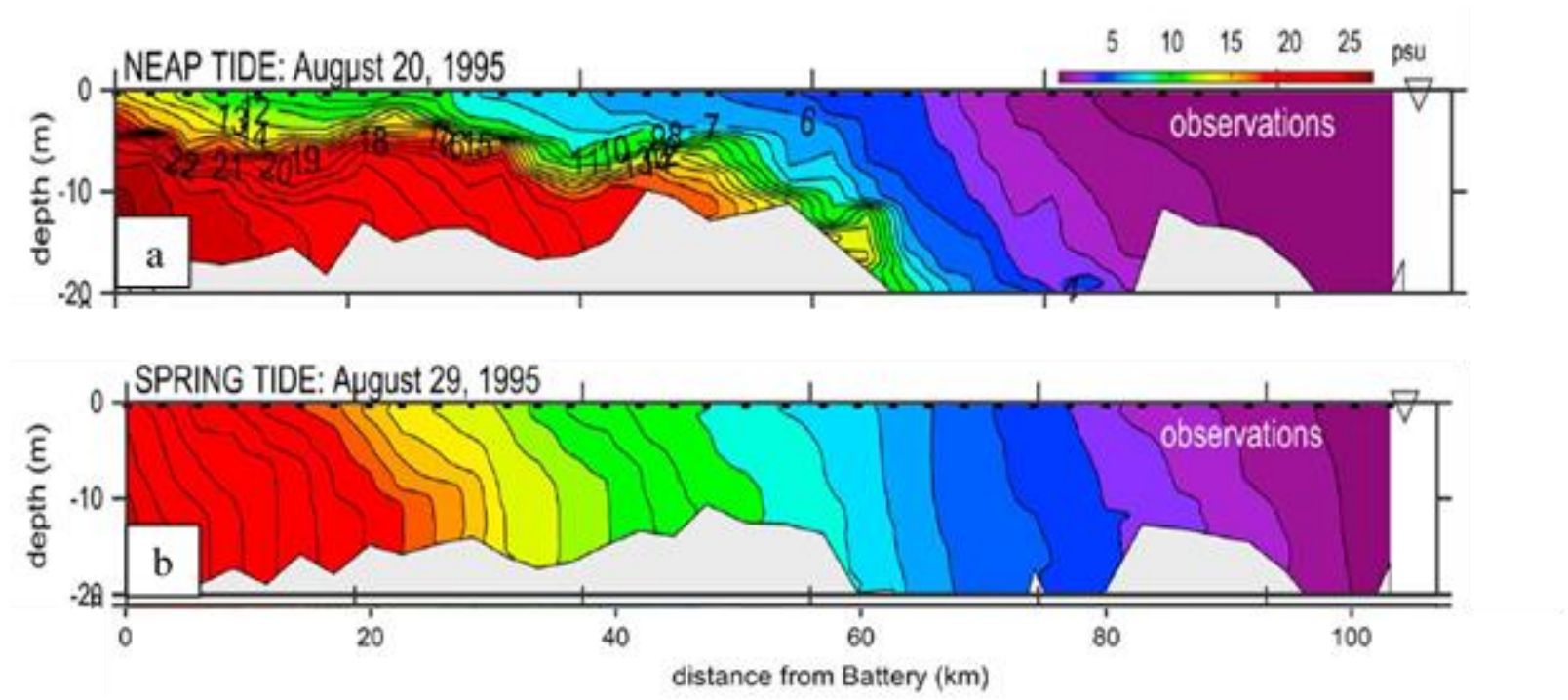

Figure 1-3. Along-Estuary distribution of stratification with 1-psu salinity contour intervals; a-Neap tide, bSpring tide, Hudson River Estuary (Ralston \& Geyer, 2019) 
Vertical salinity differences are the major factor that causes vertical density stratification, the vertical salinity gradient in estuaries and coastal seas, in most estuaries; temperature and SPM are smaller contribution factors. Stratification occurs due to the entry of freshwater from rivers, which also induces substantial horizontal gradients of density (Simpson et al., 1990). This density stratification leads to a decrease in the vertical turbulent mixing, affecting the vertical distribution of velocity and scalars and horizontal transport of scalars. The influence of stratification induced by freshwater input to a tidal estuary is represented here using a dimensionless. The Simpson number, $\mathrm{Si}=\frac{\partial_{x} b s H^{2}}{u_{*}^{2}}$, which is also called horizontal Richardson number, which describes the interaction of the longitudinal density gradient and tidal velocities that creates strains-induced periodic stratification of potential energy due to straining to the rate of production of turbulent kinetic energy when salinity is present (Simpson et al., 1990).

The shear velocity $\mathrm{u}_{*}=\sqrt{\frac{\tau_{b}}{\rho_{w}}}$ (also called the friction velocity), represents the effect of friction between the fluid and bed induced by vertical turbulent mixing of momentum; here, $\tau_{b}$ is the bed shear stress and $\rho_{w}$ is the water density. The Stratification length scale, $\mathrm{SLS}=\frac{u_{*} \frac{d \bar{u}}{d z}}{\alpha k N^{2}}$, represents the influence of density stratification on $\mathrm{u}_{*}$. A stratification length scale (SLS) ( Monin \& Obukhov, 1954) is a characteristic of boundary layer turbulence. A positive SLS refers to stable conditions (the velocity increasing), while a negative SLS refers to unstable conditions caused by advection or convection (Turner, 1973). SLS is used below to find $\mathrm{u}_{*}$ under stratified conditions. Stably stratified flows typically exhibit 
more shear in the boundary layer than present in a logarithmic profile because vertical turbulent mixing is dampened by buoyancy (Talke, 2005).

\subsection{Suspended particular matter dynamic and settling velocity}

Many estuaries efficiently trap sediment and accumulate fine particles (Schubel \& Hirschberg, 1977) that are delivered by the river to the upper estuary and then transported to the lower estuary. Thus, estuaries filter sediments and contaminations coming from the river and move toward the adjacent ocean or larger coastal system. Accumulation of SSC in an estuary, including all sorts of particles (but mainly silt and sand) moving as suspended, wash, and bedload (Hickin, 1995) depends on hydrodynamic conditions and the quantity and quality of the sediment supply, which then determine the balance between erosion and deposition.

Tidal forcing is one of the factors affecting SSC variability in coastal environments. Tide is the rise and fall of the marine water level caused by gravitational forces of the moon and sun, and the earth's rotation (Coriolis pseudo-force). The tidal range is the difference between high water level and low water level. The SSC distribution in an estuary is affected by tidal dynamics (spring-neap) and (flood-ebb), which also affect settling velocity $\left(\mathrm{w}_{\mathrm{s}}\right)$ and governs the variability of sediment transport. Sediment transport may vary on daily, tidal monthly, and seasonal times and is often well correlated with tidal range and velocity (Yang et al., 2004). Understanding SSC accumulation in an estuary is important to water quality and navigation. On longer time scales, the balance of deposition and erosion 
determines the geomorphological evolution of an estuary and affects the formation sedimentary rocks seen in the geological record (Chant et al., 2011).

Sediment transport describes the movement of fine and coarse particles in the water column due to fluid movement (Hickin, 1995). An approach to simplification of the SSC conservation equation is known as the "Rouse Balance." In this approach, the vertical SSC distribution is characterized by a single non-dimensional number, the Rouse number, $\mathrm{R}_{\mathrm{S}}=\frac{w_{s}}{k u_{*}}$, a ratio of settling velocity to vertical mixing (see details in section 4.2.1). Because horizontal transport is not important in the Rouse balance, the SPM distribution can be approximately described locally in each vertical without reference to other locations. Here, the Rouse balance is used to define the SSC profiles and describe horizontal sediment transport. The definition of $\mathrm{R}_{\mathrm{S}}$ comes from a scaling of the SPM conservation equation assuming: a) steady, laterally uniform flow and b) that the vertical velocity $w$ is so small relative to $w_{s}$.

Figure 1-4 shows typical vertical distributions of SSC under the Rouse approximation. 


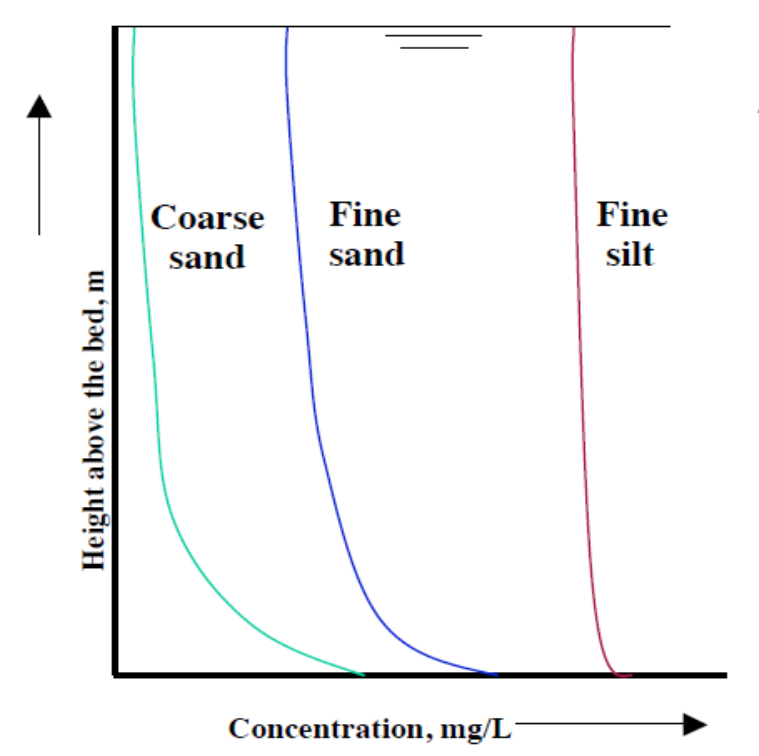

(a)

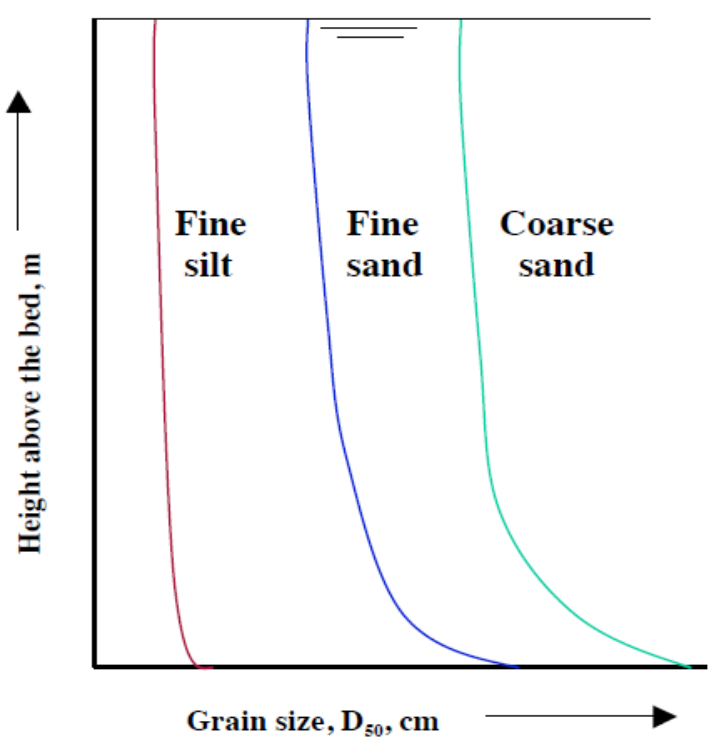

(b)

Figure 1-4(a,b). a-Typical distributions of SPM for diverse values of $R_{s}: 1.2<$ coarse sand $<2.5$, $0.8<$ fine sand $<1.2$, and fine silt $<0.8$, coarse sand is concentrated near the bed and reduces with depth as faster as than do fine sand and fine silt, b-Similarly, the grain size distribution shows that coarser particles display more vertical variation than do the vertical distribution of grain size of fine sand and silt, (Hickin, 1995).

For any given $\mathrm{u}_{*}$, silt particles, once suspended, are more uniformly distributed throughout the water column than coarser particles that settle more rapidly (e.g., fine sand and aggregates). Coarse sand is highly concentrated near the bed and declines with height at a faster rate than either fine sand or silt due to its high settling velocity, giving the typical profiles shown in Figure 1-4.

Suspended sediment transport is the amount of suspended sediment that transport with channel flow at a point, the vector transport varies in $\{\mathrm{x}, \mathrm{y}, \mathrm{z}, \mathrm{t}\}$ and is defined as:

$$
\operatorname{SSC}_{-} \mathrm{T}_{(\mathrm{x}, \mathrm{y}, \mathrm{z}, \mathrm{t})}=\mathrm{U}_{(\mathrm{x}, \mathrm{y}, \mathrm{z}, \mathrm{t})} \operatorname{SSC}_{(\mathrm{x}, \mathrm{y}, \mathrm{z}, \mathrm{t})}
$$

where SSC_T $\mathrm{T}_{(\mathrm{x}, \mathrm{y}, \mathrm{z}, \mathrm{t})}$ is the sediment transport and $\mathrm{u}_{(\mathrm{x}, \mathrm{y}, \mathrm{z}, \mathrm{t})}$ is the velocity $\{\mathrm{u}, \mathrm{v}, \mathrm{w}\}$. Therefore, sediment transport can be calculated in three dimensions from the velocity and SSC 
profiles, though this is beyond the scope of this work. The SSC field is described by a conservation equation (Section 4.2.1). Using the Rouse approximation, the SPM conservation equation can be used to estimate $w_{S}$ based on the vertical SSC distribution and known $\mathrm{u}_{*}$. Note that $w_{S}$ is a significant parameter affecting the suspended sediment transport because it affects the time that the fine and coarse particles remain in suspension throughout the water column and where particles occur in a vertically sheared flow. It is a vital parameter for the numerical modeling of sediment transport. Settling velocity can be measured by sophisticated instruments such as the floc camera (Mikkelsen et al., 2007) or an in-situ settling tube (Sequoia, 2008). In the absence of data from such instruments, an alternative method is used here to estimate bulk $w_{s}$, using field measurements of instantaneous velocity and SSC, based on use of a modified Rouse balance (Fain et al., 2001; Orton \& Kineke, 2001).

Organic and inorganic fine-grained particles in the aquatic environment are often grouped into large, porous aggregates generally called flocs (Mikkelsen \& Pejrup, 2000). Large flocs typically have a higher $w_{s}$ than their component particles and, therefore, play a significant role in rapid particle settling in estuary (Van Leussen, 1999). Floc settling velocity could be measured directly by various methods, e.g., a floc camera or in-situ settling tube (Mikkelsen et al., 2007; Sequoia, 2008). It can also be estimated from SSC and environmental conditions. For example, the Manning Floc Settling Velocity (MFSV) was defined by Manning \& Dyer (2007), based on an empirical model that be used under a wide range of SSC values, estuarine conditions, and turbulent shear. 
Settling velocity $w_{s}$ varies with water column conditions, particularly stratification. For example, stratification reduces turbulent mixing and collisions between particles, which may inhibit aggregation. On the other hand, it may also reduce small-scale shear and disaggregation (Jay et al., 2007). Eadie et al. (1991) found that $w_{s}$ values during unstratified periods were higher than during stratified conditions. In contrast, SrdićMitrović et al., (1999); Doostmohammadi \& Ardekani (2015) showed that density stratification could suppress the growth of particles, causing a decrease in $\mathrm{w}_{\mathrm{s}}$ due to increased drag on the particles into the stratified layer. The decrease in the floc settling velocity due to the effect of stratification is stronger for a suspension of particles than for an isolated particle. Overall, aggregation is complex and not simply modeled by the numerical tools or analytical methods used here. Nonetheless, stratification has been taken into consideration in calculating $u_{*}$, which is then used to calculate $\mathrm{w}_{\mathrm{s}}$.

\subsection{SPM measurement methods (acoustical and optical)}

In situ Acoustic Doppler Current Profiler (ADCP) and Optical Backscatter Sensor (OBS) can provide indirect estimates of suspended sediment concentration (SSC), because both provide backscatter signals (acoustic and optical backscatter, respectively) that can be used to measure the abundance of suspended particles. An OBS can also provide watercolumn estimates of fine particles ( Ludwig \& Hanes, 1990; Kineke \& Sternberg, 1992), while ABS responds strongly to coarse particles. Conductivity Temperature and Depth (CTD) provides conductivity, temperature, depth, and salinity readings. 
The use of ADCP profilers to estimate SSC properties is logical because an ADCP provides simultaneous, co-located estimates of both SSC (from acoustic backscatter or ABS) and velocity, but this can only be carried out if acoustic backscatter is calibrated. The major advantage of this method is ADCP records provide extensive data sets of ABS, allowing averaging over the details of local oddities in space and time. The primary disadvantages are a) the need for considerable averaging to achieve meaningful results, b) loss of a bin or two of data near-surface and bed. Loss of data near the bed is particularly crucial, and c) the need for calibration of SSC estimates from ABS by collecting watercolumn samples.

Gravimetric SPM samples collected from the water column give direct estimates unaffected by biological fouling and calibration issues (Gartner, 2002), while an ADCP can provide SSC estimates rapidly throughout most of the water column more precisely than traditional methods (Topping et al., 2007). Thus, ADCPs $(600 \mathrm{kHz}$ and $1200 \mathrm{kHz})$ were used by Geyer et al. (2007) to estimate suspended sediment in the Hudson River Estuary. Multi-frequency arrays of ADCP were used by (Topping et al., 2015) to estimate SSC in the Colorado River, Yampa River, Little Snake River, Green River, and the Rio Grande by conducting a new calibration method for varying grain size and two or more frequencies.

SSC estimation by an ADCP requires accurately measuring Acoustic Echo Intensity (AEI), which is the acoustic strength from the ADCPs used to measure depth, velocity, and SSC in the LPR. The data sets used here were collected in Fall 2009 (October 
10 to December 16) and Spring 2010 (Mach 22 to July 23). These data were collected by a measurement program called "Physical Water Column Monitoring" (PWCM), which made these two deployments in the LPR. The instrumentation deployed consisted of moored ADCP and CTD-OBS sensors, which recorded a series of 12-minute in-situ measurements at five locations in the LPR at RM "River Mile" 1.4, 4.2, 6.7, 10.2, and 13.5 (CPG, 2010). These River Mile values are equivalent to RKM "River Kilometer" values of $2.3,6.8,10.8,16.4$, and 21.7. However, the RM values are used in public documents associated with the sampling program and used here. Thus, the mooring at RM 1.4 is called 014, etc. There was also a mooring in Northern Newark Bay (NNB) during the second deployment, used for Delft3D model validation.

\subsection{Bed shear stress}

Bed shear stress is a significant variable in the riverine environment that relates flows to sediment transport (Biron et al., 2004). Resuspension of suspended sediment is initiated by shear stress exerted on the bed by the flow (Brennan et al., 2002). As the tidal current accelerates, erosion occurs, while deposition usually occurs during the deceleration of tidal currents. Therefore, the amount of suspended sediment transported by the flow is partially controlled by changing the bed flux from erosion to deposition at tidal time scales.

In the riverine and marine environment, sediment may be accumulated at the bed whenever the shear stress from the wind waves and tidal currents does not exceed the critical shear stress $\left(\tau_{c r}\right)$ value (Dronkers, 1992). Otherwise, the entire sediment load provided to an estuary from the adjacent river would be exported. The rate of bed 
accumulation (i.e., the balance of deposition and erosion) depends on the strength of waves and currents that erode sediment and the nature of the circulation that moves sediment to areas with net sedimentation; i.e., areas where $\tau_{c r}$ is rarely exceeded.

\subsection{Study period and Data Sources}

Accumulations of contaminated sediment in the LPR have led to analyses of suspended sediment in the water column. Here we analyze data from one such study. As part of the PWCM study, Ocean Surveys Inc. (OSI) collected sets of binary raw ADCP data at five stations along the miles of LPR mentioned above at time intervals of $12 \mathrm{~min}$ with $0.5 \mathrm{~m}$ bins over the water column. ADCPs provide AEI readings and frequency shift readings from which velocity and ABS are determined (Chang, 2010). The ADCPs deployed for Fall 2009 were $600 \mathrm{kHz}$ for RM 1.4 and 4.2, and $1200 \mathrm{kHz}$ for RM 6.7, 10.2, and 13.5. In spring 2010, $1200 \mathrm{kHz}$ was used at all LPR stations. For the 2010 campaign, two stations were added in Newark Bay, Newark Bay North (NBN), and Newark Bay South (NBS); these used $600 \mathrm{kHz}$ ADCPs. Two other moorings were deployed waters seaward of the Newark Bay in Kill van Kull and Arthur Kill stations, and one in the nearby Hackensack River Figure 1-1, but these are not used here.

The ADCP binary data outputs were converted to Matlab format using WinADCP software. CTD-OBS readings were converted to Matlab format from Excel spreadsheets containing data for salinity, temperature, depth, and turbidity at a time interval of $12 \mathrm{~min}$ and at 0.91 from the bed and surface river. OSI has also provided laboratory-calculated data on SSC (mg/l) samples. During the mooring period, samples were collected at three 
locations across the width of the river to measure SSC $(\mathrm{mg} / \mathrm{l})$ at a depth of $0.91 \mathrm{~m}$ below the water surface and at $0.91 \mathrm{~m}$ above the bed for different locations and times. ADCP readings and Echo Intensity (EI) were converted from counts units to ABS units (decibel $(\mathrm{dB}))$, and velocity readings $(\mathrm{m} / \mathrm{s})$ were rotated along with the orientation of the topography of the channel to be (u) velocity along with the flow of the channel and (v) velocity lateral, where the original velocities were (u) to the east and (v) to the north. The first reading has been taken $1.01 \mathrm{~m}$ and $0.86 \mathrm{~m}$ from the face of the transducer for $600 \mathrm{kHz}$ ADCP and 1200 $\mathrm{kHz}$ ADCP respectively. The distance has been calculated as: Distance $=$ Blank Distance $+0.5[$ Bin Size + Lag Length + Xmt Length $]$. All the equation variables are from WinADCP software -Ensemble statistics as in Table 1-1.

Table 1-1. First bin distance from the face of the transducer

\begin{tabular}{|c|c|c|}
\hline ADCP & $\begin{array}{c}\mathbf{6 0 0} \mathbf{~ k H z} \\
\text { Distance } \mathbf{~ m}\end{array}$ & $\begin{array}{c}\mathbf{1 2 0 0} \mathbf{~ k H z} \\
\text { Distance } \mathbf{~ m}\end{array}$ \\
\hline Blanking Distance & 0.29 & 0.25 \\
\hline Bin Size & 0.5 & 0.5 \\
\hline Lag Length & 0.24 & 0.12 \\
\hline Xmt Length & 0.71 & 0.59 \\
\hline
\end{tabular}

The river flow varied seasonally in the 2009-2010 study period, with an average of $49 \mathrm{~m}^{3} / \mathrm{s}$, about $25 \%$ above the long-term average. The maximum river flow was about $\sim 288$ $\mathrm{m}^{3} / \mathrm{s}$ during spring-freshet, while the minimum river flow was about $11.3 \mathrm{~m}^{3} / \mathrm{s}$ during the summer-dry season see Figure 1-5, which also shows variations in water levels. 


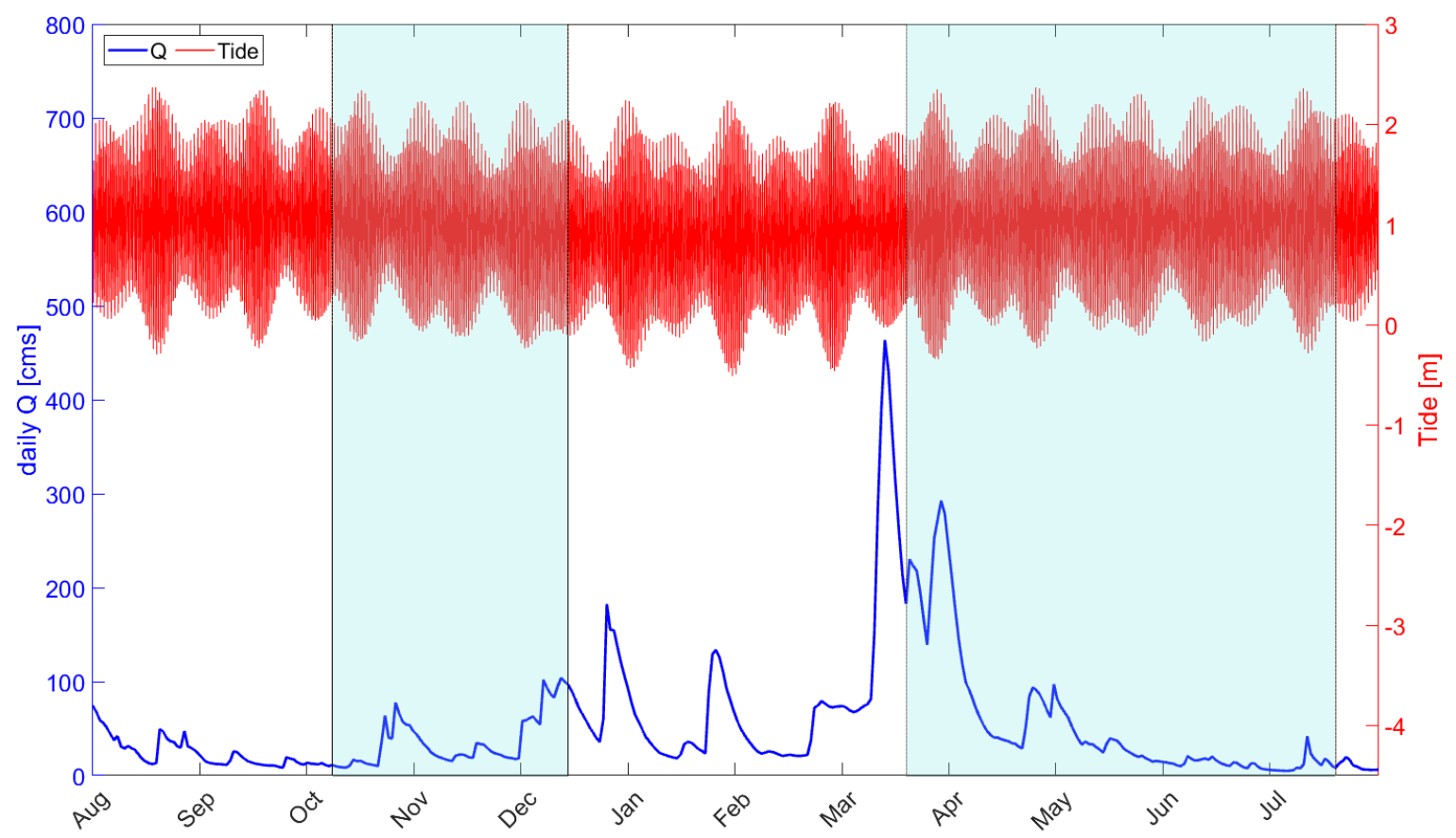

Figure 1-5. daily mean flow and water level of the LPR (Aug, 2009-July, 2010); the shadow areas are the study periods

\subsection{Research questions}

The data provided by the PWCM program motivate the research carried out in this thesis. My analyses of LPR sediment transport processes are organized in terms of the following questions:

1. Space and time variations in particles settling velocity lead to the following question: How does $w_{s}$ vary in space and time, and with external forcing by river flow and tidal range? How does salinity affect the distribution along the Lower Passaic River (LPR) of the $u_{*}$, which is used to determine $w_{s}$ ? In addition, what factors affect $w_{S}$ and how do the factors vary along the channel? 
2. The observed variability of vertical particle distributions throughout the water column leads to the second question: What are the factors, e.g., advection and erosion/deposition, that affect particle distributions (e.g., Rouse-like or ModifiedRouse)? And how SPM does the LPR carry? Furthermore, I will investigate (a) the dynamical importance of advection on fine and coarse particles; (b) the parameters that determine the variation of the fine and coarse SSC classes with the flow and tidal range, and (c) the degree to what local deposition/erosion affects $\mathrm{w}_{\mathrm{s}}$ profiles.

3. Topography, oceanographic factors, river flow, and channel curvature affect the bed shear stress distribution, leading to the final question: How do topography and oceanographic factors (e.g., tidal range to depth ratio and curvature), natural and man-made roughness elements (e.g., grains, meanders, and bridge pilings), and external forcing by river inflow influence the distribution of bed shear stress in a stratified estuary similar to the LPR, as modeled in Delft3D-FM? To answer this question, I will set up a grid of a generic, convergent estuary similar to the LPR in Delft3D-FM and run appropriate numerical scenarios. 


\section{Chapter 2 Literature review}

\subsection{Literature review}

In this section, I discuss the importance of the transport of suspended sediment and the factors that affect its distribution along a river-estuary, e.g., settling velocity, tides, salinity, and river flow. Additionally, I will show the utility of numerical modeling in analyzing the river-estuary bed shear stress.

\subsection{Suspended sediment transport and turbidity maxima in estuaries}

SSC's transport and dynamics in the estuaries are very important to determining the bed sediment distribution and the movement of sediment contaminants. The variability of SSC and its transport is meaningful not only for sedimentology, engineering, and geomorphology but also in ecology and biogeochemistry (Lindsay et al., 1996). Sediment transport refers to suspended sediment movement in the riverine and marine environment due to the combination of gravity forces and movement of the fluid acting on the particles. Suspended sediment load is the clastic material that moves through the river water column. These materials, mainly silt, and sand stay in suspension via an upward vertical turbulent flux of SSC generated at the bottom of the channel (Hickin, 1995).

Estuarine SSC is strongly influenced by velocity phase (ebb vs. flood), river flow, and tidal range, which may vary on tidal monthly and seasonal timescales. The direction of the sediment movement is controlled by the river flow in the Hudson River, according to (Geyer et al., 2001), while its amount is controlled by tidal variations (spring-neap), which is similar to the LPR system. Furthermore, tidal sediment resuspension and 
deposition are important mechanisms controlling SPM variability in partially mixed estuaries (Van de Kreeke et al., 1997). Other observations indicate that increased river flow shifts the zone of high sediment concentration seaward (Grabemann et al., 1997;

\section{Grabemann \& Krause, 2001).}

Advection is important in estuarine systems with moderate to high bed stress that traps aggregates and other relatively coarse particles (Jay \& Musiak, 1994). A two dimensional $(\mathrm{x}-\mathrm{z})$ suspended sediment balance equation has been derived for narrow estuaries by (Jay \& Musiak, 1994):

$$
\frac{\partial}{\partial t} \int_{x_{2}}^{x_{1}}<\bar{C}>\mathrm{Hdx}=\left.\left[\overline{-Q}^{R}\langle\bar{C}\rangle+\left(\left\langle\bar{U}_{v} \bar{C}_{v}\right\rangle+\left(U_{v}^{s t}+U_{v}^{s o}\right) \bar{C}_{v}>\right) \mathrm{H}\right]\right|_{x_{2}} ^{x_{1}}+\bar{V}_{f b}
$$

Equation 2-1

I

II $\quad$ III

IV

V

where: $\mathrm{U}$ is the velocity; $\mathrm{C}$ is the concentration; overbar indicates a wave cycle average; <> is the vertical average; and subscript $\mathrm{v}$ indicates the vertical deviation. In equation 2-1, term I is the inventory of SPM in the estuary between points $\mathrm{x}_{1}$ and $\mathrm{x}_{2}$, usually taken to enclose an estuarine turbidity maximum (ETM); II is river flow-export of SPM; III is the shear transport by the mean flow (usually landward); IV is the shear transport by the tidal and overtide flows (including all tidal constituents, usually but not always landward); and IV is the flux to or from the bed. Equation 2-1 describes the role of horizontal advection of vertical variations in the flow and SPM concentration in governing the SPM distribution. It also shows that horizontal advection (II-IV) and local deposition/erosion (V) are the most 
important factors in trapping particles and how tidal range and flow are involved in ETM particle trapping. See further discussion in Chapter 4.

The sediment dynamics and hydrodynamics at LPR are controlled by the estuarine circulation, river flow, and tide. Semidiurnal tides (major constituent $\mathrm{M}_{2}$ with a period of $12.42 \mathrm{~h}$ ) are much larger than the diurnal constituents, such that the tides in LPR are defined as semidiurnal dominant (Mathew \& Winterwerp, 2017). Tides entering Newark Bay through the Arther Kill and Kill van Kull propagate into the LPR with the highest currents occurring around mid-tide. The interaction of semidiurnal lunar tides M2 with the overtides M4 is the primary source of internal tidal asymmetry (Jay \& Musiak, 1996), an important feature causing vertical shear that affects sediment dynamics. The amplitudes of M2 and M4 are 0.67-0.75 $\mathrm{m}$ and 0.024-0.043 m.

Suspended sediment transport is affected by the direction of tidal current domination (flood-ebb), which depends on the asymmetry in the surface tidal. Tidal asymmetry in an estuary arises from major tidal constituents' interaction with the higher harmonic generated from the main constituents (Friedrichs \& Aubrey, 1988). The primary source of asymmetry is the interaction of semidiurnal lunar tides $\mathrm{M}_{2}$ with its overtide $\mathrm{M}_{4}$. Production of higher overtides is called "barotropic tidal asymmetry" because it distorts the free surface and causes (flood- ebb) dominant currents (Jay \& Musiak, 1996). Furthermore, river discharge can enhance the tidal asymmetry by increasing the friction, which the leading cause of the tidal distortion (Kukulka \& Jay, 2003). Under some circumstances, the tide asymmetry caused by overtide $\mathrm{M}_{4}$ (the first overtide of $\mathrm{M}_{2}$ ) 
(Jay \& Musiak, 1996) can generate a net transport load that about five times larger than that caused by symmetrical flow (Hoitink et al., 2003). Also, the interaction of the reversing barotropic pressure gradient of the tides with the non-reversing baroclinic pressure drives, along with tidally varying vertical mixing, an analogous transfer of energy to overtide internal and residual flow modes, an "internal tidal asymmetry" (Jay \& Musiak, 1996) that can cause an entire spectrum of overtide currents.

An ETM is a dynamic feature that describes a high turbidity zone due to trapping and resuspension of sediment and the aggregates in an estuary (Dyer, 1989; Jay et al., 2007; Schoellhamer et al., 2007 ). It moves landward on the flood tide and seaward on the ebb tide. Furthermore, the ETM movement depends on the river flow, although being forced out of the estuary during flood tide. Talke et al. (2009) explained that decreasing freshwater flow, increasing channel depth, and decreasing the mixing move the ETM zone upstream. Thus, during the period of low flow around $10 \mathrm{~m}^{3} / \mathrm{s}$ in LPR, the ETM is located up-estuary of RM 4.2 (Mathew \& Winterwerp, 2017). ETMs are often found at the head of the salinity intrusion. However, the LPR has multiple ETMs that are likely related to local resuspension near bridges, as well as the salinity distribution, as discussed below. Another ETM is often also found upstream of salinity intrusion, presumably due to trapping by overtides (Chant et al., 2011).

\subsection{Settling velocity}

The term aggregate was initially applied to the marine environment; it is defined as a "naturally occurring cluster or group of soil particles in which the forces holding the 
particles together are much stronger than the forces between adjacent aggregates" (Martin et al., 1955). The organic matter which joins particles together plays a significant role in forming sediment aggregates and affects particle behavior during sediment transport (Land et al., 2012). Sandy aggregate is likely to settle more quickly than those without sand, but sandy aggregates are not likely common in the LPR because of the fine bed material in most of the system.

Aggregation is largely controlled by organic binding (in which microbes play a strong role) and salinity, and particles aggregate faster in salinity water than freshwater (Burban et al., 1989). Freshwater riverine particles aggregate rapidly when entering saltwater at a salinity <2 PSU; thus, aggregation occurs at the head of the salinity intrusion when saline water particles were recycled back into meet the riverine water (Dyer, 1989). The settling velocity of large aggregates, according to Jones et al. (1998), ranges between 2 and $5 \mathrm{~mm} / \mathrm{sec}$.

Settling velocity $w_{s}$ and floc size in the marine environment are significant parameters in the modeling of sediment transport (Geyer et al., 2000; Harris \& Wiberg, 2002). Basically, $w_{s}$ varies with turbulence level, tidal stage (flood-ebb), and stratification because these factors determine the properties of the material suspended in the water column. Larger dense particles mobilized by high flow velocities have the largest $w_{S}$ values. CPG., (2010) argued that the large particles with maximal values of $w_{S}$ were seen during the flood close to the estuary mouth; smaller particles were seen on ebb, whereas the large particles are found during ebb in the upper part of LPR. This indicates that large 
particles are transported from Newark Bay into LPR by gravitational circulation and tidal asymmetry, but that further landward, large particles are transported seaward. Furthermore, large flocs play a significant role in rapid settling (Van Leussen, 1999).

Different methods can measure settling velocity. The digital camera is a common one that is used by (Mikkelsen et al., 2007) to find in situ settling velocity. Manning \& Dyer (2007) conducted a new empirical method called Manning Floc Settling Velocity (MFSV), which is a good method for its flexibility in fitting a wide range of estuarine SSC and turbulent shear conditions. CPG (2010) used field measurements of instantaneous velocity and SSC using ADCP data to estimate $w_{s}$. The major advantages of this approach are: a) there is a large database of acoustic measurements of suspended sediment and velocity; and b) velocity and concentration are simultaneous and collocated, an important factor given strong space-time variations in SPM. I follow this course of action in my analyses.

\subsection{Estuarine salinity intrusion and stratification}

Salinity intrusion into an estuary is affected by river flow, tidal forcing, and water level variations. Salinity typically decreases from the marine environment toward the head of the estuary due to the input of the freshwater (Hansen \& Rattray, 1965). Some estuaries exhibit, however, elevation salinity in the landward direction due to high evaporation and low inflow. Pritchard (1956) argues that the horizontal salinity gradient is the driving force of estuarine circulation by the horizontal pressure gradient, which increases with depth: 


$$
\frac{1}{\rho} \frac{\partial p}{\partial x}=\mathrm{g} \frac{\partial \eta}{\partial x}+\beta \mathrm{g} \frac{\partial s}{\partial x}(\mathrm{~h}-\mathrm{z})
$$

where: $\rho$ is the density of water; $\frac{\partial \mathrm{p}}{\partial \mathrm{x}}$ is the pressure gradient; $\mathrm{g}$ is acceleration of gravity; $\frac{\partial \eta}{\partial \mathrm{x}}$ is the surface slope; $\beta$ is the coefficient of saline contraction; $h$ is the water depth; and $\mathrm{z}$ is the vertical depth upward from the bottom; $\beta \mathrm{g} \frac{\partial s}{\partial x}(h-z)$ is the horizontal salinity gradient, which is zero at surface and maximum at the bottom; and $g \frac{\partial \eta}{\partial x}$ is the tidally average surface slope. Conservation of mass requires that the total pressure gradient $\frac{1}{\rho} \frac{\partial p}{\partial x}$ changes sign close to the middle of the water column. As a result, the surface water is driven seaward and bottom water landward. Furthermore, the force that balances the pressure gradient is the internal stress acting on the estuarine shear flow. Therefore, the momentum equation is simplified by considering that the pressure gradient $\frac{1}{\rho} \frac{\partial p}{\partial x}$ is approximately balanced by the vertical stress divergence, $\frac{\partial \tau}{\partial z}($ Pritchard, 1956):

$$
\tau=\rho \mathrm{A}_{\mathrm{z}} \frac{\partial u}{\partial z}
$$

Equation 2-3

where $\tau$ is the turbulent stress and $A_{z}$ is the eddy viscosity $\left(\mathrm{m}^{2} / \mathrm{s}\right) ; \frac{\partial u}{\partial z}$ is the vertical shear. Thus, the total momentum balance is:

$$
\frac{1}{\rho} \frac{\partial \tau}{\partial z}=\mathrm{g} \frac{\partial \eta}{\partial x}+\beta \mathrm{g} \frac{\partial s}{\partial x}(\mathrm{~h}-\mathrm{z})
$$

The horizontal salinity gradient in equation 2-4 drives the estuarine circulation which is balanced by the stress divergence and a surface slope that allows the two-layer flow to be steady (Jay, 2010). The surface slope drives a surface outflow that matches the near-bed inflow. 
High flow is connected with reduced salinity intrusion in the estuaries (Hansen $\boldsymbol{\&}$ Rattray, 1965; Hansen \& Rattray, 1966; MacCready, 1999; Monismith et al., 2002; Geyer \& MacCready, 2014). Accordingly, high and moderate flow contribute to washing salt out of the LPR into Newark Bay. The maximum length of salinity intrusion is about $20 \mathrm{~km}$ into the LPR (Chant et al., 2011), while the salinity is washed out of the system into Newark Bay for river discharge over about $100 \mathrm{~m}^{3} / \mathrm{s}$. According to one theoretical analysis, salinity intrusion varies inversely with the river flow to the power of $n=-1 / 3$ ( MacCready \& Geyer, 2010), but Monismith et al. (2002) found $n=-1 / 7$ in the San Francisco Bay, while $n$ is $-1 / 5$ in Hudson river estuary Oey (1984), and -0.3 (Al Bahadily, 2020) to -0.5 (Chawla et al., 2008) in the Columbia River estuary. However, the value of $n$ depends considerably on the location chosen as the origin $(\mathrm{x}=0)$, where oceanic salinity prevails (AI Bahadily, 2020), and the (MacCready \& Geyer, 2010) theory does not take into account salt transport related to internal asymmetry or complex bathymetry, both of which can be expected to influence $n . n$ at the LPR is -0.41 with bridge piers and -0.85 without bridge piers at low flow; $n$ at the LPR is -0.35 with bridge piers and -0.49 without bridge piers at high flow previous studies have not established a value of $n$ in the LPR.

The tidal range in an estuary reflects tidal forcing's intensity at the estuary boundary and mixing in the system. Xu et al. (2018) observed in a study on Yangtze River Estuary that a higher level of salinity intrusion is consistent with the higher tidal range that moves salt landward. However, Ralston et al. (2008) observed that salinity was pushed downstream during the spring tides and high discharge periods due to increased vertical mixing decreasing the estuary circulation; the Hudson is a partially mixing estuary similar 
to the LPR. Furthermore, Jay \& Smith (1990) explained that on spring tides in the Columbia River estuary, mixing increases, stratification decreases, and salinity intrusion is reduced, similar to the LPR system categorizing as a partially mixed estuary to its stratification (Corlett \& Geyer, 2020).

Not only LPR salinity intrusion change with river flow and tidal range, but stratification and circulation of the LPR estuary also change significantly. Freshwater enter from the river to the estuary produces vertical gradients of density, called density stratification (Simpson et al., 1990). The salt conservation equation describes the salinity field:

$$
\left\langle\frac{\partial \bar{S}}{\partial t}\right\rangle+u\left\langle\frac{\partial \bar{S}}{\partial x}\right\rangle+v\left\langle\frac{\overline{\partial S}}{\partial y}\right\rangle+w\left\langle\frac{\partial \bar{S}}{\partial z}\right\rangle=\frac{\partial}{\partial x}\left[\mathrm{~K}_{\mathrm{x}} \frac{\partial \bar{S}}{\partial x}\right]+\frac{\partial}{\partial y}\left[\mathrm{~K}_{\mathrm{y}} \frac{\partial \bar{S}}{\partial y}\right]+\frac{\partial}{\partial z}\left[\mathrm{~K}_{\mathrm{z}} \frac{\partial \bar{S}}{\partial z}\right] \text { Equation2-5 }
$$

where $K_{j}$ is the eddy diffusivity of salt in $x, y, z$ direction, and $\frac{\partial S}{\partial z}$ is the stratification. The steady-state slat conservation condition in a narrow estuary can be written by assuming lateral uniformity (Hansen \& Rattray, 1965):

$$
u \frac{\partial \bar{S}}{\partial x}+w \frac{\partial \bar{S}}{\partial z}=\frac{\partial}{\partial x}\left[\mathrm{~K}_{\mathrm{x}} \frac{\partial \bar{s}}{\partial x}\right]+\frac{\partial}{\partial z}\left[\mathrm{~K}_{\mathrm{z}} \frac{\partial \bar{S}}{\partial z}\right]
$$

Stacey et al. (2001) examined the balance between stratified and unstratified flow estuaries by using the dimensionless Simpson number, $\mathrm{Si}=\frac{\partial_{x} b s H^{2}}{u_{*}^{2}}$, which is also called horizontal Richardson number. It describes the interaction of the longitudinal density gradient and tidal velocities that creates strains-induced periodic stratification of potential energy due to straining to the rate of production of turbulent kinetic energy when salinity 
is present (Simpson et al., 1990). They found that Simpson number is a significant parameter in predicting the occurrence of residual-creating stratification. It had a value of $\sim 3$ on ebb tides, when reduced turbulent mixing via produced stratification. For smaller values of $\mathrm{Si}$, the vertically well-mixed condition occurs on ebb tide due to overcoming the kinetic energy of the turbulence on the stabilizing influence of tidal straining (Geyer \& MacCready, 2014). Si has been found to be the primary parameter that affects settling velocity when the salinity is present, as discussed in Chapter 3.

An estuary is a complex system with marked interaction between mixing and stratification. The intensity of mixing decreases stratification (MacCready et al., 2018), even in the neap tide when turbulence conditions are weak. Geyer \& MacCready (2013) explained that when mixing parameter $M^{2}=\frac{C_{D} U_{T}^{2}}{\omega N_{0} H^{2}}$, which is "the ratio of the tidal timescale to the vertical mixing scale", is $>1$, a tidal straining circulation that is driven by tide-induced shear. In this expression, $\mathrm{C}_{\mathrm{D}}$ is the drag coefficient; $\mathrm{U}_{\mathrm{T}}$ depth-averaged tidal velocity; $\omega$ tidal frequency; $N$. bouncy frequency; and $\mathrm{H}$ water depth. Tidal currents are, according to Hansen \& Rattray, (1965) supposed to be the dominant cause of turbulent mixing, but do not influence the net circulation in the estuary. Jay \& Smith (1990) have classified the circulation in the narrow estuaries as highly stratified, weakly stratified, and partially stratified. Each of them has a different mechanism of vertical mixing of fresh water and salt and a distinct type of residual circulation. The mixing in partially mixed estuary takes place, where the river flow is low in comparison with tidal prism; thus, tidal energy enhances the mixing of two layers ( Dyer, 1973; Al Bahadily, 2020). The mixing 
in the weakly stratified estuaries may extend throughout most of the flow ( Jay \& Smith, 1990) and prevents significant stratification from developing. The interaction between the pressure gradient, stratification, and vertical mixing causes large shears in the alongchannel velocity on the ebb, while the flood velocity profile is more uniform (Jay \& Smith, 1990). Similar arguments apply to the other two categories, highly stratified and partially mixed.

\subsection{Acoustical and optical analyses of SSC}

The development of our understanding of sediment transport processes in riverine and marine areas has benefited significantly from the development of instruments that can measure SSC rapidly. Acoustic instruments have been widely used since the 1990s to measure 3D velocities and to determine SSC from the acoustic backscatter (ABS, Thorne \& Hanes, 2002; Jay et al., 2015). An ADCP is a multibeam (there are usually three or four beams) pulsed, acoustic Doppler sonar. ADCP sonar employs the acoustic Doppler shift to remotely measure verticals profiles of water currents. It works by transmitting a high-frequency wave into the water. The sound waves hit the suspended particles and are reflected back. The Doppler shift is the change in the observed sound pitch, which results from the relative motion of the particles and the ADCP. Thus, the velocity, $u$ (in three dimensions), can be determined at a series of depths by measuring the acoustic wave's time to hit the particles and be bounced back. ABS values are related to SSC by acoustic theory, but the relationship requires calibration. The advantages of an acoustic instrument are that it does not disrupt the particles due to the low acoustic energy, and it can sample almost the entire water column simultaneously. 
Several acoustics instruments based on the scattering of sound waves have been developed to study sediment processes ( Agrawal \& Smith, 1994; Thorne \& Hardcastle, 1997; Thosteson \& Hanes, 1998; Agrawal \& Pottsmith, 2000;). Each acoustic frequency (fr) has a wavelength $(\lambda)$ related to the speed of sound (ss) according to: $s s=f r \times \lambda$. Given a speed of sound in seawater (about $0.36 \mathrm{~m} / \mathrm{s}$ ) that is a weak function of salinity, temperature, and pressure. The wavelengths of ADCPs used here, 600 and $1200 \mathrm{kHz}$, are about 2.5 and $1.25 \mathrm{~mm}$, respectively. ADCPs were originally developed to measure velocity, with SSC determination via $\mathrm{ABS}$ as an incidental side benefit. But they can be used to calculate suspended sediment transport more precisely than traditional methods (see section 3.1.2) because they simultaneously measure SSC and velocity at the same location (Topping et al., 2007). The ADCP can also be used for different practical size distribution ranges of tens to hundreds of microns (Gartner, 2002).

Downing et al. (2005) developed a method to correct for backscatter losses due to absorption and beam spreading losses in terms of instrument characteristics such as frequency, power, and transducer size. A log-linear relationship between SSC samples and ABS was used by (Holdaway et al., 1999; Gartner, 2004; Chang, 2010) to determine the time series of SSC from ABS time series. As a result, a significant agreement was achieved between ABS-derived SSC and SSC from laboratory-determined samples that matched depth and time of ABS measurements. Wall et al. (2006) used Downing's method to correct the data of echo intensity and velocity of ADCP to find suspended sediment discharge in the Hudson River, NY. Downing's method is used here. 
SSC can also be measured optically. A laboratory study was done by Ludwig \& Hanes (1990) in order to calibrate and evaluate the behavior of OBS instruments for mud and sand. The sensor was found to be useful for measuring the concentration of either suspended mud or sand, but it was relatively more sensitive to fine sediments. The SSC calibration was linear for sand while non-linear for high mud concentration. The authors didn't recommend using OBS instrument to measure sand with mud environment to avoid saturating the sensors with fine sediments during high-energy mud transport. Also, there are not sufficient OBS data from the LPR to use this instrument in this study.

\subsection{Bed shear stress variability with the oceanographic factors}

Oceanographic factors affect the erosion and deposition of sediment particles by controlling the $\tau_{b}$. Thus, $\tau_{b}$ is an indicator of local the erosion or deposition. Erosion is important in meandering channels where erosion is common. The LPR channel has numerous curves and bends, which are stabilized by rip-rap and other bank protections. Bed shear stress varies through bends with channel curvature. It is high at the inner bank at the beginning of the bend and near the outer bank at the end (Callander, 1978). Bends in the meandering channels have been examined by (Chen \& Shen, 1983); they used the relative curvature, $C_{r e l}$, (the ratio of the channel bend curve at the center, $\mathrm{r}_{\mathrm{c}}$, to the channel width, $\mathrm{c}_{\mathrm{w}}$ ) that is defined by (Bates $\boldsymbol{\&}$ Watts, 1980): "It is independent of scale changes of the data and of the parameters so it can be used to compare different data sets as well as different parameterizations of the same data set" and seems to be the significant factor in

determining bed shear stress. When $C_{r e l}>3.5$ the highest stress shear occurs near the outer 
bank of the exit curvature. However, if $1.25<C_{\text {rel }}<3.5$, two zones of the high shear stress occur, one at the outer bank of the exit curvature and another along the inner bank of the entrance reach of the bend. But if $C_{r e l}<1.25$, the highest shear stress moves to the entire inner bank of the stream bend. In general, the meanders in the LPR are fairly gradual and $C_{\text {rel }}$ is 4.5 where the highest stress occurred near the outer bank.

The bed near bridge pillars in a river is often subject to severe local scour due to high bed shear stress. Zaredehdasht et al. (2011) showed shear stress at the longitudinal section of the river. They pointed out that shear stress decreases as the distance from the bridge pier increases. This is because the flow velocity is maximum close to piers and decreases as the distance from the pier increases. In this study, the bed shear stress will be examined in cross-sections with and without bridge piers to show the effect of the bridge piers on the bed shear stress. Changes in water surface slope (and thus in the overall resistance of the flow) caused by the bridges will also be analyzed.

Human activities have often changed estuarine bed characteristics by affecting sediment transport processes, channel stability, bedform dimensions, and navigability (Kondolf, 1997). $\tau_{b}$ increased and the bed became coarser due to dredging and groynes (Frings et al., 2009) in the River Wall. However, if a system is deepened too much, fine sediments or even liquid mud can accumulate due to reduced shear stress (De Jonge et al., 2014). Geyer (1993) argued that the transport of the fine sediment is mainly controlled by the interplay between mixing, stratification, resuspension, and particles settling velocity, and that stratification strongly facilitated trapping of sediment. This process is thought to 
be important in the LPR, where the channel was deepened for navigation from about 1910 to 1980 but has since shoaled.

When water flows around bridge piers, the pier produces both form and surface drag. Form drag is a resistance force encountered body in a fluid, which is the result of a pressure gradient with high upstream pressure and low pressure downstream of the body, in a turbulent separation zone with many vortices (Bulbul, 2017; Suribabu et al., 2011). The form drag of a pier is usually larger than its skin friction, but this depends on the hydrodynamic circumstances (Bulbul, 2017). The drag forces on the bridge pier causes water levels to be elevated upstream of the pier (relative to the situation without piers) due to energy loss at the pier, as discussed in Chapter 5. Moreover, when the drag force increases, the difference between the downstream and upstream water level increases, corresponding to an increased pressure difference (Bulbul, 2017). On the other hand, density stratification reduces force the drag due to damping vertical motions and reduced vertical mixing (Castro et al., 1990). 


\section{Chapter 3 Settling Velocity variation into the Lower Passaic River Estuary}

\subsection{Introduction}

\subsubsection{General}

Estuaries efficiently trap sediment delivered to the upper estuary via the river and then transported to the lower estuary (Schubel \& Hirschberg, 1977). Thus, estuaries can filter sediments and pollutants coming from the river and moving toward the marine environment. The settling velocity distribution of SPM is crucial in riverine and coastal environments where particle settling is significant in controlling the vertical movement of SPM and, therefore, horizontal sediment transport. Thus, $w_{s}$ and SSC are significant parameters for understanding sediment transport. However, SSC in the estuarine environment is also influenced by tides, because of the role of tides in setting stratification and vertical mixing. Thus, both the numerator $\left(w_{s}\right)$ and denominator $(k u *)$ of the Rouse number are important.

Settling velocity is a core parameter affecting the time that the fine and coarse particles remain in suspension throughout the water column and the $w_{S}$ of aggregates is higher than that of particles that form the aggregate. Also, the $w_{s}$ of the unaggregated particles is usually smaller in a density stratified flow, because of reduced $u *$. Thus, the determination of $w_{s}$ is complex problem that includes particle-particle hydrodynamic interaction and density stratification (Doostmohammadi \& Ardekani, 2015). Fortunately, $w_{S}$ can be estimated based on the vertical SSC distribution from the conversation equation 
with the certain assumptions (section 3.2.3). With development of ADCP techniques to measure the flow velocity and ABS and SSC (Yuan et al., 2008), the methods of (Fain et al., 2001 and Orton \& Kineke, 2001) can be used, with some modifications, to estimate bulk $w_{s}$, based on moored ADCP records.

Therefore, I analyze in this chapter the time and space variations of $w_{s}$ in the LPR, also taking into consideration the effects of salinity stratification on $u$ * Besides, I determine the primary factors influencing $w_{s}$ and the variation of these factors in the LPR.

\subsubsection{Data Used}

The LPR estuary in New Jersey is the site of a complex Superfund cleanup because multiple pollutants are found in the water column and the bed. Understanding SPM transport, deposition, and erosion are important to designing a cleanup. Therefore, to study suspended sediment dynamics in this river, CPG (2014) deployed five pairs of Conductivity Temperature and Depth (CTD) plus Optical Backscatter Sensors (OBS) and five Acoustic Doppler Current Profilers (ADCP) along the LPR. The ADCP acoustics measured Acoustic Echo Intensity (AEI) and depth (via pressure, not all moorings) in a study of the LPR in Fall 2009 (October 10 to December 16) and Spring 2010 (Mach 22 to July 23). This program was called the Physical Water Column Monitoring (PWCM) study. ADCPs recorded in-situ measurements at five river mile (RM) locations (1.4, 4.2, 6.7, 10.2, and 13.5 at12-minute intervals; Figure 1-1. The PWCM program also collected water column samples in both 2009 and 2010 to provide laboratory-determined SSC collected at $0.91 \mathrm{~m}$ below the surface and $0.91 \mathrm{~m}$ above the bottom, coincident with the CTD-OBS 
sample locations. All ADCPs used in 2010 were $1200 \mathrm{kHz}$, while $600 \mathrm{kHz}$ ADCPs were used at RM 1.4 and 4.2 in Fall 2009.

\subsubsection{Settling velocity estimating steps}

The steps to estimate settling velocity through using ABS readings are somehow complex. First, RB has been calculated, then a calibration between RB and SSC laboratorydetermined samples has been done; after that $u_{*}$ estimated when the flow is stratified and unstratified to estimate $\mathrm{R}_{\mathrm{s}}$ and $w_{s}$. The steps are explained in Figure 3-1 and discussed in the next paragraphs.

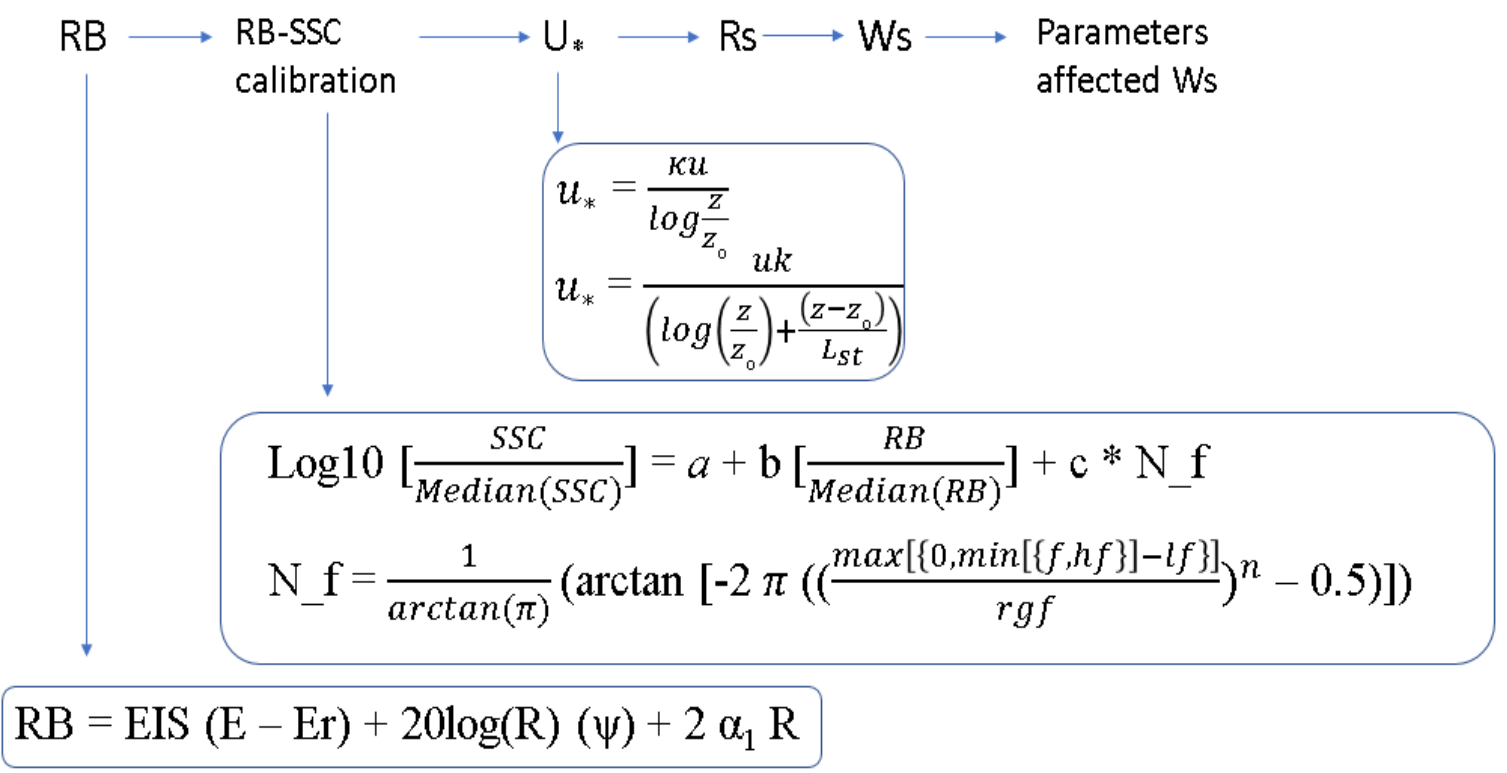

Figure 3-1: Steps of estimating settling velocity 


\subsection{Theory and methods}

\subsubsection{Relative Backscatter}

SSC can be estimated, with proper calibration data, from relative backscatter intensity measured at the ADCP transducer head. Relative backscatter $(\mathrm{RB})$ is the sum of echo intensity that is measured at the transducer plus the two-way transmission losses (Thevenot et al., 1992):

$$
\mathrm{RB}=\mathrm{EIS}(\mathrm{E}-\mathrm{Er})+2 \alpha_{1} \mathrm{R}+20 \log (\mathrm{R}) \quad \text { Equation 3-1 }
$$

where EIS is the Echo Intensity factor used to convert EI counts to $\mathrm{dB}$ (dependent on temperature), which is equal to EIS $=127.3 /(\mathrm{T}+273)$, where $\mathrm{T}$ is the temperature in ${ }^{\circ} \mathrm{C}$ and $\mathrm{E}$ is Er in counts. Er is based on the ADCP frequencies and represents the Received Signal Strength Indicator (RSSI) reference level in counts, and $\mathrm{R}$ is the slant range to the transducer of the return EI, in meter (Deines, 1999), and equal to:

$$
R=r+\frac{D}{4}
$$

Equation 3-2

where $r$ is the slant range from bin center to the face of ADCP (m); D is bin size (m); and $\alpha_{1}$ is the coefficient of the absorption of sound in the water $(\mathrm{dB} / \mathrm{m})$ that is calculated following (Schulkin \& Marsh, 1962):

$$
\alpha_{1}=8.68\left(\frac{S A f_{t} f r^{2}}{f_{t}^{2}}+\frac{B f r^{2}}{f_{t}}\right)\left(1-6.54 \times 10^{-4} \mathrm{P}\right)
$$

where A is a constant $=2.34 \times 10^{-6} ; \mathrm{S}$ is the salinity PSU; $\mathrm{f}_{\mathrm{t}}$ is the temperature-dependent frequency in $\mathrm{kHz}$, equal to $21.9 \times 10^{[6-1520 /(\mathrm{T}+273)]}, \mathrm{T}$ is the temperature in ${ }^{\circ} \mathrm{C}$; fr is the frequency in $\mathrm{kHz}$; $\mathrm{B}$ is a constant equal to $3.38 \times 10^{-6}$, and $\mathrm{P}$ is atmospheric pressure in 
$\mathrm{kg} / \mathrm{cm}^{2}$. Following Downing et al. (1995), a near-field correction due to nonspherical spreading was added to the beam spreading part in the equation (3-1):

$$
\mathrm{RB}=\mathrm{EIS}(\mathrm{E}-\mathrm{Er})+20 \log (\mathrm{R})(\psi)+2 \alpha_{1} \mathrm{R}
$$

where $\Psi$ is ADCP near field correction equal to:

$$
\Psi=\frac{1+1.35 z_{1}+\left(2.5 z_{1}\right)^{3.2}}{1.35 z_{1}+\left(2.5 z_{1}\right)^{3.2}}
$$

Equation 3-5

Here, $\mathrm{Z}_{1}=\frac{\mathrm{R}}{\mathrm{R}_{\mathrm{cr}}}$ and $\mathrm{R}_{\mathrm{cr}}=\frac{\pi\left(\frac{T D}{2}\right)}{\lambda}$, TD is the transducer diameter $(\mathrm{m})$, and $\lambda$ is the wavelength (m).

Figure 3-2 $(a, b)$ shows p-contour plots of RB for each time series station for the Fall-2009 and Spring- 2010 data. These values of RB must then be converted to SSC, using a calibration based on SSC in water samples
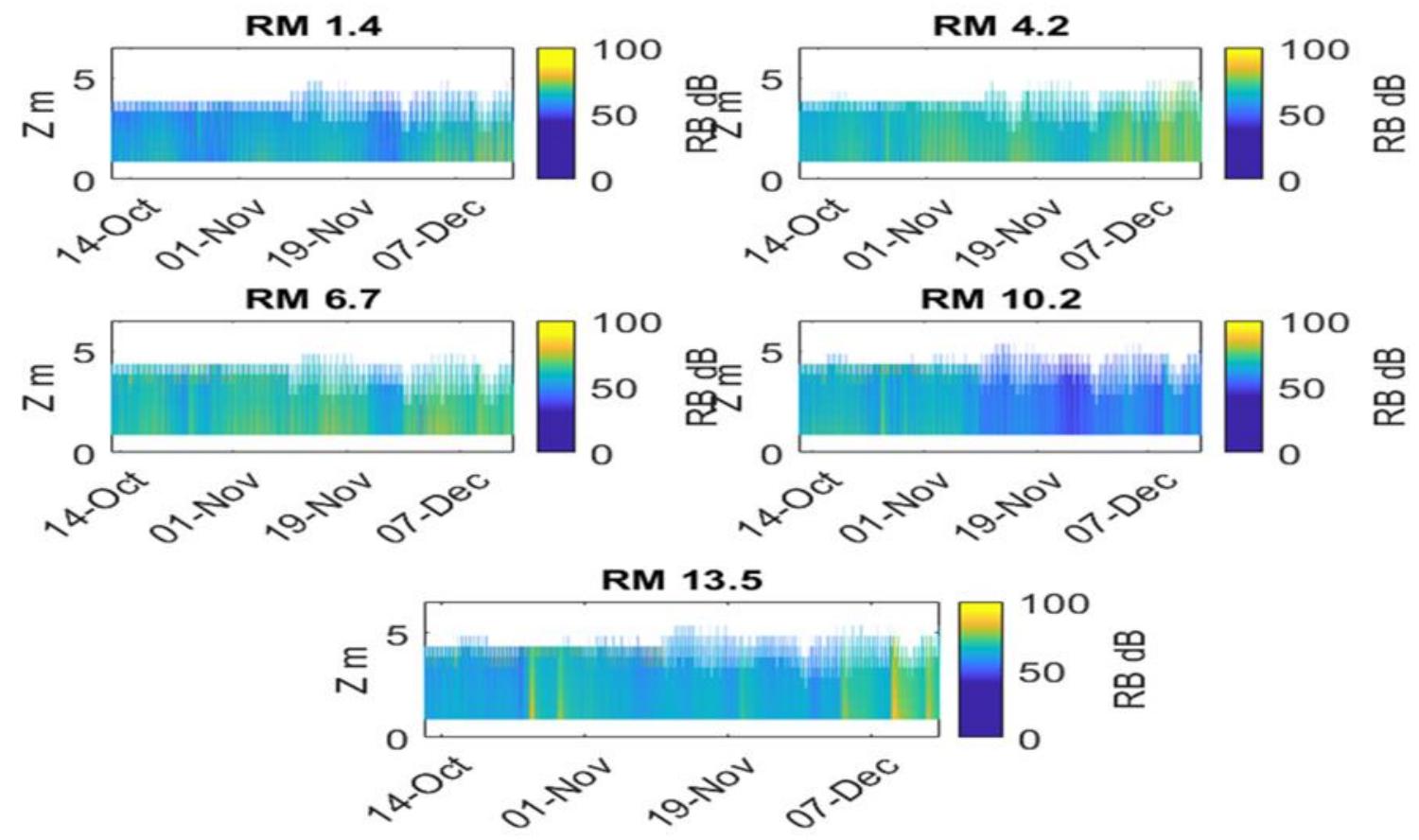

(a) Fall 

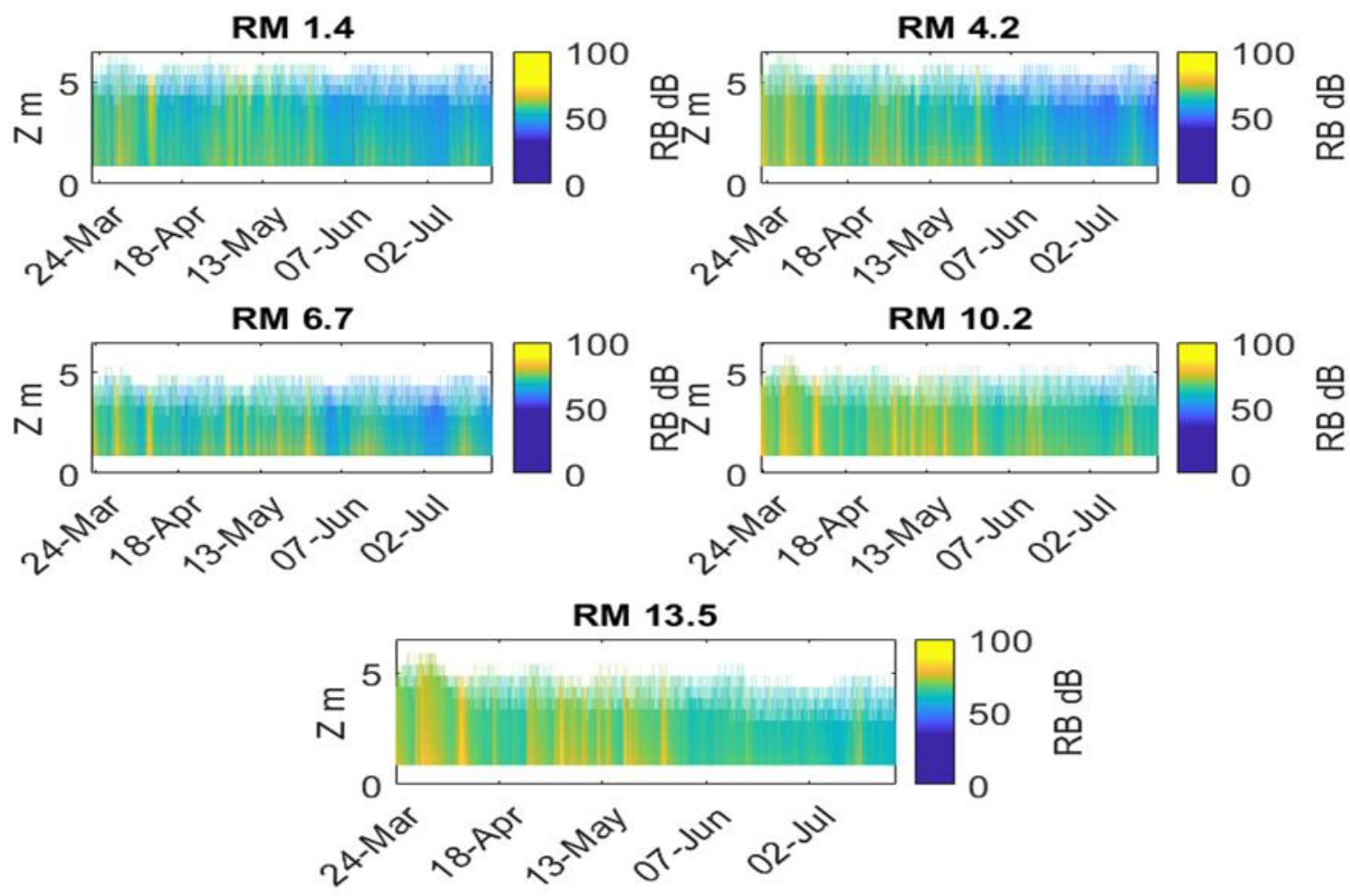

(b) Spring

Figure 3-2. Time series of depth-resolved RB for fall and spring RM

To calibrate SSC against RB Chang (2010) and CPG (2010) followed Holdaway and Gartner's procedure by using the sonar equation $S S C=10^{\left(a_{0}+b_{0}{ }^{*} R B\right)}$, where $a_{0}$ and $b_{o}$ are constants, and RB is the relative backscatter. Their regression between water samples and RB for spring 2010 is separated into the low and high flow to get a more accurate coefficient regression and decrease the variability in the RB-SSC relationships. But due to frequent, large flow variations in spring 2010, several large jumps in SSC occurred when the calibration changed. To overcome this problem, a new form of normalized non-linear multiple regression is applied in the equation (3-6) by adding the flow as a parameter. River 
flow is defined here as the sum of the two largest sources, the LPR at Dundee Dam plus Saddle River. The average discharge for Fall (October-December) is 35.5 and spring (March-July) is $54.7 \mathrm{~m}^{3} / \mathrm{sec}$.

The RB values were transformed SSC in non-dimensional form using the following equation:

$$
\log 10\left[\frac{S S C}{\operatorname{Median}(S S C)}\right]=\mathrm{a}+\mathrm{b}\left[\frac{R B}{\operatorname{Median}(R B)}\right]+\mathrm{c} * \mathrm{~N}_{\mathrm{f}} \quad \text { Equation 3-6 }
$$

where $\mathrm{a}, \mathrm{b}$ and $\mathrm{c}$ are station dependent constants, $\mathrm{N}_{\mathrm{f}}$ is a normalization of flow that is given by:

$$
\mathrm{N}_{\mathrm{f}}=\frac{1}{\arctan (\pi)}\left(\arctan \left[-2 \pi\left(\left(\frac{\max [\{0, \min [\{f, h f\}]-l f\}]}{r g f}\right)^{n}-0.5\right)\right]\right) \quad \text { Equation 3-7 }
$$

where $\mathrm{f}$ is the flow, hf is the high flow, If is the low flow, $\mathrm{n}$ is a constant that ranges between 0.1-3 and rgf is the regular flow and equal to hf-lf, SSC refers here to suspended sediment samples that are laboratory-determined. The inclusion of the $\mathrm{N}_{\mathrm{f}}$ terms accounts for the fact that the mean size of the SPM particles in transport varies rather strongly with the flow. The correlation coefficient $\mathrm{R}^{2}$ and $\mathrm{a}, \mathrm{b}$, and c constants are in Table 3-1 (a, b). Figure 3-3 $(a, b)$ shows the distribution of the vertically average SSC for the Fall and Spring deployments for all ADCP stations. 
Table 3-1. Correlation coefficients $\mathrm{R}^{2}$ and the constants of the multiple linear regression Eq 3-6 a- Fall 2009

\begin{tabular}{|c|c|c|c|c|c|}
\hline $\mathbf{R M}$ & $\mathbf{1 . 4}$ & $\mathbf{4 . 2}$ & $\mathbf{6 . 7}$ & $\mathbf{1 0 . 2}$ & $\mathbf{1 3 . 5}$ \\
\hline $\mathbf{R}^{\mathbf{2}}$ & 0.89 & 0.98 & 0.91 & 0.82 & 0.95 \\
\hline $\mathbf{a}_{\mathbf{0}}$ & -3.23 & -3.45 & -2.38 & -2.26 & -2.04 \\
\hline $\mathbf{b}_{\mathbf{o}}$ & 3.34 & 3.5 & 2.18 & 2.41 & 1.96 \\
\hline $\mathbf{c}_{\mathbf{o}}$ & 0.10 & 0.10 & -0.18 & 0.11 & -0.07 \\
\hline
\end{tabular}

b- Spring 2010

\begin{tabular}{|c|c|c|c|c|c|}
\hline $\mathbf{R M}$ & $\mathbf{1 . 4}$ & $\mathbf{4 . 2}$ & $\mathbf{6 . 7}$ & $\mathbf{1 0 . 2}$ & $\mathbf{1 3 . 5}$ \\
\hline $\mathbf{R}^{\mathbf{2}}$ & 0.90 & 0.85 & 0.92 & 0.82 & 0.91 \\
\hline $\mathbf{a}_{\mathbf{0}}$ & -1.11 & -1.12 & -2.41 & -2.93 & -2.35 \\
\hline $\mathbf{b}_{\mathbf{0}}$ & 1.06 & 1.39 & 2.61 & 2.92 & 2.15 \\
\hline $\mathbf{c}_{\mathbf{0}}$ & -0.09 & 0.10 & -0.05 & 0.21 & -0.14 \\
\hline
\end{tabular}

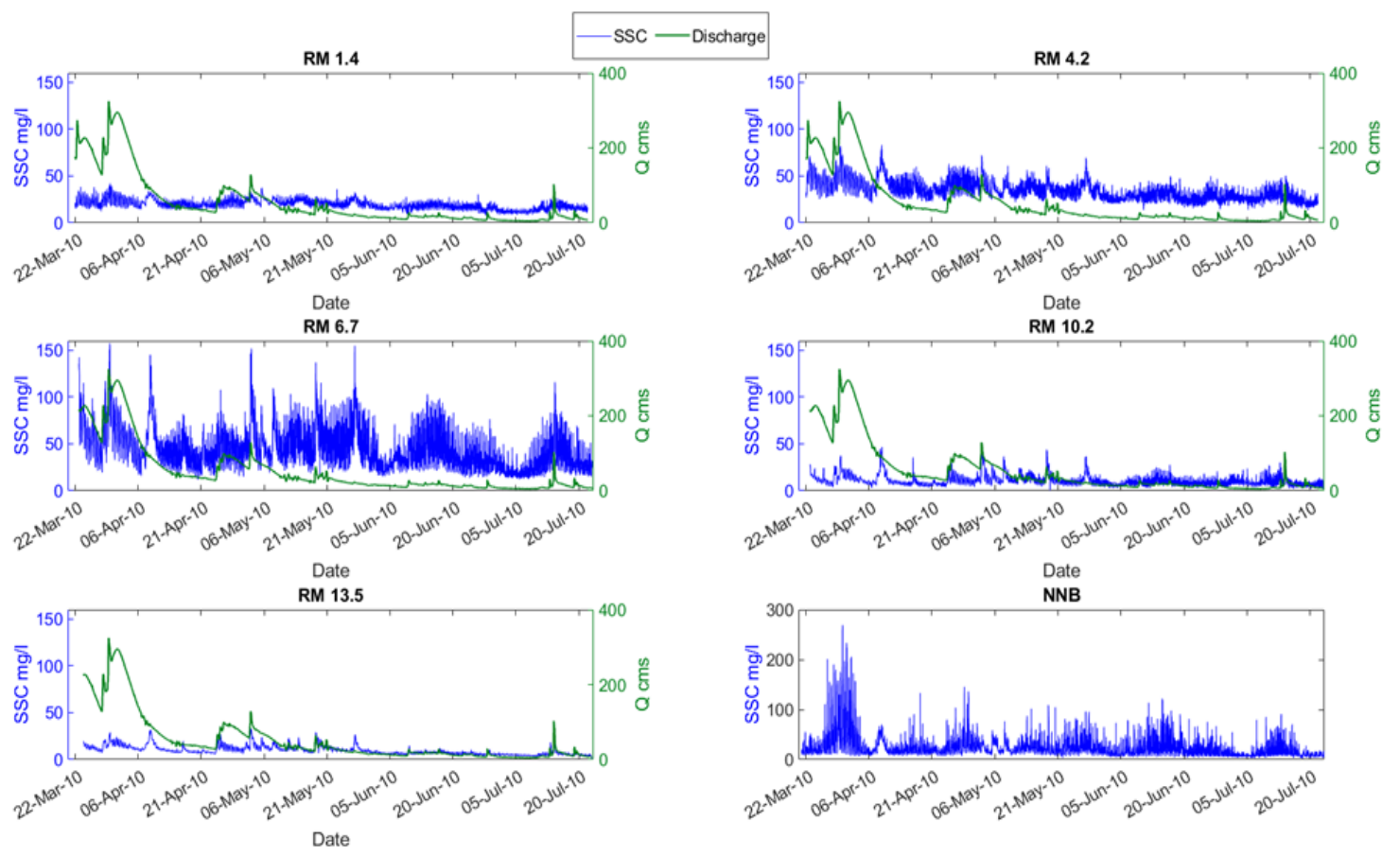

(a) Fall 


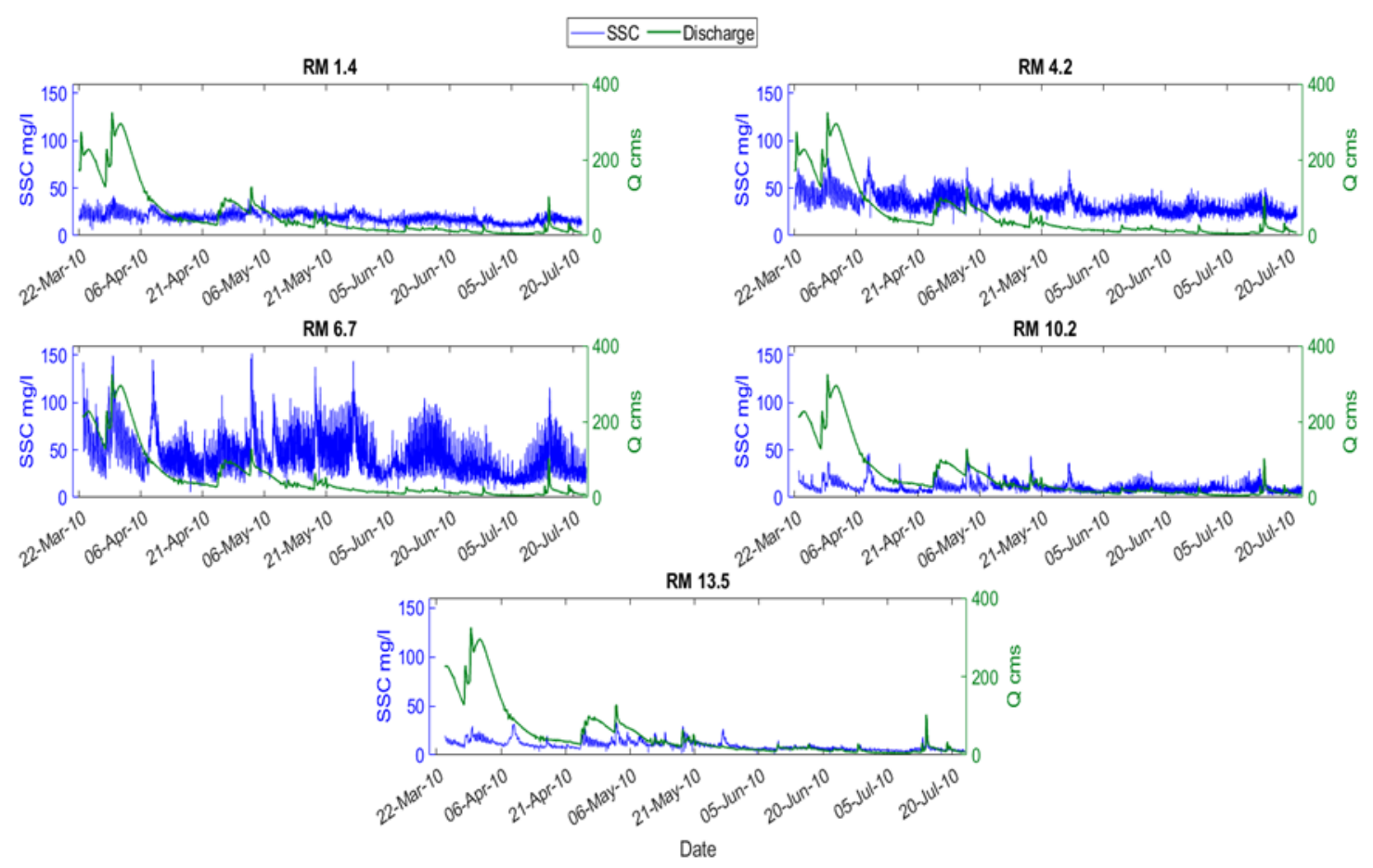

(b) Spring

Figure 3-3(a,b). Distribution of SSC in LPR a-Fall and b-Spring, the concentration close to the estuary mouth is much higher tnan up-estury

\subsubsection{Bed stress and stratification effects on bed stress}

Bed stress $\left(\tau_{b}\right)$ is the tangential force of moving water against the river bed. The skin-friction part of $\tau_{b}=\rho u_{*}^{2}$ (where $u_{*}^{2}$ is the friction or shear velocity) controls erosion and deposition of sediment particles, so it is important to determine its value. When the flow is stratified due to the presence of salinity in the LPR, vertical turbulent momentum transfer is suppressed. Accordingly, shear velocity decreases in magnitude when the flow is stratified. Thus, the effect of stratification has been taken into consideration in calculating shear velocity when salinity intrusion is present. Here the effect of stratification 
on shear velocity is calculated when the differences between the top and bottom salinity intrusion is greater than 1 PSU, by using the linear fit of the lowest four-velocity bins to calculate $u_{*}$. Under stratified conditions, friction velocity $u_{*}$ is calculated by using the log-linear velocity equation (Turner, 1973):

$$
u_{*}=\frac{u k}{\left(\ln \left(\frac{z}{z_{\mathrm{o}}}\right)+\frac{\left(z-z_{\mathrm{o}}\right)}{L_{s t}}\right)}
$$

Where: $\mathrm{u}$ is the velocity $(\mathrm{m} / \mathrm{s}) ; \kappa$ is kappa $=0.41$; and $\mathrm{z}$ is the depth $(\mathrm{m})$. Also, $z \circ$ is the bed roughness length $(\mathrm{m})$, estimated from the intercept of the regression analysis at the bed as in Table 3-2. SLS is the stratification length scale, and $z_{\circ}$. When SLS is positive, $u_{*}$ decreases (Turner, 1973):

$$
\mathrm{SLS}=\frac{u_{*} \frac{d \bar{u}}{d z}}{\alpha k N^{2}}
$$

Equation 3-9

where: $\frac{d \bar{u}}{d z}$ is the velocity shear in the tidal flow, $\alpha=5.5$, and $\mathrm{N}^{2}$ is the buoyancy frequency given by:

$$
N^{2}=-\frac{g}{\rho_{\mathrm{o}}} \frac{\partial \rho}{\partial z}=-\frac{g}{\rho_{\mathrm{o}}} \frac{\Delta \rho}{\Delta z}
$$

A negative $\mathrm{L}_{\text {st }}$ refers to unstable stratification, while a positive SLS indicates stable stratification. In the stratified condition, the mixing is damped by buoyancy (Talke, 2005). The shear velocity when stratification is absent is calculated for the lowest four bins by linear least-square fit following logarithmic velocity equation:

$$
u_{*}=\frac{\kappa u}{\log \frac{z}{z_{o}}}
$$


Figure 3-4 shows the $\mathrm{u}_{*}$ time-series for all LPR moorings for Fall and Spring. The convention used here is that $\mathrm{u}_{*}$ is positive on flood and negative on the ebb.

Table 3-2. $\mathrm{z}_{\mathrm{o}}$ average values for Fall and Spring RMs

\begin{tabular}{|c|c|c|}
\hline \multirow{2}{*}{ RM } & Fall & Spring \\
\cline { 2 - 3 } & \multicolumn{2}{|c|}{$\mathbf{Z}_{\mathbf{o}} \mathbf{~}$} \\
\hline $\mathbf{1 . 4}$ & 0.0033 & 0.0028 \\
\hline $\mathbf{4 . 2}$ & 0.0034 & 0.0032 \\
\hline $\mathbf{6 . 7}$ & 0.0041 & 0.0037 \\
\hline $\mathbf{1 0 . 2}$ & 0.0050 & 0.0048 \\
\hline $\mathbf{1 3 . 5}$ & 0.0054 & 0.0051 \\
\hline
\end{tabular}

RM 1.4

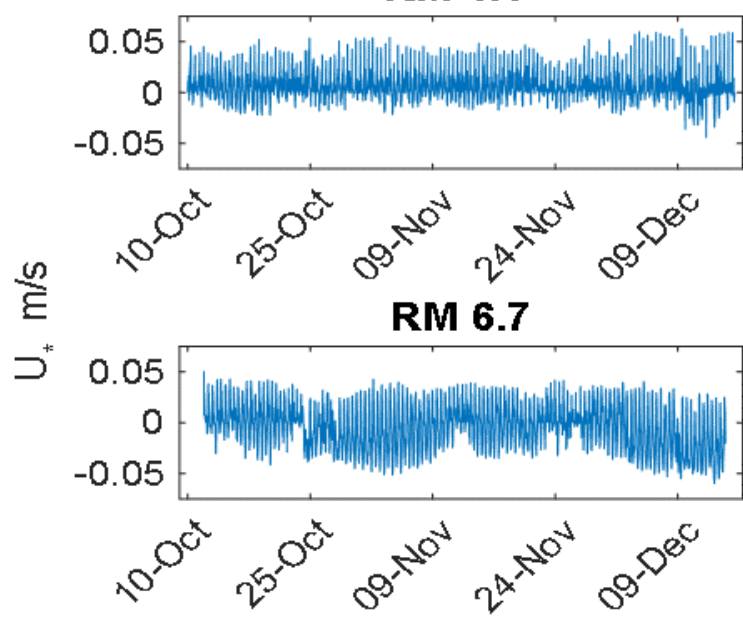

RM 4.2

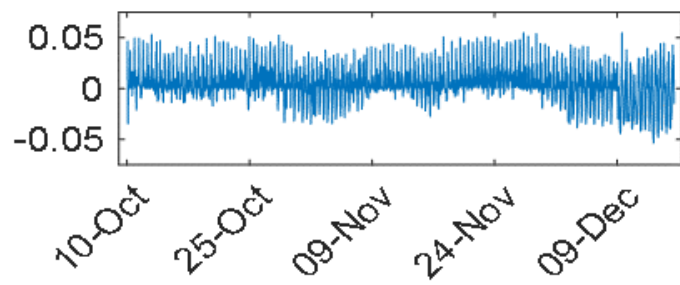

RM 10.2

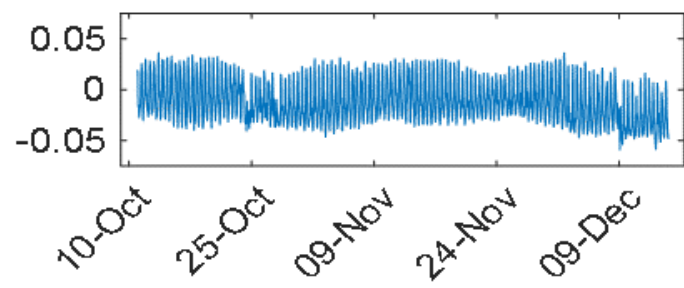

RM 13.5

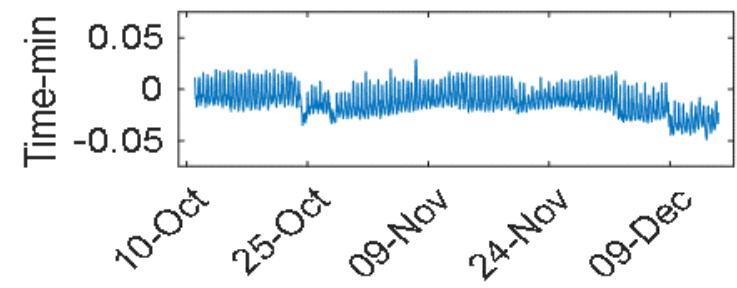

(a) Fall 

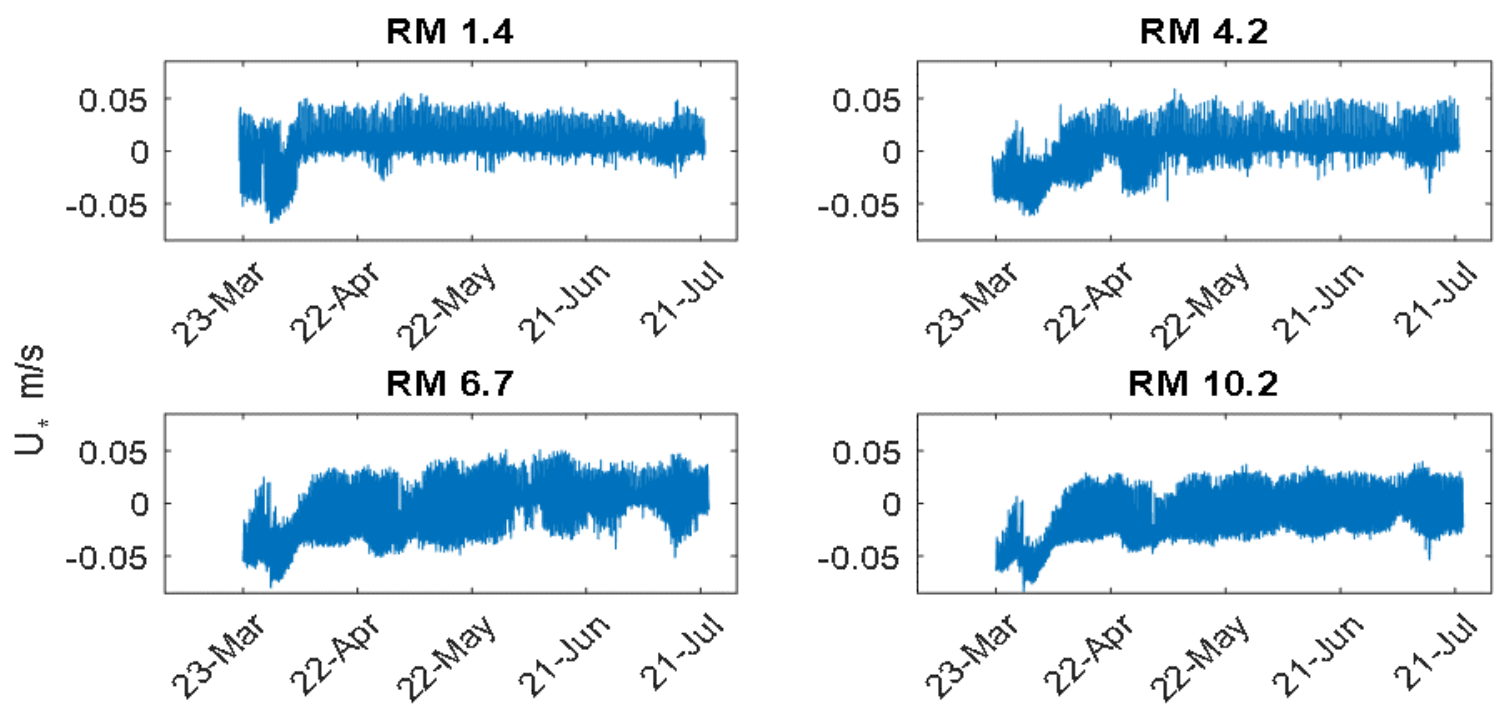

RM 13.5

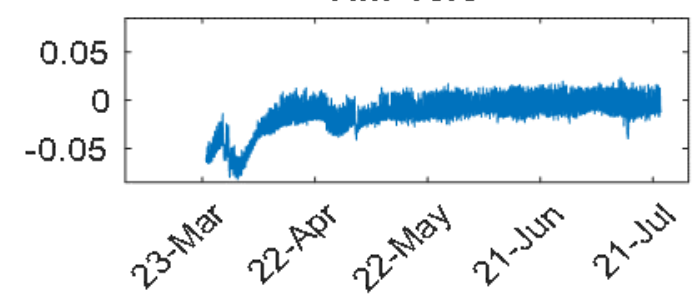

(a) Spring

Figure 3-4 (a-b). time-series of Shear velocity distribution in Fall and Spring

\subsubsection{Bulk settling velocity}

The settling velocity $w_{s}$ of different size classes of suspended sediment particles is a significant parameter in modeling the transport of sediment. It depends on particle properties, which vary with water column condition; for example, $w_{s}$ values during unstratified periods were found to be higher than during stratified conditions. Thus, it is important to include stratification in calculating shear velocity, which is used later in determining bulk settling velocity, $w_{s}$ depending on field measurements of suspended 
sediment and velocity throughout the water column. This approach's primary benefit is based on a large dataset suspended sediments and velocities measurements; thus less sensitive to a local oddity in space and time (CPG, 2010). This $w_{s}$ is designed to capture as well as possible with one value the settling properties of the SPM in the water column.

A bulk settling velocity, $\mathrm{w}_{\mathrm{sb}}$, is the average settling velocity of the distribution of particles in the water column at any one time and place. It can be used to understand factors that govern the SPM field as a whole. A $\mathrm{w}_{\mathrm{sb}}$ was determined for each of the ADCP profiles (at 12-minute intervals) of SSC using the $u_{*}$ values determined from 3-8 and 3-11, following the procedure of Fain et al. (2001). First, the Rouse Number $\left(R_{S}\right)$ is obtained by linear fit of 3-12 to the SPM profile, then $u_{*}$ is obtained from 3-13:

$$
\begin{aligned}
\frac{C}{C_{\text {ref }}} & =\left(\frac{z}{z_{\text {ref }}}\right)^{R_{S}} \\
\mathrm{R}_{\mathrm{S}} & =\frac{w_{S}}{u_{*} \kappa}
\end{aligned}
$$

where $\mathrm{C}$ is the concentration; $\mathrm{C}_{\text {ref }}$ is the concentration at the bottom (first bin); $\mathrm{z}$ bin height, $z_{\text {ref }}$ is the first bin height; $w_{s}$ is settling velocity; $u_{*}$ shear velocity, and $\kappa$ is Von Karman constant $(\kappa=0.41)$.

\subsection{Calibration and Results}

Calibration of ADCP relative backscatter (RB) to SSC was an important first step in analyzing the Physical Water Column Monitoring (PWCM) data set. The PWCM program provided a set of ADCP data with a vertical bin size of $0.5 \mathrm{~m}$ and a sampling interval of 12 minutes during Fall 2009 (October to December) and Spring 2010 (March to 
July) for RM 1.4, 4.2, 6.7, 10.2, and 13.5. Table 3-1(a, b) shows the relationship of SSC grab samples with RB and the flow; the agreement is reasonable, despite some scatter. Also, a few outliers SSC were removed before the regression was carried out - it is thought that they were related to differences in time and depth between grab samples and ADCP. The top and bottom water-column SSC samples were about $0.91 \mathrm{~m}$ above the bottom and $0.91 \mathrm{~m}$ from the surface, whereas the depth of the first bin of ADCP $600 \mathrm{kHz}$ was about $1.5 \mathrm{~m}$ and about $1.35 \mathrm{~m}$ for ADCP $1200 \mathrm{kHz}$ above the bed, so the depth match of the top and bottom bins with the water column samples was imperfect. Furthermore, the time of SSC grab samples was a little bit different from ADCP sample times.

Figure 3-5 shows the settling velocity $w_{s}$ distribution in space and time, Figure 3-6 shows a histogram of the logarithmic settling velocity $w_{s}$ distribution, and Figure 3-7 shows the $25^{\text {th }}, 50^{\text {th }}$, and $75^{\text {th }}$ percentile of time series settling velocity, and Table 3-3 shows the mean, median, $25^{\text {th }}$, and $75^{\text {th }}$ values of settling velocity along the LPR. Figure 3-5 suggests that $w_{s}$ was higher during high flow periods upriver of salinity intrusion due to increasing the shear stress and, as a result, resuspension of coarser sediment particles. Moreover, the $w_{s}$ distribution and box plot show that the highest $w_{s}$ values are at the mouth of the estuary due to high tide currents and aggregate the particles via salinity. However, the mean $w_{s}$ was highest during Spring at RM 10.2, and at RM 6.7 and 10.2 during fall. Most of very low $w_{s}$ values occurred at ebb-slack at the brackish stations when the stratification is typically strong, which lead to the increase in the drag force acting on the particles causing to decrease the $w_{s}$ to the minium. However, up-estuary, low $w_{s}$ occurred 
at flood-slack due to high water energy. Furthermore, the skewness analysis shows the skew is positive at all mooring locations, with higher skewness down-estuary due to the coarse sediment.
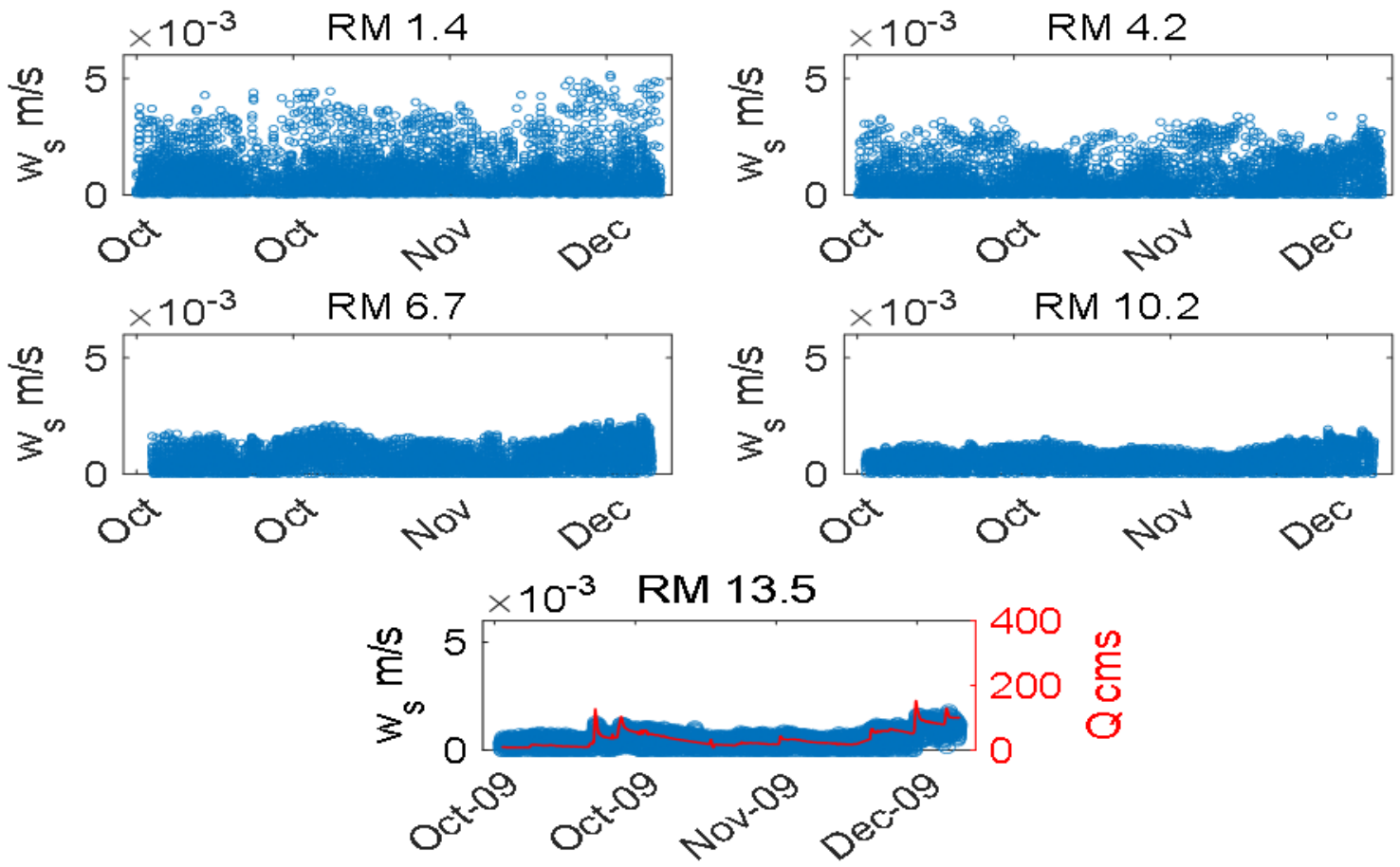

(a) Fall 

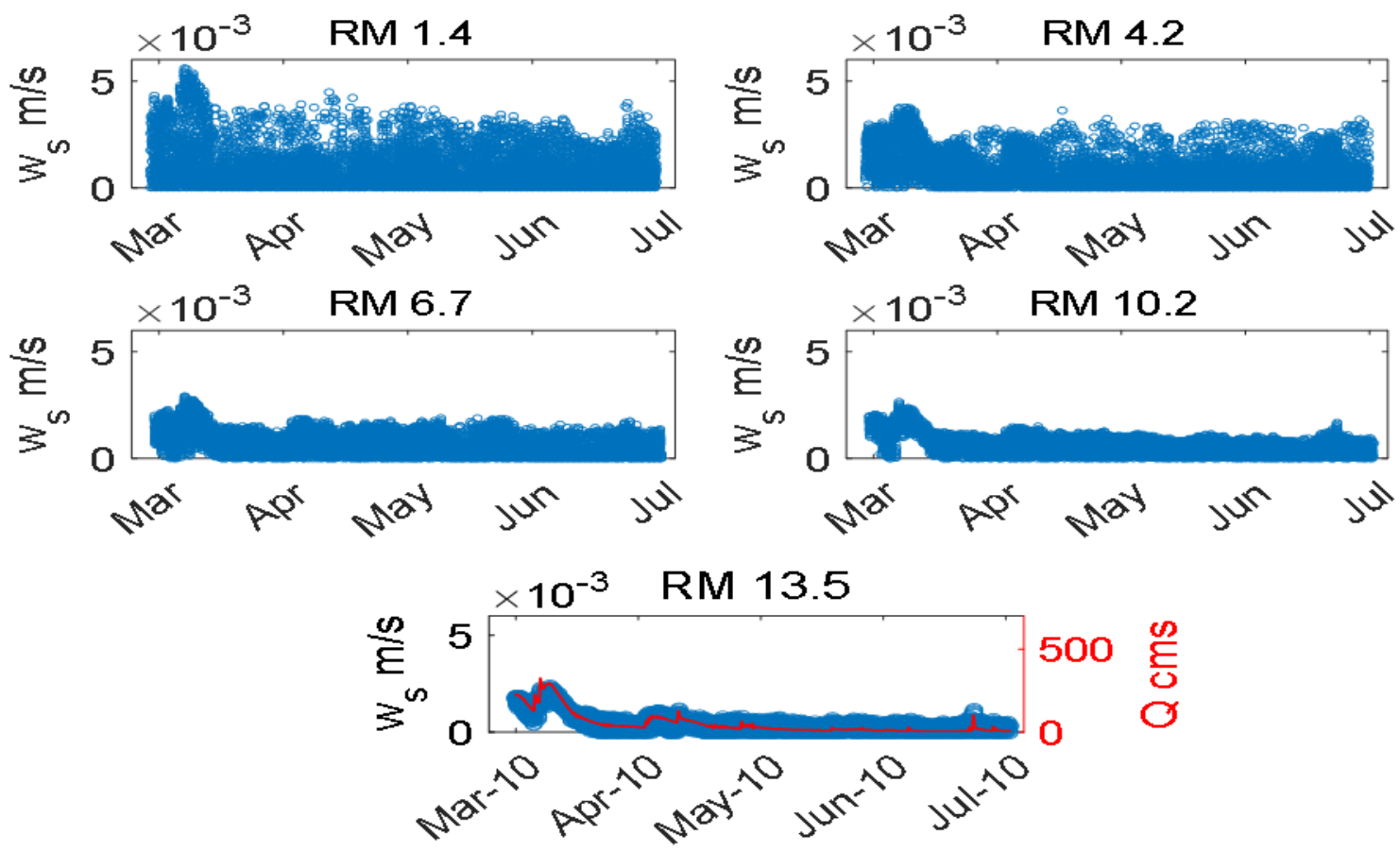

(b) Spring

Figure 3-5. Distribution of Settling velocity in space and time 


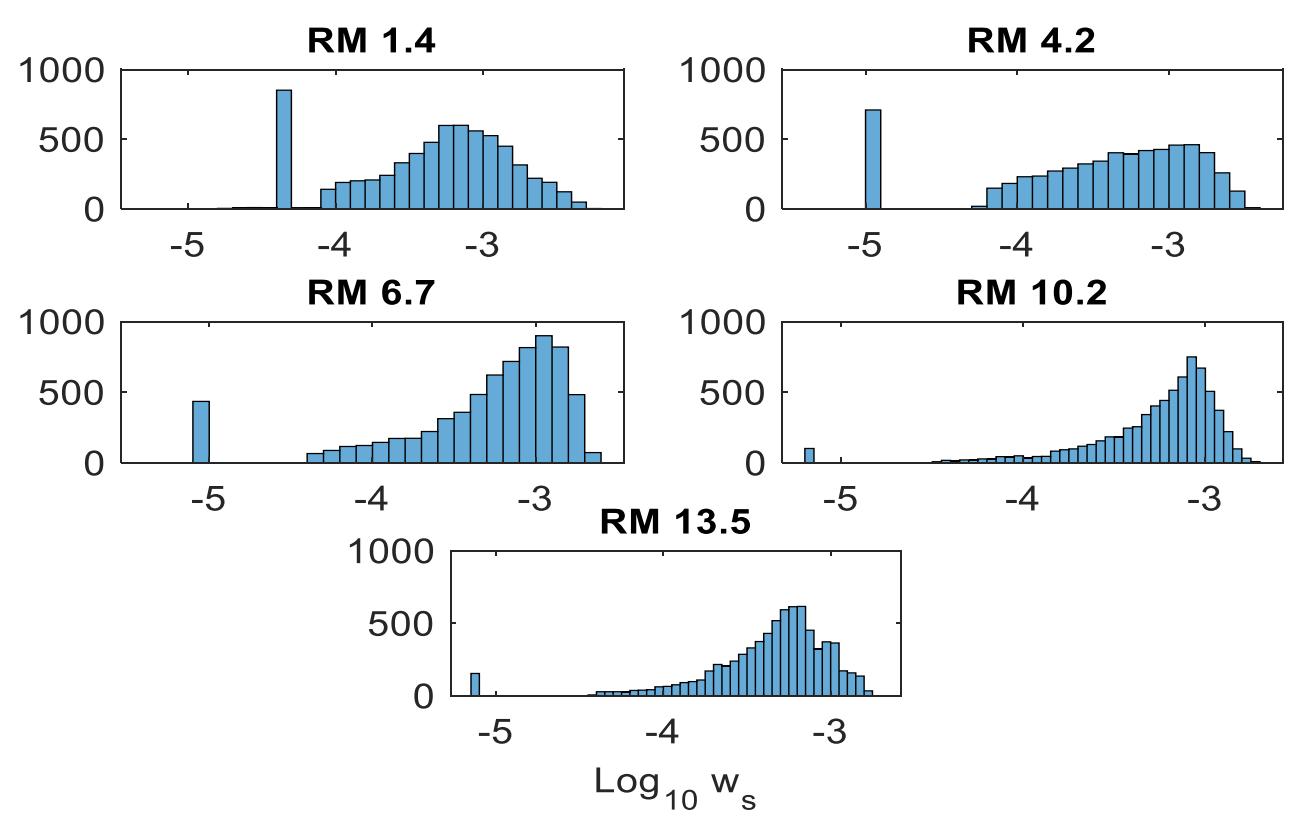

(b) Fall
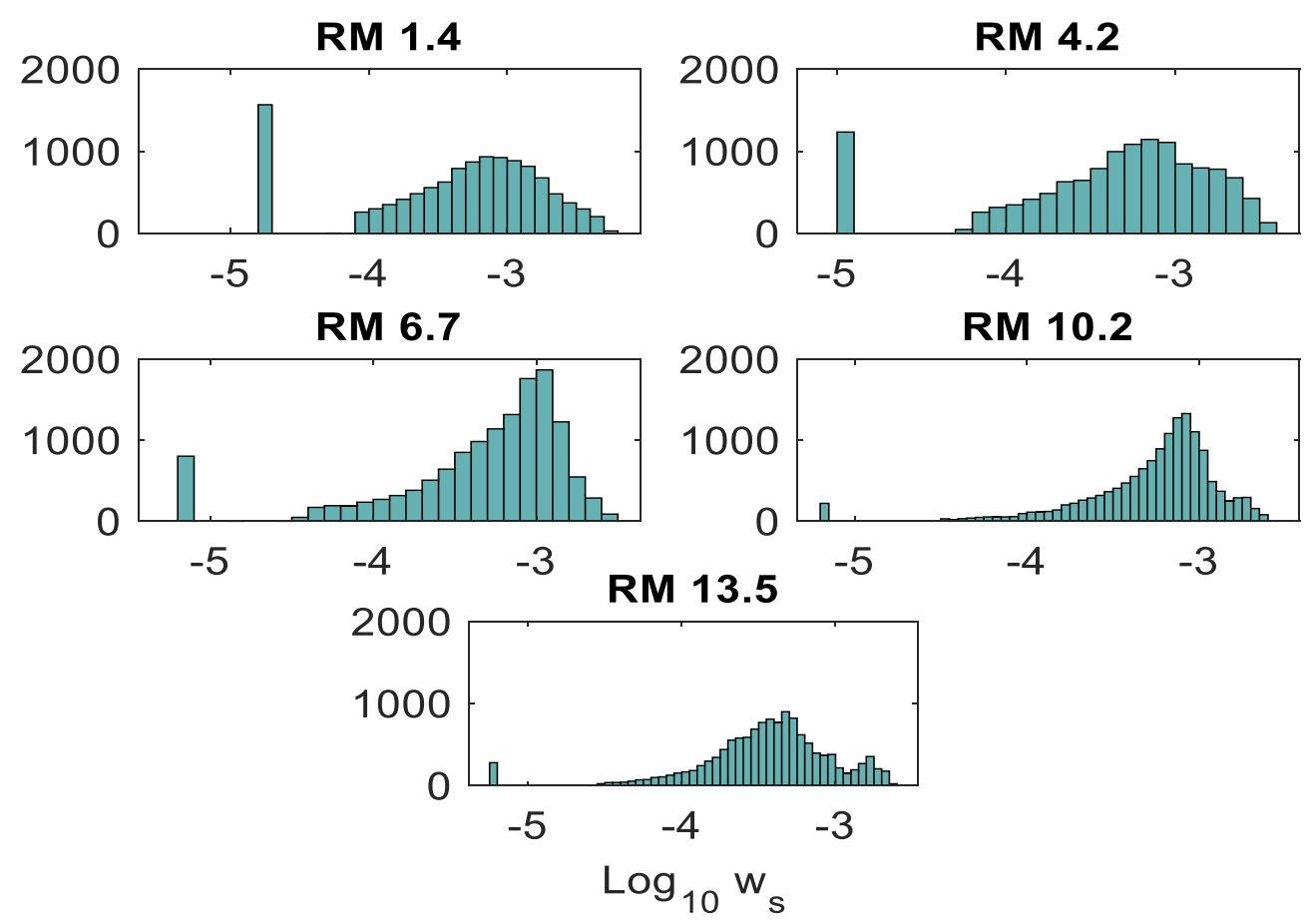

(b) Spring

Figure 3-6(a,b):Histogran distribution of $\log w_{S}$ 


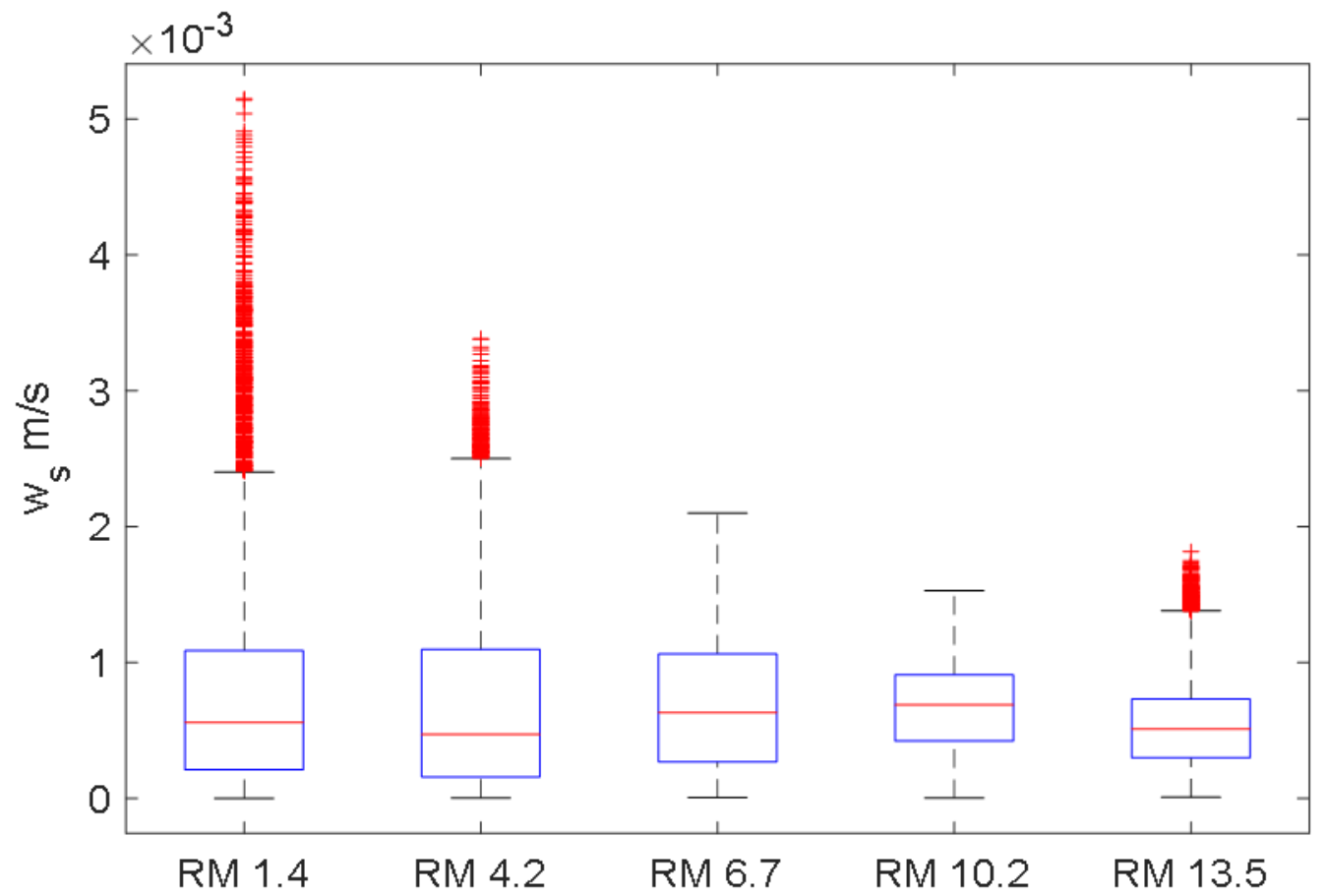

(a) Fall

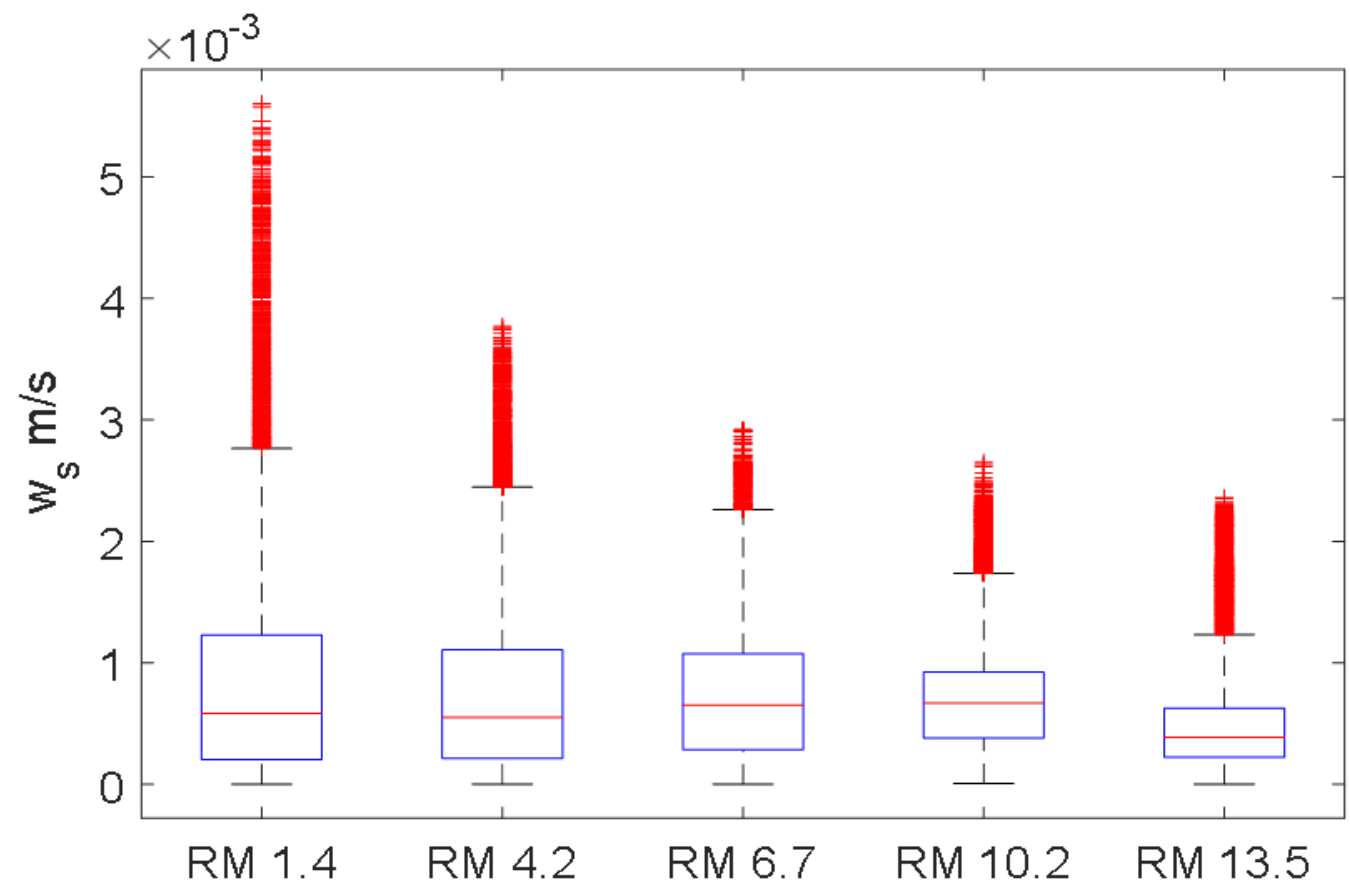

(a) Spring

Figure $3-7.25^{\text {th }}, 50^{\text {th }}$, and $75^{\text {th }}$ of the time-series settling velocity 
Table 3-3. Mean, median, $25^{\text {th }}$, and $75^{\text {th }}$ settling velocity in $\mathrm{m} / \mathrm{s}$ for Fall and Spring RMs

\begin{tabular}{|c|c|c|c|c|c|c|c|c|}
\hline \multirow{2}{*}{ RM } & \multicolumn{4}{|c|}{ Fall2009 } & \multicolumn{4}{c|}{ Spring2010 } \\
\cline { 2 - 9 } & Mean & Median & $\mathbf{2 5}^{\text {th }}$ & $\mathbf{7 5}^{\text {th }}$ & mean & Median & 25th & 75th \\
\hline $\mathbf{1 . 4}$ & $8.0 \times 10^{-4}$ & $5.6 \times 10^{-4}$ & $2.1 \times 10^{-4}$ & $1.1 \times 10^{-3}$ & $8.9 \times 10^{-4}$ & $5.8 \times 10^{-4}$ & $2.0 \times 10^{-4}$ & $1.1 \times 10^{-3}$ \\
\hline $\mathbf{4 . 2}$ & $7.1 \times 10^{4}$ & $4.7 \times 10^{-4}$ & $1.5 \times 10^{-4}$ & $1.1 \times 10^{-3}$ & $7.8 \times 10^{-4}$ & $5.5 \times 10^{-4}$ & $2.1 \times 10^{-4}$ & $1.1 \times 10^{-3}$ \\
\hline $\mathbf{6 . 7}$ & $7.5 \times 10^{-4}$ & $6.8 \times 10^{-4}$ & $3.0 \times 10^{-4}$ & $1.1 \times 10^{-3}$ & $7.3 \times 10^{-4}$ & $6.5 \times 10^{-4}$ & $2.8 \times 10^{-4}$ & $1.1 \times 10^{-3}$ \\
\hline $\mathbf{1 0 . 2}$ & $6.7 \times 10^{-4}$ & $6.7 \times 10^{-4}$ & $3.9 \times 10^{-4}$ & $9.1 \times 10^{-4}$ & $7.1 \times 10^{-4}$ & $6.6 \times 10^{-4}$ & $3.8 \times 10^{-4}$ & $9.2 \times 10^{-4}$ \\
\hline $\mathbf{1 3 . 5}$ & $5.4 \times 10^{-4}$ & $5.1 \times 10^{-4}$ & $2.9 \times 10^{-4}$ & $7.3 \times 10^{-4}$ & $5.2 \times 10^{-4}$ & $3.9 \times 10^{-4}$ & $2.2 \times 10^{-4}$ & $6.3 \times 10^{-4}$ \\
\hline
\end{tabular}

\subsubsection{Importance of parameters in controlling settling velocity}

A robust multiple non-linear regression was applied to determine the major factors affecting bulk $w_{s}$. Robust regression re-weights the outer points without removing them (Leffler \& Jay, 2009). This regression has shown that normalized settling velocity is the best fit with normalized mean velocity, tidal range, and flow in the upper estuary (RM 6.7, 10.2, and 13.5) where the average salinity is sometimes less than 2 PSU:

$$
\text { N_Ws }=a_{1}+b_{1} * \mathrm{~N} \_\mathrm{u}^{2}+c_{1} * N_{-} T R^{n_{1}}+d_{1} * N_{-} f^{n_{1}}
$$

Equation 3-14

where $a_{1}, \mathrm{~b}_{1}, \mathrm{c}_{1}$, and $\mathrm{d}_{1}$ are constants to be determined from the regression, $\mathrm{n}_{1}$ is an exponent that ranges $0.5 \leq \mathrm{n}_{1} \leq 2.5, \mathrm{~N}_{-} \mathrm{W}_{\mathrm{s}}$ is the normalized settling velocity, $\mathrm{N} \_\mathrm{u}$ is normalized instantaneous velocity, $\mathrm{N}_{-} \mathrm{TR}$ is normalized tidal range, and N_f is normalized discharge. Variables are normalized by dividing them by the maximum values of each variable. Furthermore, the regression is applied separately on the flood and ebb of the tidal cycle. The results have shown a good correlation between $w_{s}$ and the related variables with 
correlation coefficient ranging from 0.74 to 0.98 with $n$ ranges $0.5 \leq \mathrm{n}_{2} \leq 1.7$, depending on the station.

Normalized $w_{s}$ in the lower estuary (average salinity $>2$ PSU) is often a function of the Simpson number (Burchard et al., 2010; Monismith et al., 1996; Simpson et al., 1990; Stacey \& Monismith, 2001) more than of velocity. But it is also related to normalized tidal range and flow (RMs 1.4 and 4.2). Thus, a regression in the following four used:

$$
\text { N_ws }=a_{2}+b_{2} * \mathrm{Si}+c_{2} * N_{-} T R^{n_{2}}+d_{2} * N_{-} f^{n_{2}}
$$

where Si is the Simpson number (also called the horizontal Richardson Number), which describes the interaction of the longitudinal density gradient and tidal velocities that creates strains-induced periodic stratification of potential energy due to straining to the rate of production of turbulent kinetic energy when salinity is present:

$$
\mathrm{Si}=\frac{\partial_{x} b s H^{2}}{u_{*}^{2}}
$$

where: $\partial_{\mathrm{x}} \mathrm{bs}$ is the average longitudinal buoyancy difference taken between adjacent stations, and bs $=-\mathrm{g} \beta \mathrm{S}, \beta=7.8 \times 10^{-4} \mathrm{PSU}^{-1}$ is the haline contractivity, $\mathrm{S}$ is the salinity in $\mathrm{PSU}$, and $\mathrm{H}$ is the water depth in (m). Clearly, $\mathrm{Si}$ is the most important factor in setting $w_{s}$ in the stratified part of the estuary. Overall, the results have shown a high correlation between $w_{s}$ and the related variables with correlation coefficient ranging from 0.79 to 0.93 with $n$ ranges $0.7 \leq n_{2} \leq 2$ as shown in Table 3-4. 
Table 3-4. Correlation coefficients and $\mathrm{n}$ values for fall and spring RM

(a) Fall

\begin{tabular}{|c|c|c|c|c|c|c|}
\hline $\mathbf{R M}$ & \multirow{3}{*}{$\begin{array}{l}\overrightarrow{8} \\
\stackrel{\theta}{I}\end{array}$} & $\mathbf{R}^{2}$ & $\mathbf{n}_{2}$ & \multirow{3}{*}{$\frac{0}{0}$} & $\mathbf{R}^{2}$ & $\mathbf{n}_{2}$ \\
\hline 1.4 & & 0.86 & 1 & & 0.85 & 1.3 \\
\hline \multirow[t]{2}{*}{4.2} & & 0.84 & 2 & & 0.79 & 2 \\
\hline & & R2 & $\mathbf{n}_{1}$ & & R2 & $\mathbf{n}_{1}$ \\
\hline 6.7 & \multirow{3}{*}{$\frac{\overrightarrow{0}}{8}$} & 0.72 & 1.5 & \multirow{3}{*}{$\frac{0}{0}$} & 0.74 & 1.7 \\
\hline 10.2 & & 0.96 & 0.5 & & 0.86 & 0.5 \\
\hline 13.5 & & 0.95 & 0.3 & & 0.87 & 0.4 \\
\hline
\end{tabular}

(a) Spring

\begin{tabular}{|c|c|c|c|c|c|c|}
\hline $\mathbf{R M}$ & \multirow{3}{*}{$\frac{\vec{O}}{\mathbb{E}}$} & $\mathbf{R}^{2}$ & $\mathbf{n}_{2}$ & \multirow{3}{*}{ 总 } & $\mathbf{R}^{2}$ & $\mathbf{n}_{2}$ \\
\hline 1.4 & & 0.93 & 2 & & 0.8 & 1.5 \\
\hline \multirow[t]{2}{*}{4.2} & & 0.91 & 1.4 & & 0.83 & 0.7 \\
\hline & & $\overline{\mathbf{R}^{\mathbf{2}}}$ & $\mathbf{n}_{1}$ & & $\mathbf{R}^{2}$ & $\mathbf{n}_{1}$ \\
\hline 6.7 & \multirow{3}{*}{$\frac{\vec{g}}{8}$} & 0.87 & 0.6 & \multirow{3}{*}{ 음 } & 0.89 & 1.4 \\
\hline 10.2 & & 0.98 & 0.5 & & 0.97 & 0.5 \\
\hline 13.5 & & 0.99 & 1.5 & & 0.98 & 1.4 \\
\hline
\end{tabular}

In general, $w_{s}$ is affected primarily by density stratification at the mouth of LPR while it is strongly affected by velocity further landward. For ADCP stations that are close to the estuary mouth (RM 1.4 and 4.2), higher $w_{s}$ are correlated with lower values of $\mathrm{Si}$ during ebbs, while mixing reduces stratification, particle sizes, and $w_{s}$ during floods. For the RMs $6.7,10.2$, and 13.5 , velocity is the primary variable that affects the settling velocity together with TR and flow. The highest $w_{s}$ occurred with low velocities during ebb-slack 
periods, and it is correlated with low tide, while there is no clear relationship with the flow. On the other hands, the lowest $w_{s}$ occurred with high velocities in high water, flood-slack periods, and correlated with high tide Figure 3-8 (a,b).
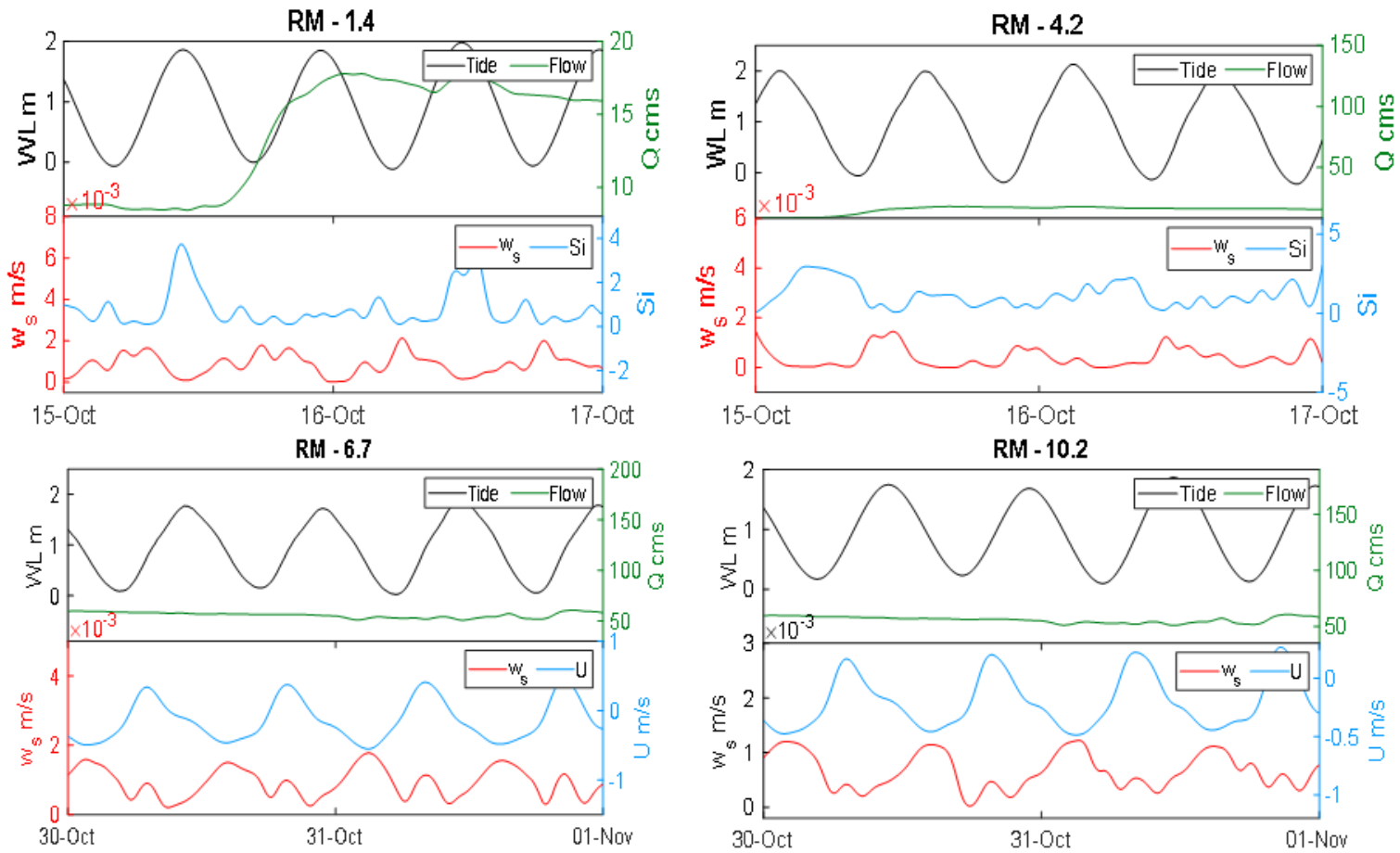

RM -13.5

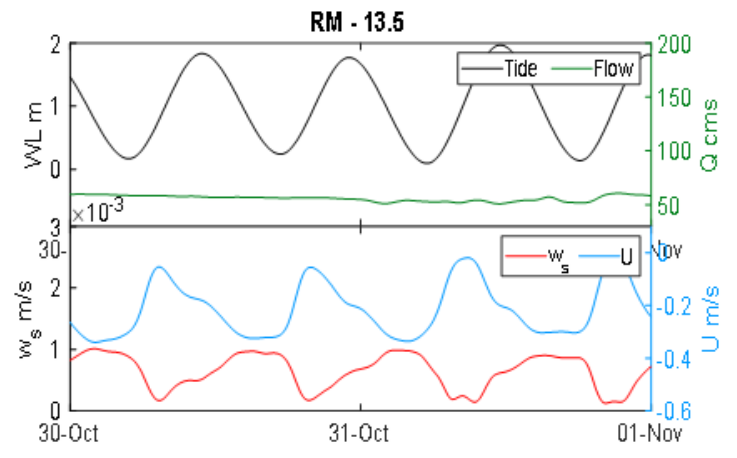

(a) Fall 

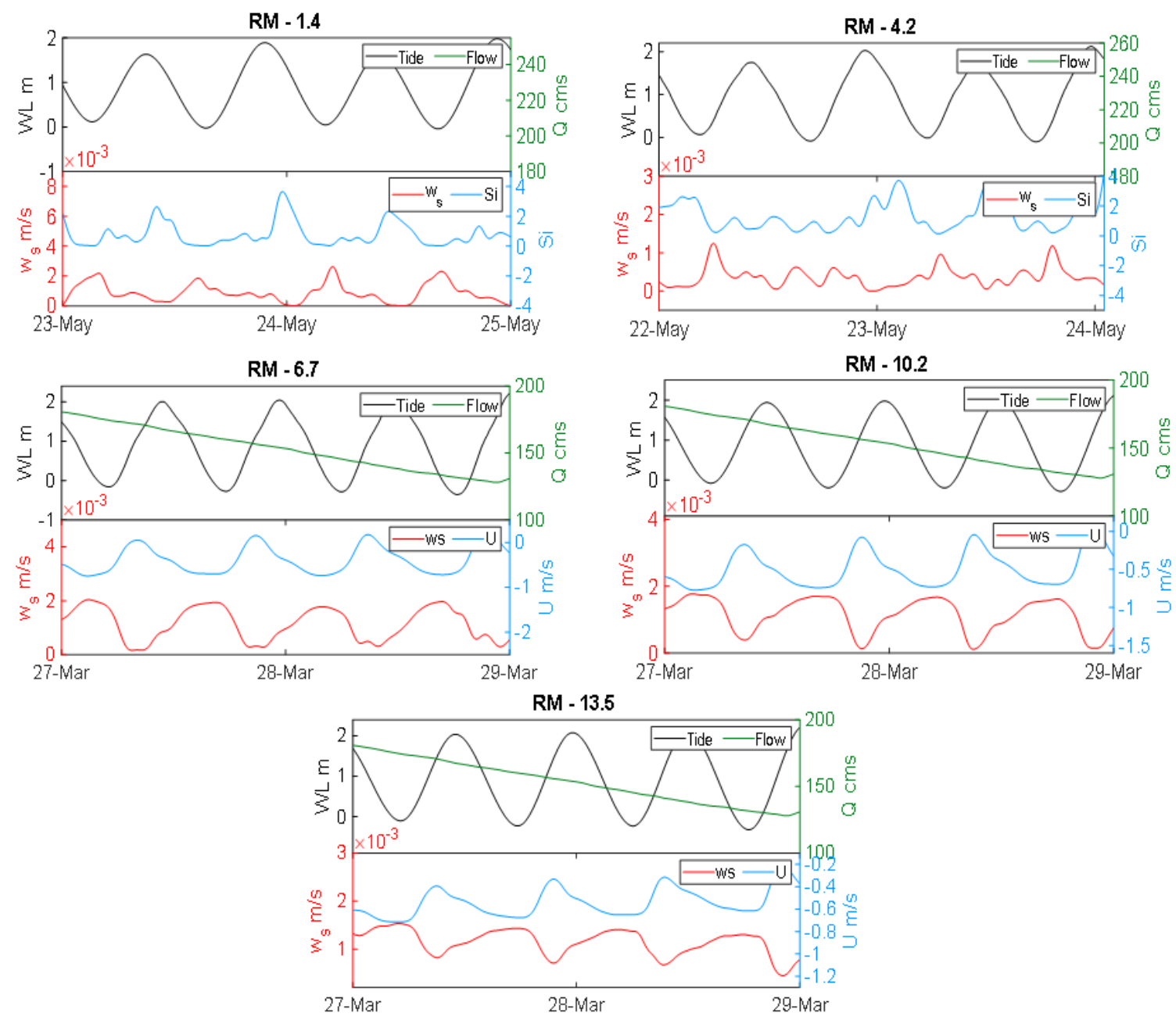

(a) Spring

Figure 3-8(a, b). Examples of the variations of $w_{S}$ with flow and $\mathrm{Si}$ (near mouth; 1.4- 4.2), and with tidal velocity and river flow at upriver stations $(6.7,10.2$, and 13.5$)$ 


\subsection{Summary and conclusion}

The purpose of this chapter was to examine via data analysis space and time variations of $w_{s}$ in the LPR, taking into consideration the effect of salinity on the shear velocity in the LPR, based on data from five ADCP moorings collected in Fall 2009 and Spring 2010. Further, the factors influencing $w_{S}$ were determined by multiple linear regression.

To carry out the analyses of $w_{s}$, it was first necessary to determine SSC from RB data from the ADCPs. A new multiple non-linear regression was used between gravimetric SSC samples with RB to determine SSC from the ADCP data. This regression considered SSC as a function of RB and normalized river flow. This approach was necessary because poorly defined changes in the SPM size distribution occurred as flow varied. The resulting $\mathrm{R}^{2}$ values were between 0.82-0.98 for Fall 2009 and 0.82-0.92 for Spring 2010.

Equation 3-12 was then used to estimate the Rouse number $R_{s}$ for each SSC profile determined from ABS. Finally, it was necessary to determine the shear velocity $\mathrm{u}_{*}$ so that $w_{s}$ could be determined from $R_{s}$. Shear velocity $\mathrm{u}_{*}$ is linked with the bed roughness and stratification; therefore, shear velocity was calculated by taking into consideration the effect of salinity and bed roughness. Then, the logarithmic velocity equation was applied when the flow was unstratified, while a log-linear equation was applied when the flow was stratified via using instantaneous velocity readings. Combining these methods together gave a reasonable distribution of shear velocity along LPR. 
In the seaward part of the estuary (RM 1.4 and 4.2), where salinity is present, aggregates are formed, and mixing is reduced via stratification. The highest $w_{s}$ values occurred close to the estuary mouth, due to the resuspension of coarse particles as salinity intrusion moves landward. Here, the Simpson number Si is found to be the main parameter that controls $w_{s}$, with tidal range TR and river flow playing secondary roles. The presence of salinity and a moderately strong horizontal salinity gradient affect settling velocity through $\mathrm{Si}$ at the two most landward stations. This is consistent with the fact that the salt front is found about RM 4.2 on the flood, according to Mathew \& Winterwerp (2020) and the salinity intrusion modeling presented in Chapter 5 .

At stations landward of RM 6.7, the salinity is usually less than 2 PSU. The highest settling velocity was lower than at the brackish stations farther seaward. Far upriver, velocity is the primary variable that is correlated with $w_{s}$ together with TR and flow. In general, maximum $w_{s}$ decreases landward, reflecting the predominance of unaggregated fines and decreasing tidal energy. This occurs despite the presence of sand in the bed landward of about RM 8; apparently this material is not re-suspended often enough to affect the overall statistics. Higher $w_{s}$ near the estuary mouth reflect the predominance of coarser, aggregated particles.

At brackish stations, maximum $w_{S}$ occurs at flood slack when $\mathrm{Si}$ is typically small, and stratification is weak. Minimum $w_{s}$ coincides with larger $\mathrm{Si}$ at the ebb slack when the stratification is stronger. Peak $w_{s}$ tends to appear during ebb slack due to low water energy, while the minimum $w_{s}$ occurred with flood slack due to high currents. On the other hand, 
at the landward station, maximum $w_{s}$ occurs at ebb slack when the velocity is typically small, while the minimum $w_{s}$ coincides with larger velocity during flood due to high water energy and at high-water flood slack. 


\section{Chapter 4 Suspended sediment variations in the Lower Passaic River}

\subsection{Introduction}

An estuary is defined as a transition region in which the freshwater of fluvial origin is mixed with marine saltwater, producing vertical stratification and a horizontal density gradient (Hansen \& Rattray, 1965; Wilson, 1977). Estuaries are complex, and their physical processes depend on many variables such as tidal forcing, river inflow, and wind stress. Estuaries can filter sediments and contaminations coming from the river and moving toward the marine environment. Moreover, sediment accumulation in an estuary, the balance between erosion and deposition, depends on hydrodynamic conditions and the quantity and quality of sediment supplied (Hickin, 1995). Erosion includes the movement and transport of particles mainly from the boundary, while deposition involves sediment placement and transport.

The LPR drains into Newark Bar and is part of the larger New York-New Jersey Harbor estuary (Iannuzzi \& Ludwig, 2004). The LPR has suffered highly deleterious effects due to more than 200 years of urbanization and industrialization. It is the site of a complex Superfund cleanup, and the United States Environmental Protection Agency announced its plan to remediate this area in April of 2014. Among the contaminants of concern in the LPR are lead, 2,3,7,8 TCDD, mercury, PCBs, PAHs, pesticides, Chlordane, and copper (The Louis Berger Group \& Battelle, 2014). When these substances are found in the water column, they are mostly attached to fine suspended sediment and 
aggregates. Accordingly, it is important to distinguish the different behaviors of fines, aggregates, and other coarse materials.

Tidal forcing affects SSC variability in the marine environment on multiple time scales: spring-neap, flood-ebb, and annual to 18.6-year cycles of tidal range, all of the influence the variability of sediment transport. Thus, sediment transport is well correlated with tidal range and velocity (Yang et al., 2004). Furthermore, the transport of fine particles in the partially mixed estuary is mainly controlled by the interaction between turbulent mixing, stratification, resuspension, and the settling velocity of the suspended particles (Geyer, 1993).

In this chapter, I investigate the vertical variability of SSC in the water column, leading to the question:

- What are the factors, e.g., advection and erosion/deposition, that affect particle distributions (e.g., Rouse-like or Modified-Rouse)?

Furthermore, I will analyze:

a) The dynamical importance of advection on fine and coarse particles.

b) The parameters that determine the variation of the fine and coarse SSC classes with the flow and tidal range.

c) The degree to what local deposition/erosion affects $\mathrm{w}_{\mathrm{s}}$ profiles. 


\subsection{Materials and Method}

\subsubsection{Profile Analyses}

The importance of the Rouse number can be seen by scaling the local Suspended Particulate Matter (SPM) conservation equation (Jay et al., 2007), neglecting horizontal diffusion:

$$
\begin{array}{ccccc}
\frac{\partial c}{\partial t}+\mathrm{u} & \frac{\partial c}{\partial x}+\mathrm{v} \frac{\partial c}{\partial y}+\left(\mathrm{w}-w_{S}\right) & \frac{\partial c}{\partial z}=\frac{\partial}{\partial z}\left(\mathrm{k}_{\mathrm{c}} \frac{\partial c}{\partial z}\right) & \text { Equation 4-1 } \\
\text { I } & \text { II } & \text { III } & \text { IV } & \mathrm{V}
\end{array}
$$

where $\mathrm{c}$ is the concentration, ( $\mathrm{u}, \mathrm{v}$, and $\mathrm{w})$ are the velocities in $\mathrm{x}, \mathrm{y}, \mathrm{z}$ direction, $\mathrm{w}_{\mathrm{s}}$ is the settling velocity and $\mathrm{k}_{\mathrm{c}}$ is the vertical eddy diffusivity; in further analysis the $\mathrm{v}$ and $\mathrm{w}$ velocities are neglected by assuming that the flow is laterally uniform and that the wvelocity is small in comparison with $\mathrm{w}_{\mathrm{s}}$. A simplification based on scaling is used to yield a local balance at any point above the bed. The result of scaling the mass conservation equation is a non-dimensional SPM equation in four terms, with associated scales:

$$
\begin{gathered}
\frac{H}{T k u_{*}}+\frac{U H}{L k u_{*}}+\frac{w_{S}}{k u_{*}}=1 \\
\text { I II } \quad \text { IV }
\end{gathered}
$$

Equation 4-2

where $\mathrm{T}$ is the time, $\mathrm{H}$ is the depth, and $\mathrm{L}$ is the length. The non-dimensional numbers represent: I acceleration; II along channel advection; IV the Rouse number $\mathrm{Rs}=\frac{\mathrm{W}_{\mathrm{s}}}{\mathrm{ku}_{*}}($ Rouse \& Ince, 1957) which represents the ratio between settling velocity and vertical mixing, and $\mathrm{V}$ is the turbulent mixing, relative to which the remaining terms are compared. The traditional Rouse or local balance occurs when terms I and II are small relative to IV and 
$\mathrm{V}$. This does not mean that IV and V are equal, just that they are the largest terms. The behavior of the vertical distribution of SSC varies with flow conditions, and it is, for example, sometimes affected by along channel advection. Thus, this study describes two kinds of vertical SSC distributions "Rouse-like" profiles and "Modified-Rouse". The former applies when there is an approximate balance of IV and V, while the latter includes the effect of horizontal advection on particles distribution. An inverse analysis method is

used to represent "Rouse-like" profiles. A perturbation method is used to fit "ModifiedRouse" profiles via numerical solution of the resulting differential equation when the advection is dominant.

\subsubsection{Multiple size classes}

In addition to defining $\mathrm{a} \mathrm{w}_{\mathrm{sb}}$ for each profile (in Chapter 3 ), profiles with sufficient vertical extent were described in terms of two settling velocities because water samples indicated the presence of multiple sizes of SPM. A $\mathrm{w}_{\mathrm{s}}=0.05 \mathrm{~mm} / \mathrm{s}$ was used to represent the fines (wash load to medium silt), and $10 \mathrm{~mm} / \mathrm{s}$ for RM 1.4 and 4.2 and $7 \mathrm{~mm} / \mathrm{s}$ for RM 6.7, 10.2, and 13.5 to represent the coarser load (fine sand above salinity intrusion and aggregate in the salinity intruded part of the system). These values were chosen based on the analysis by CPG (2010). Because the number of ADCP depths was limited (usually less than 10), it was not possible to fit more than two size classes of SPM, though more may be present. 
A typical Rouse-like SSC profile, unaffected by advection and deposition/erosion, shows a monotonic decrease in SSC away from the bed. Accordingly, SSC profilers have been separated to Rouse-like and modified-Rouse depending on the sign of the covariance:

$$
\operatorname{Cov}(\mathrm{c}, \mathrm{z})=\frac{\sum_{i=1}^{n}\left(c_{i}-\bar{c}\right)\left(z_{i}-\bar{z}\right)}{n-1}
$$

Where: $\mathrm{c}$ is SPM concentration, $\bar{c}$ the average SPM concentration and $\bar{z}$ the average depth. A negative Cov indicates a Rouse-like profile in which c decreases with the height from the bed, z. Profiles with a positive Cov (c increasing with height $\mathrm{z}$ ) are assumed to be affected by advection (Modified-Rouse). The deposition or erosion that may affect the SSC profile is discussed below, but this situation is believed not to be common in the ADCP data analyzed here.

The concentration of each settling class at a reference depth is determined using non-negative least square regression (NNLR; Fain et al., 2001; Ling et al., 2006) for Rouse-like profiles. Specifically, the output of NNLS regression is the concentration at the bottom bin for each individual time and $\mathrm{w}_{\mathrm{s}}$ value. The concentration throughout the water column for each size class is then determined by applying equation (3-12), where the output of the NNLS regression represents the concentration at the bottom bin. Figure 4-1(a-b) shows the $\mathrm{R}^{2}$ between fitted and SSC for "Rouse-like" profiles, and Figure 4-2 (a-b) shows the results of inverse analyses for selected profiles. 

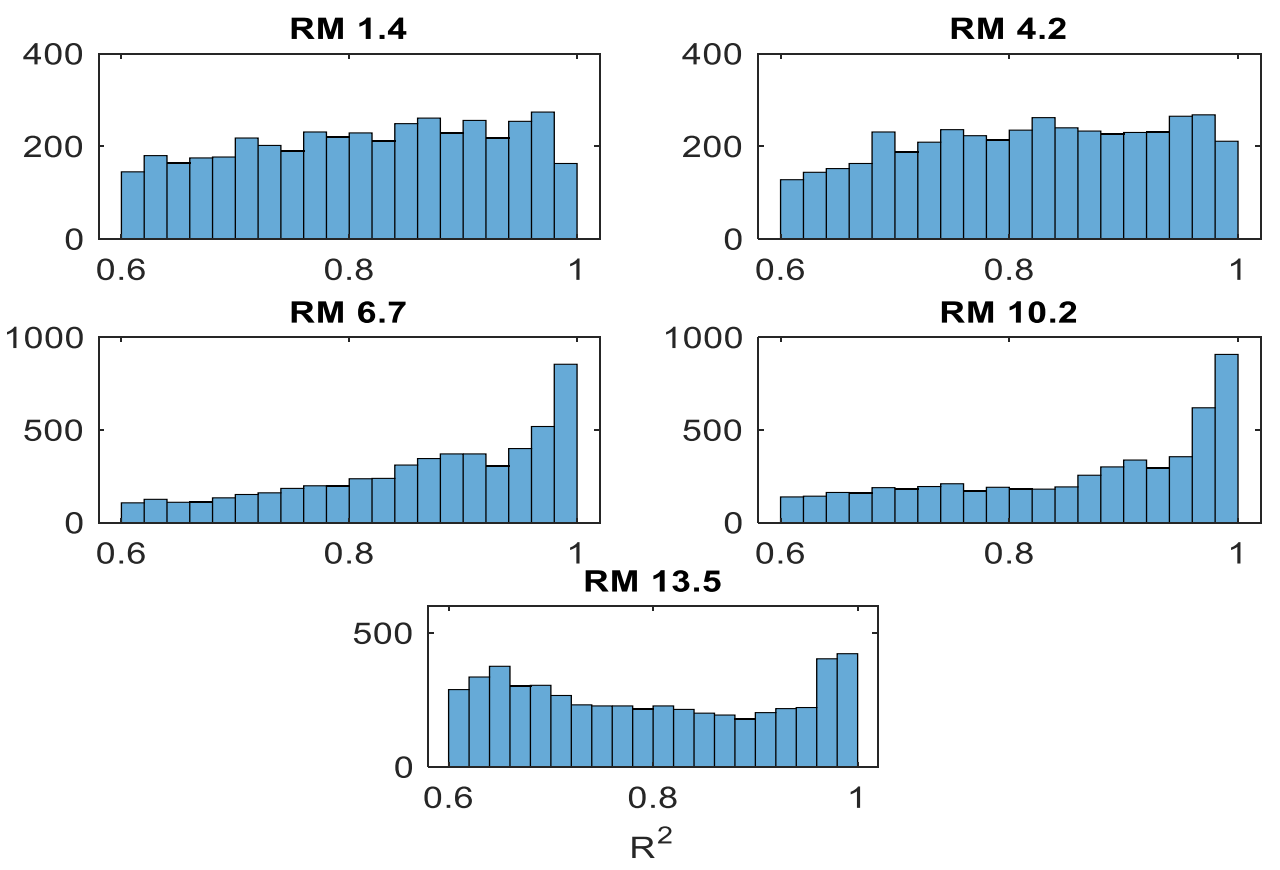

a- Fall
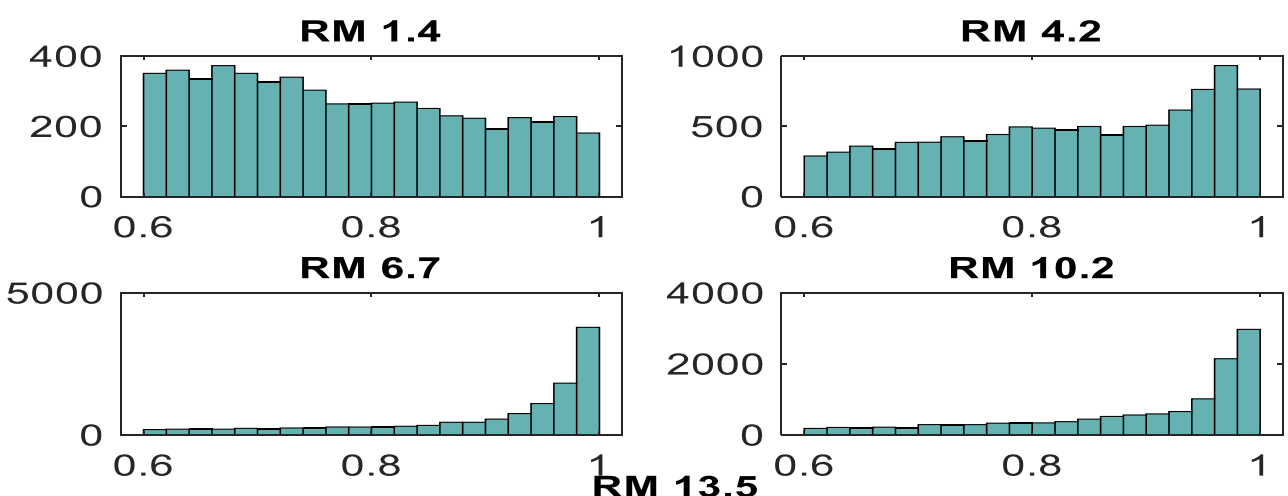

Figure 4-1(a, b). Histogram of $\mathrm{R}^{2}$ values for fitting of SSC for the Rouse-like profiles 

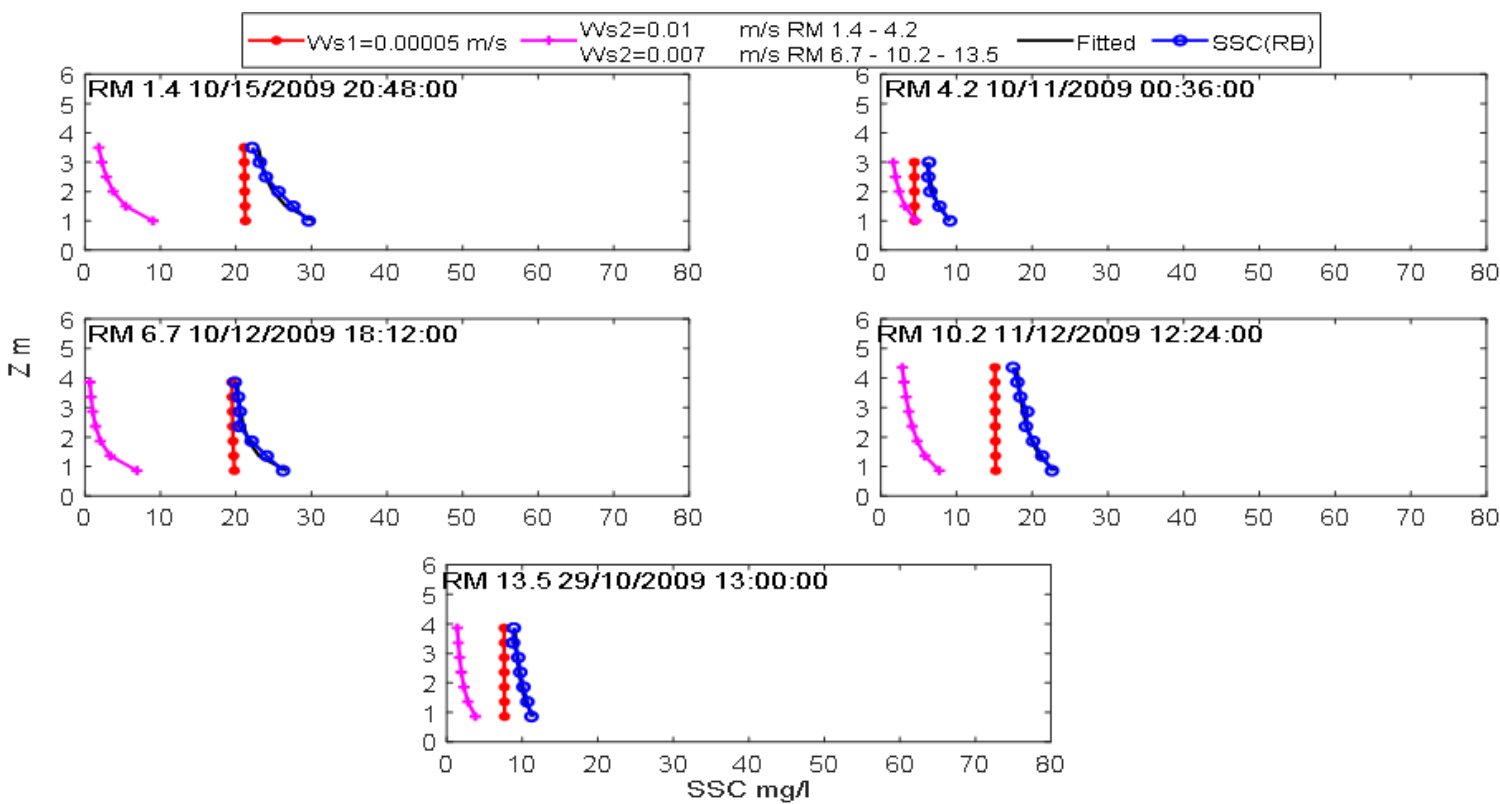

a- Fall

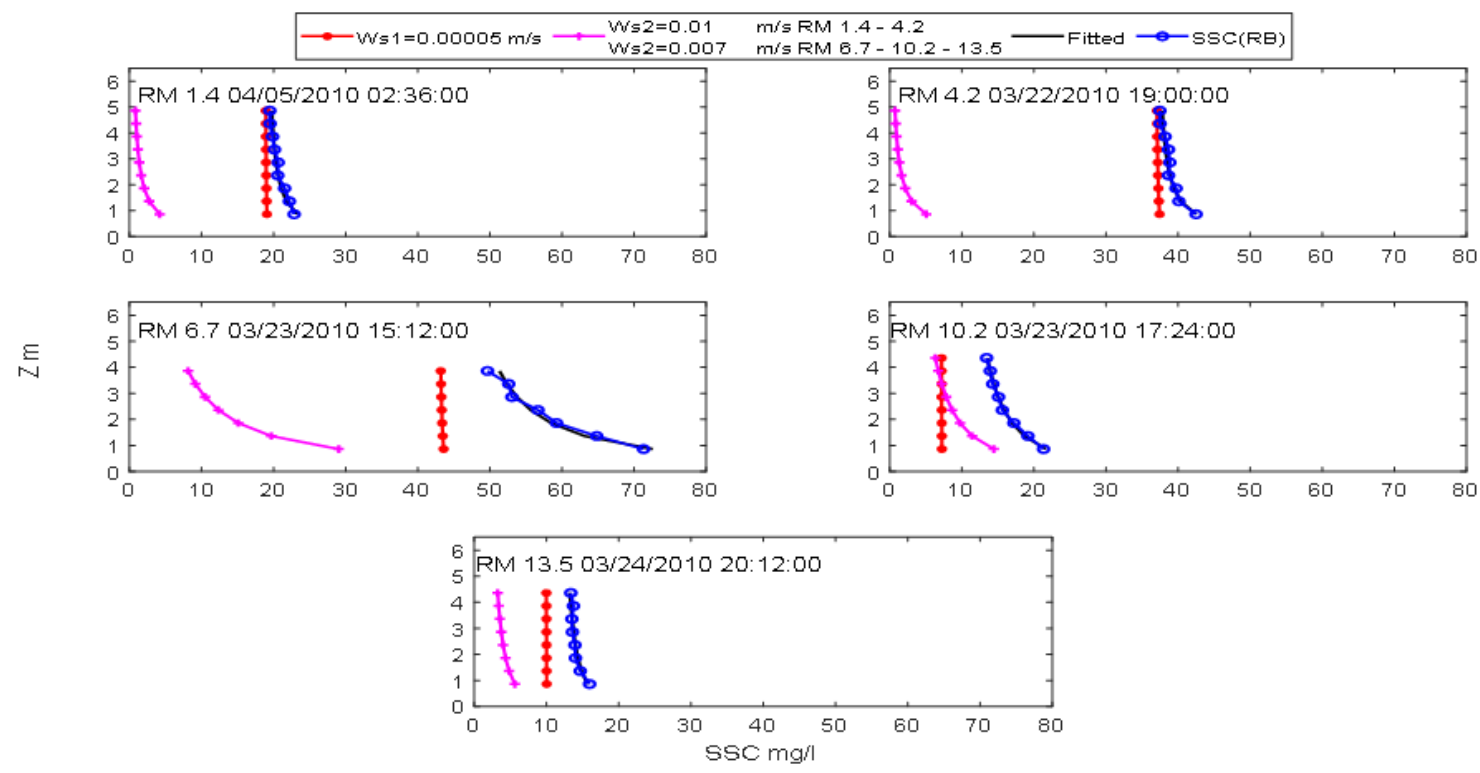

\section{b- Spring}

Figure 4-2(a,b). Examples of "Rouse-like" profilers of SSC distribution for each station 
For profiles that did not exhibit Rouse-like behavior, a perturbation method is applied to represent SSC of "Modified-Rouse" profiles to give an approximate solution for the distribution of the vertical particles when it is affected by horizontal advection:

$$
\mathrm{C}_{(\mathrm{z})}=\mathrm{C}_{\mathrm{a}(\mathrm{z})}+\varepsilon \mathrm{C}_{\mathrm{b}(\mathrm{z})} \quad \text { Equation 4-4 }
$$

where $\mathrm{Ca}$ is $\mathrm{SSC}$ from NNLR, $\varepsilon$ is average per profile for the scaling ratio of advection term (II) to the turbulent term (3-15-V) in the SPM equation (3-15); $\varepsilon$ is given by:

$$
\varepsilon=\frac{\Delta u}{u} \mathrm{R}_{\mathrm{s}} \frac{\Delta S S C}{S S C_{\text {ref }}}
$$

where $\Delta \mathrm{u}$ is the velocity difference between two bins, $\mathrm{u}$ is the average velocity, and $\Delta \mathrm{SSC}$ is the horizontal SSC difference between two adjacent stations. Typically, $\varepsilon$ is between -0.4 and 0.4 Figure $4-3$. Ideally, $\varepsilon$ should be $<0.1$ or so in a perturbation method, but the method still fits the profiles quite well, even when $\varepsilon$ is larger than 0.1 .

$\mathrm{C}_{\mathrm{b}}$ is then the numerical solution of the order epsilon equation:

$$
\mathrm{u} \frac{\partial C_{a}}{\partial x}+\mathrm{w}_{\mathrm{s}} \frac{\partial C_{b}}{\partial z}=\frac{\partial}{\partial y}\left(\mathrm{k}_{\mathrm{c}} \frac{\partial C_{b}}{\partial z}\right)
$$

The "Dsolve" function in the Matlab software is applied for a numerical solution with boundary conditions: $\mathrm{C}_{\mathrm{b}}(1)=\operatorname{SSC}(1)$ and $\frac{\partial \mathrm{C}_{\mathrm{b}}}{\partial \mathrm{z}}=[\operatorname{SSC}(1)-\operatorname{SSC}(2)] / \Delta \mathrm{z}$ at the bed. In general, the calculated "modified-Rouse" profiles matched observed SSC profiles well. Figure 4-3(a, b) shows $\varepsilon$ range for fine and coarse in Fall and Spring, Figure 4-4(a, b) shows the $\mathrm{R}^{2}$ between fitted and SSC for "Modified-Rouse" profiles, and Figure 4-5(a, b) shows the results of the perturbation method. 

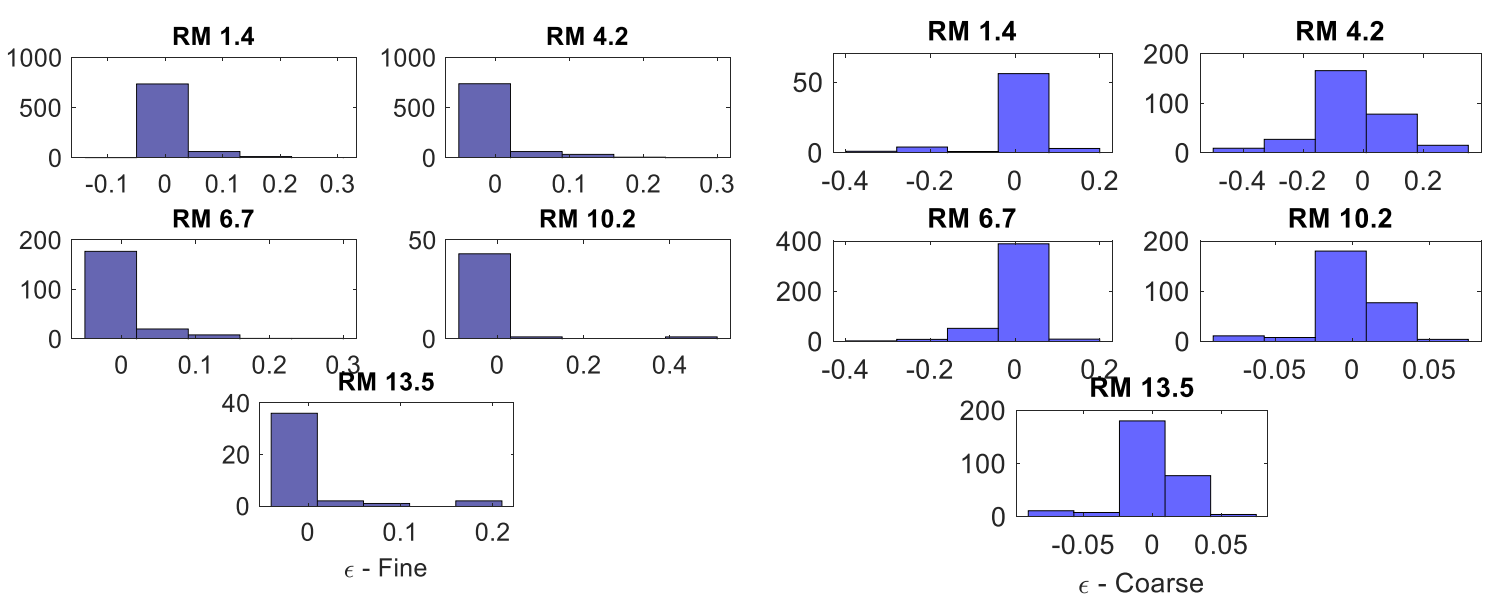

a- Fall
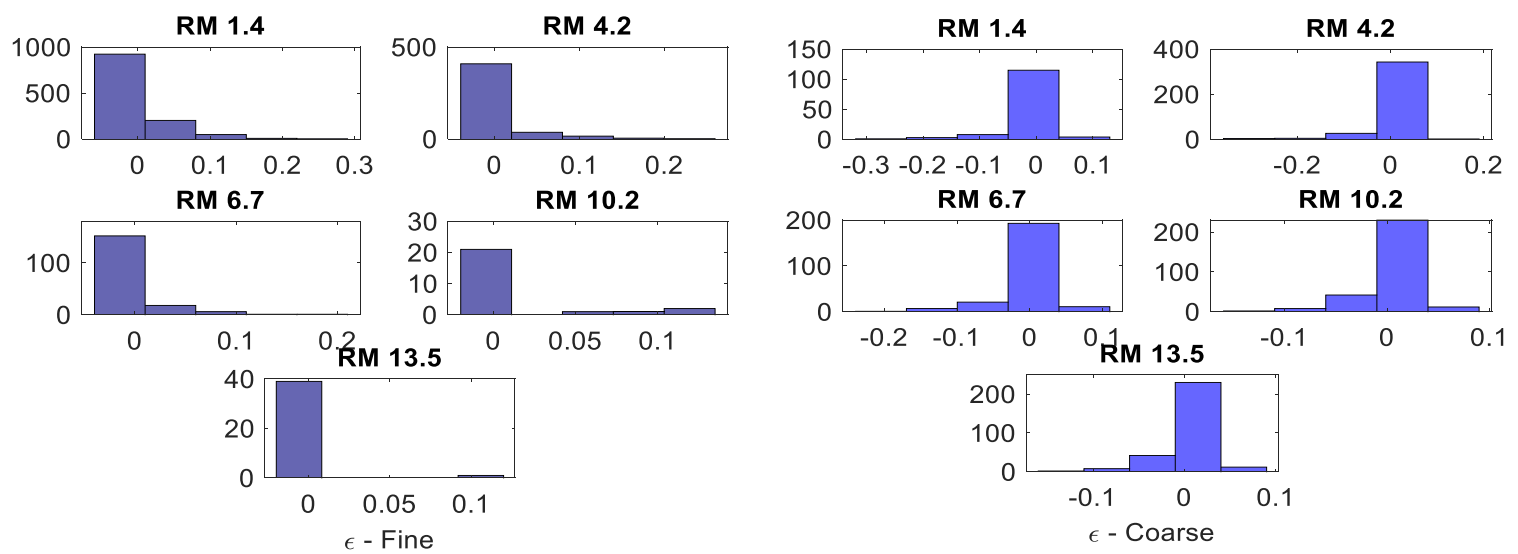

\section{b- Spring}

Figure 4-3(a,b). $\varepsilon$ ranges for fine and coarse SSC in Fall and Spring 

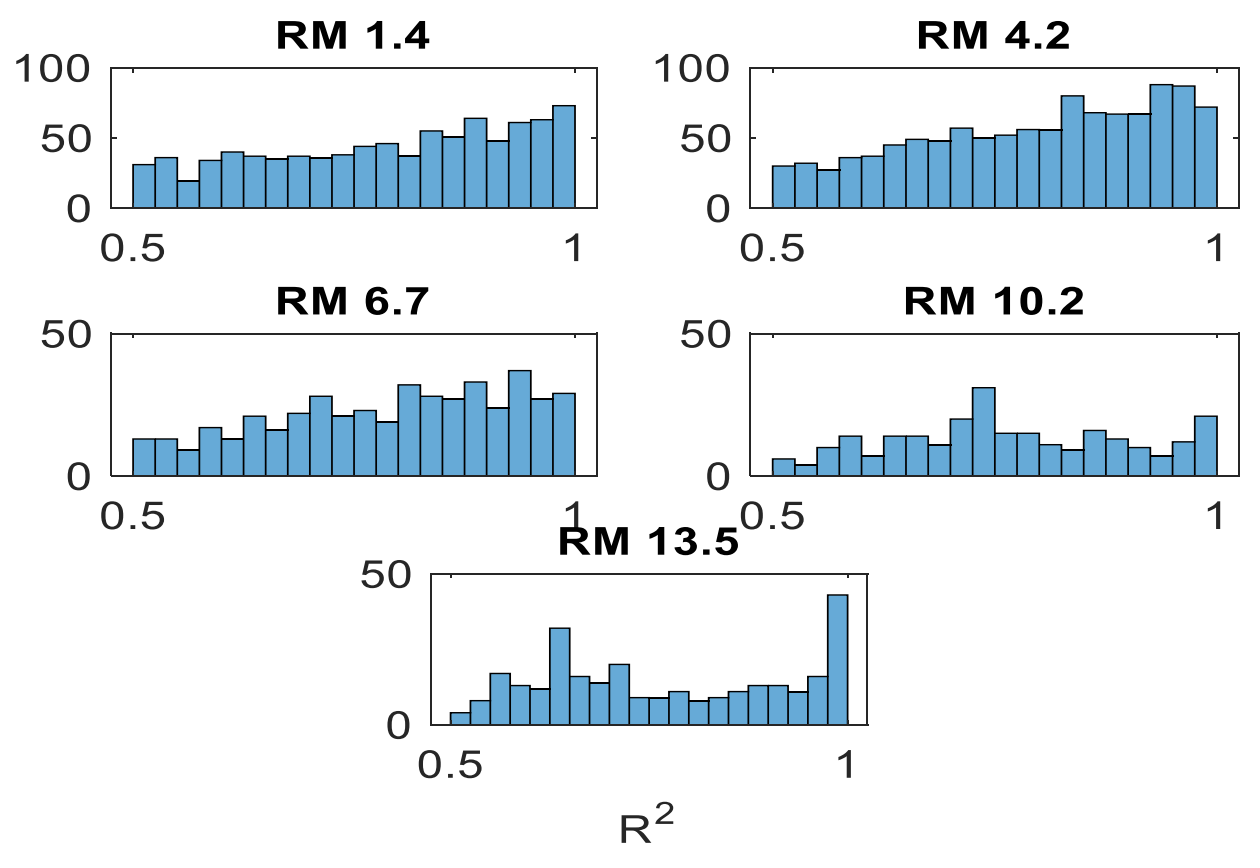

a- Fall
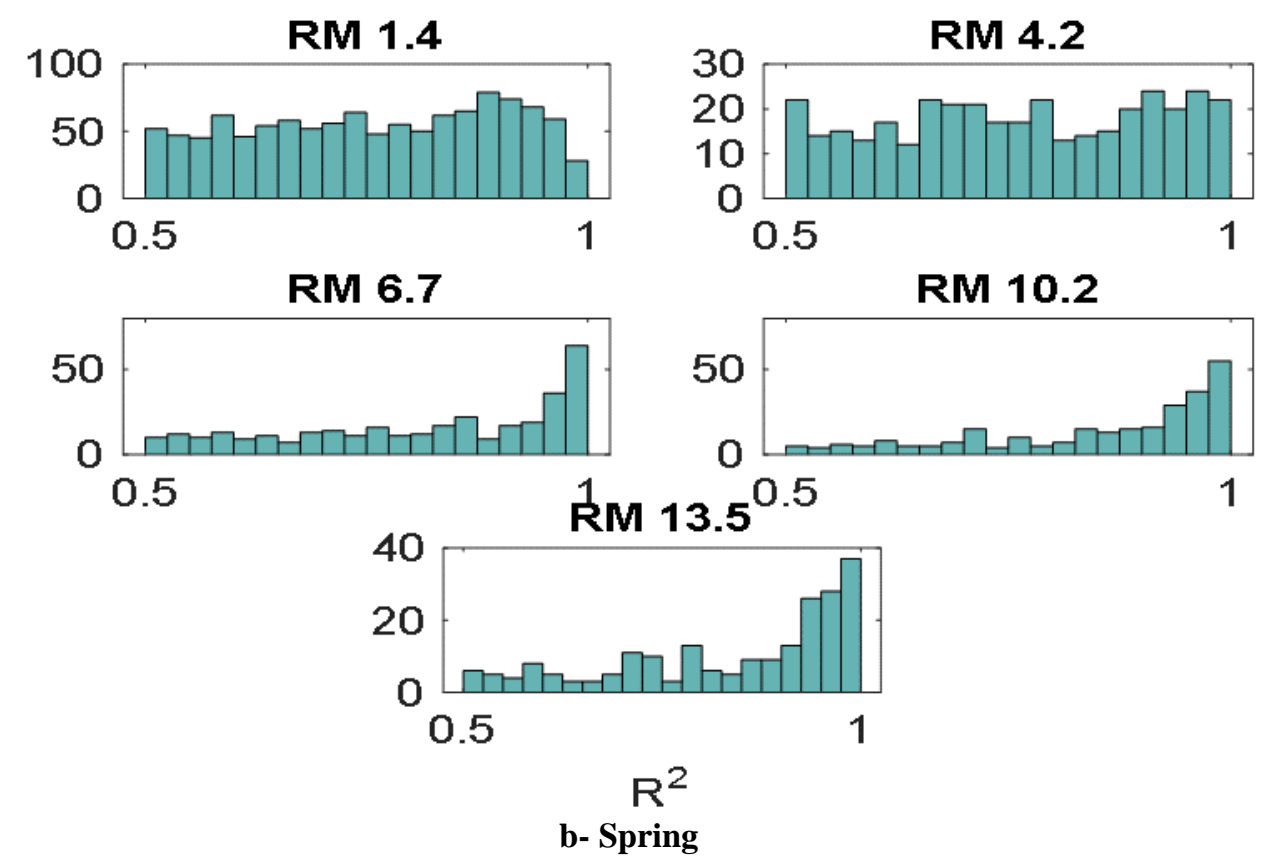

Figure 4-4(a,b). $\mathrm{R}^{2}$ between Fitted and SSC for Modified-Rouse profiles 

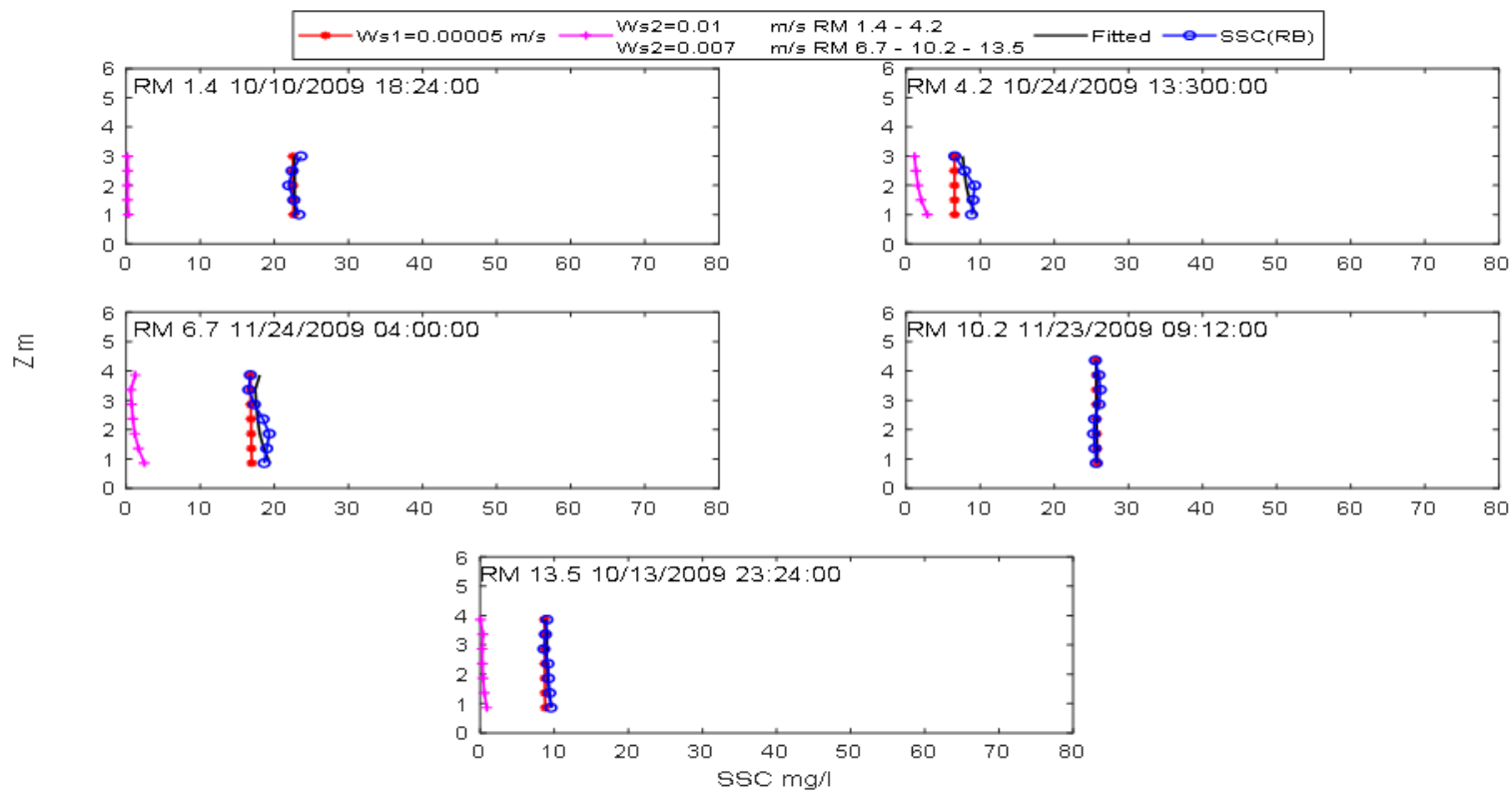

(a) Fall

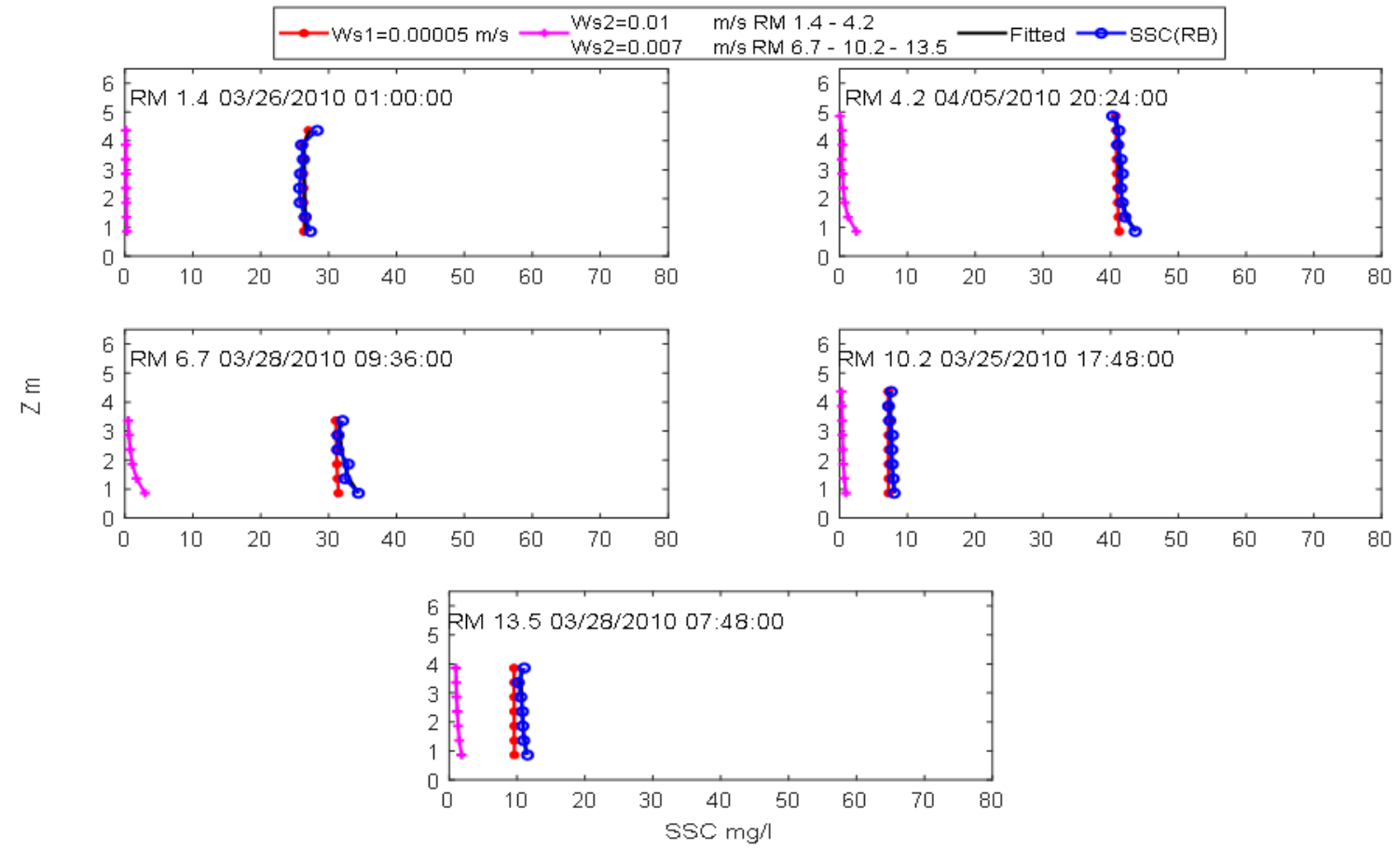

(b) Spring

Figure 4-5(a,b). Examples of "Modified-Rous" profilers of SSC distribution for each RM 
Understanding the relationship between transport and erosion/deposition processes is needed to interpret SSC profiles. The erosion/deposition of fine particles has been evaluated by comparing shear bed stress with the fine-silt critical shear stress. Coarse particles are expected to less erodible and settle more rapidly due to their higher $\tau_{b}$ and $\mathrm{w}_{\mathrm{S}}$ (larger Rouse \# $\mathrm{R}_{\mathrm{s}}$ ). Thus, large particles are likely to be more affected only when there are tidal velocities close to the bed. Advection number, represented by advection number A (defined below), represents the advection process that effect the particles distribution throughout the water column which leads to occure Modified- Rouse profiles via its effects on the fine particles, particularly when mixing is inhabited (SLS is positive); modifiedRouse profiles were not found (or needed) for the coarse particles.

Analysis of the importance of advection requires the definition of a parameter that represents the advection process. In this study, scaling for the long-estuary advection term is derived by scaling the steady-state SPM conservation equation 4-1 for both fine and coarse SSC to include $\mathrm{w}_{\mathrm{S}}$ in the advection term, comparing all terms to vertical mixing. The scaling variables are:

$$
\frac{U H}{w_{s} L_{x}}-1 \approx \frac{u_{*} k}{w_{s}}
$$

where the term (1) is along channel advection Number A; $U$ is the velocity; " $L_{x}$ is the horizontal distance over which a particle, once suspended, settles (without mixing) a distance H" (Fain et al., 2001; Jay et al., 2007), here I used $L_{x}$ the distance from the station $(\mathrm{RM})$ to the nearest bridge; and $\mathrm{w}_{\mathrm{S}}$ is the fine and coarse particles settling velocity; (2) is 
the ratio of settling to the vertical mixing; and (3) is the inverse Rouse number. I will use advection number A below to:

a) Investigate the importance of advection in controlling "Modified-Rouse" profiles.

b) Discuss the importance of advection in controlling the variability of surface/bottom SSC.

c) Controlling SSC by advection.

\subsection{Calibration and results}

\subsubsection{Importance of advection in controlling Rouse profiles}

Advection transports SSC in the water column that has been eroded at the bed and mixed up into the flow. This often happens at the front of an advancing salt front during the flood and can result in much higher SSC levels near the bed than higher in the water column. Also, shear in the tidal flow and high velocities near the surface can cause "inverted" profiles, with maxima well above the bed; this typically occurs on ebb near a retreating salt front. Both situations require $\left|\frac{\partial S S C}{\partial x}\right|$ to be large. However, it is likely that strong vertical mixing associated with bridges can also cause "inverted" profiles due to overturns. This is perhaps the most likely situation in the LPR, because of the large number of bridges, though there are no moorings close to a bridge to examine this issue. Any of these situations can distort the shape of SPM profiles, often making them "modifiedRouse" instead of Rouse-like. However, SPM profile shapes are also influenced by deposition/erosion, not accounted for in the Rouse analysis, which assumes no net deposition or erosion. Thus, it is necessary to distinguish advection effects on the SPM 
profile of the impact of deposition and erosion. In general, the advection is higher during the spring tide, which leads to an increase $\tau_{b}$. Not surprisingly, the coarse concentration of SSC generally increases during the spring tide (due to high bed stress) and decreases during the neap tide due to net erosion.

"Modified-Rouse" profiles" (with positive covariance) are found when the advection \# A is high (greater than the mean), especially when vertical mixing is inhabited, allowing a highly sheared tidal flow that can transport SSC from other locations. This was noticed from the in-situ data such that (49-68\%, depending on station and season) of the profiles are found to be "Modified- Rouse" with high advection and low mixing (high $u_{*}$ ). In fall, the periods of Modified-Rouse profiles are found mostly on neap when the SLS is positive (stably stratified) at stations close to the estuary mouth. But there are also some cases on spring tides during the Spring season during the periods when A is greater than the mean Figure 4-6 and Table 4-1.

Table 4-1. The percentage of Modified-Rouse Profiles

\begin{tabular}{|c|c|c|c|c|c|}
\hline RM & $\mathbf{1 . 4}$ & $\mathbf{4 . 2}$ & $\mathbf{6 . 7}$ & $\mathbf{1 0 . 2}$ & $\mathbf{1 3 . 5}$ \\
\hline Fall \% & 19.2 & 20.4 & 8.5 & 6.0 & 4.8 \\
\hline Spring \% & 18.9 & 7.4 & 3.0 & 2.3 & 1.8 \\
\hline
\end{tabular}




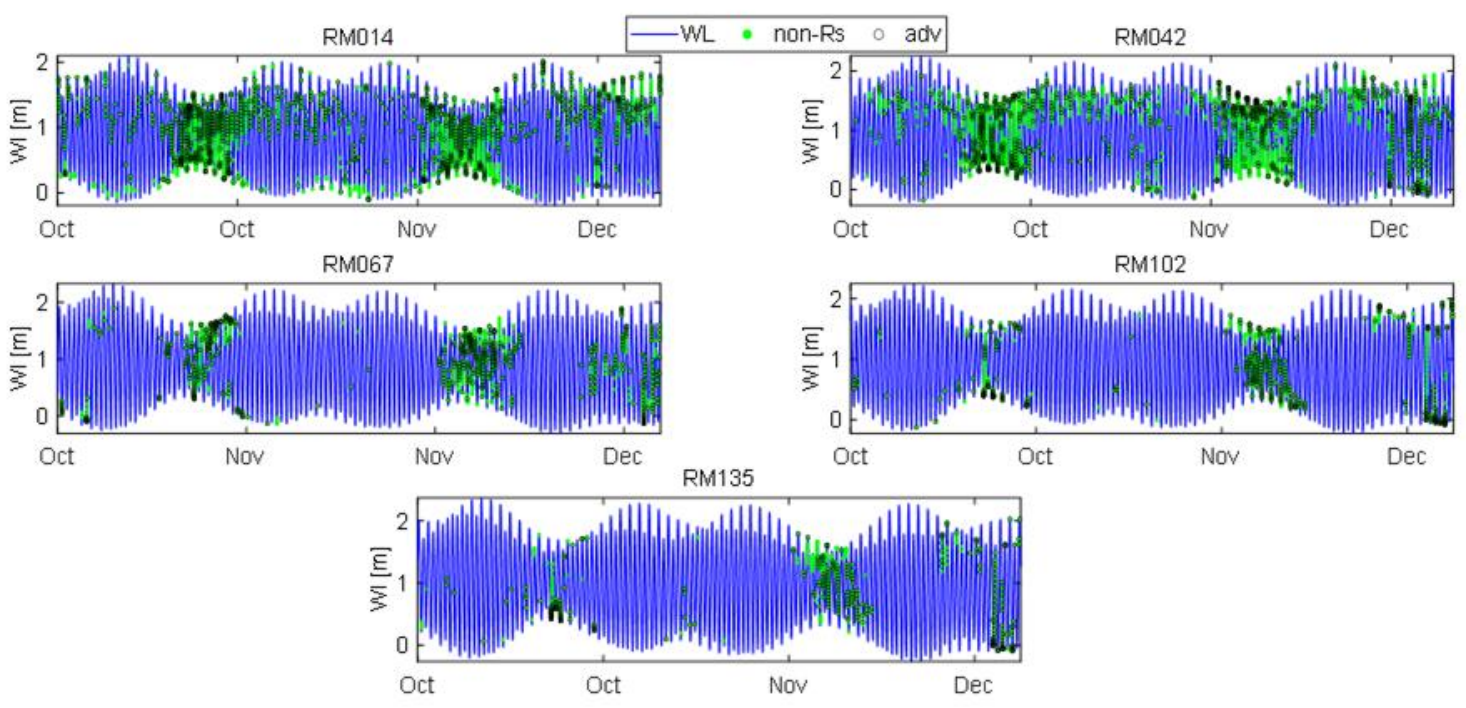

(a) Fall
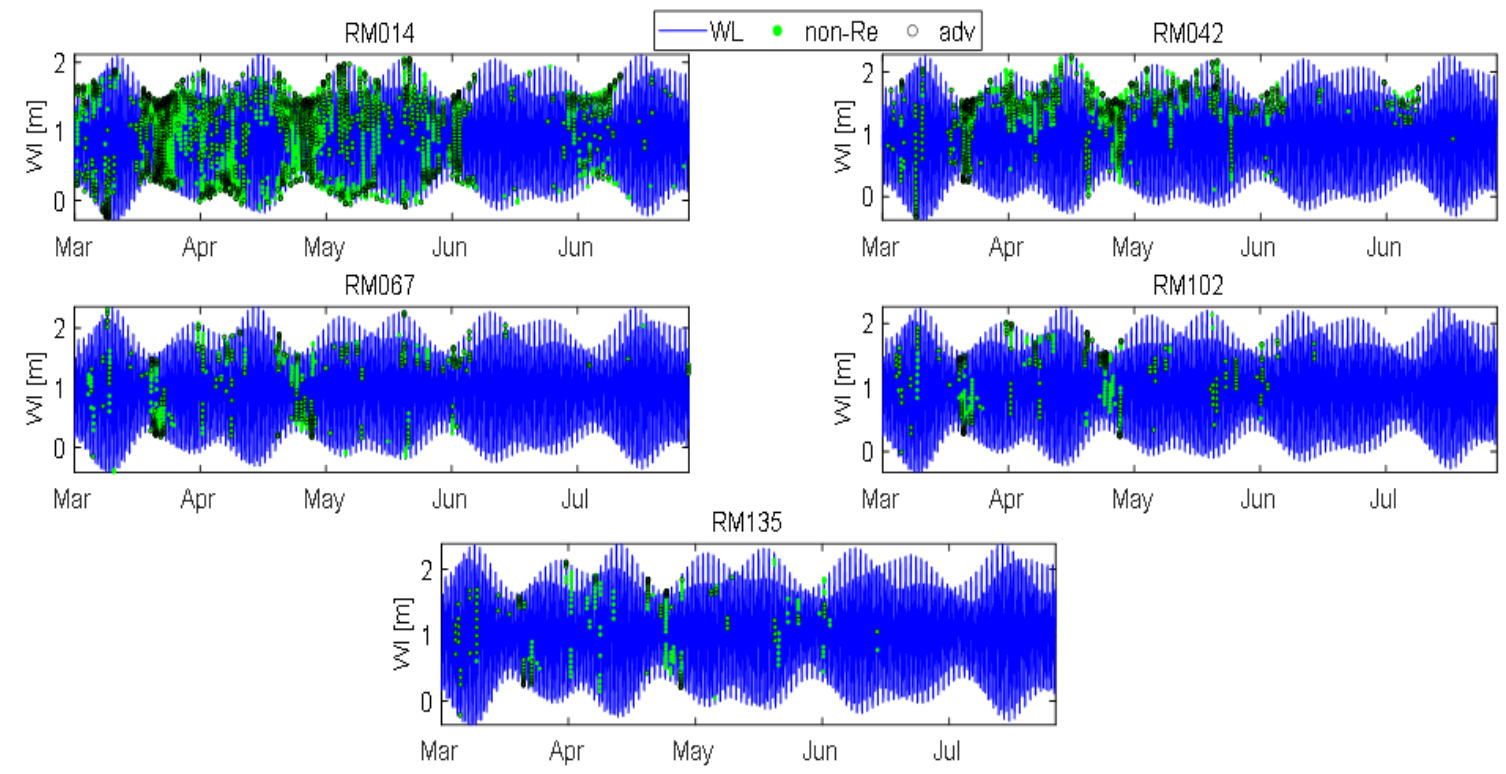

(a) Spring

Figure 4-6 (a, b). Modified-Rouse profile periods with (green dots) due to the effect of the high advection (black circle) 
Overall, advection is the essential factor that causes the vertical distribution of the SSC profilers to be "Rouse-like" or "Modified-Rouse". The "Modified-Rouse" profiles" are found when the advection \# A is high (greater than the mean), i.e., mainly when the mixing is inhabited on neap tides. Modified Rouse profiles were not found to be important for coarse material that remains close to the bed, and Modified Rouse profiles were not needed to represent profiles of the coarse size class. On the other hand, advection and Modified Rouse profiles were important for fines under a variety of conditions. However,

fines settle slowly (settling time scale $T=\frac{H}{w_{s}}$ of 27.5 to $55 \mathrm{hrs}$ for 5 to $10 \mathrm{~m}$ depth), so that, once eroded or supplied, they remain in the water column throughout the tidal cycle. Also, Modified Rouse profiles appear important primarily on neap tides, when erosion is less likely. All of these factors point to advection rather than erosion/deposition cycles as the cause of Modified Rouse profiles, so the momentum balance used (Eq 4-1) here to analyze SSC profiles is appropriate.

\subsubsection{Importance of advection in controlling the variability of surface/bottom SSC}

The advection influences SSC throughout the water column and erosion/deposition near the bed, and these processes are associated with tidal cycle (spring-neap), with higher currents and SSC during spring than neap. Therefore, SSC in river-estuary is typically affected by the tidal cycle down-estuary, and the magnitudes of the SSC and the advection are positively correlated with the tidal cycle. At the same time, SSC and advection are affected by the flow (high/low) up-estuary. 
Near the bed, during the periods of accelerating advection, SSC increases rapidly than near-surface SSC, which is associated with erosion via increase bed shear stress. The coarse SSC increases near the surface and bed as the advection increases, reaching the maximum at the flood slack water. On the other hand, the fine SSC increases when the advection decelerates reaching the maximum at the ebb slack water.

Figure 4-7(a, b) shows typical Fall (a) and Spring (b) variations in A, $\tau_{b}$, and fine and coarse SSC. It suggests the highest concentrations of fines near the surface and near the bed at the entrance typically took place on ebb with negative advection $(A<0)$. Fine SSC profiles are frequently influenced by horizontal advection, as suggested by Figure 4-7 and discussed in the following paragraphs. In contrast to the surface, the highest concentrations of coarse particles near the bed occurred with high current via erosion, which indicates that the variation in the coarse suspended sediment is controlled mainly by settling/resuspension processes, which reflects the variation in the tidal energy and current velocity. 

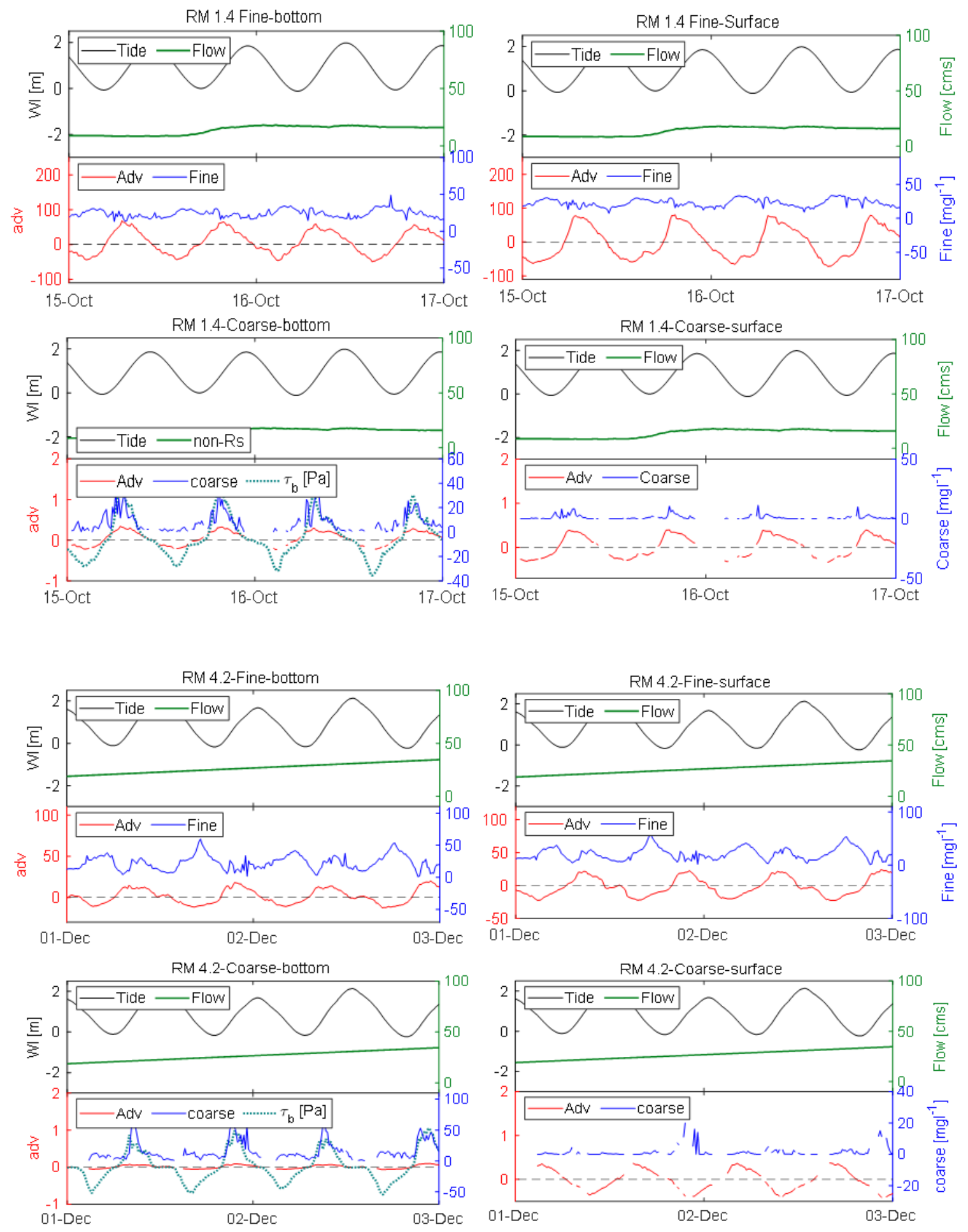

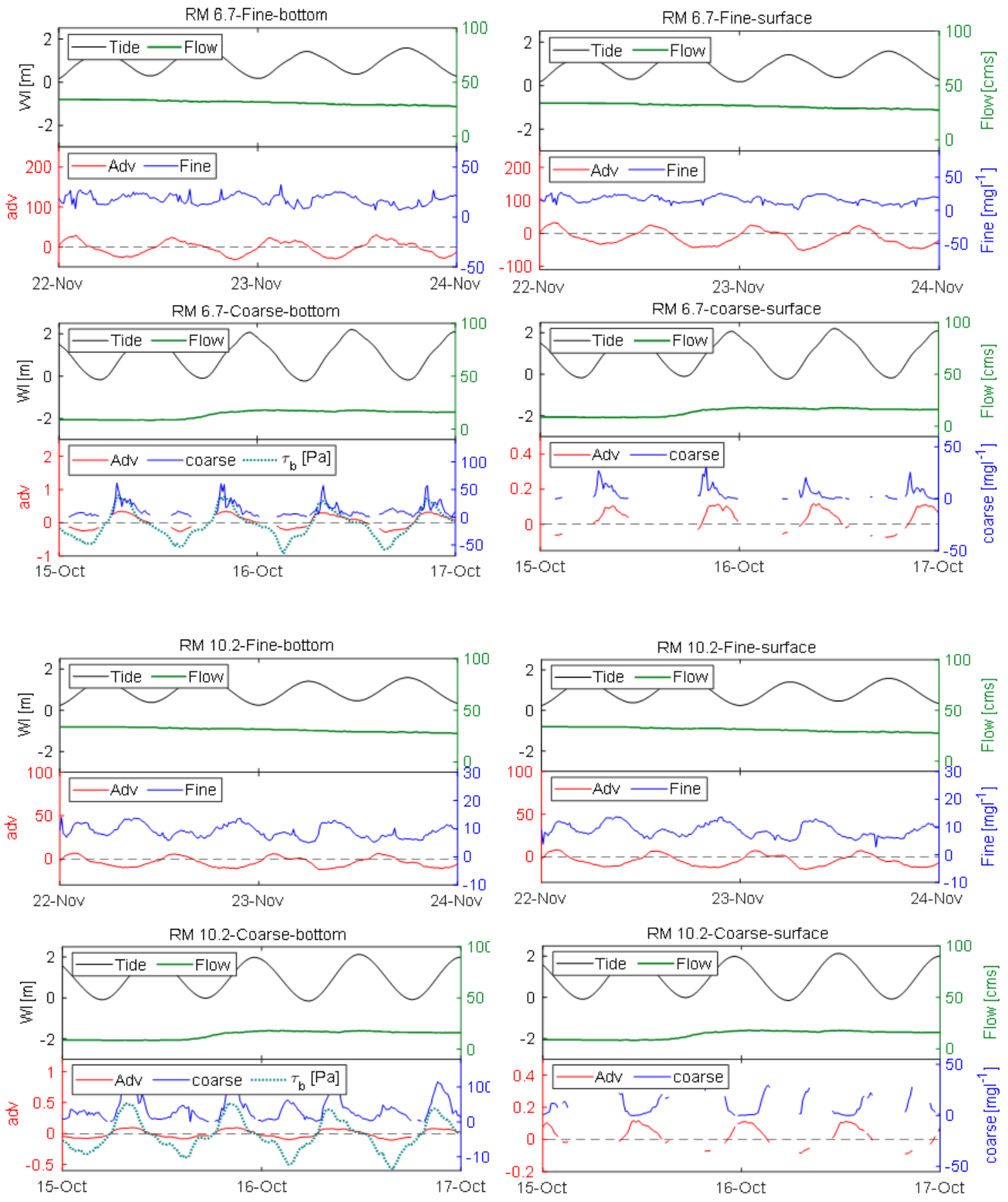

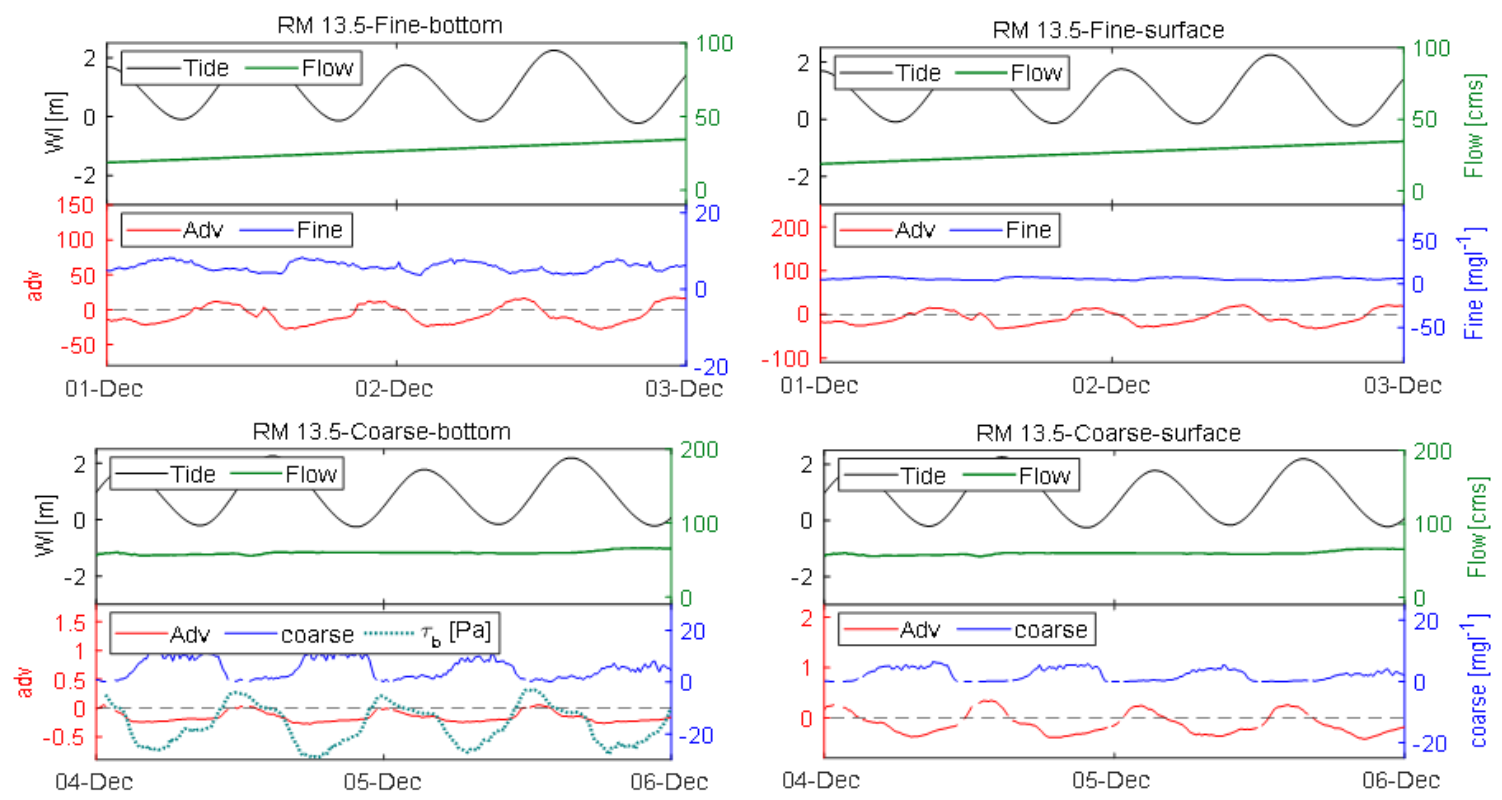

(a) Fall
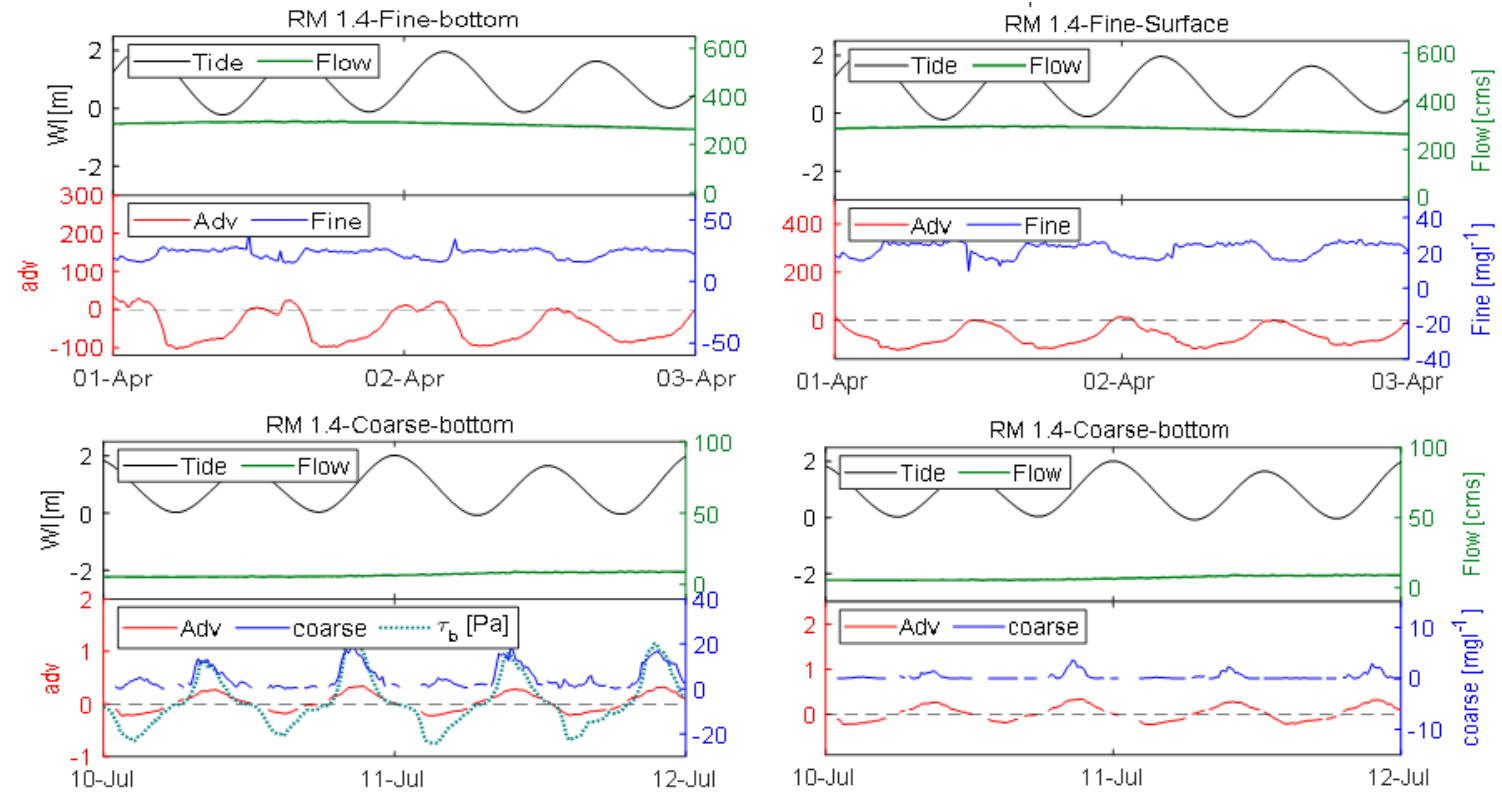

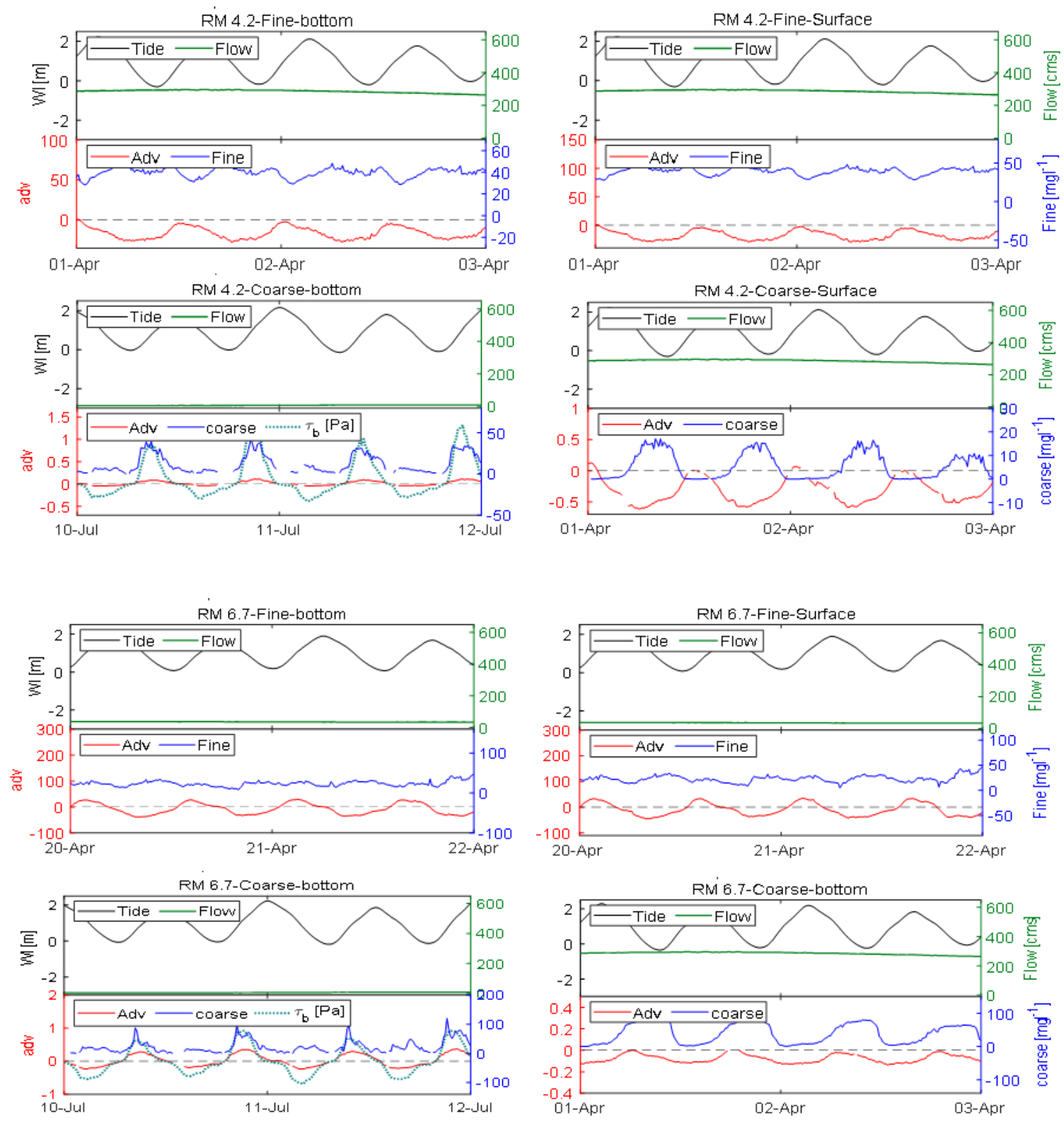

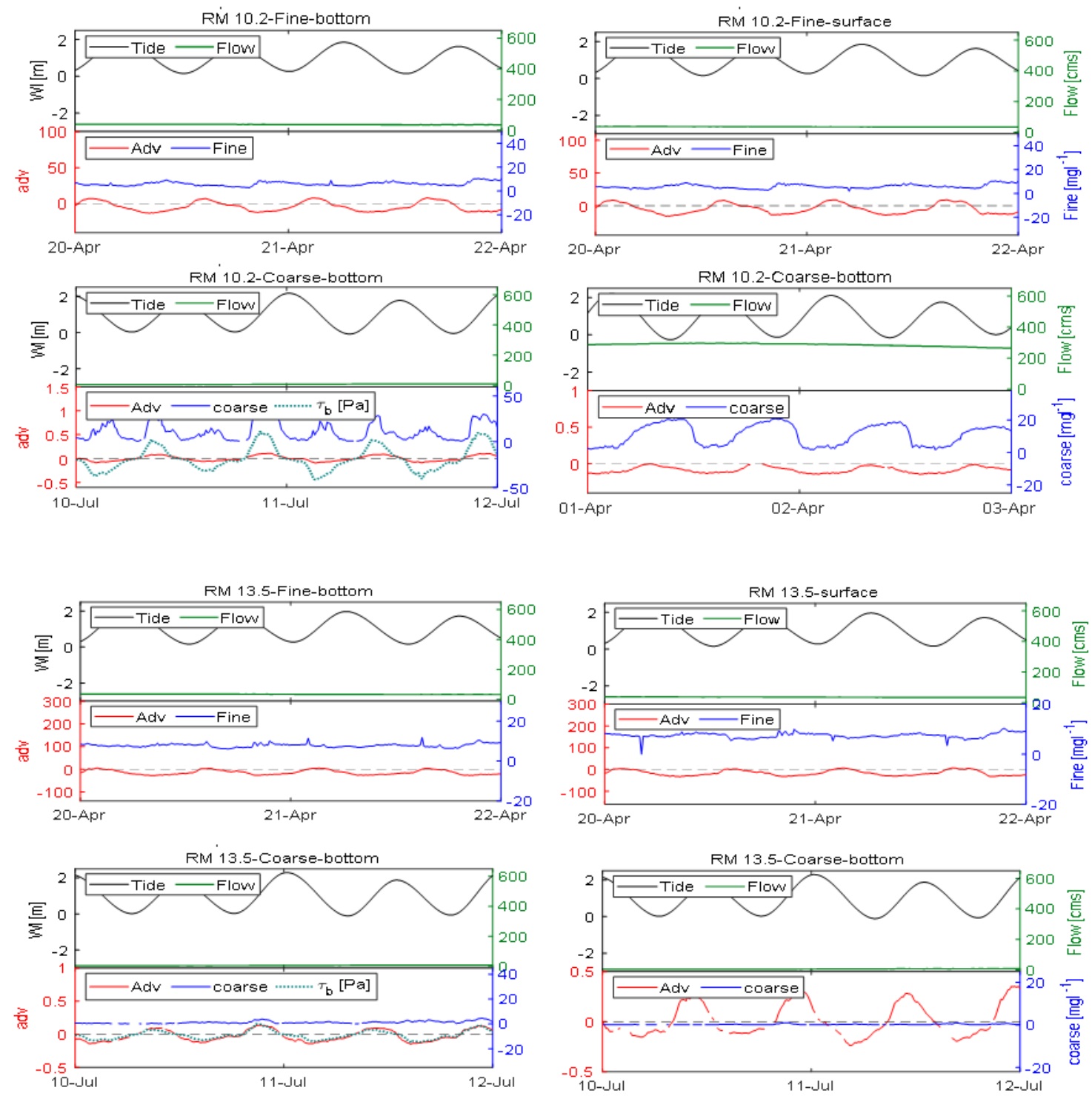

\section{(b) Spring}

Figure 4-7 (a, b). Variation of fine and coarse particles near the surface and bottom with advection and tide

The form of the scaling number (A) in equation (4-7) suggests that velocity $u$, settling velocity $w_{s}$, and settling length scales are the significant variables that affect along 
channel advection. However, it is also useful to look at the effects of larger-scale, forcing variables that do not appear in equation (4-7). To understand the various factors that influence A, multiple nonlinear regression using "robustfit" Matlab function was applied separately on flood and ebb of the tidal cycle. Extensive trial-and-error experimentation with this regression shows that $\mathrm{A}$ is the best fit with the normalized velocity, tidal range, and flow. Thus, the following regression relationship was used:

$$
\mathrm{A}=\mathrm{a}_{3}+\mathrm{b}_{3} * \mathrm{~N} \_\mathrm{u}+\mathrm{c}_{3} * N_{-} T R^{\wedge} n_{3}+\mathrm{d}_{3} * N_{-} f^{\wedge} n_{3} \quad \text { Equation 4-8 }
$$

where $\mathrm{a}_{3}, \mathrm{~b}_{3}, \mathrm{c}_{3}$, and $\mathrm{d}_{3}$ are constants to be calculated from the "robustfit" regression, $\mathrm{n}_{3}$ is a constant that ranges from $0.5 \leq \mathrm{n}_{3} \leq 2.0$, A is the horizontal advection term, $\mathrm{N} \_\mathrm{u}$ is normalized velocity, N_TR is normalized tidal range, and N_f is normalized discharge. Here, the tidal range is the difference between the higher high water (HHW) and lower low water (LLW) for the 13-hr period centered on the time of the regression, velocity is the signed instantaneous velocity, and flow is the daily-averaged river flow. All variables are normalized by dividing them by the maximum value for each variable. The regression was done separately for different cases (flood (Fld), ebb, fine, coarse, near the bed (Bot), and near the surface (Sur)) to show the effect of A in each one. The results show that the A is positively correlated within the velocity and tidal cycle, increasing and decreasing approximately in phase with an excellent correlation coefficient between A with $N \_u$, N_TR, and N_f as shown in Table 4-2. 
Table 4-2. R2 between A vs. N_u, $N_{-} T R$, and $N_{-} f$

\begin{tabular}{|c|c|c|c|c|c|c|c|c|c|}
\hline \multirow{2}{*}{$\mathbf{R M}$} & \multicolumn{5}{|c|}{ Fall } & \multicolumn{4}{|c|}{ Spring } \\
\hline & & & $\mathbf{R}^{2}$ & & $\mathbf{R}^{2}$ & & $\mathbf{R}^{2}$ & & $\mathbf{R}^{2}$ \\
\hline \multirow{4}{*}{1.4} & \multirow{4}{*}{ 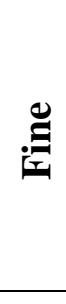 } & Ebb-Bot & 0.98 & \multirow{4}{*}{ 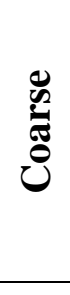 } & 0.98 & \multirow{4}{*}{ 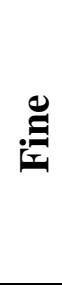 } & 0.99 & \multirow{4}{*}{ ن⿺辶 } & 0.99 \\
\hline & & Ebb-Sur & 0.75 & & 0.71 & & 0.76 & & 0.81 \\
\hline & & Fld-Bot & 0.97 & & 0.99 & & 0.99 & & 0.99 \\
\hline & & Fld-Sur & 0.88 & & 0.88 & & 0.88 & & 0.93 \\
\hline \multirow{4}{*}{4.2} & \multirow{4}{*}{ 总 } & Ebb-Bot & 0.98 & \multirow{4}{*}{ 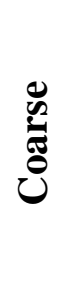 } & 0.98 & \multirow{4}{*}{ 总 } & 0.99 & \multirow{4}{*}{ 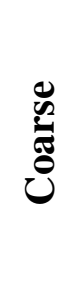 } & 0.99 \\
\hline & & Ebb-Sur & 0.90 & & 0.96 & & 0.84 & & 0.88 \\
\hline & & Fld-Bot & 0.99 & & 0.99 & & 0.98 & & 0.98 \\
\hline & & Fld-Sur & 0.97 & & 0.97 & & 0.97 & & 0.98 \\
\hline \multirow{4}{*}{6.7} & \multirow{4}{*}{ 导 } & Ebb-Bot & 0.82 & \multirow{4}{*}{ 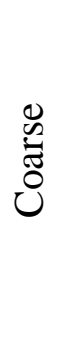 } & 0.85 & \multirow{4}{*}{ 墨 } & 0.98 & \multirow{4}{*}{ 茪 } & 0.99 \\
\hline & & Ebb-Sur & 0.92 & & 0.93 & & 0.93 & & 0.97 \\
\hline & & Fld-Bot & 0.91 & & 0.99 & & 0.99 & & 0.99 \\
\hline & & Fld-Sur & 0.93 & & 0.98 & & 0.99 & & 0.99 \\
\hline \multirow{4}{*}{10.2} & \multirow{4}{*}{ 导 } & Ebb-Bot & 0.77 & \multirow{4}{*}{$\begin{array}{l}0 \\
\tilde{\Xi} \\
\tilde{\Xi}\end{array}$} & 0.80 & \multirow{4}{*}{ 声 } & 0.97 & \multirow{4}{*}{$\begin{array}{l}0 \\
\tilde{\Xi} \\
\tilde{\Xi} \\
0\end{array}$} & 0.98 \\
\hline & & Ebb-Sur & 0.70 & & 0.78 & & 0.95 & & 0.97 \\
\hline & & Fld-Bot & 0.97 & & 0.94 & & 0.98 & & 0.98 \\
\hline & & Fld-Sur & 0.95 & & 0.95 & & 0.99 & & 0.99 \\
\hline \multirow{4}{*}{13.5} & \multirow{4}{*}{ 总 } & Ebb-Bot & 0.85 & \multirow{4}{*}{ 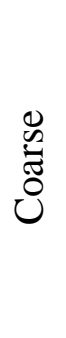 } & 0.87 & \multirow{4}{*}{ 兽 } & 0.99 & \multirow{4}{*}{$\begin{array}{l}0 \\
\tilde{W} \\
\tilde{D} \\
0\end{array}$} & 0.99 \\
\hline & & Ebb-Sur & 0.90 & & 0.92 & & 0.95 & & 0.98 \\
\hline & & Fld-Bot & 0.93 & & 0.92 & & 0.99 & & 0.99 \\
\hline & & Fld-Sur & 0.91 & & 0.92 & & 0.98 & & 0.99 \\
\hline
\end{tabular}




\subsection{Control SSC by advection and erosion/deposition}

In a sedimentary environment, horizontal advection and erosion/deposition are essential processes affecting the vertical distribution of SSC in the water column. Deposition or erosion of fines changes the amount of SPM in the water column. In general, local erosion happens during periods of increasing currents and deposition during periods of deceleration. The average variation in coarse SSC is controlled by resuspension-settling processes connected with cyclic variations in local velocity, as suggested by the Rouse number. Vertical average SSC is less affected by the high and low velocity for fine particles due to slower settling of the fine particles during periods of high-velocity Figure $4-8$. The average SSC variation is substantial for coarse particles. It is associated with cyclical erosion/deposition. Close to the estuary mouth, relatively coarse particles (aggregates) are suspended during periods of high shear stress. The average SSC for coarse particles is correlated with $A$, which varies strongly with the tide. That is, high values of both A and coarse SSC are both caused by strong currents, so they are correlated with each other, but they are not causally connected. Landward of salinity intrusion during periods of high flow such as the one from December 8 to December 15 in Fall and March 25 to April 10 in Spring, the coarse SSC variation is correlated with the bed stress, rather than the tidal stage. 


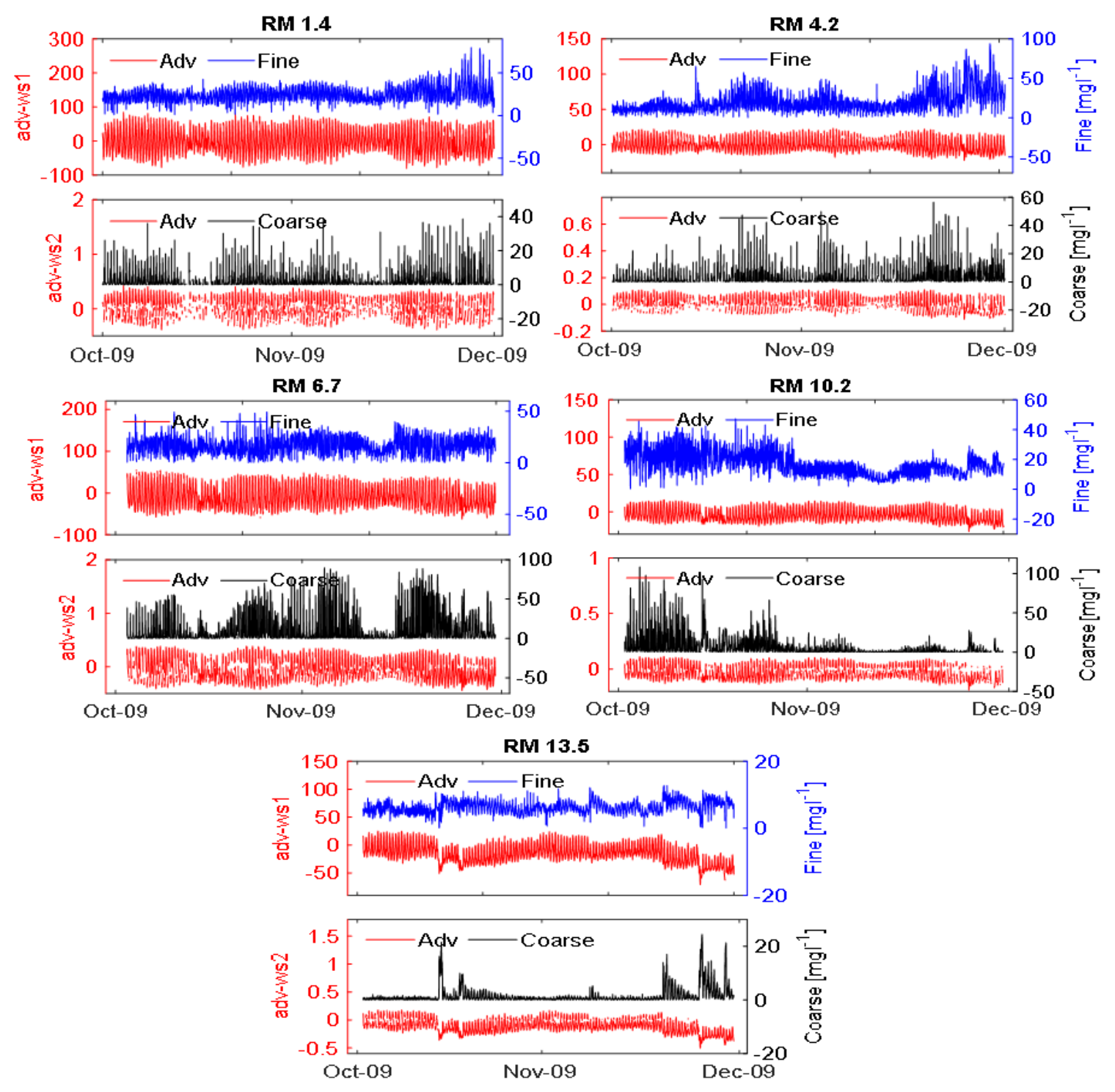

(a) Fall 

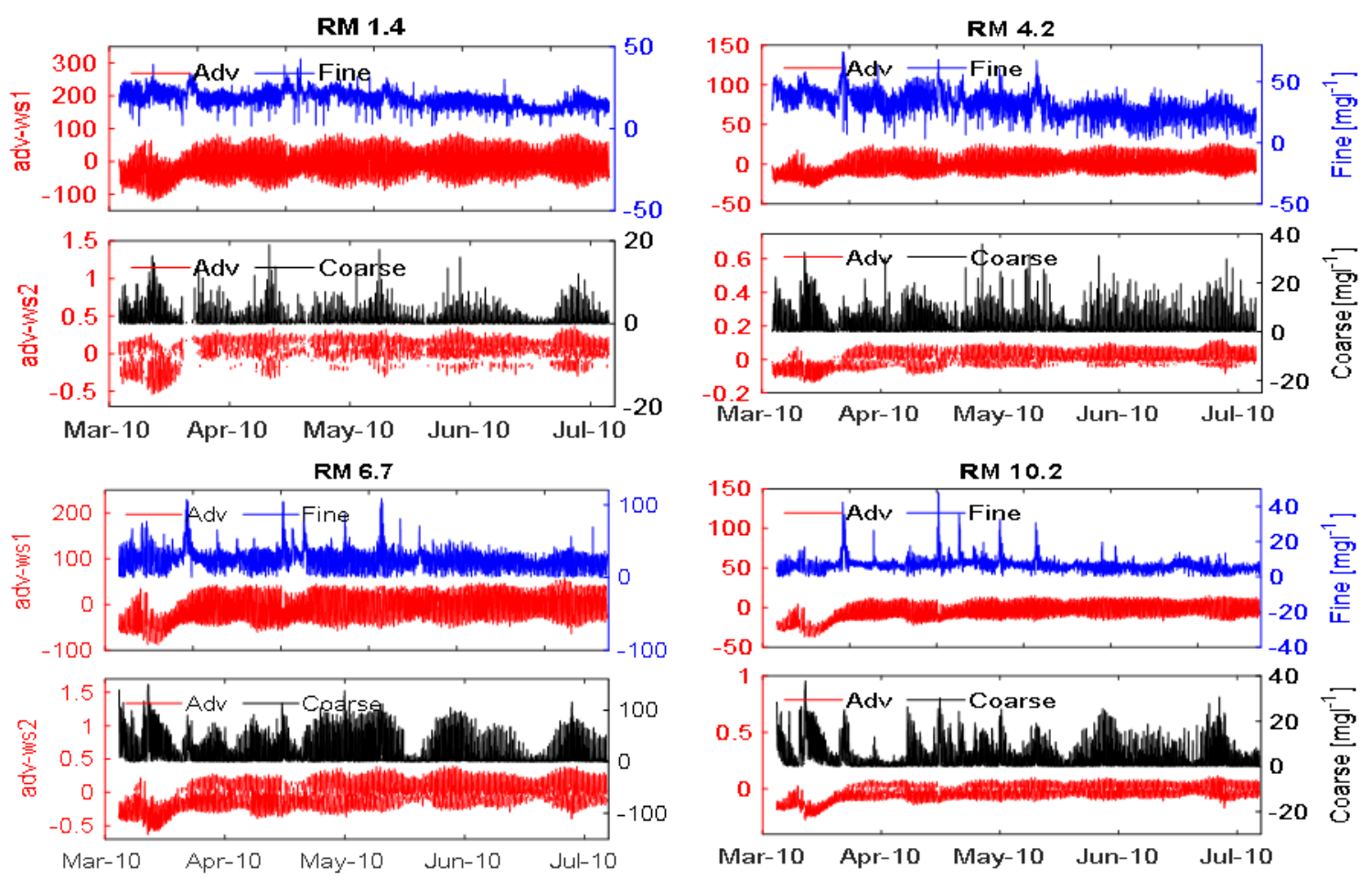

Mar-10 Apr-10 May-10 Jun-10 Jul-10

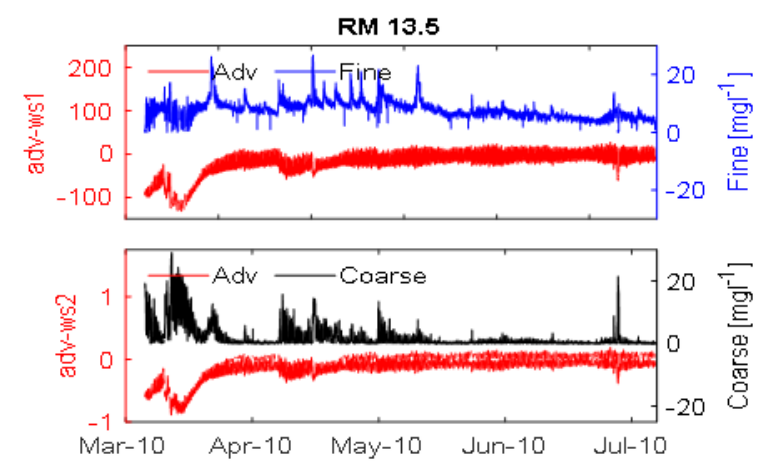

\section{(b) Spring}

Figure 4-8. Average variation of fine and coarse particles with advection 


\subsection{Dynamical variations of SSC}

SSC is strongly dependent on the daily tides, and there is also substantial springneap variation in the records from mooring close to the LPR mouth. Thus, SSC is expected to have two peaks during the tidal cycle (if settling-resuspension particles govern SSC variability), and SSC values are higher on spring than neap tides. During low flow periods, SSC is sometimes higher during the flood than ebb due to the characteristic flooddominance of LPR currents (Mathew \& Winterwerp, 2020). On the other hand, SSC is strongly related to river flow in the tidal freshwater part of the system.

Sedimentation processes (transport and deposition/erosion of suspended sediment) in microtidal estuaries with tidal range $<2 \mathrm{~m}$, on the East Coast of the United states estuaries, are controlled by variations in river flow, tidal range, and density circulation (Allen et al., 1980). A short and weakly tidal estuary is expected to have generally low SSC. In contrast, high SSC in estuary would most likely be related to either a longer estuary, high sediment load associated during floods, wave resuspension, or seawater carrying SSC derived from coastal wave activity (Uncles et al., 1994; Uncles et al., 2002). Tidally-cycle variations of SSC are related to the tidal phase (ebb-flood) in the LPR and the longitudinal motion of sediment controlled by river flow and the spring-neap cycle. In the lower part of the LPR, SSC varies significantly with tidal range (e.g., RM014) while it is strongly affected by river flow closer to Dundee Dam (e.g., RM 135), as suggested by Dyer (1987) (Appendix). 
The average SSC for two classes near the surface and bottom is shown in Table 4-3. Furthermore, Moored data has shown the concentration varies from low close to Dundee Dam to higher seaward.

Table 4-3. mean fine and coarse classes near the surface and bottom

\begin{tabular}{|c|c|c|c|c|c|c|c|c|}
\hline \multirow{2}{*}{ RM } & \multicolumn{4}{|c|}{ Fall-2009 } & \multicolumn{5}{c|}{ Spring-2010 } \\
\cline { 2 - 9 } & Surface & bottom & Surface & bottom & Surface & bottom & Surface & bottom \\
\cline { 2 - 9 } & $\begin{array}{c}\text { Fine } \\
\mathbf{m g} / \mathbf{l}\end{array}$ & $\begin{array}{c}\text { Fine } \\
\mathbf{m g} / \mathbf{l}\end{array}$ & $\begin{array}{c}\text { Coarse } \\
\mathbf{m g / l}\end{array}$ & $\begin{array}{c}\text { Coarse } \\
\mathbf{m g} / \mathbf{l}\end{array}$ & $\begin{array}{c}\text { Fine } \\
\mathbf{m g} / \mathbf{l}\end{array}$ & $\begin{array}{c}\text { Fine } \\
\mathbf{m g} / \mathbf{l}\end{array}$ & $\begin{array}{c}\text { Coarse } \\
\mathbf{m g} / \mathbf{l}\end{array}$ & $\begin{array}{c}\text { Coarse } \\
\mathbf{m g} / \mathbf{l}\end{array}$ \\
\hline $\mathbf{1 . 4}$ & 24.6 & 26.8 & 1.3 & 7.5 & 17.6 & 19.9 & 0.46 & 4.9 \\
\hline $\mathbf{4 . 2}$ & 19.3 & 20.7 & 1.7 & 11.6 & 30.8 & 33.6 & 1.4 & 10.9 \\
\hline $\mathbf{6 . 7}$ & 17.0 & 18.0 & 8.1 & 21.4 & 25.7 & 27.3 & 15.8 & 35.8 \\
\hline $\mathbf{1 0 . 2}$ & 17.0 & 17.4 & 4.6 & 13.8 & 6.7 & 6.9 & 3.2 & 7.7 \\
\hline $\mathbf{1 3 . 5}$ & 6.2 & 6.4 & 1.0 & 2.7 & 7.8 & 8.1 & 1.6 & 3.9 \\
\hline
\end{tabular}

Bed shear stress was found to be the primary driver for variations of vertically averaged SSC. Normalized shear stress together with TR and flow were the best parameters that fit SSC in the lower estuary, while other sampling locations need more investigation. The relationship used was:

$$
\text { N_SSC }=\mathrm{a}_{5}+\mathrm{b}_{5} * \mathrm{~N} \_\mathrm{B} \_\mathrm{sh}+\mathrm{c}_{5} * N_{-} T R^{\wedge} n_{5}+\mathrm{d}_{5} * N_{-} f^{\wedge} n_{5} \quad \text { Equation 4-9 }
$$

where N_SSC is the normalized SSC; N_B_sh is normalized shear stress $\mathrm{a}_{5}, \mathrm{~b}_{5}, \mathrm{c}_{5}$, and $\mathrm{d}_{5}$ are constants calculated from the "robustfit" regression and $n_{5}$ ranges from $0.5 \leq n_{5} \leq 2$. The results have shown that the $\mathrm{R}^{2}$ ranges from (0.70-0.89). 


\subsection{Conclusion}

In this research, I have examined SPM dynamics of a heavily contaminated partially urban estuary, the LPR, via data analysis, taking into consideration the effect of the salinity on the shear velocity and the importance of advection. Moreover, I have demonstrated the importance of the variables affecting the average SSC. The time series employed were a series of 12-minute in-situ measurements of velocity and ABS of five ADCP readings provided by the PWCM program at five river mile (RM) locations (1.4, 4.2, 6.7, 10.2, and 13.5). The moored ADCP covered the period for more than eight months in Fall 2009 and Spring 2010. OBS provided the salinity readings at the near top and bottom.

Calibration of ADCP backscatter to SSC was a vital preliminary step in this study; there was a reasonable agreement between SSC estimated from ADCP data with laboratory-determined SSC samples. A modified SPM calibration was used that included river flow as part of the calibration. The application of multiple regressions between SSC grab samples with RB and normalization of flow ranged from very good to excellent correlation coefficients. The $\mathrm{R}^{2}$ was between (0.82-0.98) for Fall 2009 and (0.82-0.92) for Spring 2010.

Analyses of results from five stations along LPR have shown that the mean SSC is moderate compared with other river estuaries such as Columbia River Estuary (Gelfenbaum, 1983) and Hudson River estuary (Woodruff et al., 2001). Moored data has shown the total load for the study period (Fall and Spring) varies from low $\left(0.5 \times 10^{2}\right.$ ton/m width) close to Dundee Dam to higher seaward (11.9x10² ton/m width). 
SSC profiles have been classified as "Rouse-like" or "Modified-Rouse", as essentially defined by the advection parameter A. Thus, "Modified-Rouse" profiles" are found when the advection \# A is high (greater than the mean), especially near the LPR entrance when the mixing is low. This was noticed from the in-situ data such that (49-68\%, depending on station and season) of the profiles are found to be "Modified- Rouse", with high advection and low mixing. The periods of Modified-Rouse profiles are found mostly on neap when the stratification length scale SLS is positive.

The vertical variability of coarse particles is in phase with horizontal advection (parameterized by A), with the peak of SSC concentration for both settling classes tending to occur on the flood Figure 4-8 (a-b). On the other hand, fine particles are less affected by advection due to slower settling and advection of fine sediment during high-velocity periods. Furthermore, SSC variation is significantly related to the tidal-cycle (neap-spring), especially close to the estuary mouth, where the river outflow is small relative to tidal currents. Close to the Dundee dam, flow is a dominant factor controlling SSC.

Vertically averaged SSC is mainly correlated to shear stress close to the estuary mouth (1.4 and 4.2), together with TR and flow, while upriver RMs still need more investigation. The vertical average SCC distribution shows that the maximum concentration of both SSC classes took place during low flow (Fall season) during the early flood, on spring tides for the brackish stations. At the same time, SSC is linked with river flow at the up-estuary stations. During high flows (Spring season), maximum SSC occurred during the late ebb on spring tides. 


\section{Chapter 5 Bed shear stress variation and its causes}

\subsection{Introduction}

Previous chapters have dealt with the properties of LPR suspended sediments. This chapter discusses the hydrodynamic conditions leading to sediment erosion, deposition, and transport in the LPR, focusing on bed stress $\tau_{b}$, analyzed using a $3 \mathrm{D}$ numerical modeling approach. This approach is chosen because $\tau_{b}$ is the most significant flow variable in the estuarine environment that links flow conditions and sediment transport and much easier to calculate than actual sediment transport processes. Thus, I calculate $\tau_{b}$ to understand the deposition and erosion and the processes that influence it. Sediment may accumulate on the bed and the banks when the bed shear stress from the river flow and tidal currents does not exceed a critical value. As the tidal current accelerates, resuspension of coarser material occurs via erosion, while deposition usually occurs during the deceleration of tidal currents. Finer sediments are less affected by deposition/erosion because they stay in the water column longer.

The LPR channel has numerous curves and bends, and $\tau_{b}$ varies through bends with channel curvature (Callander, 1978). Therefore, it is important to investigate the significance of bed stress distribution along the curves. Bends in the meandering channels have been examined by (Chen \& Shen, 1983) using the relative curvature $C_{r e l}$ ratio, which is the ratio of the channel bend curve at the center, $\mathrm{r}_{\mathrm{c}}$, to the channel width, $\mathrm{c}_{\mathrm{w}}$. When $C_{\text {rel }}$ $>3.5$, the highest stress shear occurs near the outer bank of the exit curvature. However, if $1.25<C_{r e l}<3.5$, two zones of the high shear stress occur, one at the outer bank of the exit 
curvature and another along the inner bank of the bend's entrance reach. But if $C_{r e l}<1.25$, the highest shear stress moves to the entire inner bank of the stream bend. Dalrymple $\boldsymbol{\&}$ Choi (2007) observed two factors controlling the relative curvature: a) channel with high flow tends to be wider, wider in curvature, comparable with the low flow; and b) straighter channel associated with steeper hydraulic gradients produced higher velocities (Schumm \& Khan, 1972). Furthermore, Prokocki (2017) explained down-estuary regions that are tidally-influenced usually have straighter channels than are farther upriver. On the other hand, tidal-channels tend to have more curvature as tidal velocities decrease landward. Therefore, the overall large-scale curvature pattern (from down-estuary to up-estuary) is a “straight-meandering-straight" channel (Dalrymple et al., 1992).

The bed around bridge piers in a river is often subject to severe local scour due to high bed shear stress. The flow velocity is maximum close to piers and decreases as the distance from the pier increases. Zaredehdasht et al. (2011) analyzed the $\tau_{b}$ distribution in a longitudinal section of a river near a bridge pier; the shear stress increases linearly upstream of a bridge pillar. On the other hand, the $\tau_{b}$ has irregular variation downstream of bridge pillars due to flow separation and vortex formation. It is expected that the LPR disturbance should extend about $100 \mathrm{~m}$ behind the bridge piers, equivalent to five piers diameter. The direction in which the effect is most important varies, depending on the direction of the strongest currents. This is usually downstream during neap tides, when river flow dominates, and upstream during spring tide when tidal flow dominates. 
Piers also obstruct the flow, causing an increase in the water level and drag force on the bridge's upstream side due to energy dissipation in the flow, as seen in Figure 5-1. Unfortunately, the slope cannot be calibrated because water levels were taken from pressure sensors on the ADCPs, and no absolute reference to a reference datum is possible. That is, the water level is known relative to the bed but is unknown relative to mean sea level.

The piers in the model generated to represent LPR obstruct around $20-30 \%$ of the width. The increase in the water level is responsible for the scouring action by increasing $\tau_{b}$; drag increases due to the pressure differences between upstream and downstream water levels, and there is a pressure drop around the piers associated with acceleration of the flow (i.e., a Bernoulli effect). The magnitude of form drag over the pier surface is equal to the drag force and skin friction on the pillar in the opposite direction (Bulbul, 2017). 


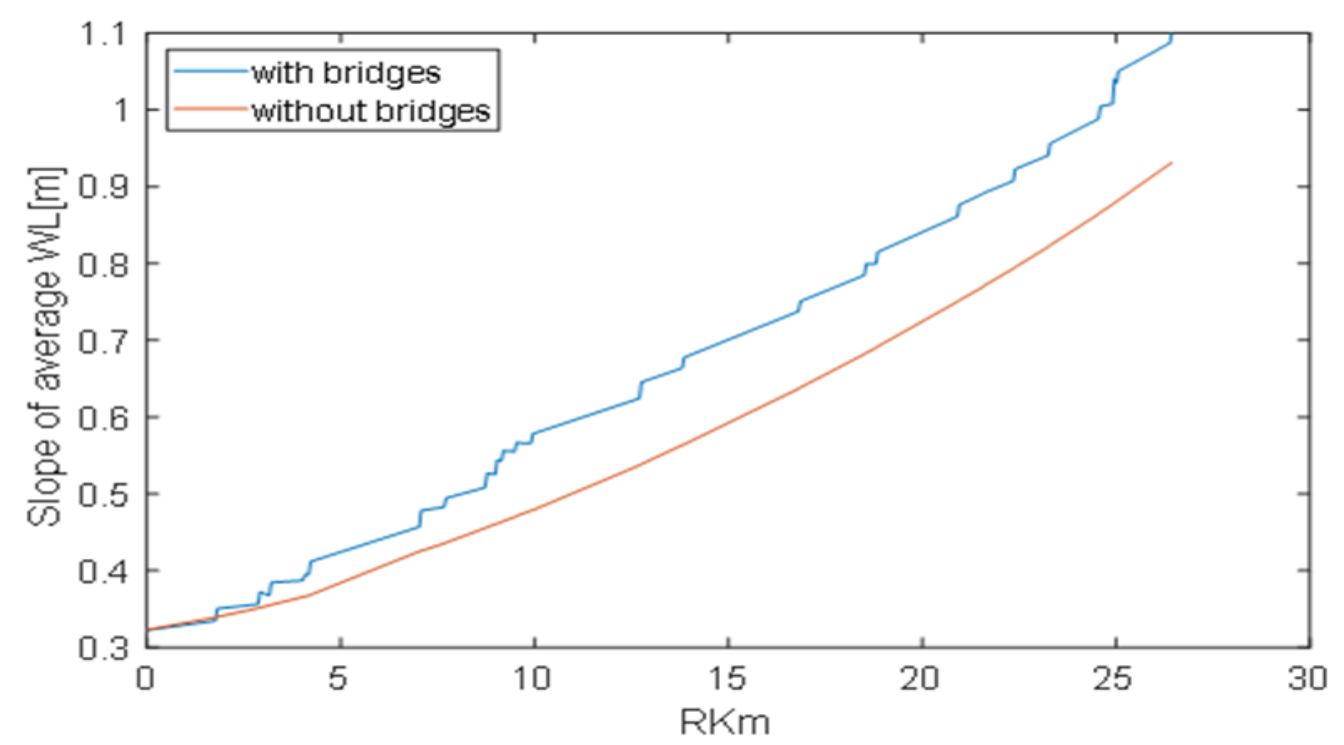

(a) High flow $\left(\sim 295 \mathrm{~m}^{3} / \mathrm{sec}\right)$

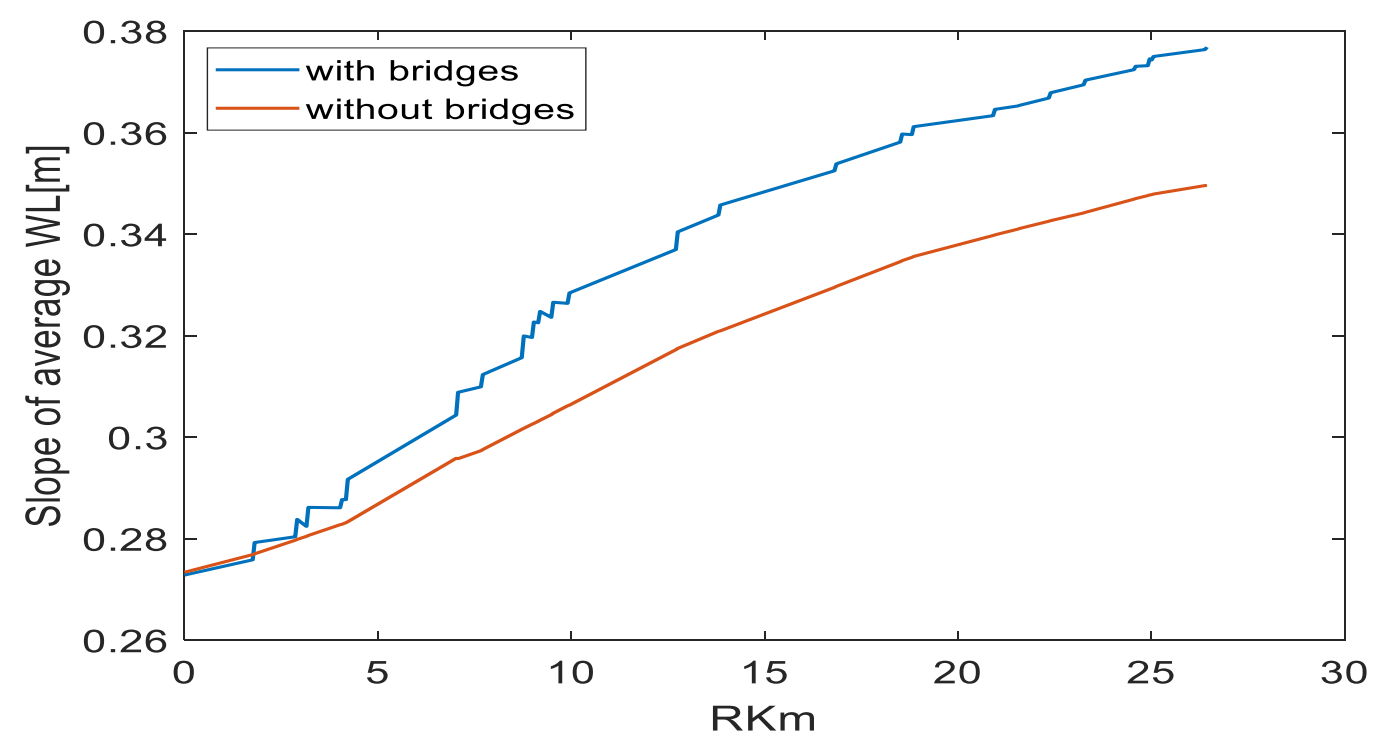

(b) Low flow $\left(\sim 5 \mathrm{~m}^{3} / \mathrm{sec}\right)$

Figure 5-1(a,b). Water level slope with/without bridge piers

In this chapter, I demonstrate the variability of the bed shear stress up/downstream the bridge piers by studying the following scenarios: 
1- Oceanographic factors, channel curvature, and tidal range to depth ratio on the bed shear stress.

2- Natural and human-made elements, such as meanders and bridge pillars, on the shear stress distribution.

3- Variations in external forcing by the river together with the above two points on the distribution of bed shear stress in a stratified estuary are similar to the LPR.

In addition to the above, the scenarios have been chosen to show:

a) The effect of the bridge piers on bed shear stress up and downstream of piers.

b) The effect of river flow (high/low) on the bed shear with two different bed roughness values (rough/smooth).

c) The effect of the meander bend (Hooke, 1975) on shear stress (maximum at the outside of the bend); for realism, this area is wider and deeper by $2 \mathrm{~m}$.

\subsection{Bed shear stress modeling}

The flow exerts shear stress on the bed, i.e., the bed stress $\tau_{b}$. To understand the $\tau_{b}$ distribution along the LPR, and to enhance understanding of estuaries in general, a 3D conceptual river-estuary numerical model has been set up in Delft3D-FM, somewhat similar to that used by Familkhalili \& Talke (2016); it has a simplified depth distribution, convergence, curvature, and width that resemble the LPR and Newark Bay. The grid contains 11504 cells in the horizontal, with grid spacing $\sim(\mathrm{x}=30, \mathrm{y}=20) \mathrm{m}$ at the upstream river end and $\sim(\mathrm{x}=110, \mathrm{y}=100 \mathrm{~m})$ in the Newark Bay. Furthermore, the grid is locally refined to be $(x=10, y=10 \mathrm{~m})$ for a distance $(\sim 160 \mathrm{~m})$ up/downstream of five bridge pies in 
downtown Newark to examine the effects of bridge piers in greater detail . There are 15 vertical sigma levels. A meander has been set up in the model to approximate the natural system and help understand meanders' effects. The depth at the meander's outside bend is taken $2 \mathrm{~m}$ deeper than the opposite side, close to the natural situation. Soar $\&$ Thorne (2001) found that the highest scour depth occurs when the ratio of the radius of the curvature to the width is two. In this case, energy loss is minimized, and flow energy maximized at the bend. Much of the analysis that follows focuses on downtown Newark shown in Figure 5-2, and on the effects of the bridges and the meander it contains.

Bottom friction has been represented using Chezy coefficient (CZ). For most runs, the $\mathrm{CZ}$ at Kill van Kull (KVK) was 50 and then decreased gradually to 30 at Dundee dam (rough). This parameterization was used because it was found to be the most realistic. Additional runs were made made using $\mathrm{CZ}=70$ at Kill van Kull, decreasing gradually to 50 (smooth). The bed stress scenarios listed in Table 5-1 were used to examine the effects of roughness, river flow, and tidal range on bed stress and salinity intrusion.

Table 5-1. bed shear stress scenarios

\begin{tabular}{|c|c|c|c|c|}
\hline Scenarios & System Status & $\begin{array}{l}\text { High flow } \\
\text { (cms) }\end{array}$ & $\begin{array}{c}\text { Low flow } \\
\text { (cms) }\end{array}$ & $\begin{array}{c}\text { Chezy } \\
\text { Bay-River }\end{array}$ \\
\hline 1 & \multirow{2}{*}{$\begin{array}{l}\text { with Bridge } \\
\text { piers }\end{array}$} & \multirow{2}{*}{$270-320$} & \multirow{2}{*}{$5-10$} & $50-30$ \\
\hline 2 & & & & $70-50$ \\
\hline 3 & \multirow{2}{*}{$\begin{array}{l}\text { without Bridge } \\
\text { piers }\end{array}$} & \multirow{2}{*}{$270-320$} & \multirow{2}{*}{$5-10$} & $50-30$ \\
\hline 4 & & & & $70-50$ \\
\hline
\end{tabular}




\subsection{Boundary conditions and model validation}

I applied the river discharge, tidal forcing, and salinity at model boundaries, because these are the primary external forces that affect the $\tau_{b}$. The 12-minutes tidal forcing (from NOAA), salinities at KVK from the moorings at those locations, zero salinity at Dundee Dam, and river flow (sum of Passaic plus Saddle River flows, input at Dundee Dam) were used to drive 5-month runs (March 25 to July 20) for each scenario.

The model is initially validated with observed water levels at the USGS tide gauge at station \#01392650, at Newark, NJ (at about RM 0 of the LPR), and the various ADCP mooring locations in the LPR. Model results show a reasonable agreement with observed variations in water level (), harmonic analysis results for $\mathrm{M}_{2}$ and $\mathrm{M}_{4} / \mathrm{M}_{2}$ (Figure 5-4), and salinity (Figure 5-5). Table 5-2 shows model performance in terms of correlation coefficient $\left(\mathrm{R}^{2}\right)$ and Root Mean Square Error (RMSE) for all water level stations.

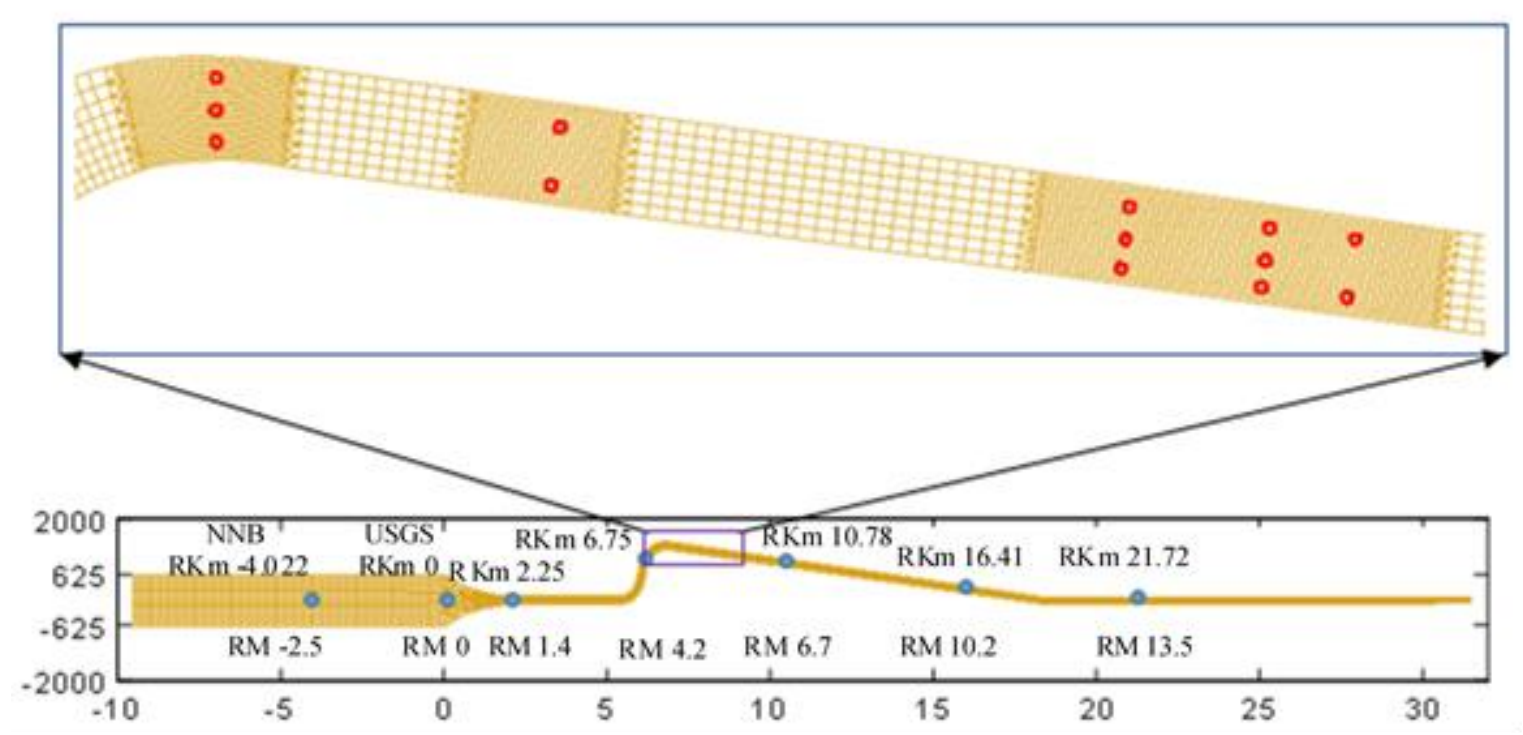

$\mathrm{Km}$

Figure 5-2. The plan view of the Newark Bay and LPR grid 
RM 0
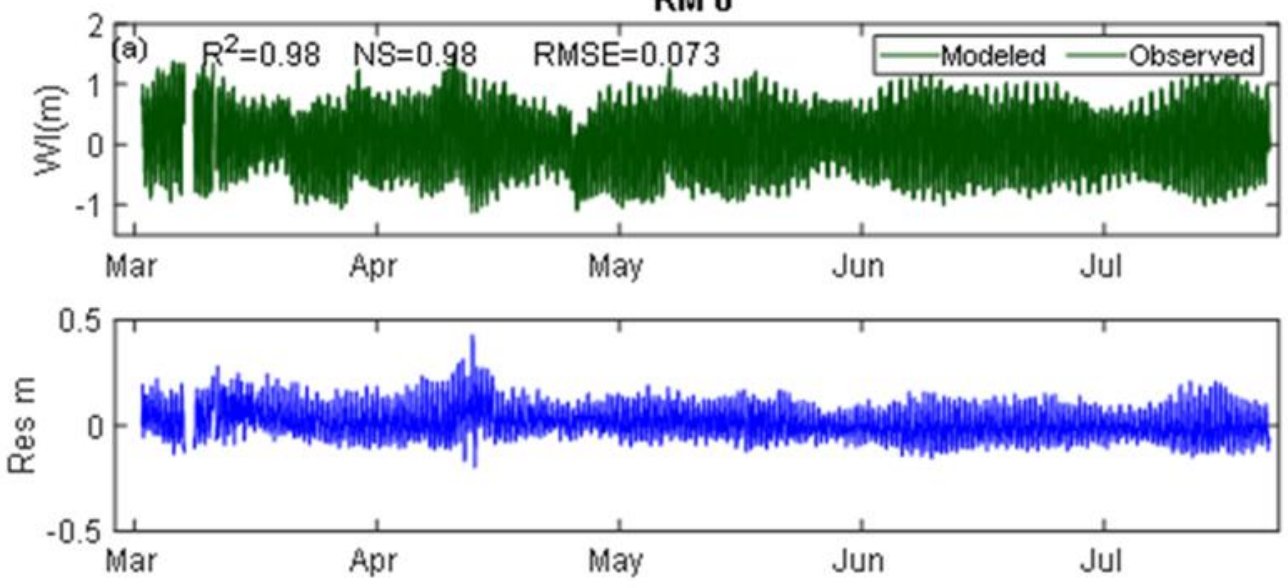

RM 1.4
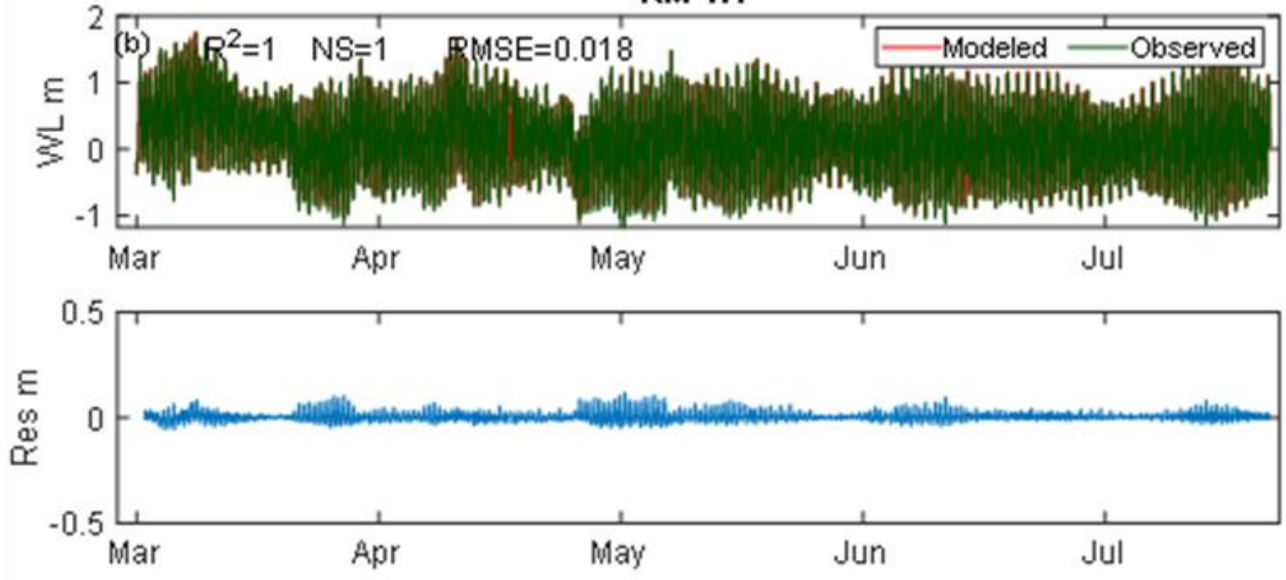

RM 4.2
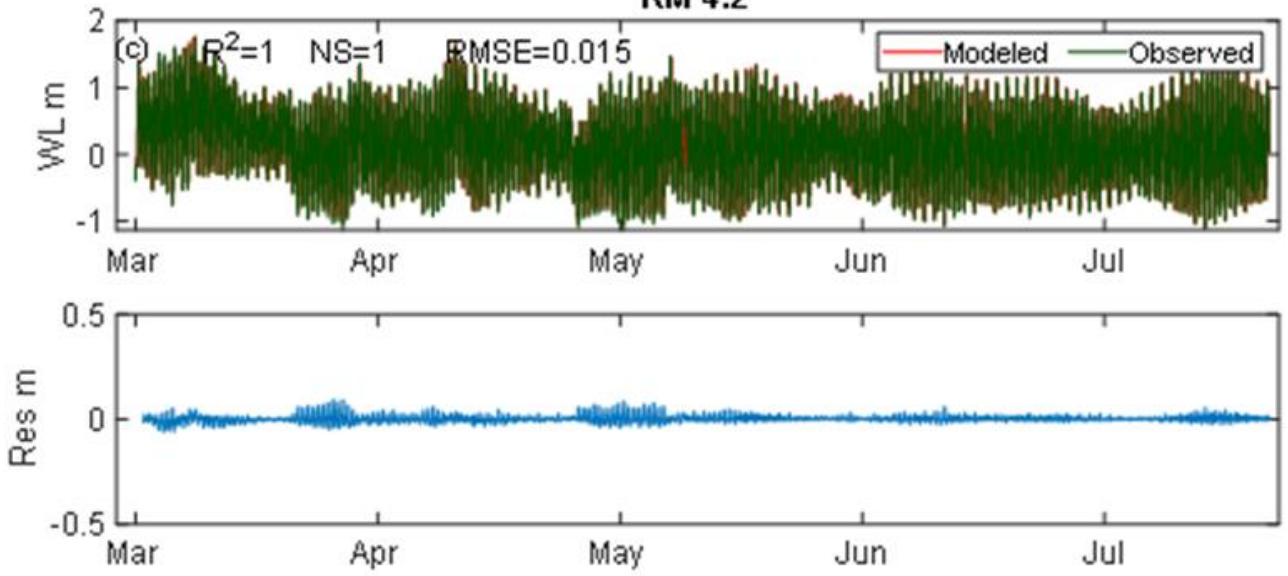
RM 6.7
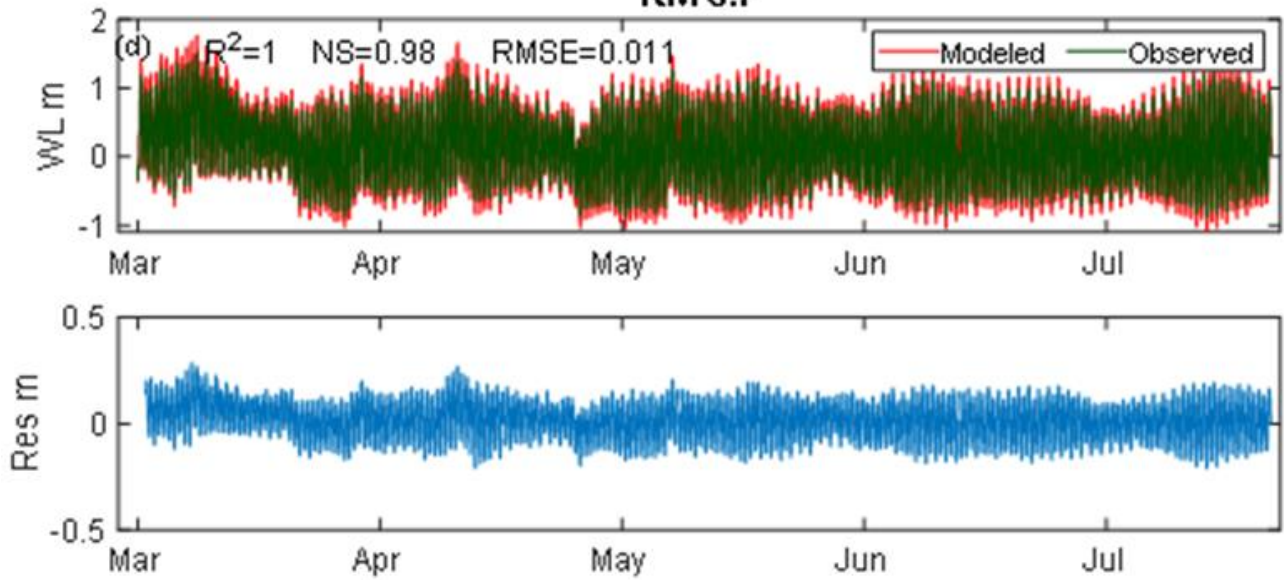

Spring 102
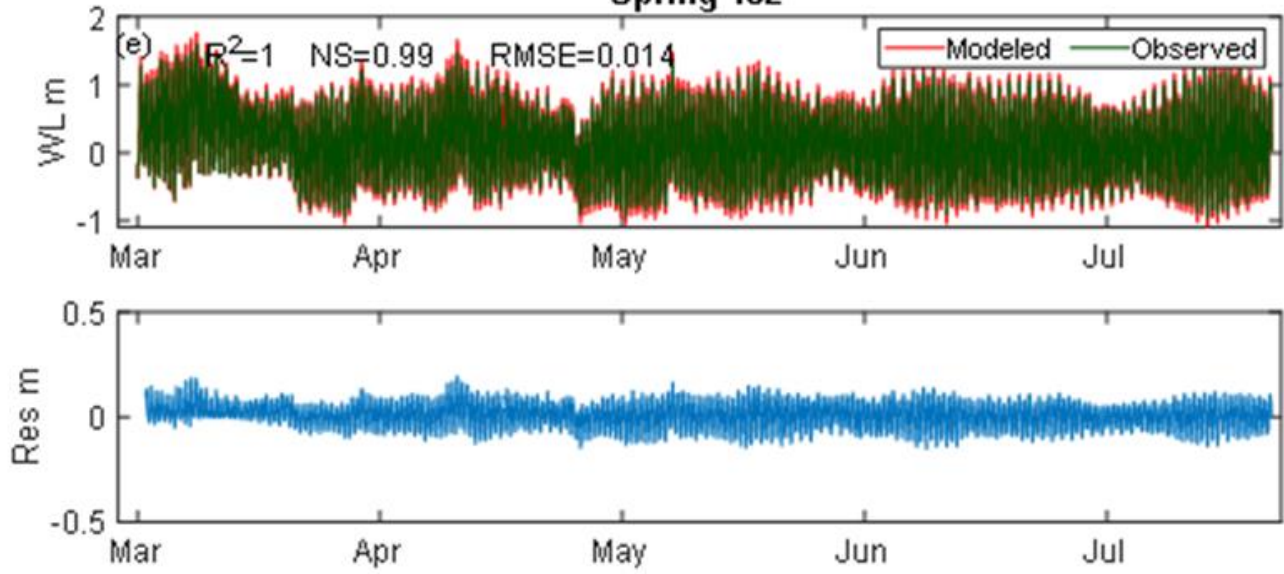

RM 13.5
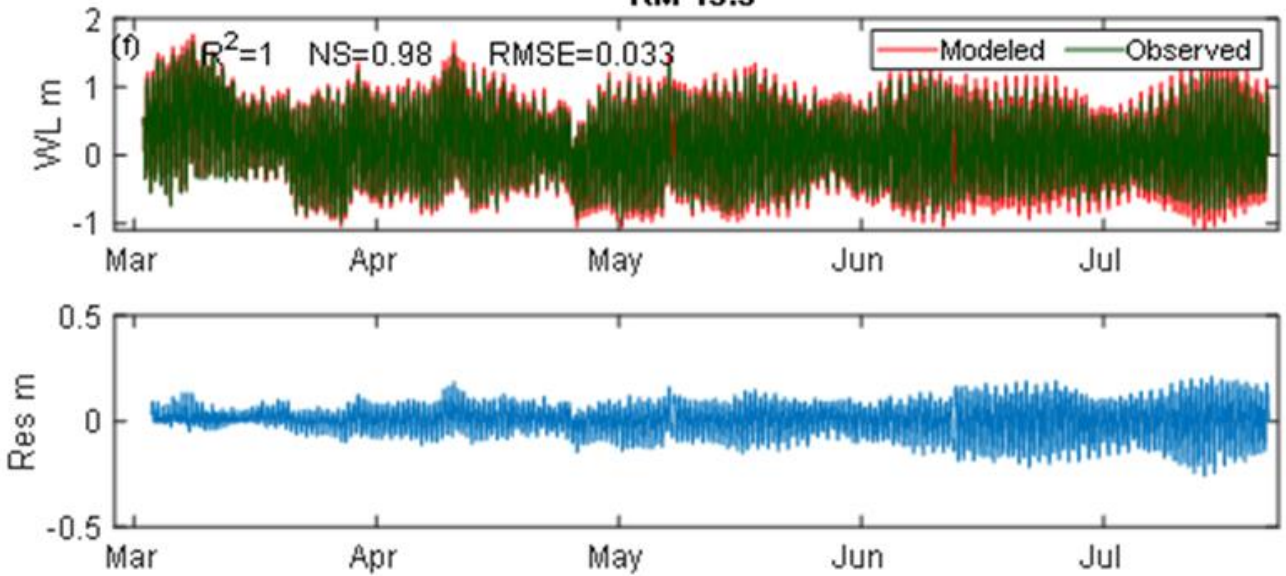

Figure 5-3 (a,b,c,d,e,f). Observed - Modeled water level; the blue the blue plot is the error for each case (modeled-observed) 

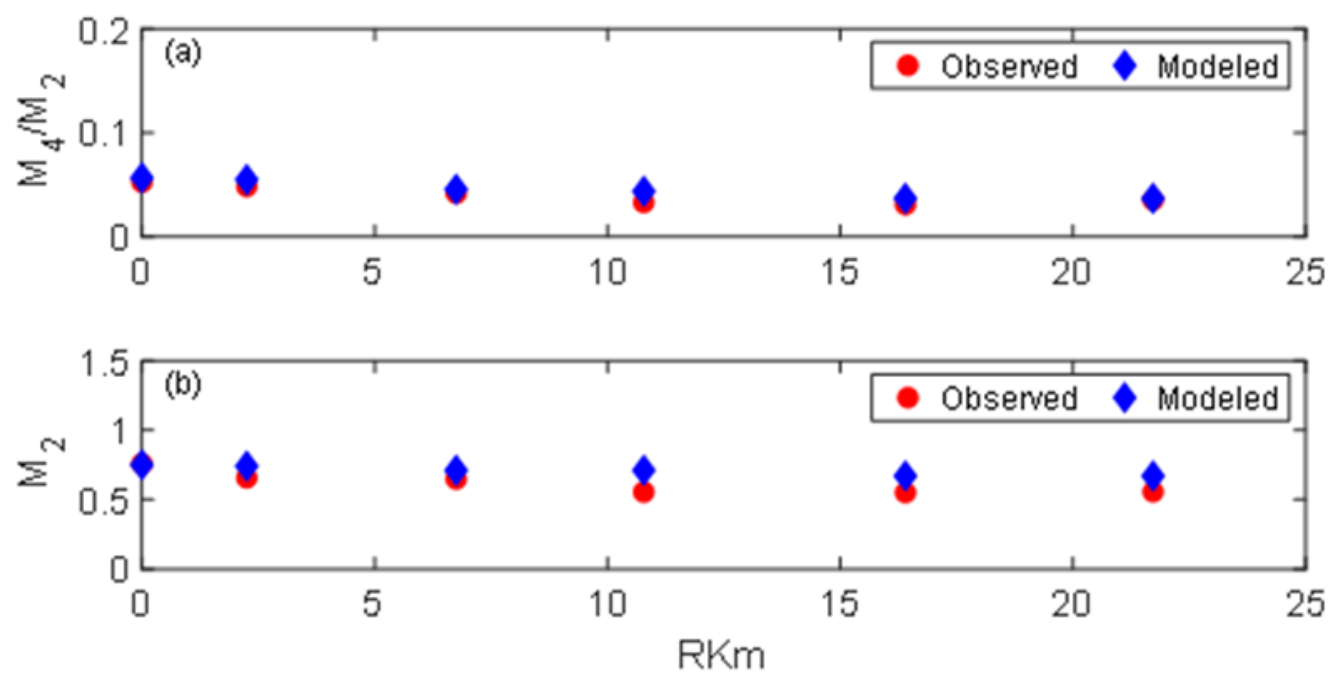

Figure 5-4 (a, b). Constituent analysis of observed vs. modeled, a-M4/M2 b-M2

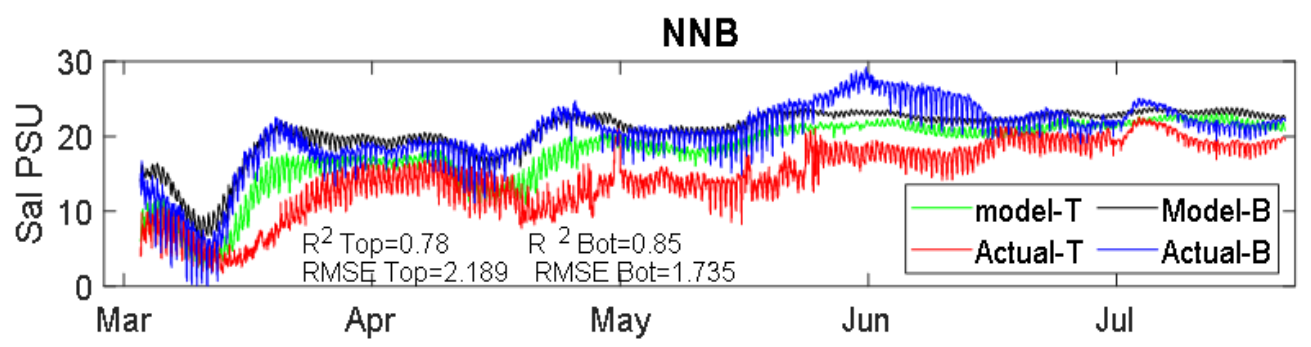

\section{2}

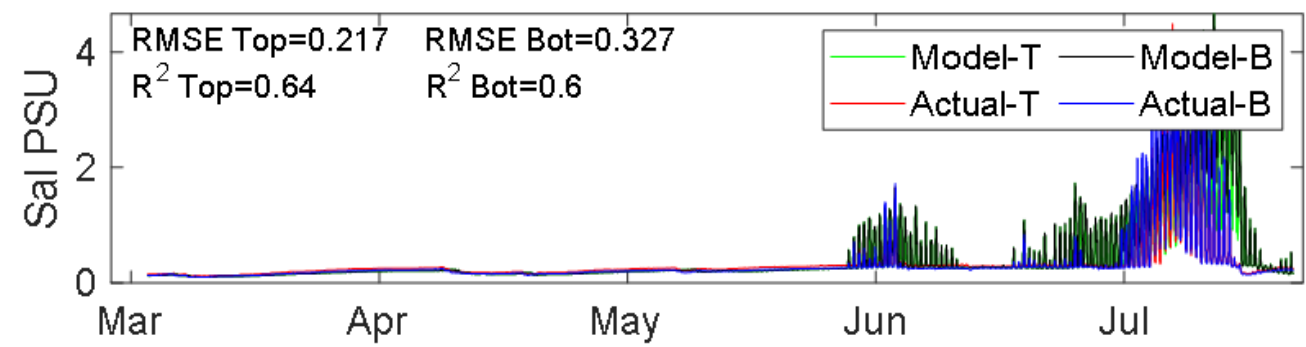

Figure 5-5. Top and Bottom actual vs. modeled Salinity at NNB and RM 10.2 
Table 5-2. $\mathrm{R}^{2}$ of WL and Salinity (Top-Bottom) at LPR

\begin{tabular}{|c|c|c|c|c|c|c|}
\hline \multirow{2}{*}{ RM } & \multicolumn{2}{|c|}{ WL } & \multicolumn{2}{c|}{ Salinity Top (psu) } & \multicolumn{2}{c|}{ Salinity Bottom (psu) } \\
\cline { 2 - 7 } & $\mathbf{R}^{\mathbf{2}}$ & $\mathbf{R M S E}$ & $\mathbf{R}^{\mathbf{2}}$ & $\mathbf{R M S E}$ & $\mathbf{R}^{\mathbf{2}}$ & $\mathbf{R M S E}$ \\
\hline $\mathbf{N N B}$ & - & - & 0.78 & 2.189 & 0.85 & 1.735 \\
\hline $\mathbf{0}$ & 0.89 & 0.073 & - & - & - & - \\
\hline $\mathbf{1 . 4}$ & 1 & 0.018 & 75 & 2.003 & 0.74 & 2.172 \\
\hline $\mathbf{4 . 2}$ & 1 & 0.015 & 0.85 & 1.177 & 0.66 & 2.949 \\
\hline $\mathbf{6 . 7}$ & 1 & 0.011 & 0.63 & 1.317 & 0.61 & 1.617 \\
\hline $\mathbf{1 0 . 2}$ & 1 & 0.014 & 0.64 & 0.217 & 0.60 & 0.342 \\
\hline $\mathbf{1 3 . 5}$ & 1 & 0.033 & 0.95 & 0.012 & 0.95 & 0.012 \\
\hline
\end{tabular}

\subsection{Results and analysis}

\subsubsection{Bed Shear stress}

Bridge piers strongly affect the flow, deposition, and erosion through their influence on the velocity field and $\tau_{b}$. The major flow features around the piers involve a vertically deflected flow in front of the cylinder, a horseshoe vortex upstream of the piers, a flow separation around the piers, and wake vortices zone downstream of it (Bulbul, 2017), all of which contribute to drag. Also, flow intensity and geometric conditions affect the maximum $\tau_{b}$ and vortex strength. An example of a vertically averaged flow and salinity, and stratification are shown in Figure 5-6. The detailed features described by Bulbul (2017) cannot be directly modeled here, because the grid resolution does not allow this. Nonetheless, the modeled features bear a qualitative resemblance to observations. 
a- Flow
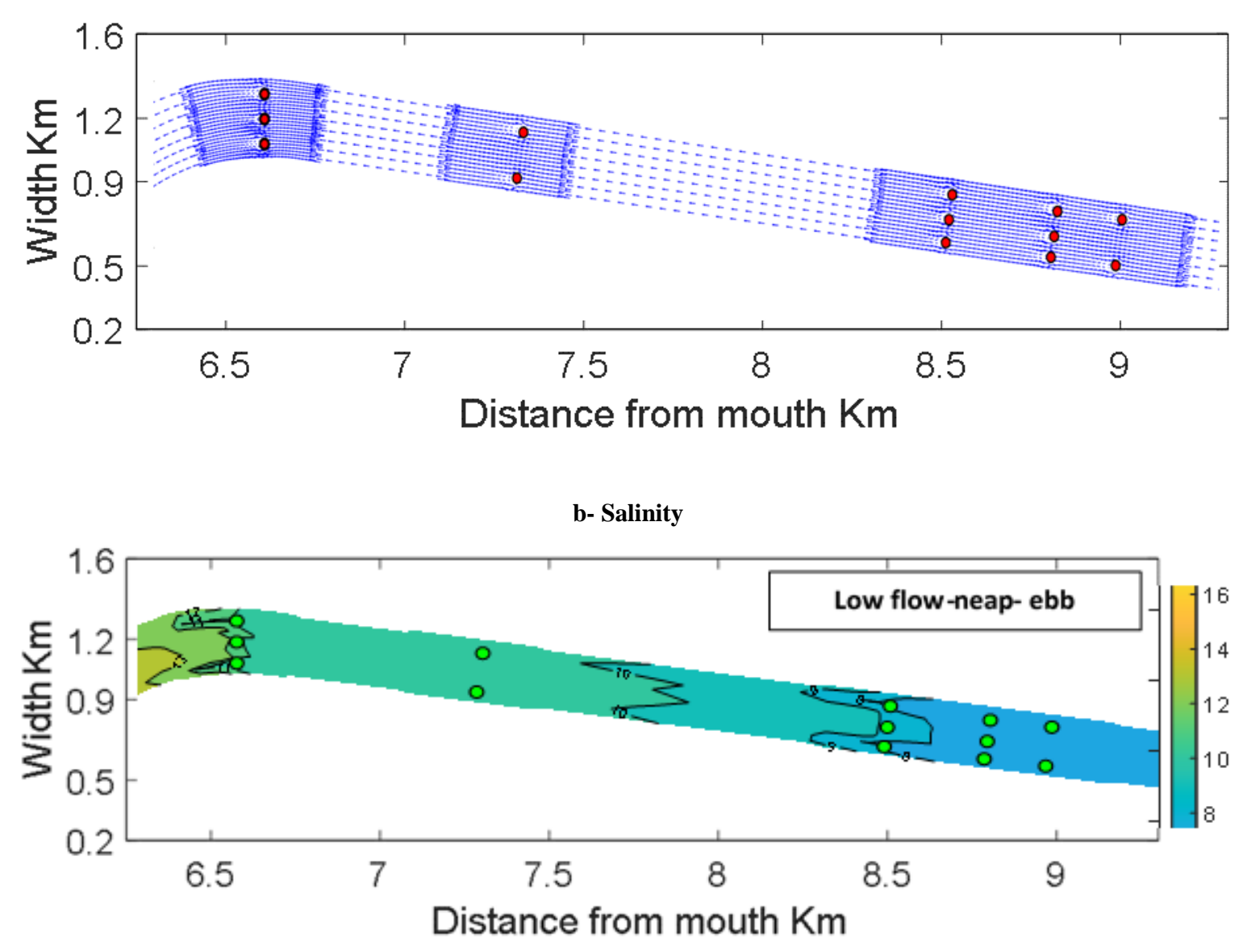

Figure 5-6. Velocity and salinity development around bridges piers at downtown Newark. Flow is from right to left

Numerical modeling shows a strong influence of piers on $\tau_{b}$ upstream vs. downstream of the five bridges in downtown Newark selected as a case study; Figure 5-7. Specifically, $\tau_{b}$ is higher on the upstream side of piers with high river flow than with low flow, because river flow is the strongest source of current in this area. In contrast, the $\tau_{b}$ is higher on the downstream side of piers with low flow due to the effect of the tidal force. However, in general, at high flow, the direction of the $\tau_{b}$ is seaward upstream on ebb 
following the direction of the flow and tide and landward downstream, probably due to a combination of estuarine circulation and internal tidal asymmetry. While, at low flow, the direction of the $\tau_{b}$ is landward downstream on flood where barotropic and baroclinic pressure gradients work together on the flood and landward upstream via vortex formation. Maximum stress at high flow is on ebb due to combining river flow and tide forces directions, and on the flood with low flow via the effect of tide force and estuarine circulation.

The results of the tidal range to depth ratio Figure 5-8 show that this ratio is positively correlated with $\tau_{b}$, however there no clear difference between this ratio up and downstream of bridge piers.

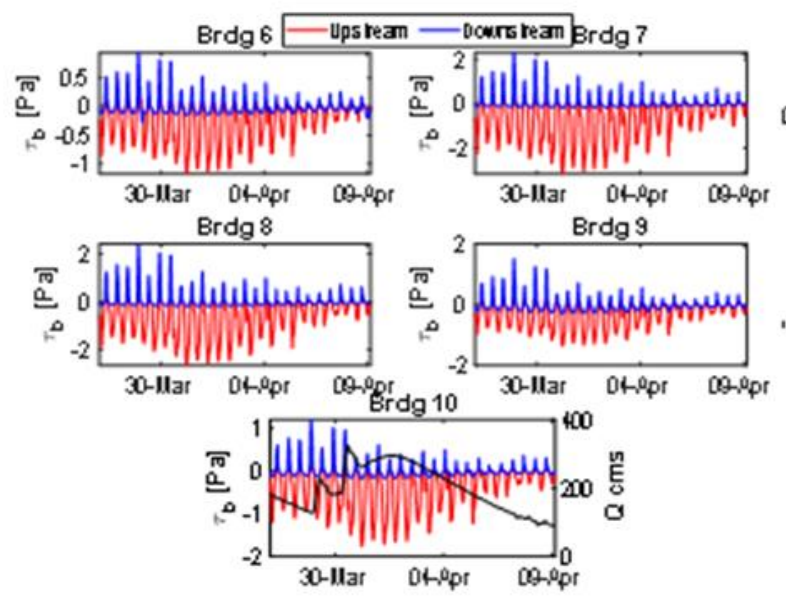

a1: High Flow
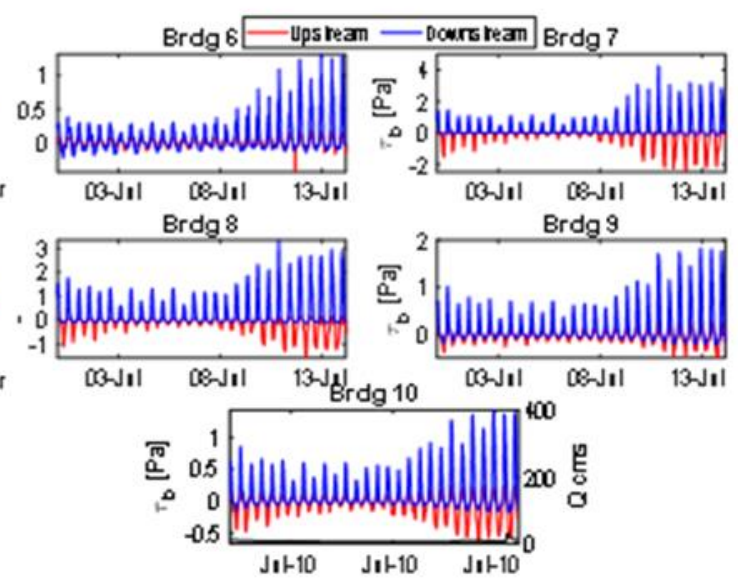

a2: Low Flow

a- Chezy 50-30 

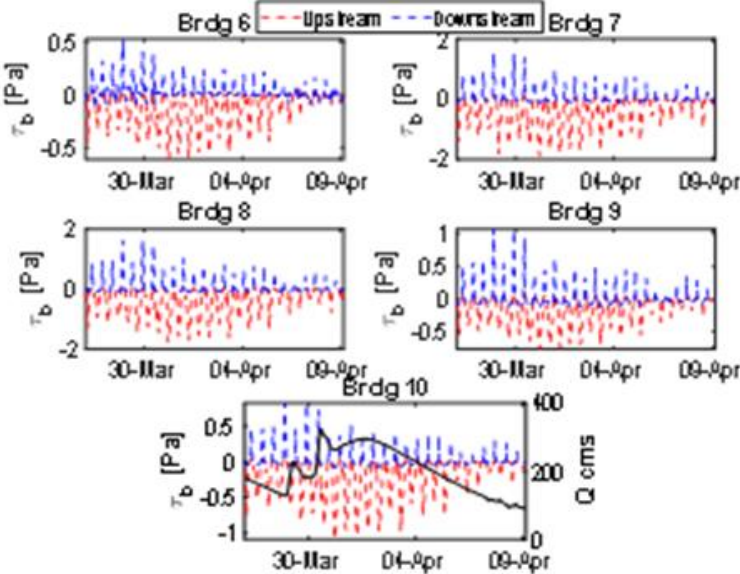

b1: High Flow
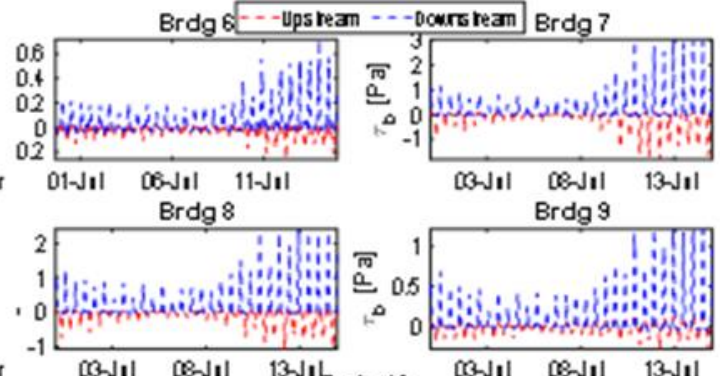

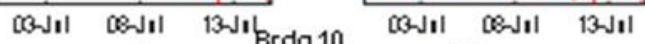

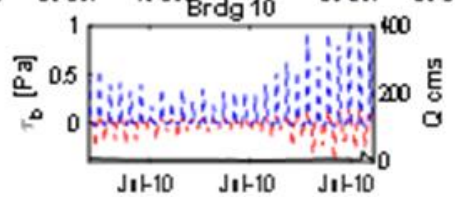

b2: Low Flow

\section{b- Chezy 70-50}

Figure 5-7. Bed shear stress up/downstream bridges piers a- rough bed b- smooth bed 

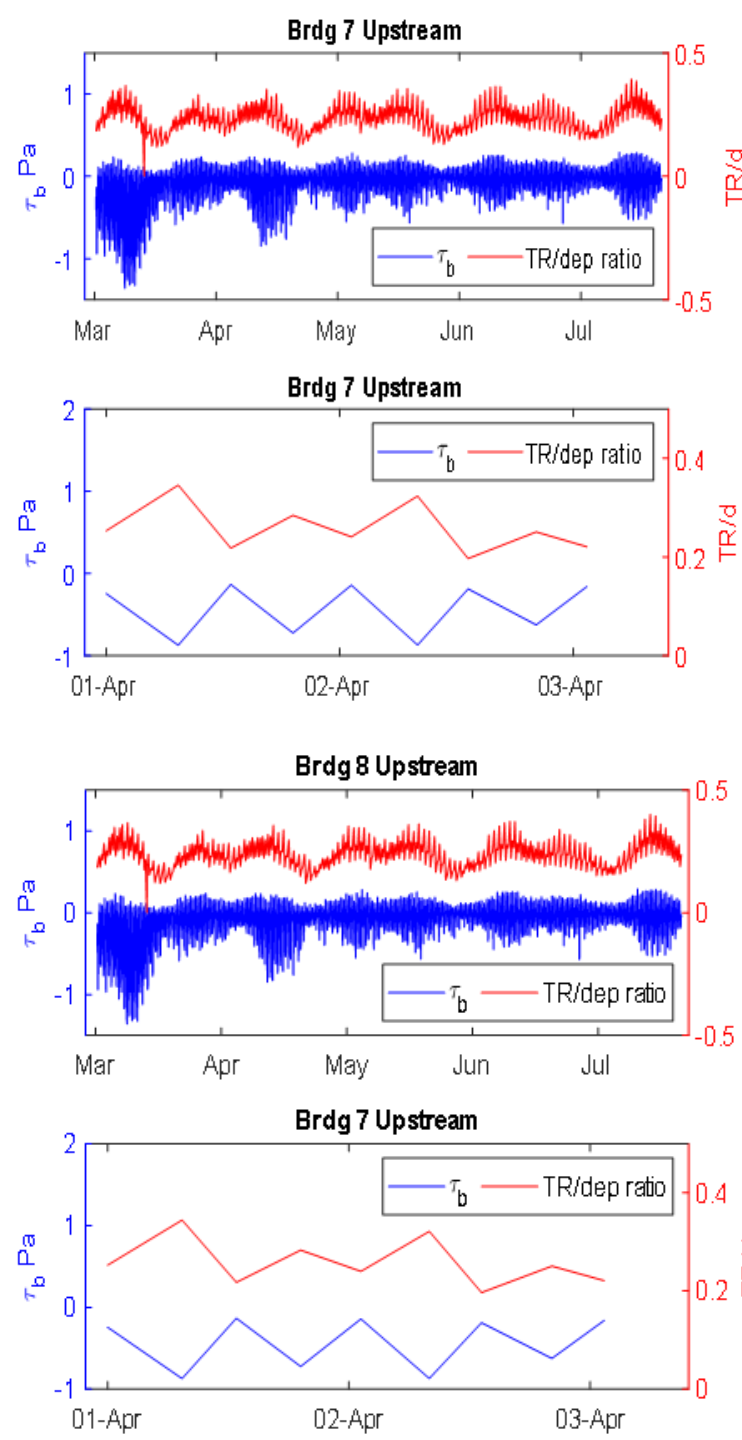

Figure 5-8. Variations of $\tau_{b}$ and the ratio of tidal range to the depth.
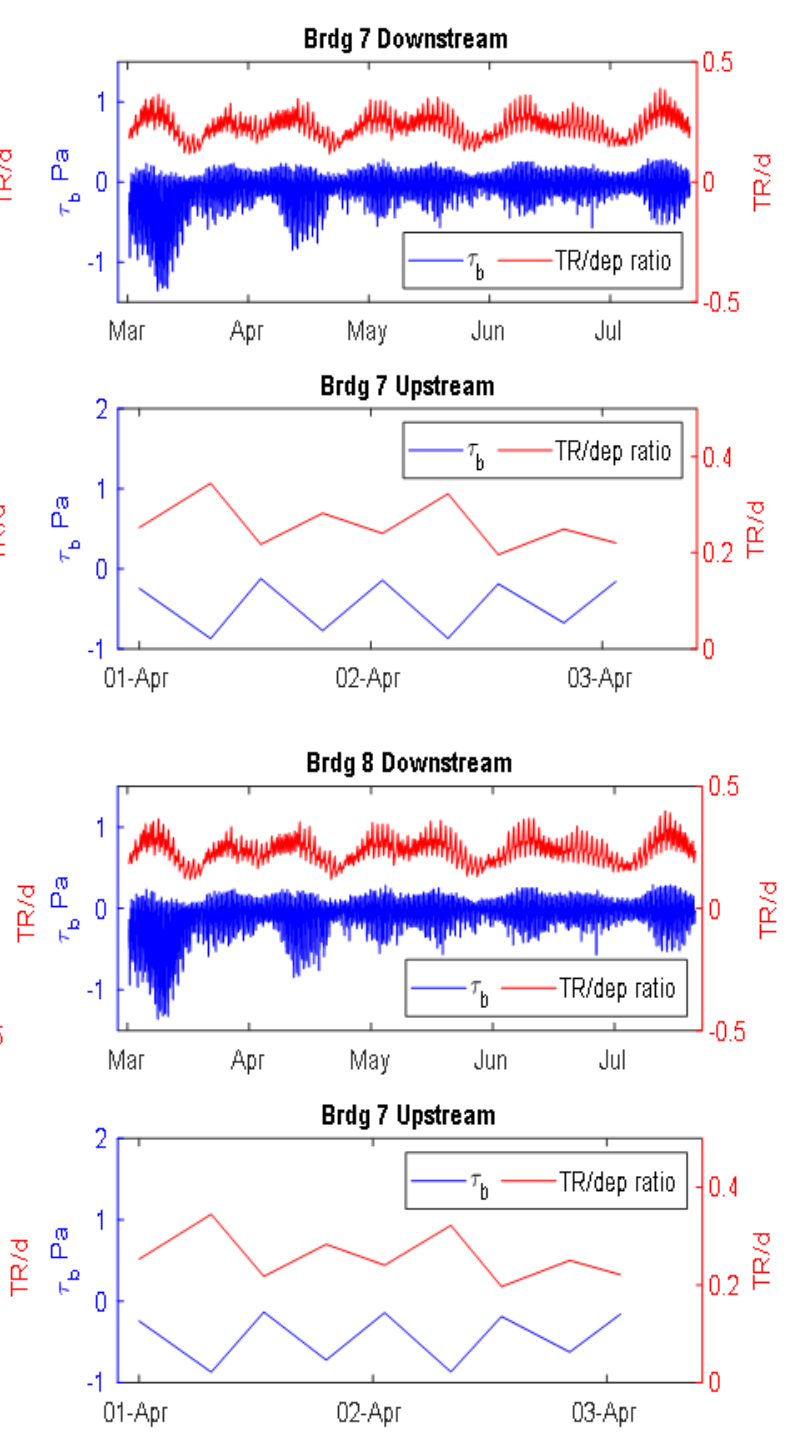
curvature and depends on the flow force in the river estuary. Spatial plots of $\tau_{b}$ show that the maximum bed stress is on the bend's outer bank with a high river flow because ebb tidal currents are reinforced by river flow. In contrast, the highest bed stress is on the inner bank on flood- low flow is due to the tide force's effect is shown in Figure 5-9 where barotropic and baroclinic pressure gradients work together on the flood.

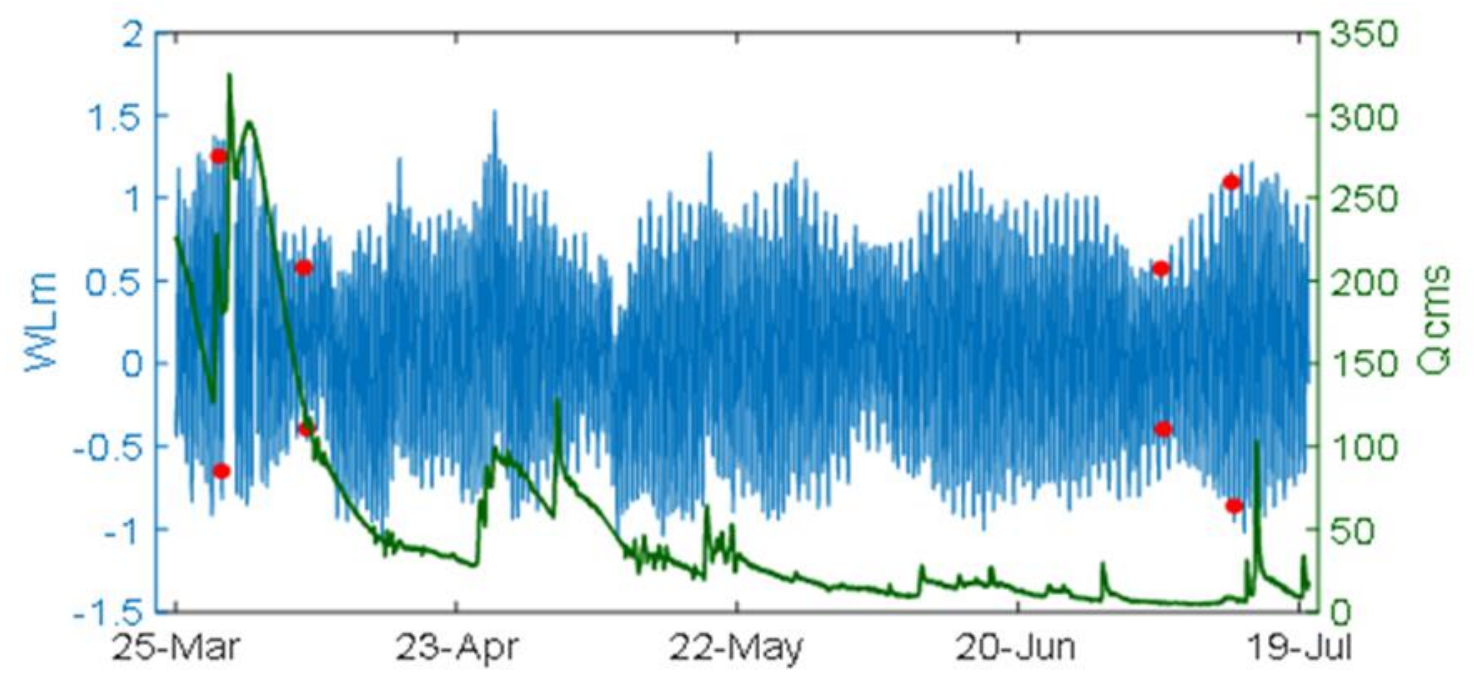

Figure 5-9. Times of spring- ebb plots in color maps 


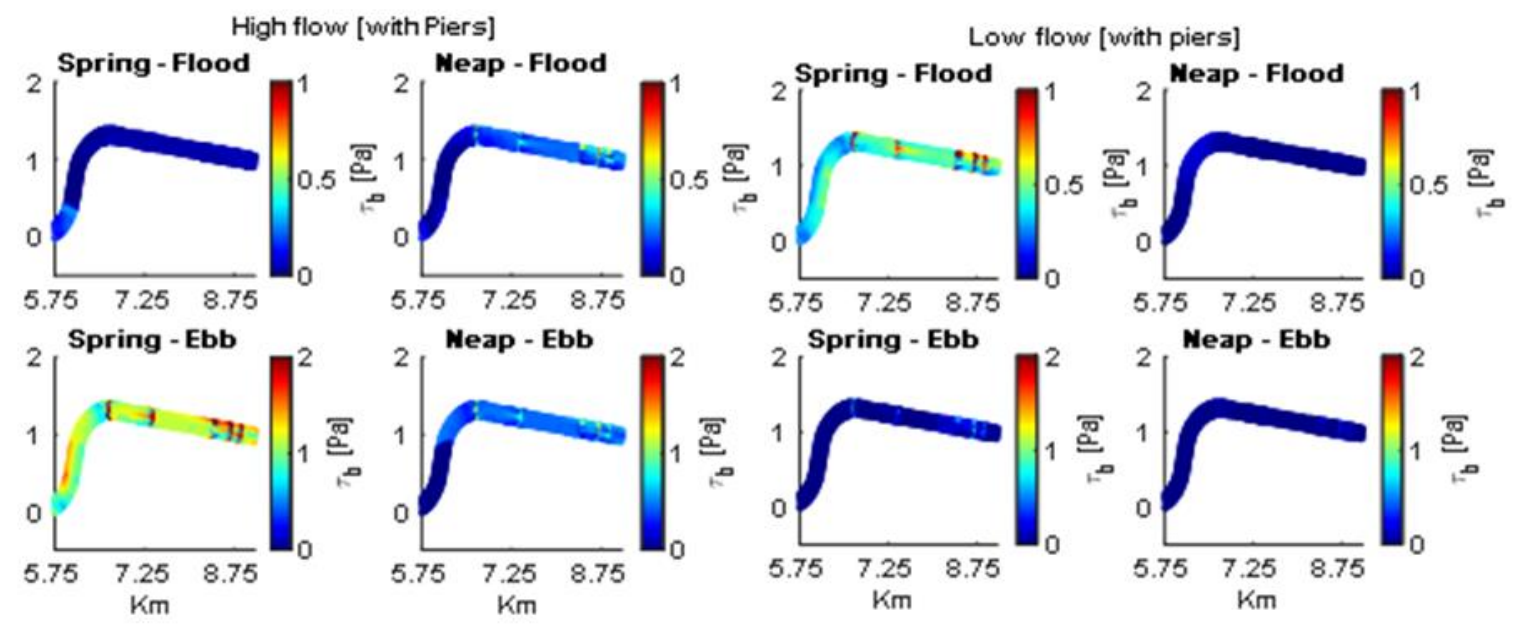

a- Chezy (50-30)

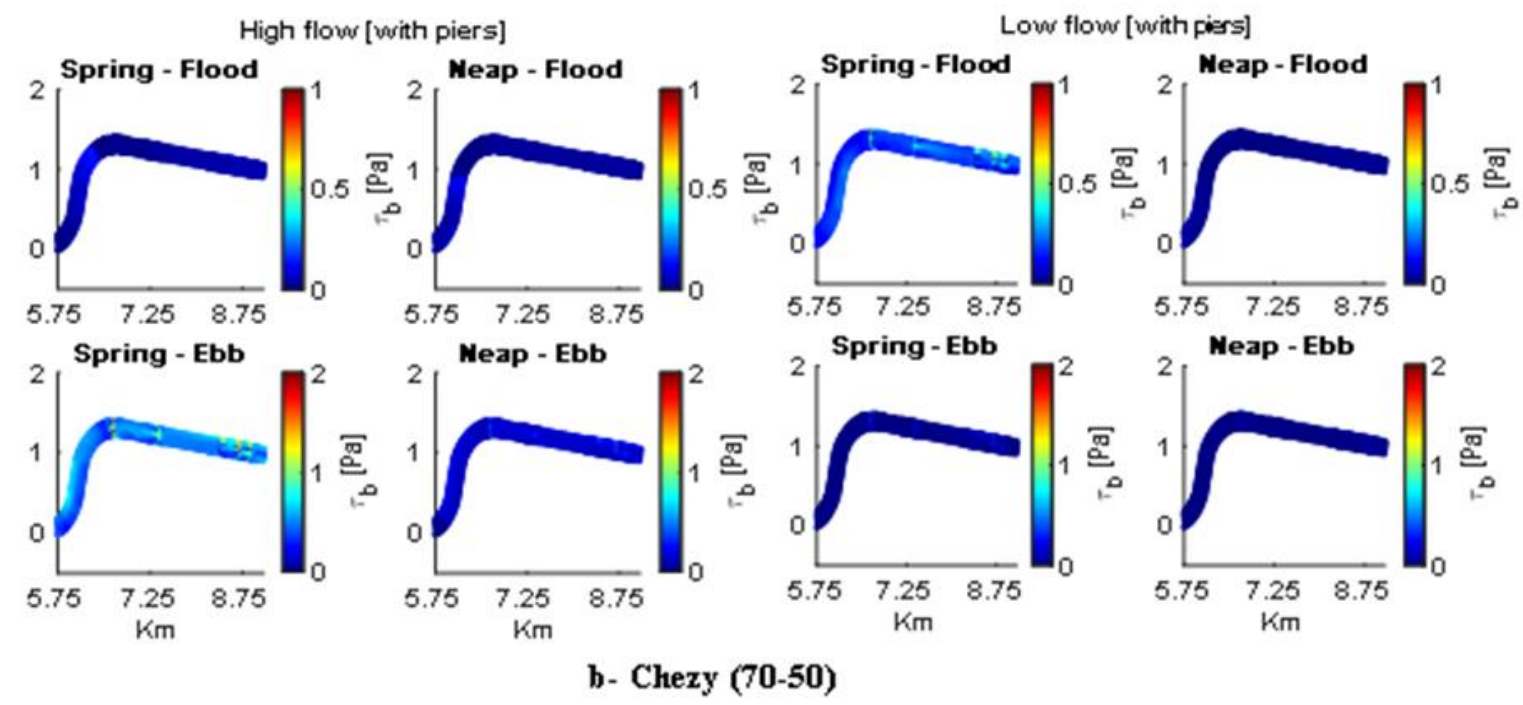

Figure 5-10. Bed stress color map for five bridges piers in downtown Newark and the bend for different bed roughness a- Chezy (50 at Bay-River at 30) b- Chezy (70 at Bay-River at 50) 

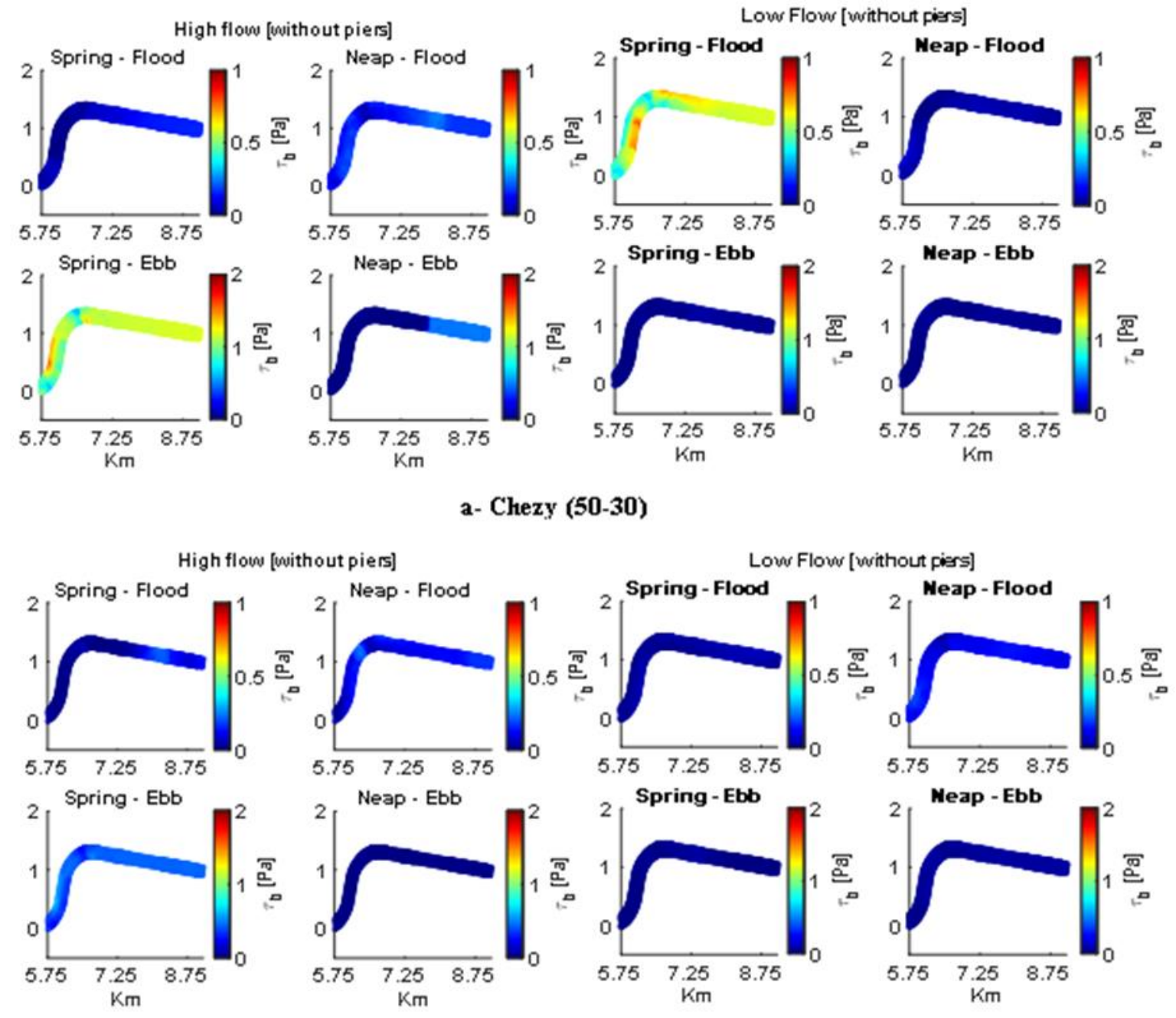

a- Chezy (70-50)

Figure 5-11. Bed stress color map without bridges piers for different bed roughness a- Chezy (50 at Bay-30 at River) b- Chezy (70 at Bay-50 at River)

\subsubsection{Bed erosion}

Strong vertical variation of SSC often exists in the riverine and marine environment, especially near the bed where sediment erosion and deposition occur. Near the bottom, strong currents can cause erosion or resuspension of bed sediments when $\tau_{b}$ 
exceeds $\tau_{c r}$. In contrast, a gradual reduction in the $\tau_{b}$ leads to slowdown or termination of the erosion process (Sheng \& Villaret, 1989). The Delft3D model shows that the erosion mostly occurs (as judged by bed stress levels) at the outsiders of the bend and around and between bridge piers due to the decrease in the cross-sectional area at the bridge locations. This can be seen in Figure 5-12, which shows show the percentage of the cells in the section between RKm 5.75 and 9 where erosion occurs out of the total number of cells (4948). Erosion is deemed to occur when $\tau_{b}$ is greater that $\tau_{c r} ; \tau_{c r}$ is assumed to be $0.35 \mathrm{~Pa}$, appropriate for LPR coarse SPM fractions (CPG, 2010). The number of cells where erosion occurs is greater with the high flow than low flow, as shown in Table 5-3. Moreover, both tide and flow are important so that the highest percentage of the erosion cells is seen on the Spring-Ebb with high flow when both strong tidal currents and high river flow act in the same direction. Furthermore, the analyses show that the maximum $\tau_{b}$ occurs close to bridges (within about $100 \mathrm{~m}$ upstream and $100 \mathrm{~m}$ downstream; bridge 7 as an example). Near bridge $7, \tau_{b}$ is about twice as large with bridges than without ( $\left.\mathrm{RKm} 7.7\right)$, as shown in Table 5-4.

Table 5-3. The fraction of the erosion points between RKm 5.75 and 9

\begin{tabular}{|c|c|c|c|c|}
\hline Flow & $\begin{array}{c}\text { \% Spring- } \\
\text { Flood }\end{array}$ & $\begin{array}{c}\text { \% Spring- } \\
\text { Ebb }\end{array}$ & $\begin{array}{c}\text { \% Neap- } \\
\text { Flood }\end{array}$ & $\begin{array}{c}\text { \% Neap- } \\
\text { Ebb }\end{array}$ \\
\hline High Flow & 0 & 97 & 5 & 56 \\
\hline Low Flow & 69 & 5 & 0 & 0 \\
\hline
\end{tabular}


Table 5-4.The maximum $\tau_{b}$ around bridge 7 and at RKm 7.7 without bridges

\begin{tabular}{|c|c|c|c|c|}
\hline & $\begin{array}{c}\text { Spring-Flood } \\
\tau_{b} \mathrm{~Pa}\end{array}$ & $\begin{array}{c}\text { Spring-Ebb } \\
\tau_{b} \mathrm{~Pa}\end{array}$ & $\begin{array}{c}\text { Neap-Flood } \\
\tau_{b} \mathrm{~Pa}\end{array}$ & $\begin{array}{c}\text { Neap-Ebb } \\
\tau_{b} \mathrm{~Pa}\end{array}$ \\
\cline { 2 - 5 } & \multicolumn{5}{|c|}{ High Flow } \\
\hline $\begin{array}{c}\text { Around Brdg- } \\
\mathbf{7 ~ R K m ~ 7 . 3}\end{array}$ & 0.07 & 2.28 & 0.51 & 0.88 \\
\hline Rkm 7.7 & 0.04 & 1.21 & 0.25 & 0.46 \\
\hline & \multicolumn{5}{|c|}{ Low Flow } \\
\hline $\begin{array}{c}\text { Around Brdg } \\
\text { 7 RKm 7.3 }\end{array}$ & 1.02 & 0.93 & 0.15 & 0.11 \\
\hline Rkm 7.7 & 0.56 & 0.32 & 0.14 & 0.07 \\
\hline
\end{tabular}



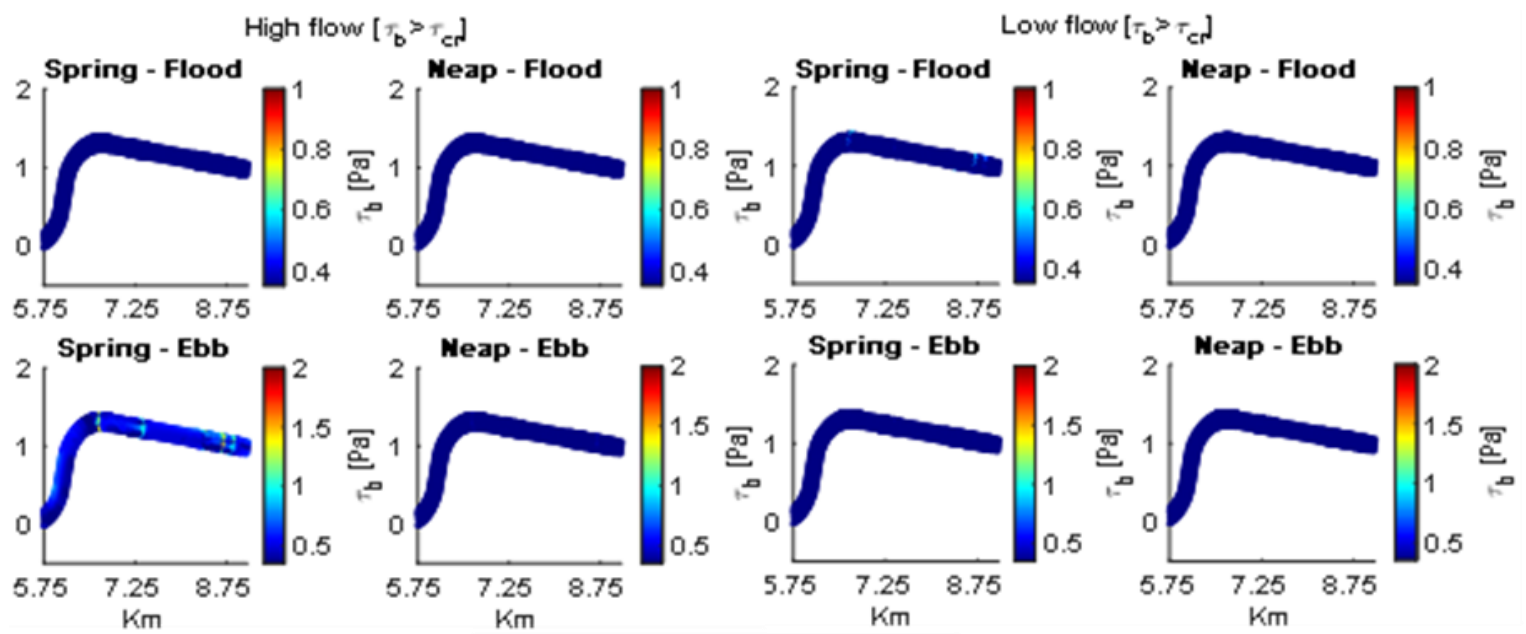

a-Chezv (50-30)

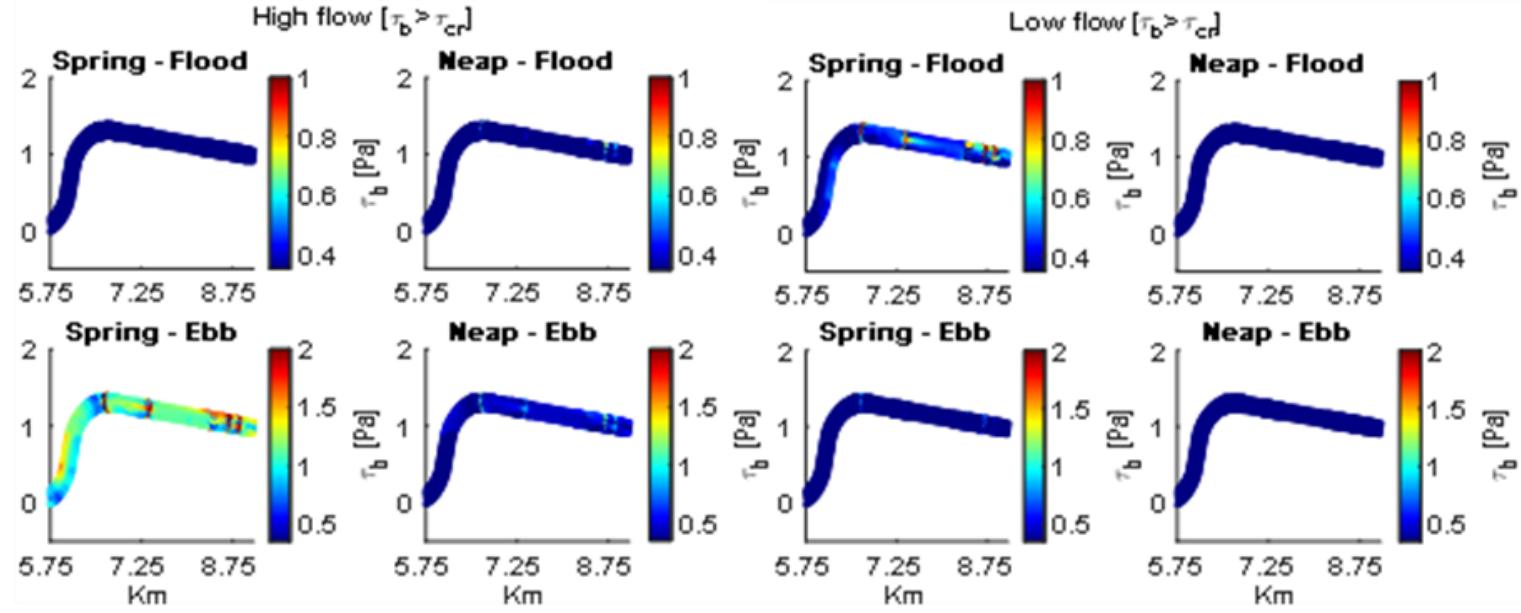

b- Chezv (70-50)

Figure 5-12. Erosion color map showing the ratio $\frac{\tau_{b}}{\tau_{c r}}$ with bridges piers for different bed roughness aChezy (50 at Bay-River at 30) b- Chezy (70 at Bay-River at 50)

\subsubsection{Salinity intrusion}

During the spring low-flow period (July), salinity intrusion is increased due to decreased river flow. Theory also suggests that deepening an estuary and channel $15 \%$ in 
depth corresponds with doubling the exchange flow and pushing salinity intrusion landward due to increased stratification (Chant et al., 2018; Ralston \& Geyer, 2019). However, this theoretical increase in two-layer flow is not always observed in nature, and no information exists as to how the LPR would react (or has reacted in the past) to changing depths. In particular, the large number of bridges in the system may strongly alter the response of the system. Here we investigate the influence of LPR bridge piers on salinity intrusion.

Model results suggest that tidally averaged salinity intrusion, measured by the position of the X2 (2 PSU near the bed) contour, varies inversely with river flow as:

$$
\begin{gathered}
\frac{X 2}{X 2_{\max }}=\left(\frac{Q}{Q_{\max }}\right)^{-n} \\
\operatorname{Ln}[\mathrm{X} 2]=\mathrm{X} 2_{\max }-n * \operatorname{Ln}\left[\frac{Q}{Q_{\max }}\right]
\end{gathered}
$$

where $\mathrm{X} 2_{\max }$ is the maximum salinity intrusion at very low flow, $\mathrm{Q}$ is the flow, and $Q_{\max }$ is the maximum flow. The parameter $n$ was determined by regression analysis of the daily mean X2 as in Table 5-5; see Table 5-5 for results. The results in Table 5-5 are known to be sensitive to the choice of the origin from which X2 is calculated (Al Bahadily, 2020). X2 was placed at mouth of Newark Bay.

Table 5-5: $\mathrm{n}$ values with/without bridges piers

\begin{tabular}{|c|c|}
\hline & n values \\
\hline With bridges & -0.126 \\
\hline Without Bridges & -0.132 \\
\hline
\end{tabular}


Mixing at bridge piers reduced stratification and estuarine circulation (MacCready \& Geyer, 2010). Thus, piers likely increase the exponent of Q because they increase mixing and decrease stratification. LPR salinity intrusion contours during low flow and high are shown in Figure 5-13(a,b) with different bed roughness, with/without bridge piers, and for flood and ebb. The results show that when the bed is rough, there is a small decrease in salinity intrusion (X-2 moves seaward). Furthermore, mixing is strong at flood-low and high flow, which leads to an absence of the stratification while the stratification is apparent in the ebb. Table 5-6 shows the 2-psu salinity intrusion (X2) for sixteen cases at low and high flow. Clearly, the presence of bridge piers reduces salinity intrusion. However, I also note that the system with/without bridges is still stratified under ebb-low and high flow conditions that have been observed, so the model is somewhat overestimating vertical mixing.

Table 5-6. 2-psu (X2) for salinity intrusion in the LPR at a- low flow b- High flow

(a) Low flow

\begin{tabular}{|c|c|c|c|}
\hline & $\mathrm{X} 2 \mathrm{~km}$ & $\mathrm{X} 2 \mathrm{~km}$ \\
\hline & & With piers & Without piers \\
\hline \multirow{2}{*}{ 촐 } & Spring-Ebb & 20.650 & 25.384 \\
\hline & Spring-Flood & 22.317 & 25.650 \\
\hline \multirow{2}{*}{ 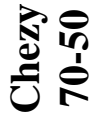 } & Spring-Ebb & 24.150 & 31.484 \\
\hline & Spring-Flood & 25.450 & 31.517 \\
\hline
\end{tabular}


(a) High flow

\begin{tabular}{|c|c|c|c|}
\hline & X2 km & X2 km \\
\hline & & With piers & Without piers \\
\hline \multirow{2}{*}{ స్తి } & Spring-Ebb & 1.447 & 3.151 \\
\hline & Spring-Flood & 6.066 & 6.588 \\
\hline \multirow{2}{*}{ 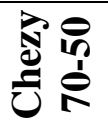 } & Spring-Ebb & 2.685 & 3.218 \\
\hline & Spring-Flood & 6.432 & 7.623 \\
\hline
\end{tabular}
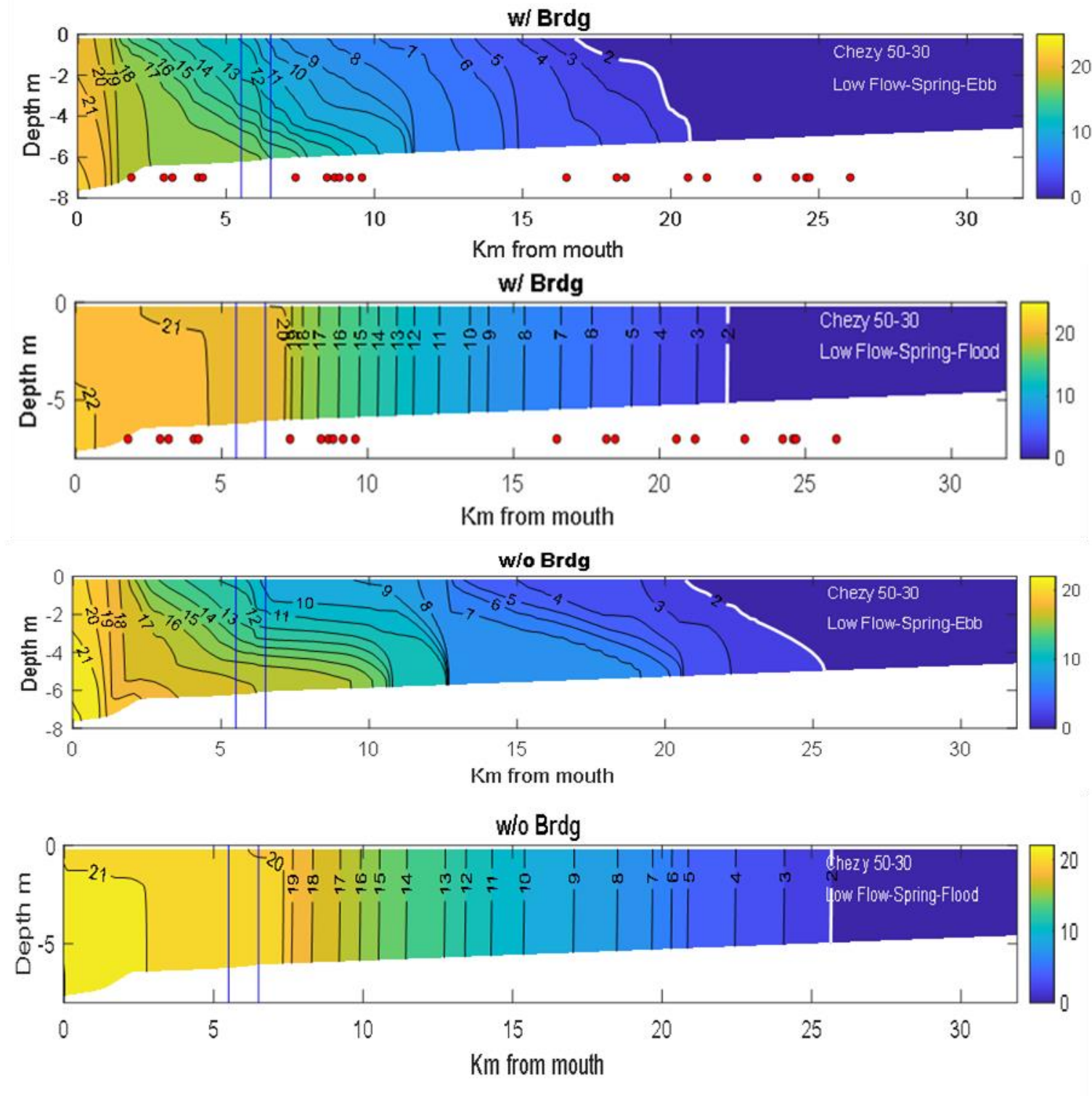

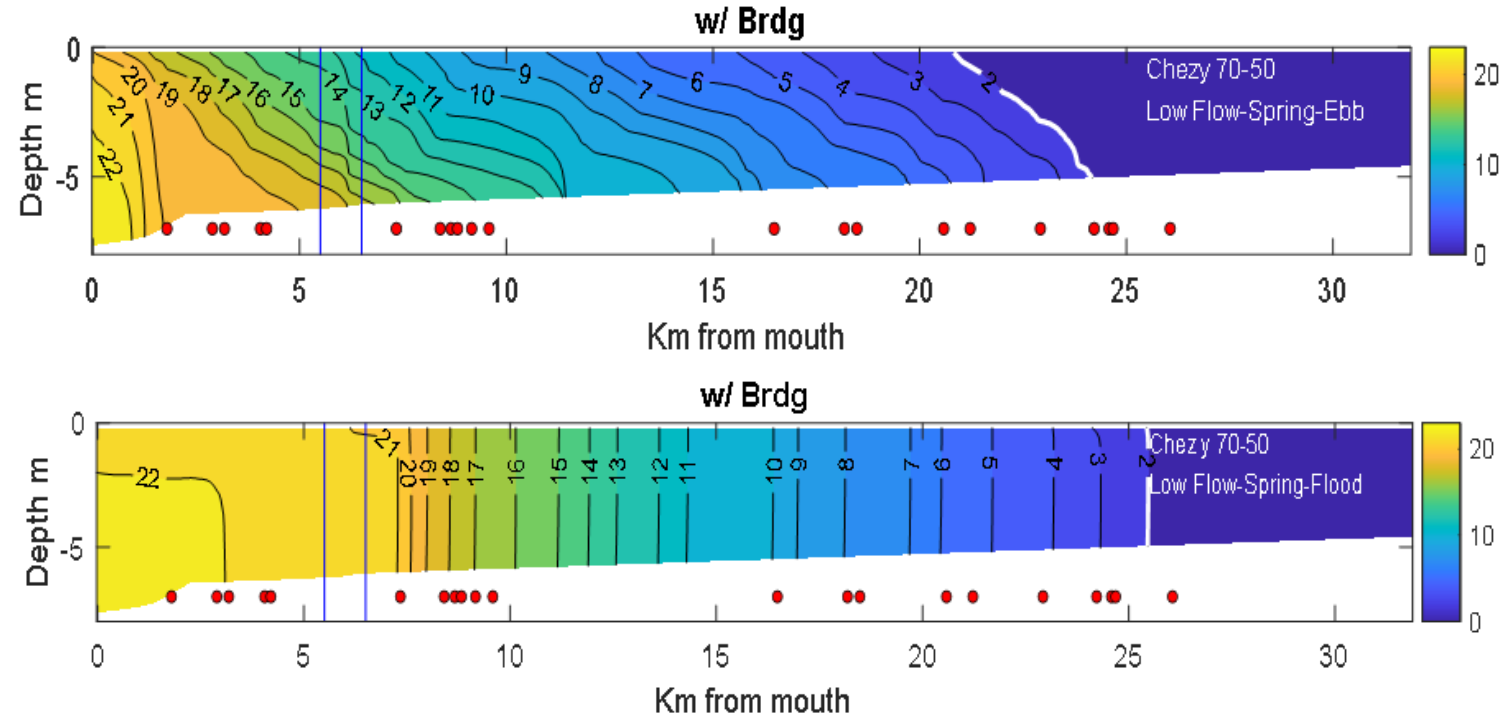

w/o Brdg
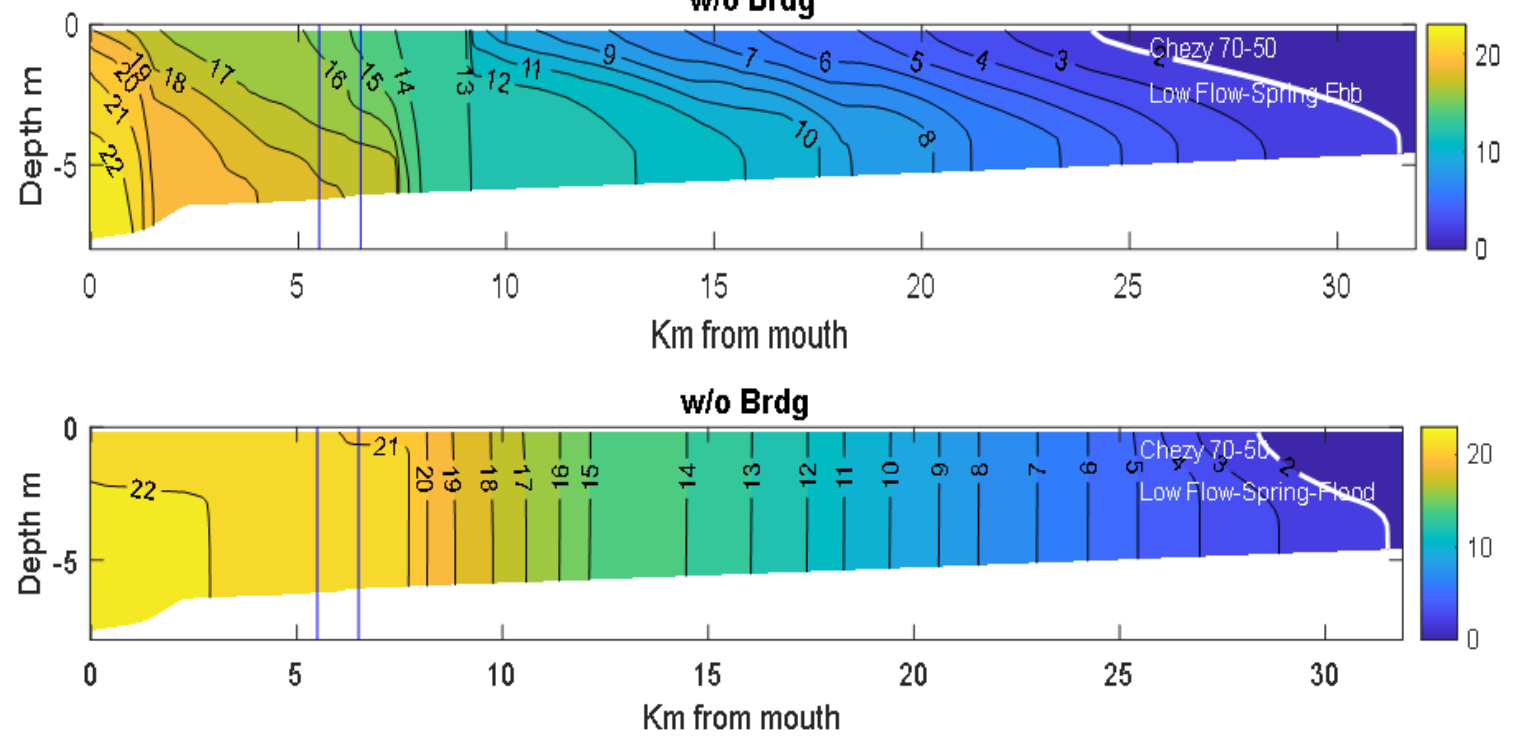

(a)Low flow 

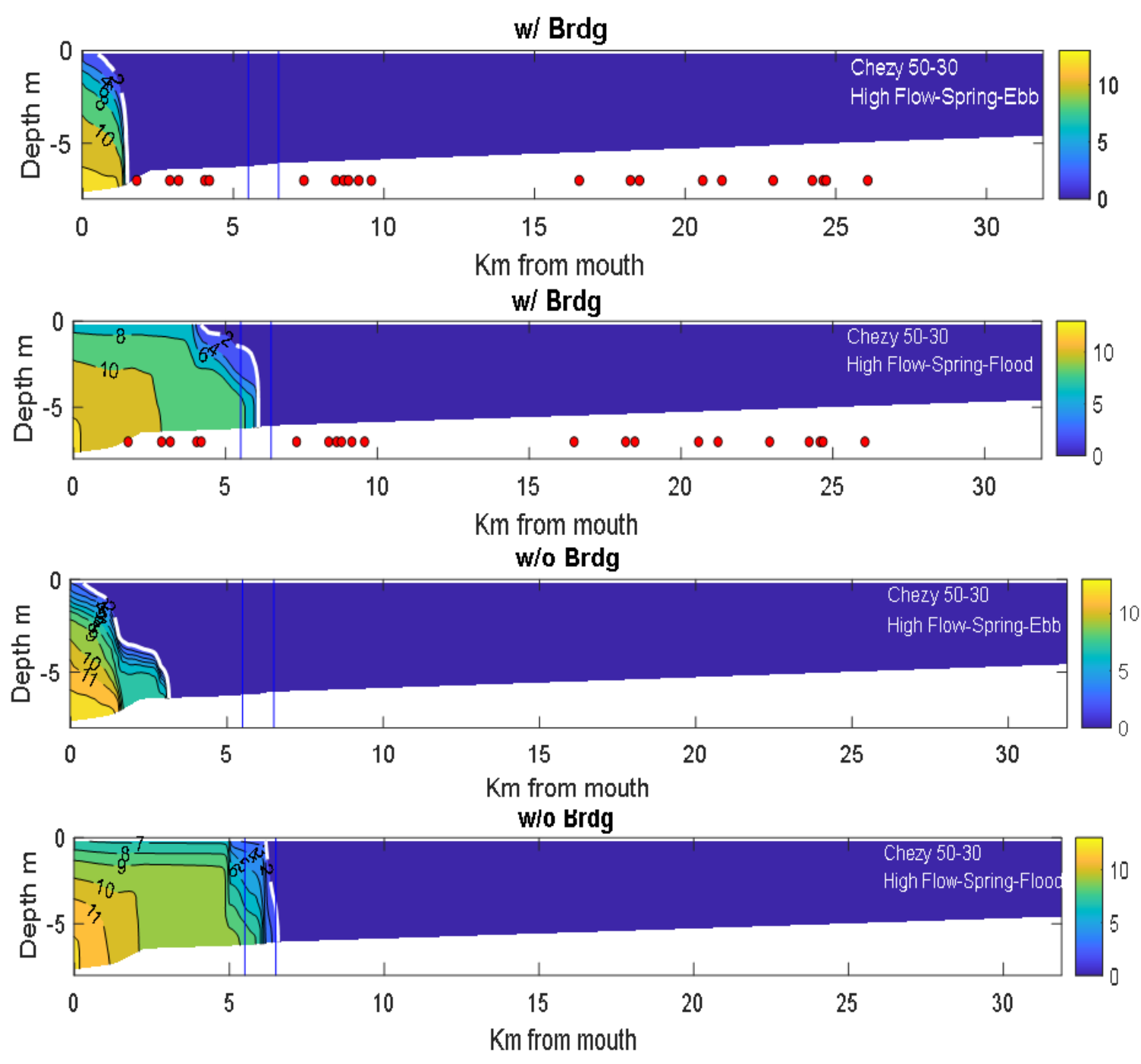


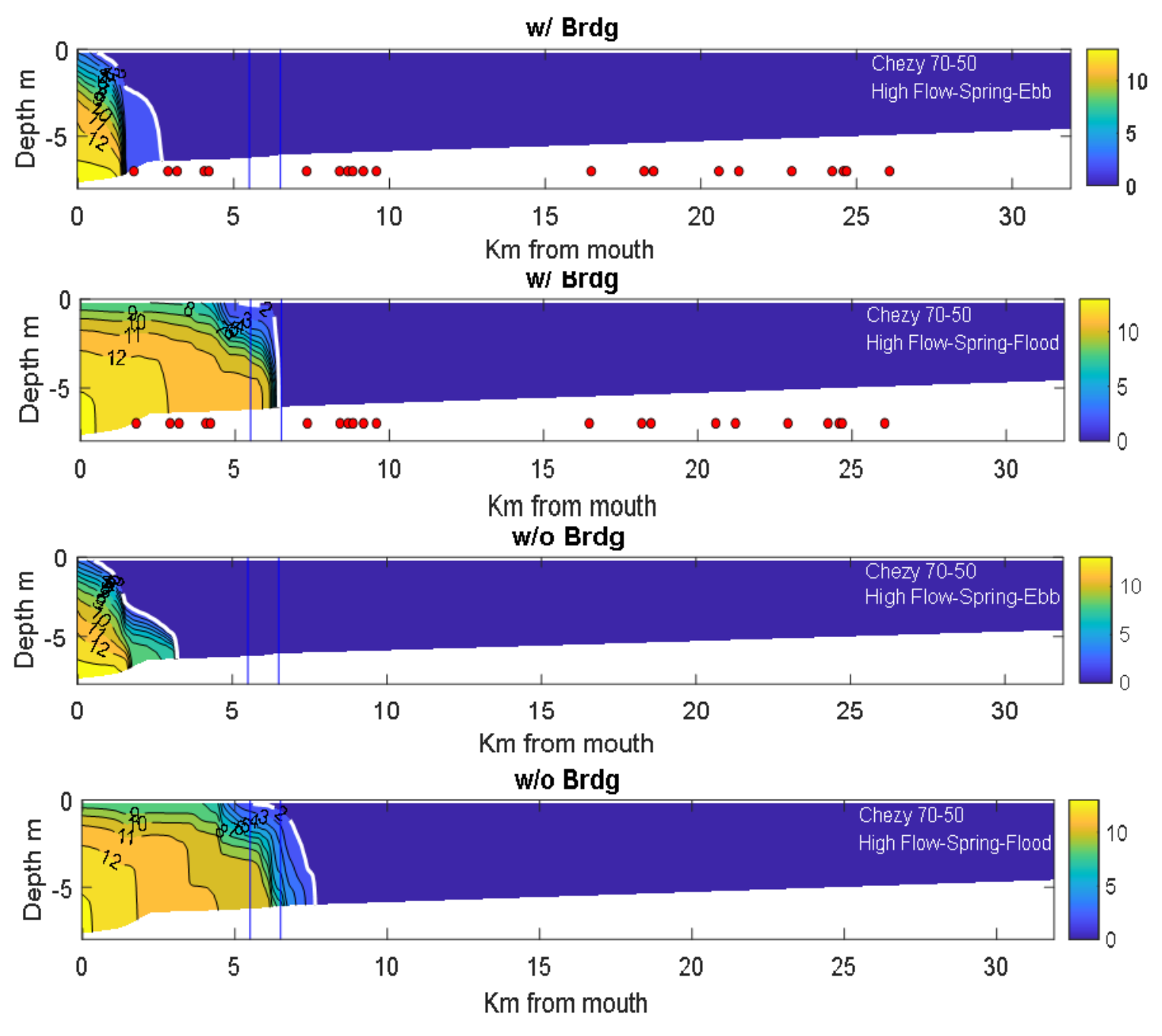

(b) High flow

Figure 5-13(a,b). Vertical salinity section for low flow, spring tide for ebb and flood conditions, with two different bed roughness; the white contour line refer to the 2 psu isohaline. X-2 is the position of the 2 PSU contour near the bed. The red circles refer to the bridge's location, and the blue lines refer to the curvature location. 


\subsubsection{Stratification}

The level of stratification throughout the water column is significant in controlling the vertical mixing and the vertical distribution of SPM. The stratification appears linearly in the buoyancy frequency $\mathrm{N}^{2}$ (Equation 3-10) so that the stratification strength is directly proportional to $\mathrm{N}^{2}$. Thus, $\mathrm{N}^{2}$ (based on bottom minus surface density) is a useful way to describe density stratification. $\mathrm{N}^{2}>0$ is assumed stable, $0.1<\mathrm{N}^{2}<0.0$ is taken as neutrally stable, and $\mathrm{N}^{2}<-0.1 \mathrm{~kg} \mathrm{~m}^{-3}$ is unstable stratification.

Numerical modeling shows a strong influence of flow and bridge piers on stratification. The stratification is generally stable as expected, and stable stratification moves landward during the flood, with low flow-ebb, and without piers (Figure 5-14(a)). Under these conditions, the only areas of unstable stratification occur in the meander. On ebb-high flow, there is an apparent mixing around bridge piers, which leads to localized unstable stratification. During high-flow floods, the stable stratification moves further seaward while unstable stratification occurs in curves. During low-flow floods, increased mixing (decreased stratification) appears near piers and curves (Figure 5-14(b)). 


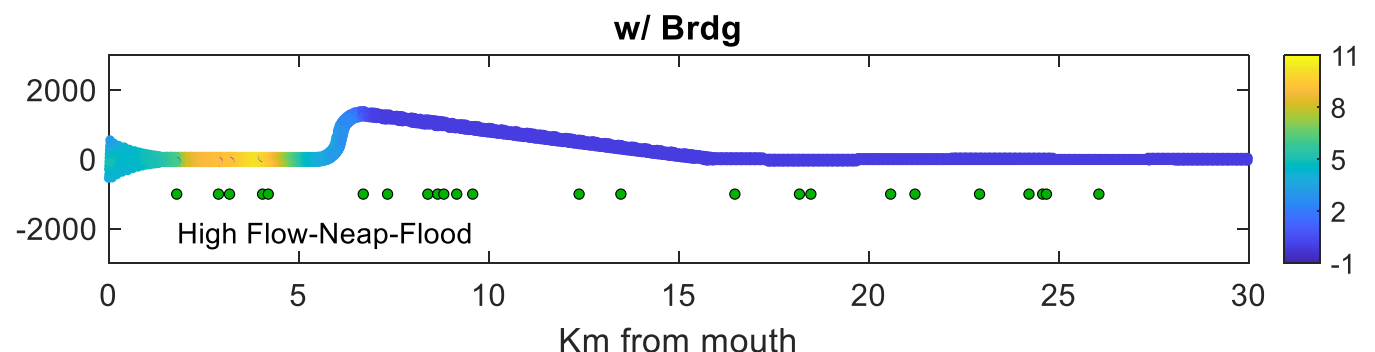

w/o Brdg

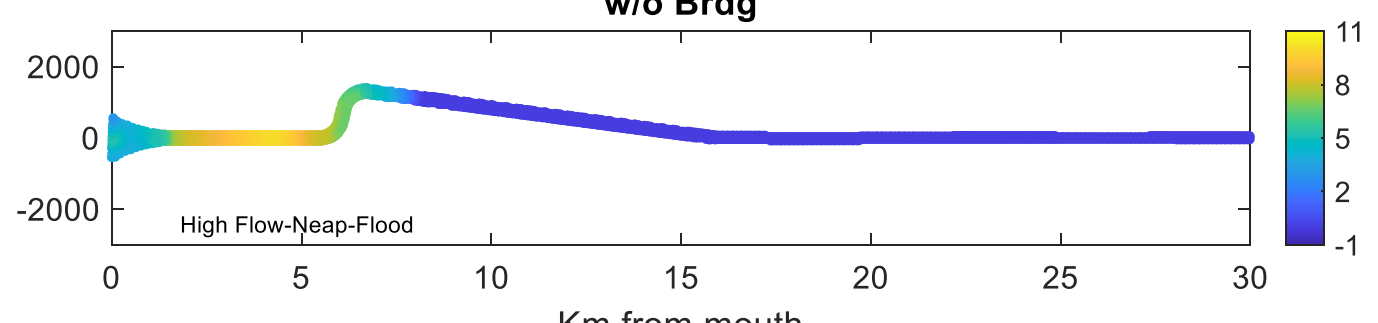

$\mathrm{Km}$ from mouth

w/ Brdg

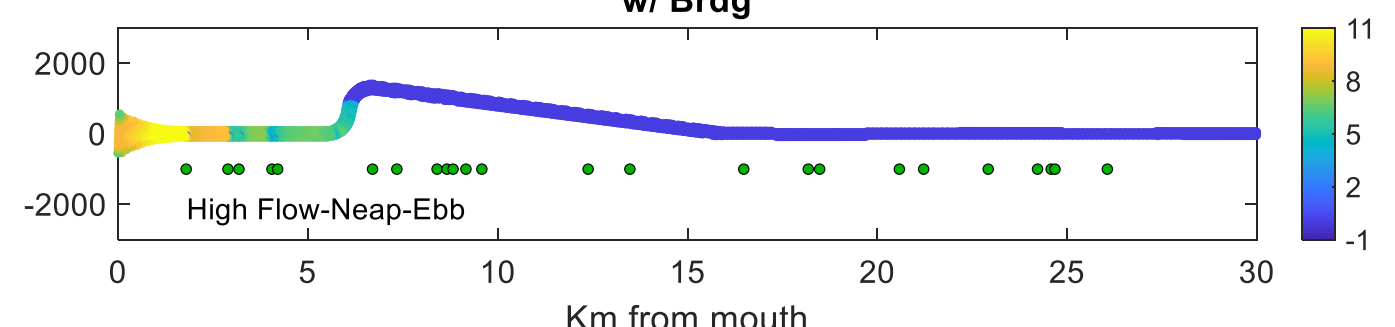

$\mathrm{Km}$ from mouth

w/o Brdg

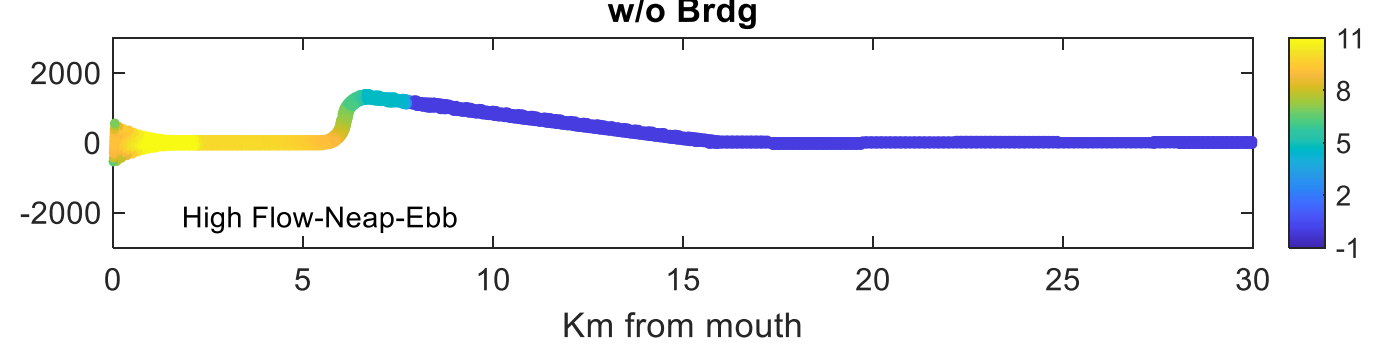

(a) High Flow 

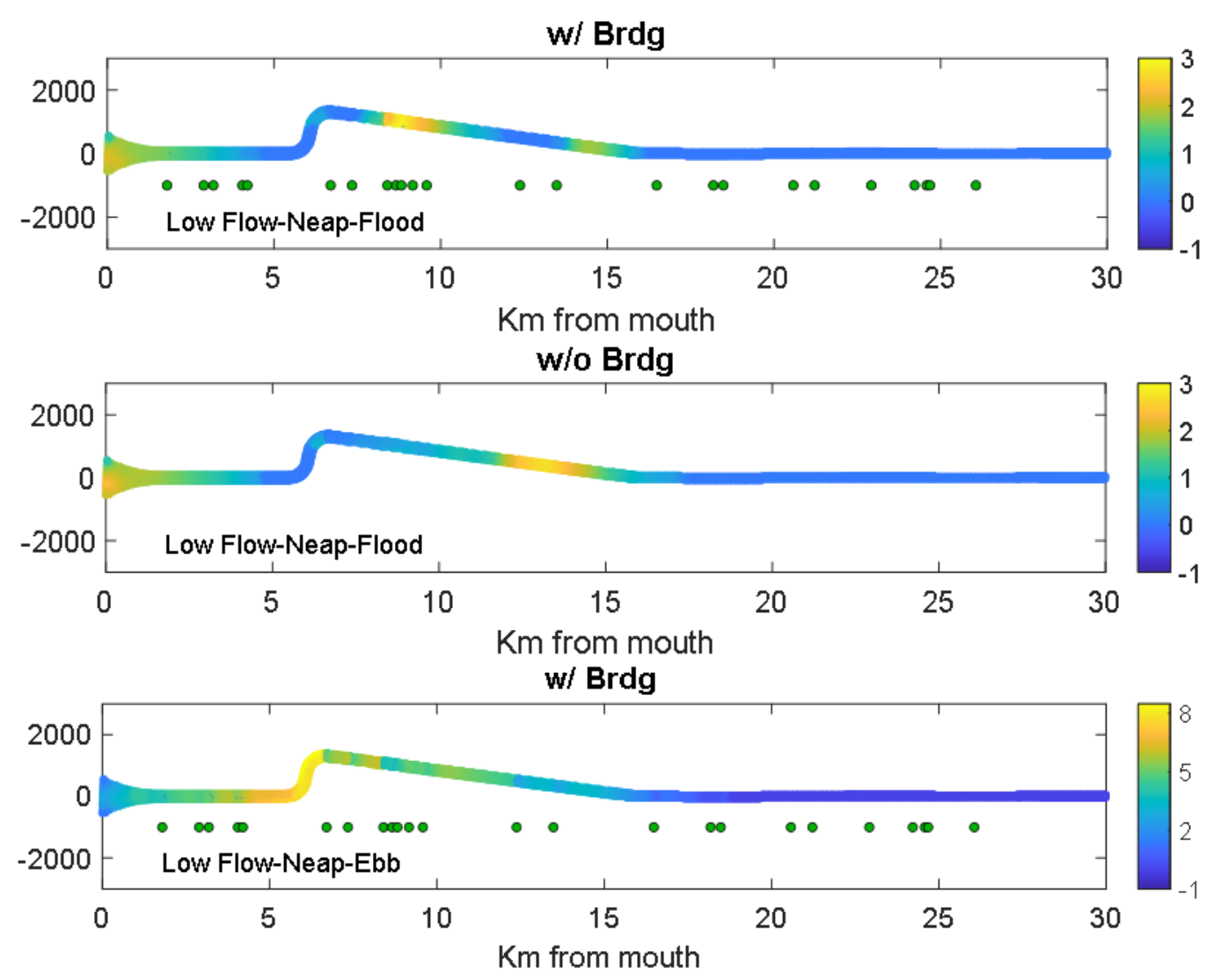

w/o Brdg

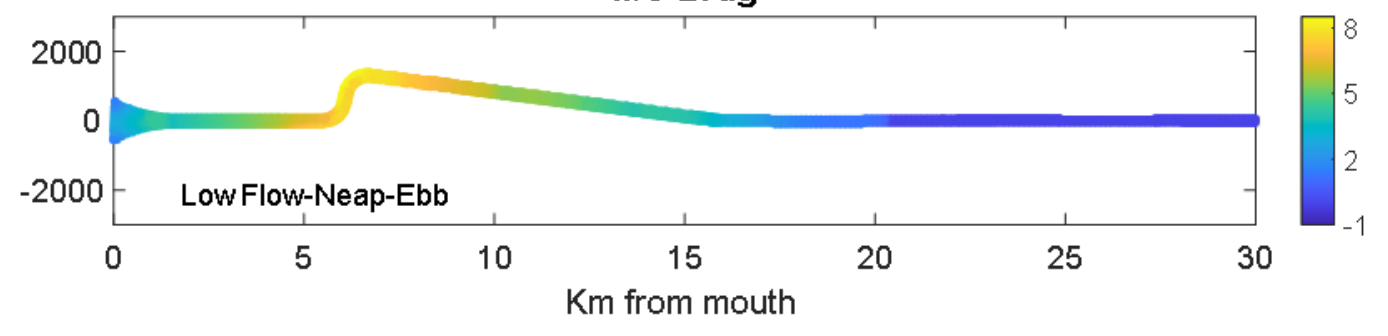

(b) Low Flow

Figure 5-14. The effect of the flow and piers on the stratification along LPR, stratification is the density differential between two riverine layers due to salinity and temperature differences or a combination of both. 


\subsection{Conclusion}

In this chapter, I have examined via numerical model the distribution of bed shear stress, stratification, and salinity intrusion in the LPR, by constructing in Delft3D-FM a 3D conceptual river-estuary numerical model with idealized depth, convergence, curvature, and width that resemble the LPR and Newark Bay. The tidal forcing and salinity at KVK were used at Newark Bay to represent the period March 25 to July 20, 2010. The river inflow used was the sum of the Passaic and Saddle Rivers during this period. Salinity, water level data, and salinity from the 5 ADCP moorings between RM 1.4 and 13.5, water level from a USGS gauge near RM 0, salinity at NNB, and salinity at RM 10.2 were used to verify the model. The model is used to study the variability of bed shear stress, stratification, and salinity and the importance of the specified bed roughness, and the effects of bridge piers in the model system. Results show a reasonable agreement with observed water level and salinity, in addition to the effect of bridge piers on the water level slope, considering that the model is designed to be conceptual, not a detailed representation of the system.

Model bed stress up/downstream of bridge piers show that $\tau_{b}$ is higher upstream for high flow than low flow, and with rough bed (Chezy 50-30) than the smoother bed (Chezy 70-50). The direction of the $\tau_{b}$ is primarily seaward far upstream due to high flow velocities on ebb caused by river flow, especially during high flow periods. On the other hand, $\tau_{b}$ is higher downstream of piers on flood during low-flow periods due to the effect of the tidal currents and estuarine circulation. 
The bed stress maps show that the highest bed stress values occur around bridge piers and along the outer bank of meanders. The results of different cases in Figure 5-10 show that the maximum $\tau_{b}$ is at spring-tide ebb during high flow periods. It occurs at spring-tide flood with low flow due to estuarine circulation, tidal asymmetry (Speer $\boldsymbol{\&}$ Aubrey, 1985), and possibly internal tidal asymmetry. The latter effect is caused in the presence of a strong horizontal density gradient, such that the barotropic and baroclinic pressure gradients work together on the flood but oppose each other on the ebb (Jay \& Musiak, 1996; Jay \& Smith, 1990). Moreover, without bridges piers, $\tau_{b}$ is varies gradually along the channel from high landward to low seaward for the high flow and vice versa with the low flows, while bridge piers introduce strong irregularities in $\tau_{b}$. Finally, $\tau_{b}$ at the large channel bend (relative curvature $\sim 4.5$ ) has maximum bed stress at the outer bank of the bend for the high flow while it occurs at the inner bank with low flow.

The erosion maps of the ratio of $\tau_{b}$ to $\tau_{c r}$ show that the maximum erosion took place at the high flow (spring-ebb) and low flow (spring flood), while there is very little erosion in other situations (Figure 5-12). Bridge piers and higher bed roughness increase erosion capability.

Bridge piers and increased bed roughness in the model significantly decrease salinity intrusion. Thus, salinity contour lines occur further landward without bridge piers and with lower bed roughness due to the effects of piers and bed roughness on increasing the vertical mixing. Bridge piers and meanders also strongly influence stratification. The stratification is stable down-estuary on high-flow neap-floods and ebbs both with and 
without piers, because stratification damps mixing. Moreover, the stable stratification moves landward farther without piers more than with piers. Still, the effect of piers is apparent on low-flows, particularly on neap-floods, where there is unstable stratification around bridge piers that allows increased mixing. But there is no unstable stratification on the following neap-ebbs, when higher stratification damps, mixing. Furthermore, the unstable stratification occurred around curvature and the landward without bridge piers at neap-flood while it just took place farther landward with neap-ebb. In general, on low flows, both the stable and unstable stratification move landward farther with low flow/without piers more than with high flow. 


\section{Chapter 6 Summary and Conclusion}

\subsection{Summary}

This study has analyzed the suspended sediment dynamics of the Lower Passaic River Estuary (LPR), New Jersey, which has suffered severe harmful effects from industrialization and urbanization. Altered bathymetry over the last 140 years has changed the river's ability to trap sediments. While dredging in the LPR began ca. 1880, major dredging of the system began about 1910. The major changes in the bathymetry have been due to: a) dredging to obtain a deep navigation channel; b) filling of shoreline and adjacent wetland areas that have narrowed the channel and reduced tidal prism, c) the construction of 25 bridges in the $28.5 \mathrm{~km}$ long LPR that have constricted the channel laterally and caused scour around bridge piers, and d) construction of Dundee Dam, which limited tidal intrusion into the system.

This dissertation focused on three questions. In the first question (Chapter 3), I have investigated via data analysis the variation of suspended sediment dynamic concentration along with LPR, considering the effect of tidal forcing and stratification on estuarine hydrodynamics, shear velocity, and bed shear stress. I analyzed the effect of stratification on the $w_{s}$ in the salty part of the system, and then I investigated the effect of the freshwater on settling velocity $w_{s}$ in the low salinity part of the system. Moreover, the primary variables and parameters that affect $w_{s}$ down-estuary (Simpson number $\mathrm{Si}$ ) and up-estuary $\left(\mathrm{u}^{2}\right)$ have been determined together with tidal range and flow as secondary variables. 
In the second question (Chapter 4), I analyzed the factors, e.g., advection and erosion/deposition, that affected the distribution of fine and coarse particles throughout the water column. Specifically, I classified the SSC profiles as "Rouse-like" or "ModifiedRouse", and I found the advection is the main factor affecting this division. Furthermore, down-estuary, SSC variation was related to the tidal cycle (neap-spring and daily), while the river inflow is a dominant factor controlling SSC up-estuary. Moreover, the main variables and parameters that affect vertically averaged SSC at brackish stations and landward of salinity intrusion have been determined; the most important parameters are eddy diffusivity and bed shear stress near the mouth and eddy diffusivity upriver, while the tidal range and flow are important secondary variables at all stations.

To answer the third question (Chapter 5), I constructed a Delft3D-FM model of a conceptual, stratified estuary similar to the LPR. Model predictions of water level were validated with observed water levels at the USGS tide gauge at station \#01392650, at Newark, NJ (at about RM 0 of the LPR), and the various ADCP mooring locations in the LPR. Salinity intrusion was validated at all ADCP stations. Modeling results show a reasonable agreement with observed water level and salinity. Using this model, I investigated how a series of factors influenced the bed shear stress distribution, salinity intrusion, and stratification. The factors analyzed included topography river flow, channel curvature, tidal range to depth ratio, and bed roughness. Besides, the effects of man-made roughness elements (bridge pilings) were investigated. The bed stress scenarios that I have examined as in (section 5.2). 


\subsection{Conclusions}

In the first research question (Ch.3), I investigated the variations of settling velocity $w_{s}$ along with LPR and the factors influencing these variations. I modified and improved the Fain et al. (2001) method. Therefore, I was able to use instantaneous velocity and SSC values to determine settling velocity $w_{s}$ in space and time for a wide range of conditions. In the seaward part of the estuary (at stations RM 1.4, 4.2, and 6.7), where salinity is present, and mixing is reduced via vertical density stratification, stratification has been considered in calculating shear velocity. Also, the stratification leads to the formation of aggregates; thus, the highest settling velocity occurred close to the estuary mouth when coarse particles were resuspended by elevated tidal currents. Here, the Simpson number Si is found to be the main parameter that controls settling velocity $w_{s}$ with tidal range TR and river flow playing secondary roles. settling velocity is inversely linked with $\mathrm{Si}$ and flow while it is positively associated with tidal range. On the other hand, at the landward end of the estuary (at stations RM 6.7, 10.2, and 13.5) where the salinity is usually less than 2 PSU, velocity was found to be the primary variable that predicted settling velocity, with tidal range TR and river flow playing secondary roles where the settling velocity inversely correlated with the flow velocity. In general, $w_{S}$ values gradually decreased in the landward direction.

Furthermore, close to the estuary (at stations 1.4 and 4.2), maximum $w_{s}$ occurs at ebb slack when $\mathrm{Si}$ is typically small, and stratification is weak, while the minimum $w_{S}$ coincides with larger $\mathrm{Si}$ at the flood slack when the stratification is stronger. On the other 
hand, at the landward (at stations 6.7, 10.2, and 13.5), maximum $w_{s}$ occurs at ebb slack when the velocity is typically small while the minimum $w_{s}$ coincides with the larger velocity at the flood slack, probably due to high turbulence levels and supply of unaggregated particles from the river upstream of Dundee Dam.

For the second research question (Ch.4), I examined the dynamics determining the vertical distribution of SPM in the LPR using SSC estimated from ADCP backscatter (ABS). Calibration of ABS to SSC was accomplished using an SPM calibration that included both ABS and normalized river flow because the particle size distribution apparently changed as a function of flow. Calibration was carried out using a robust multiple linear regression of $\log 10[\mathrm{SSC}]$ in water column samples against Log10[ABS] and normalized flow. This form of the calibration was more effective than the use of calibration based on ABS alone. The correlation coefficients of the multiple regressions between SSC grab samples with RB and normalization of flow were between (0.82-0.98) for Fall 2009 and (0.82-0.92) for Spring 2010. The results showed that the mean SSC in the LPR is moderate compared to other river estuaries such as Columbia River Estuary (Gelfenbaum, 1983) and Hudson River estuary (Woodruff et al., 2001). Moored data has shown the quantity varies from low $\left(0.5 \times 10^{2}\right.$ ton/m width $)$ close to Dundee Dam to higher seaward $\left(11.9 \times 10^{2}\right.$ ton/m width).

A simplified form of SPM conservation, the Rouse balance, is often used to describe SPM profiles. The Rouse balance suggests that vertical turbulent dispersion of SPM is balanced by particle settling locally in each water column. Not all SPM profiles in 
LPR could be explained in this way because many are affected by advection. Thus, profiles were divided into "Rouse-like" and "Modified Rouse", the latter being strongly influenced by horizontal SPM advection, and a bulk $w_{S}$ was determined for each profile. Advection was represented by the advection parameter $\mathrm{A}=\frac{U H}{w_{S} L_{x}}$; it was found to be the primary factor that caused profiles of SSC to be "Modified-Rouse". The "Modified-Rouse" profiles" occur when A is high (greater than the mean).

Vertically averaged SSC is mainly associated with shear stress close to the LPR mouth (1.4 and 4.2). The distribution of vertically average SCC shows the maximum concentration of both SSC classes took place with the low flow (Fall) in slack after the floods with high velocity. At the same time, it has happened with the high flow (Spring) in slack after ebb, due to previously suspended river from upriver and river input SPM.

SPM is not made up of a single size of particle - there is always a more or less broad distribution of particle sizes and settling velocities, so it was desirable to used the available SPM profiles to estimate the prevalence of multiple size classes. Given that the SSC estimates from ABS were used (typically 4-10 values in the water column), it was possible only to consider "fine SPM" (give $\left.w_{s}=0.05 \mathrm{~mm} / \mathrm{s}\right)$ and "coarse SPM" $\left(w_{S}=10\right.$ $\mathrm{mm} / \mathrm{s})$. A robust fit regression method was used to find profiles of fine and coarse SSC to all available SSC profiles (from ABS), taking into account the "Modified Rouse" profiles often characteristic of fine particles. Coarse particles, located closer to the bed, were less affected by advection, and they were adequately described as "Rouse-like". The results have shown the percentage of as "Rouse-like" is higher landward of salinity intrusion (95\% 
in Fall and 98\% in Spring at RM 13.5); advection is weak and stratification absent in this part of the system. In comparison, at station RM 13.5, the percentage of Modified Rouse profiles is 19\% in both Fall and Spring due to the stratification and higher advection effect.

Vertically averaged SSC variations are significantly related to the tidal-cycle (neapspring), especially close to the estuary mouth, where the river outflow is small relative to tidal currents. In contrast, close to the Dundee dam, flow is a dominant factor in controlling SSC. Average SSC is mainly associated with shear stress in the RMs close to the estuary (1.4 and 4.2), while other RMs need more investigation. The vertically average SCC distribution shows that, for the the low flow (Fall) period, the maximum concentration of both SSC classes took place on slack after strong floods. During high flow (Spring) periods maximum concentrations occurred on slack after ebbs with low velocities. Moreover, I concluded that the advection is prominent during neap tides with low currents than on spring tides. The results agree with those of Fain et al., (2001) for the Columbia River Estuary.

In the final research question (Ch.5), I have demonstrated the effect of bridge piers and bed roughness on the distribution of bed shear stress, stratification, and salinity intrusion. A 3D conceptual river-estuary numerical model has been generated in Delft3DFM with idealized depth, convergence, curvature, and width that resemble the LPR and Newark Bay.

The results show that in the more landward parts of the system, $\tau_{b}$ is higher with high flow/rough bed (Chezy 50-30) than a low flow/smooth bed (Chezy 70-50); here, 
maximum $\tau_{b}$ is directed seaward. On the other hand, $\tau_{b}$ is higher downstream during low flows and directed landward due to the combined effect of the tidal forces and estuarine circulation. Furthermore, the highest stress is around the bridge piers and outer sides of bends during high flows while near the inner bank of bends with low flow due to affect the high tidal force. Previous research shows that bridges cause deflected flow around the piers, leading to horseshow formation and increasing the bed stress near the bed, which causes erosion of the sediment (Beheshti \& Ataie-Ashtiani, 2016). Besides, the wake vortices formation downstream the piers lead to disturbance of the flow and increase the mixing throughout the water column. My model results are similar, though the detailed flow structures described by Beheshti \& Ataie-Ashtiani (2016) cannot be represented with the model grid employed. Moreover, without bridges piers, $\tau_{b}$ decreases relatively uniformly along the channel from high near Dundee Dam to low near the LPR entrance during high flow, and vice versa with during low flows. Moreover, most erosion took place, for high flows on spring-tide ebbs, and during low flow on spring-tide floods, in both cases, the highest erosion was around bridge piers; there was little erosion in other cases.

Analyses of modeled LPR salinity intrusion and stratification show clear effects of bridge piers and bed roughness. Salinity intrusion is larger without bridge piers and with lower bed roughness due to the effects of both in increasing the mixing. Moreover, the salinity intrusion moved farther landward without bridges because bridge-induced mixing inhibits two-layer flow due to increased mixing. Mixing generated by piers caused unstable stratification near bridges on low-flow neap-floods, but this is absent of flood. At the same 
time, unstable stratification occurred in bends and at the landward end of salinity intrusion. Both the stable stratification and unstable stratification are pushed landward with low flow and without piers more than with high flow.

\subsection{Further steps and recommendations}

Several steps could be taken to improve this research. I would recommend taking the laboratory-determined suspended sediment concentration at the exact depth and time with ABS readings, making the calibration between them more accurate. Further investigation is also needed to address the relationship between suspended SSC and salinity intrusion relative to channel depth, and the effects of modifications of the estuary mouth (width and depth) on suspended sediment dynamics. It would also be useful in a future study to model fine sediment transport (not just bed stress) and to make the model grid more realistic. Furthermore, future studies could enhance my modeling results by taking the effect of freshwater from the Hudson River on the LPR.

\section{Implications for other systems}

This study of the LPR demonstrates that SSC levels in the LPR are moderate. Even so, previous studies (CPG, 2010) indicate that SSC is important to contaminant transport. It has also demonstrated the importance of variables (i.e., settling velocity, salinity, river flow, and bed shear stress) on the suspended sediment concentration in a river-estuary represented by LPR. These physics are the same in each estuary; however, the factors that affected them are different: tide, topography, flow, and salinity, depending on the estuary 
location. Therefore, other systems can benefit from LPR findings; but results will be system-specific.

This study also emphasizes the complex dynamics in the LPR, and likely in other estuaries. This complexity needs to be better understood to support remediation efforts. Furthermore, the effects of bridge piers on the bed shear stress, salinity, and stratification have been investigated; they are strong. There is very little published on bridge effects on estuarine processes, yet they are ubiquitous in estuaries. The LPR is a good case study precisely because it is a fairly extreme case. 


\section{References}

Agrawal, Y. C., \& Pottsmith, H. C. (2000). Instruments for particle size and settling velocity observations in sediment transport. Marine Geology, 168(1-4), 89-114. https://doi.org/10.1016/S0025-3227(00)00044-X

Agrawal, Y. C., \& Smith, H. C. P. (1994). Laser diffraction particles in Stress. Continental Shelf Research, 14(10).

Al Bahadily, A. (2020). Effect of River Discharge, Estuarine Bathymetry, and Climate Change on the Columbia River Estuary Salinity Intrusion. Portland State University.

Allen, G. P., Salomon, J. C., Bassoullet, P., DU Penhoat, Y., \& DE Grandpre, C. (1980). Effects of tides on mixing and suspended sediment transport in macrotidal esturies. Sedimentary Geology, 26, 69-90.

Bates, D. M., \& Watts, D. G. (1980). Relative Curvature Measures of Nonlinearity Author. Royal Statistical Society, 42(1), 1-25.

Becherer, J., Stacey, M. T., Umlauf, L., \& Burchard, H. (2015). Lateral Circulation Generates Flood Tide Stratification and Estuarine Exchange Flow in a Curved Tidal Inlet. Journal of Physical Oceanography, 45(3), 638-656. https://doi.org/10.1175/jpo-d-14-0001.1

Beheshti, A. A., \& Ataie-Ashtiani, B. (2016). Scour Hole Influence on Turbulent Flow Field around Complex Bridge Piers. Flow, Turbulence and Combustion, 97(2), 451474. https://doi.org/10.1007/s10494-016-9707-8

Biron, P. M., Robson, C., Lapointe, M. F., \& Gaskin, S. J. (2004). Comparing different methods of bed shear stress estimates in simple and complex flow fields. Earth Surface Processes and Landforms, 29(11), 1403-1415. https://doi.org/10.1002/esp.1111

Brennan, M. L., Schoellhamer, D. H., Burau, J. R., \& Monismith, S. G. (2002). Tidal asymmetry and variability of bed shear stress and sediment bed flux at a site in San Francisco Bay, USA. Proceedings in Marine Science, 5(C), 93-107. https://doi.org/10.1016/S1568-2692(02)80010-9

Bulbul, M. M. (2017). Drag charactristics of a historical bridge pier. Middle East Technical University.

Burban, P. Y., Lick, W., \& Lick, J. (1989). The flocculation of fine-grained sediments in estuarine waters. Journal of Geophysical Research, 94(C6), 8323-8330. https://doi.org/10.1029/JC094iC06p08323

Burchard, H., Hetland, R. D., Schulz, E., \& Schuttelaars, H. M. (2010). Drivers of residual estuarine circulation in tidally energetic estuaries: Straight and irrotational channels 
with parabolic cross section. Journal of Physical Oceanography, 41(3), 548-570. https://doi.org/10.1175/2010jpo4453.1

Callander, R. A. (1978). River Meandering. Annual Reviews Inc., 10.

Castro, I. P., Snyder, W. H., \& Baines, P. G. (1990). Obstacle drag in stratified flow. The Royal Society Publishing, 429(1876), 119-140.

Chang, G. (2010). Lower Passaic River suspended solids concentration ( SSC ) determinations from Acoustic Backscatter ( ABS ). Sea Engineering, Inc.

Chant, R. J., Fugate, D., \& Garvey, E. (2011). The shaping of an estuarine superfund site: Roles of evolving dynamics and geomorphology. Estuaries and Coasts, 34(1), 90105. https://doi.org/10.1007/s12237-010-9324-Z

Chant, R. J., Sommerfield, C. K., \& Talke, S. A. (2018). Impact of Channel Deepening on Tidal and Gravitational Circulation in a Highly Engineered Estuarine Basin. Estuaries and Coasts, 41(6), 1587-1600. https://doi.org/10.1007/s12237-018-0379-6

Chawla, A., Jay, D. A., Baptista, A. M., Wilkin, M., \& Seaton, C. (2008). Seasonal variability and estuary-shelf interactions in circulation dynamics of a river-dominated estuary. Estuaries and Coasts, 31(2), 269-288. https://doi.org/10.1007/s12237-0079022-7

Chen, G., \& Shen, H. W. (1983). River Curvature-width ratio effect on shear stress. In Proceedings Conference on Rivers, New Orlando, LA (pp. 687-699). In:Elliott, C.M. (Ed).

Corlett, W. B., \& Geyer, W. R. (2020). Frontogenesis at Estuarine Junctions. Estuaries and Coasts, 43(4), 722-738. https://doi.org/10.1007/s12237-020-00697-1

CPG. (2010). Lower Passaic River RI / Fs Newark, New Jersey Appendix M - Attachment $\mathrm{F}$, Draft settling velocity analusis.

Dalrymple, R. W., \& Choi, K. (2007). Morphologic and facies trends through the fluvialmarine transition in tide-dominated depositional systems: A schematic framework for environmental and sequence-stratigraphic interpretation. Earth-Science Reviews, 81(3-4), 135-174. https://doi.org/10.1016/j.earscirev.2006.10.002

Dalrymple, R. W., Zaitlin, B. A., \& Boyd, R. (1992). Estuarine facies models : conceptual basis and stratigraphic implications. Journal of Sedimentary Petrology, 62(6), 11301146. https://doi.org/10.1306/D4267A69-2B26-11D7-8648000102C1865D

De Jonge, V. N., Schuttelaars, H. M., van Beusekom, J. E. E., Talke, S. A., \& de Swart, H. E. (2014). The influence of channel deepening on estuarine turbidity levels anddynamics, as exemplified by the Ems estuary. Estuarine, Coastal and Shelf Science, 139, 46-59. https://doi.org/10.1016/j.ecss.2013.12.030

Deines, K. L. (1999). Backscatter estimation using broadband acoustic Doppler current 
profilers. In in Oceans 99 MYS/IEEE conference Proceedings, (p. September 13-16). Seattle, Washington.

Doostmohammadi, A., \& Ardekani, A. M. (2015). Suspension of solid particles in a density stratified fluid. Physics of Fluids, 27(023302). https://doi.org/10.1063/1.4907875

Downing, A., Thorne, P. D., \& Vincent, C. E. (2005). Backscattering from a suspension in the near field of a piston transducer. The Journal of the Acoustical Society of America, 97(3), 1614-1620. https://doi.org/10.1121/1.412100

Dronkers, J. (1992). Tide-Induce d Residual Transport of Fine Sedimen t. Physics of Shallow Estuaries and Bays, 16, 228-243.

Dyer, K. R. (1973). Estauries: A physical Introduction. London: John Wiley \& Sons.

Dyer, K. R. (1987). Coastal and Estuarine Sediemnt Dynamics. John Wily and Sons. New York.

Dyer, K. R. (1989). Sediment processes in estuaries: future research requirements. Journal of Geophysical Research, 94(C10). https://doi.org/10.1029/jc094ic10p14327

Eadie, B. J., Bell, G. L., \& Hawley, N. (1991). Sediment trap study in the Green Bay mass balance program : Mass and organic carbon fluxes, resuspension, and particle settling velocities. Great Lakes Envirunmental Research Laboratory.

Environmental Protection Agencey, (EPA). (2014). Appendix F: Engineering Evaluations, Lower Eight Miles of the Lower Passaic River.

Fain, A. M. V., Jay, D. A., Wilson, D. J., Orton, P. M., \& Baptista, A. M. (2001). Seasonal and tidal monthly patterns of particulate matter dynamics in the Columbia River Estuary. Estuaries, 24(5), 770. https://doi.org/10.2307/1352884

Familkhalili, R., \& Talke, S. A. (2016). The effect of channel deepening on tides and storm surge: A case study of Wilmington, NC. Geophysical Research Letters, 43(17), 91389147. https://doi.org/10.1002/2016GL069494

Friedrichs, C. T., \& Aubrey, D. G. (1988). Nonlinear tidal distortion in shallow well-mixed estuaries: a Synthesis. Estuarine, Coastal and Shelf Science, 27, 521-545. https://doi.org/10.1016/0272-7714(90)90054-U

Frings, R. M., Berbee, B. M., Erkens, G., M.G., K., \& J.P., G. (2009). Human-induced changes in bed shear stress ansd bed grain size in the River Wall (The Netherlands) during the past 900 years. Earth Surface Processes and Landforms, 34, 503-514. https://doi.org/10.1002/esp

Gartner, J. W. (2002). Estimation of suspended solids concentrations based on acoustic backscatter intensity: Theoretical background. Turbidity and Other Sediment Surrogates Workshop, 3. 
Gartner, J. W. (2004). Estimating suspended solids concentrations from backscatter intensity measured by acoustic Doppler current profiler in San Francisco Bay, California. Marine Geology, 211(3-4), 169-187. https://doi.org/10.1016/j.margeo.2004.07.001

Gelfenbaum, G. (1983). Suspended-sediment response to semidiurnal and fortnightly tidal variations in a mesotidal estuary: Columbia River, U.S.A. Marine Geology, 52(1-2), 39-57. https://doi.org/10.1016/0025-3227(83)90020-8

Geyer, W. R. (1993). The importance of suppression of turbulence by stratification on the estuarine turbidity maximum. Estuaries, 16(1), 113-125. https://doi.org/10.2307/1352769

Geyer, W. R., Hill, P., Milligan, T., \& Traykovski, P. (2000). The structure of the Eel river plume during floods. Continental Shelf Research, 20(16), 2067-2093. https://doi.org/10.1016/S0278-4343(00)00063-7

Geyer, W. R., \& MacCready, P. (2013). The Estuarine circulation. Annual Review of Fluid Mechanics, 46(1), 175-197. https://doi.org/10.1146/annurev-fluid-010313-141302

Geyer, W. R., \& MacCready, P. (2014). The Estuarine Circulation. Annual Review of Fluid Mechanics, 46(1), 175-197. https://doi.org/10.1146/annurev-fluid-010313-141302

Geyer, W. R., Trowbridge, J. H., \& Bowen, M. M. (2000). The Dynamics of a Partially Mixed Estuary*. Journal of Physical Oceanography, 30(8), 2035-2048. https://doi.org/10.1175/1520-0485(2000)030<2035:tdoapm>2.0.co;2

Geyer, W. R., Woodruff, J. D., \& Traykovski, P. (2001). Sediment Transport and Trapping in the Hudson River Estuary. Estuaries, 24(5), 670. https://doi.org/10.2307/1352875

Grabemann, I., \& Krause, G. (2001). On different time scales of suspended matter dynamics in the Weser Estuary. Estuaries, 24(5), 688-698. https://doi.org/10.2307/1352877

Grabemann, I., Uncles, R. J., Krause, G., \& Stephens, J. A. (1997). Behaviour of turbidity maxima in the Tamar (U.K.) and Weser (F.R.G.) Estuaries. Estuarine, Coastal and Shelf Science, 45(2), 235-246. https://doi.org/10.1006/ecss.1996.0178

Group, C. P. (2010). Lower Passaic River Ri / Fs Newark, New Jersey Appendix M Attachment a Draft Fall and Spring Pwcm Abs-Ssc and Obs-Ssc Regressions.

Hansen, D. V., \& Rattray, M. (1965). Gravitational circulation in straits and estuaries. Journal of Marine Research, 32, 104-122.

Hansen, D. V., \& Rattray, M. (1966). New dimensions in estuary classification. Limnology and Oceanography, $X I(3), 319-326$.

Harris, C. K., \& Wiberg, P. (2002). Across-shelf sediment transport: Interactions between suspended sediment and bed sediment. Journal of Geophysical Research, 107(C1). 
https://doi.org/10.1029/2000jc000634

Hela, I., Carpenter, C. A., \& McNulty, J. K. (1957). Hydrography of a positive, shallow, tidal bar-built estuary (report on the hydrography of the polluted area of Biscayne Bay). Bulletin of Marine Science, 7(1), 47-99.

Hickin, E. J. (1995). River Geomorphology. Wiely (Vol. 44). https://doi.org/10.1023/A:1006813004972

Hoitink, A. J. F., Hoekstra, P., \& Van Maren, D. S. (2003). Flow asymmetry associated with astronomical tides: Implications for the residual transport of sediment. Journal of Geophysical Research: Oceans, 108(10), 1-8. https://doi.org/10.1029/2002jc001539

Holdaway, G. P., Thorne, P. D., Flatt, D., Jones, S. E., \& Prandle, D. (1999). Comparison between ADCP and transmissometer measurements of suspended sediment concentration.pdf. Continental Sheif Research, 19, 421-441.

Hooke, R. B. (1975). Distribution of Sediment Transport and Shear Stress in a Meander Bend. The Journal of Geology, 83(5), 543-565.

Huntley, S. L., Wenning, R. J., Su, S. H., Bonnevie, N. L., \& Paustenbach, D. J. (1996). Geochronology and Sedimentology of the Lower Passaic River, New Jersey. Estuaries, 18(2), 351-361. https://doi.org/10.2307/1352317

Iannuzzi, T., \& Ludwig, D. (2004). Historical and current ecology of the lower Passaic River. Urban Habitats, 2(1), 147-173.

Jay, D. A. (2010). Estuarine variability. In A. Valle-Levinson (Ed.), Contemporary Issues in Estuarine Physics (pp. 62-99). Cambridge: Cambridge University Press.

Jay, D. A., \& Dungan S., J. (1990). Circulation, density distribution and neap-spring transitions in the Columbia River Estuary. Progress in Oceanography, 25(1-4), 81112. https://doi.org/10.1016/0079-6611(90)90004-L

Jay, D. A., \& Musiak, J. D. (1994). Particle trapping in estuarine tidal flows. Journal of Geophysical Research, 99(C10), 20445-20461. https://doi.org/10.1029/94jc00971

Jay, D. A., \& Musiak, J. D. (1996). Internal tidal asymmetry in channel flows: Origins and consequences. Mixing in Estuarine and Coastal Seas.

Jay, D. A., Orton, P. M., Chisholm, T., Wilson, D. J., \& Fain, A. M. V. (2007). Particle trapping in stratified estuaries: Consequences of mass conservation. Estuaries and Coasts, 30(6), 1095-1105. https://doi.org/10.1007/BF02841399

Jay, D. A., \& Smith, J. D. (1990a). Residual circulation in shallow estuaries: 1. Highly stratified, narrow estuaries. Journal of Geophysical Research, 95(C1), 711. https://doi.org/10.1029/JC095iC01p00711 
Jay, D. A., \& Smith, J. D. (1990b). Residual circulation in shallow estuaries: 2. Weakly Stratified and Partially Mixed, Narrow estuaries. Journal of Geophysical Research, 95(Ci), 711. https://doi.org/10.1029/JC095iC01p00711

Jay, D. A., Talke, S. A., Hudson, A., \& Twardowski, M. (2015). Estuarine turbidity maxima revisited: Instrumental approaches, remote sensing, modeling studies, and new directions. Developments in Sedimentology, 68, 49-109. https://doi.org/10.1016/B978-0-444-63529-7.00004-3

Jeffrey W. G. (U.S. Geological Survey, W. R. D. (2002). Estimation of Suspended Solids Concentrations Based on Acoustic Backscatter Intensity: Theoretical Background. Turbidity and Other Sediment Surrogates Workshop, April 30 - May 2, 2002, Reno, $N V, 3$.

Jones, S. E., Jago, C. F., Bale, A. J., Chapman, D., Howland, R. J. M., \& Jackson, J. (1998). Aggregation and resuspension of suspended particulate matter at a seasonally stratified site in the southern North Sea: Physical and biological controls. Continental Shelf Research, 18(11), 1283-1309. https://doi.org/10.1016/S0278-4343(98)00044-2

Kineke, G. C., \& Sternberg, R. W. (1992). Measurements of high concentration suspended sediments using the optical backscatterance sensor. Marine Geology, 108(3-4), 253258. https://doi.org/10.1016/0025-3227(92)90199-R

Kondolf, G. M. (1997). Hungry water: Effects of dams and gravel mining on river channels. Environmental Management, 21(4), 533-551. https://doi.org/10.1007/s002679900048

Kukulka, T., \& Jay, D. A. (2003). Impacts of Columbia River discharge on salmonid habitat: 2. Changes in shallow-water habitat. Journal of Geophysical Research: Oceans, 108(9). https://doi.org/10.1029/2003jc001829

Land, L. E., Kolker, A. S., \& Gambrell, R. P. (2012). Biotic and abiotic controls on sediment aggregation and consolidation: Implications for geochemical fluxes and coastal restoration. Marine Environmental Research, 79, 100-110. https://doi.org/10.1016/j.marenvres.2012.05.012

Leffler, K. E., \& Jay, D. A. (2009). Enhancing tidal harmonic analysis: Robust (hybrid L1 I L2) solutions. Continental Shelf Research, 29(1), 78-88. https://doi.org/10.1016/j.csr.2008.04.011

Lerczak, J. A., Geyer, W. R., \& Chant, R. J. (2006). Mechanisms driving the timedependent salt flux in a partially stratified estuary. Journal of Physical Oceanography, 36(12), 2296-2311. https://doi.org/10.1175/JPO2959.1

Lindsay, P., Balls, P. W., \& West, J. R. (1996). Influence of tidal range and river discharge on suspended particulate matter fluxes in the Forth estuary (Scotland). Estuarine, Coastal and Shelf Science, 42(1), 63-82. https://doi.org/10.1006/ecss.1996.0006 
Ling, R. F., Lawson, C. L., \& Hanson, R. J. (2006). Solving Least Squares Problems. Journal of the American Statistical Association (Vol. 72). Philadelphia: Society for Industrial and Applied Mathematics. https://doi.org/10.2307/2286501

Ludwig, K. A., \& Hanes, D. M. (1990). A laboratory evaluation of optical backscatterance suspended solids sensors exposed to sand-mud mixtures. Marine Geology, 94(1-2), 173-179. https://doi.org/10.1016/0025-3227(90)90111-V

MacCready, P., \& Geyer, W. R. (2010). Advances in Estuarine Physics. Annual Review of Marine Science, 2(1), 35-58. https://doi.org/10.1146/annurev-marine-120308081015

MacCready, P., Geyer, W. R., \& Burchard, H. (2018). Estuarine Exchange Flow Is Related to Mixing through the Salinity Variance Budget. Journal of Physical Oceanography, 48(6), 1375-1384. https://doi.org/10.1175/jpo-d-17-0266.1

MacCready, Parker, \& MacCready, P. (1999). Estuarine Adjustment to Changes in River Flow and Tidal Mixing. Journal of Physical Oceanography, 29(4), 708-726. https://doi.org/10.1175/1520-0485(1999)029<0708:EATCIR>2.0.CO;2

Manning, A. J., \& Dyer, K. R. (2007). Mass settling flux of fine sediments in Northern European estuaries: Measurements and predictions. Marine Geology, 245(1-4), 107122. https://doi.org/10.1016/j.margeo.2007.07.005

Martin, J. P., Martin, W. P., Page, W. A., Raney, W. A., \& DE Ment, J. D. (1955). Advance in Aggregation- Soil Aggregation. New York.

Mathew, R., \& Winterwerp, J. C. (2017). Surficial sediment erodibility from time-series measurements of suspended sediment concentrations: development and validation. Ocean Dynamics, 67(6), 691-712. https://doi.org/10.1007/s10236-017-1055-2

Mathew, R., \& Winterwerp, J. C. (2020). Sediment dynamics and transport regimes in a narrow microtidal estuary. Ocean Dynamics. https://doi.org/10.1007/s10236-02001345-9

Mikkelsen, O. A., \& Pejrup, M. (2000). In situ particle size spectra and density of particle aggregates in a dredging plume. Marine Geology, 170(3-4), 443-459. https://doi.org/10.1016/S0025-3227(00)00105-5

Mikkelsen, Ole A., Hill, P. S., \& Milligan, T. G. (2007). Seasonal and spatial variation of floc size, settling velocity, and density on the inner Adriatic Shelf (Italy). Continental Shelf Research, 27(3-4), 417-430. https://doi.org/10.1016/j.csr.2006.11.004

Monin, A. S., \& Obukhov, A. M. (1954). Basic laws of turbulent mixing in the surface layer of the atmosphere. Tr. Akad. Nauk SSSR Geophiz. Inst, 24(151), 163-187. Retrieved from http://mcnaughty.com/keith/papers/Monin_and_Obukhov_1954.pdf

Monismith, S. G., Burau, J. R., \& Stacey, M. T. (1996). Stratification dynamics and 
gravitational circulation in northern San Francisco Bay. San Francisco Bay: The Ecosystem. Ecosystem, J. T. Hollibaugh, Ed., (American Association for the Advancement of Science), 123-153.

Monismith, S. G., Kimmerer, W., Burau, J. R., \& Stacey, M. T. (2002). Structure and flowinduced variability of the subtidal salinity field in northern San Francisco Bay. Journal of Physical Oceanography, 32(11), 3003-3019. https://doi.org/10.1175/1520-0485(2002)032<3003:safivo>2.0.co;2

Oey, L. Y. (1984). On steady salinity distribution and circulation in partially mixed and well mixed estuaries. Journal of Physical Oceanography. https://doi.org/10.1175/1520-0485(1984)014<0629:OSSDAC>2.0.CO;2

Orton, P. M., \& Kineke, G. C. (2001). Comparing calculated and observed vertical suspended-sediment distributions from a Hudson River Estuary turbidity maximum. Estuarine, Coastal and Shelf Science, 52(3), 401-410. https://doi.org/10.1006/ecss.2000.0747

Pritchard, D. W. (1956). The Dynamic Structure of a Coastal Plain Estuary. Journal of Marine Research, 15(1), 33-42.

Prokocki, E. W. (2017). The sedimentology of bedforms to barforms within tidallyinfluenced fluvial zones (TIFZS):Lower Columbia River, OR/WS, USA, and the Lower Chehalis River, WS, USA. University of illinois at Urbana-Champaign.

Ralston, D. K., \& Geyer, W. R. (2019). Response to Channel Deepening of the Salinity Intrusion, Estuarine Circulation, and Stratification in an Urbanized Estuary. Journal of Geophysical Research: Oceans, 124(7), 4784-4802. https://doi.org/10.1029/2019JC015006

Ralston, D. K., Geyer, W. R., \& Lerczak, J. A. (2008). Subtidal salinity and velocity in the Hudson River estuary: Observations and modeling. Journal of Physical Oceanography, 38(4), 753-770. https://doi.org/10.1175/2007JPO3808.1

Rouse, H., \& Ince, S. (1957). History of hydraulics. Cover Publications, INC. New York.

Schubel J.R., \& Hirschberg D.J. (1977). Estuary Graveyards Climatic change and the important of the estuarine environment.

Schulkin, M., and H. W. M. (1962). Sound absorption in sea water. The Journal of the Acoustical Society of America. https://doi.org/10.1121/1.381574

Schumm, S. A., \& Khan, H. R. (1972). Experimental study of channel patterns. America Bulletin 83, 1755-1770.

Sequoia, S. (n.d.). Estimating the Size-Dependent Settling Velocity of Suspended Particles Using the LISST-ST. Retrieved from http://www.sequoiasci.com/

Sheng, Y. P., \& Villaret, C. (1989). Modeling the effect of suspended sediment stratifcation 
on bottom exchange processes. Journal of Geophysical Reshearch, 94(C10), 1442914444.

Simpson, J. H., Brown, J., Matthews, J., \& Allen, G. (1990). Tidal straining, density currents, and stirring in the control of estuarine stratification. Estuaries, 13(2), 125. https://doi.org/10.2307/1351581

Soar, P. J., \& Thorne, C. R. (2001). for Meandering Rivers Coastal and Hydraulics Laboratory.

Speer, P. E., \& Aubrey, D. G. (1985). A study of non-linear tidal propagation in shallow inlet/estuarine systems Part II: Theory. Estuarine, Coastal and Shelf Science, 21(2), 207-224. https://doi.org/10.1016/0272-7714(85)90097-6

Srdić-Mitrović, A. N., Mohamed, N. A., \& Fernando, H. J. S. (1999). Gravitational settling of particles through density interfaces. Journal of Fluid Mechanics, 381, 175-198. https://doi.org/10.1017/S0022112098003590

Stacey, M. T., Burau, J. R., \& Monismith, S. G. (2001). Creation of residual flows in a partially stratified estuary, 106(NO. C8), 17013-17037.

Suribabu, C. R., Sabarish, R. M., Narasimhan, R., \& Chandhru, A. R. (2011). Backwater Rise and Drag Characteristics of Bridge Piers under Sub- critical Flow Conditions. European Water, 36(2010), 27-35.

Talke, S. A. (2005). An Investigation on the hydrodynamics and sediment dynamics on an intertidal mudflat in central San Francisco Bay. Ph.D. Thesis, 301 pp., University of California-Berkeley, Berkeley, California.

Talke, S. A., De Swart, H. E., \& De Jonge, V. N. (2009). An idealized model and systematic process study of oxygen depletion in highly turbid estuaries. Estuaries and Coasts, 32(4), 602-620. https://doi.org/10.1007/s12237-009-9171-y

Talke, S. A., \& Jay, D. A. (2020). Changing Tides: The Role of Natural and Anthropogenic Factors. Annual Review of Marine Science, 12, 121-151. https://doi.org/10.1146/annurev-marine-010419-010727

Talke, S. A., Orton, P., \& Jay, D. A. (2014). Increasing storm tides in New York Harbor,1844-2013. Geophysical Research Letters, 41(9), 3149-3155. https://doi.org/10.1002/2014GL061184.Received

The Louis Berger Group, I., \& Battelle, H. (2014). Remedial Investigation Report for the Focused Feasibility Study of the Lower Eight Miles of the Lower Passaic River.

Thevenot, M. M., Prickett, T. L., \& Kraus, N. C. (1992). Tylers beach, Nirginia, dredged material plume monitoring project 27 Septemper to 4 October 1991. Washigton, DC.

Thorne, P. D., \& Hanes, D. M. (2002). A review of acoustic measurement of small-scale sediment processes. Continental Shelf Research, 22(4), 603-632. 
Thorne, P. D., \& Hardcastle, P. J. (1997). Acoustic measurements of suspended sediments in turbulent currents and comparison with in-situ samples. The Journal of the Acoustical Society of America, 101(5), 2603-2614. https://doi.org/10.1121/1.418501

Thosteson, E. D., \& Hanes, D. M. (1998). A simplified method for determining sediment size and concentration from multiple frequency acoustic backscatter measurements. The Journal of the Acoustical Society of America, 104(2), 820-830. https://doi.org/10.1121/1.423356

Topping, D. J., Wright, S. A., Griffiths, R. E., \& Dean, D. J. (2015). Physically based method for measuring suspended-sediment concentration and grain size using multifrequency arrays of single-frequency acoustic-Doppler profilers. Proceedings of the 3rd Joint Federal Interagency Conference on Sedimentation and Hydrologic Modeling, April 19-23, 834-846.

Topping, D. J., Wright, S. A., Melis, T. S., \& Rubin, D. M. (2007). High-Resolution Measurements of Suspended- Sediment Concentration and Grain Size in the Colorado River in Grand Canyon Using a Multi- Frequency Acoustic System. Proceedings of the Tenth International Symposium on River Sedimentation, 3, 330-339.

Turner, J. S. (1973). Bouyancy Effects in Fluids. Cambridge.

Uncles, R. J., Barton, M. L., \& Stephens, J. A. (1994). Seasonal variability of fine-sediment concentrations in the turbidity maximum region of the tamar estuary. Estuarine, Coastal and Shelf Science.

Uncles, R. J., Stephens, J. A., \& Smith, R. E. (2002). The dependence of estuarine turbidity on tidal intrusion length, tidal range and residence time. Continental Shelf Research, 22(11-13), 1835-1856.

Van de Kreeke, J., Day, C. M., \& Mulder, H. P. J. (1997). Tidal variations in suspended sediment concentration in the Ems estuary: Origin and resulting sediment flux. Journal of Sea Research, 38(1-2), 1-16. https://doi.org/10.1016/S13851101(97)00040-3

Van Leussen, W. (1999). The variability of settling velocities of suspended fine-grained sediment in the Ems estuary. Journal of Sea Research, 41(1-2), 109-118. https://doi.org/10.1016/S1385-1101(98)00046-X

Wall, G. R., Nystrom, E., \& Litten, S. (2006). Use of an ADCP to compute suspended sediment discharge in the tidal Hudson River, NY. Proceedings, 8th Federal Interagency Sedimentation Conference. Retrieved from http://www.gcmrc.gov/library/reports/physical/Fine_Sed/8thFISC2006/8thFISC/Ses sion 7C-2_Wall.pdf

Wang, T., Geyer, W. R., \& MacCready, P. (2017). Total Exchange Flow, Entrainment, and Diffusive Salt Flux in Estuaries. Journal of Physical Oceanography, 47(5), 1205- 
1220. https://doi.org/10.1175/jpo-d-16-0258.1

Water, P., Monitoring, C., \& Program, S. (2014). Lower Passaic River restoration project physical water column monitoring sampling program characterization summary draft Lower Passaic River study area RI / FS prepared for: Physical Water Column Monitoring Sampling Program Characterization Summary - D, (March).

Wilson, R. E. (1977). A Model of dynamic in the Lower Potomac River Estuary. Springer, 18(2), 177-187.

Woodruff, J. D., Geyer, W. R., Sommerfield, C. K., \& Driscoll, N. W. (2001). Seasonal variation of sediment deposition in the Hudson River estuary. Marine Geology, 179(1-2), 105-119. https://doi.org/10.1016/S0025-3227(01)00182-7

Xu, Z., Ma, J., Wang, H., Hu, Y., Yang, G., \& Deng, W. (2018). River discharge and saltwater intrusion level study of Yangtze River Estuary, China. Water (Switzerland), 10(6), 1-22. https://doi.org/10.3390/w10060683

Yang, S. L., Zhang, J., \& Zhu, J. (2004). Response of suspended sediment concentration to tidal dynamics at a site inside the mouth of an inlet: Jiaozhou Bay (China). Hydrology and Earth System Sciences, 8(2), 170-182. https://doi.org/10.5194/hess-8170-2004

Yuan, Y., Wei, H., Zhao, L., \& Jiang, W. (2008). Observations of sediment resuspension and settling off the mouth of Jiaozhou Bay, Yellow Sea. Continental Shelf Research, 28(19), 2630-2643. https://doi.org/10.1016/j.csr.2008.08.005

Zaredehdasht, E., Hassunizadeh, H., Mahmoodian, S. M., Aryanfar, A., Akbari, M., \& Ghasempour, M. (2011). An examination of the water erosion incursion intoo the bridge pillars through the method of slipping the pillars using the numerical model of data analysis of Fluent. Australian Journal of Basic and Applied Sciences, 5(9), 1321. 


\section{Appendix}

Variation of fine and coarse SSC with tidal cycle and velocity in Fall and Spring

Fall RM 1.4

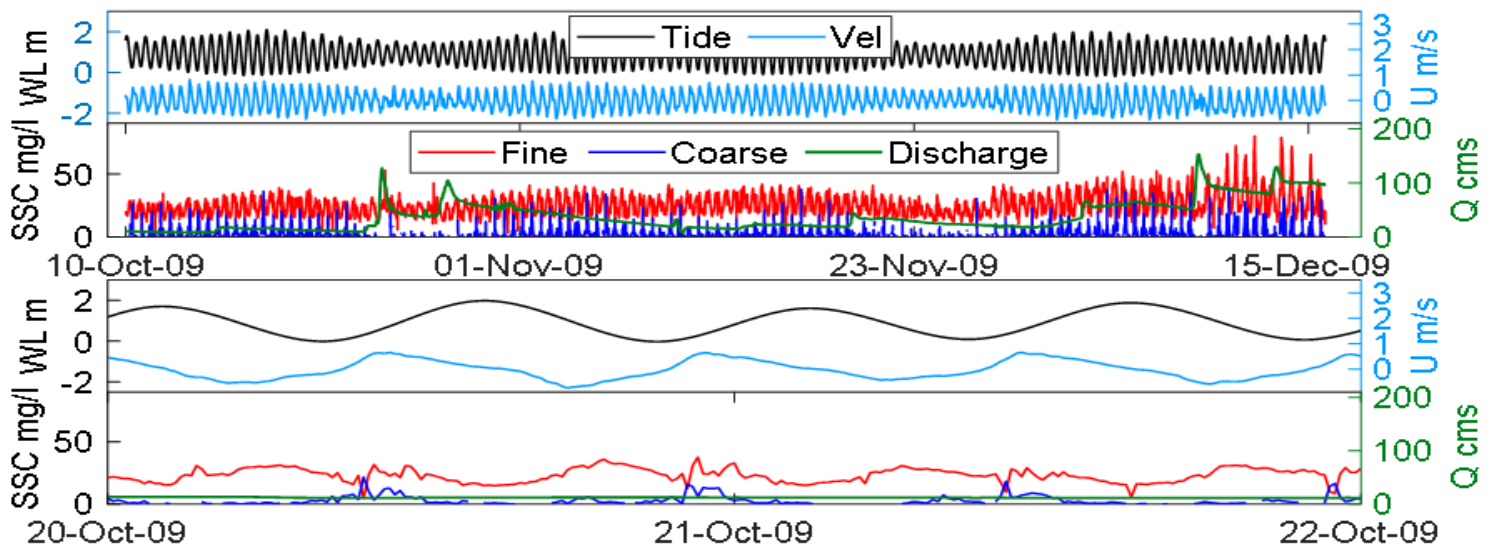

Fall RM - 4.2
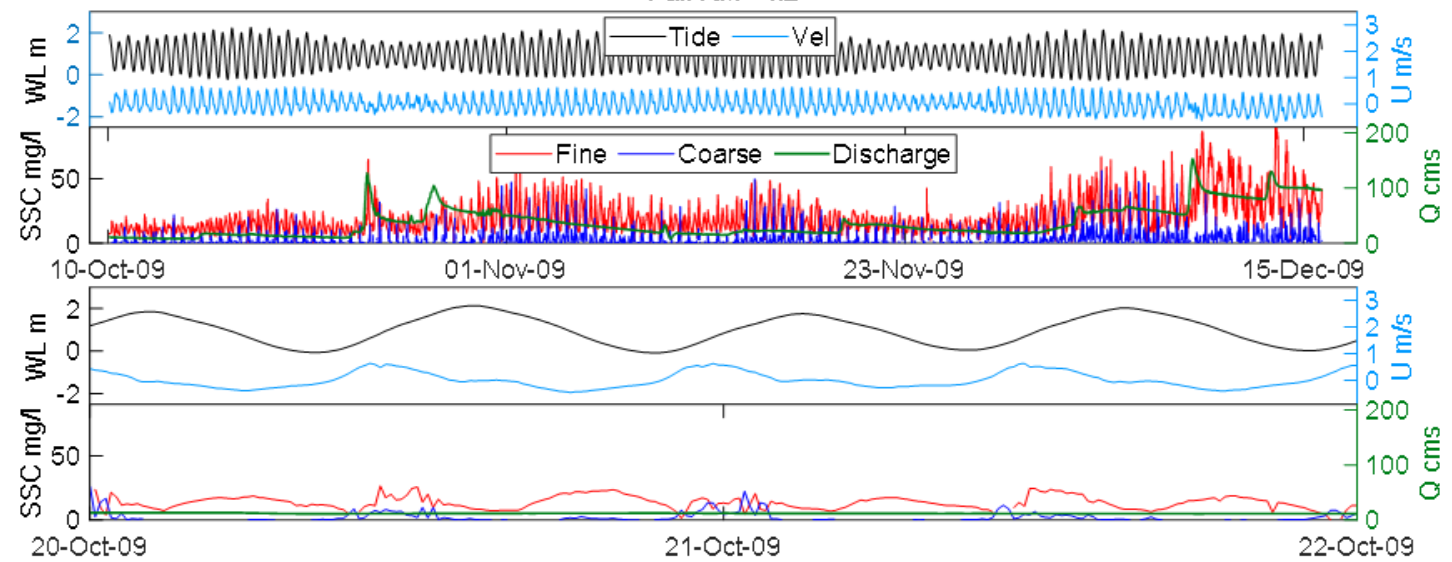

Fall RM - 6.7
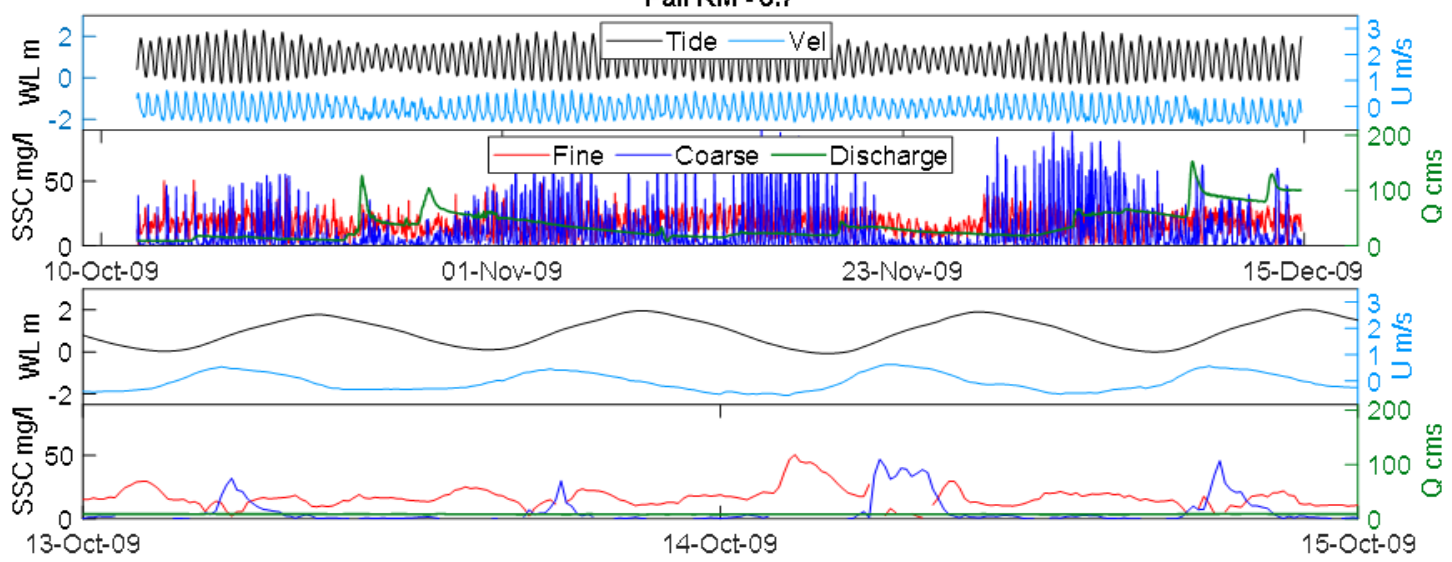
Fall RM - 10.2

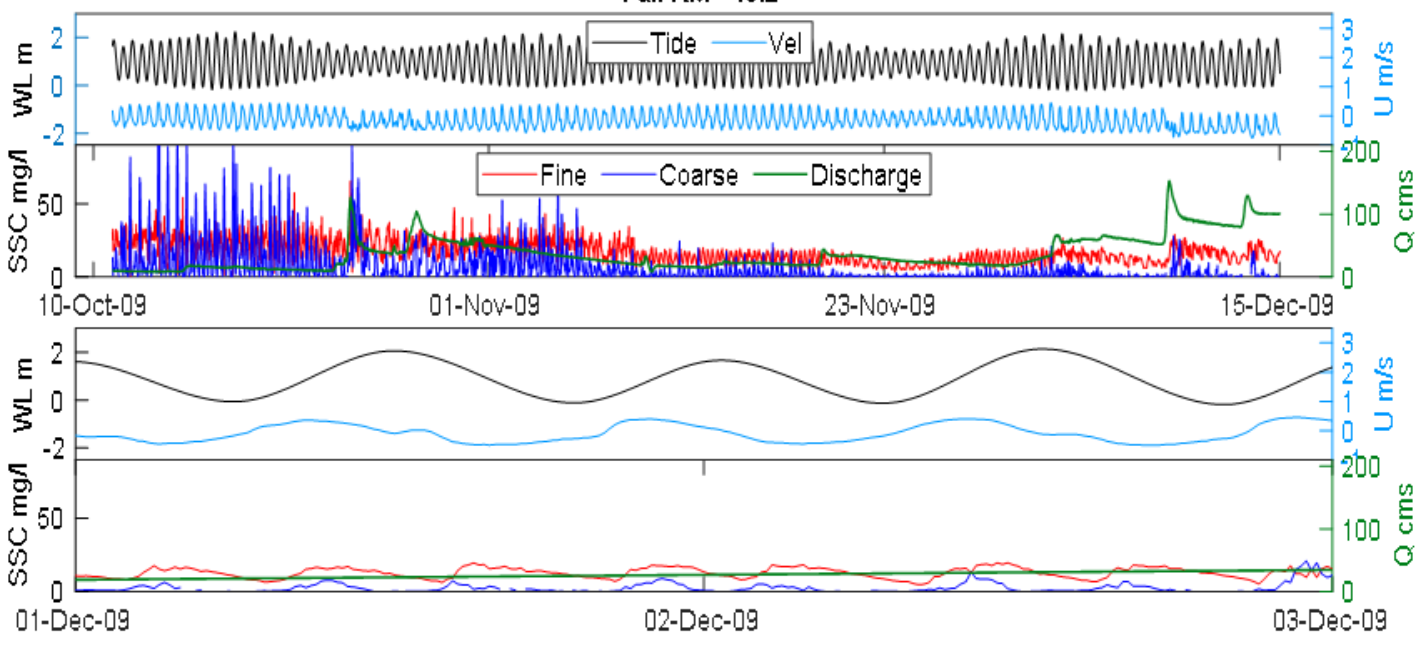

Fall RM - 13.5

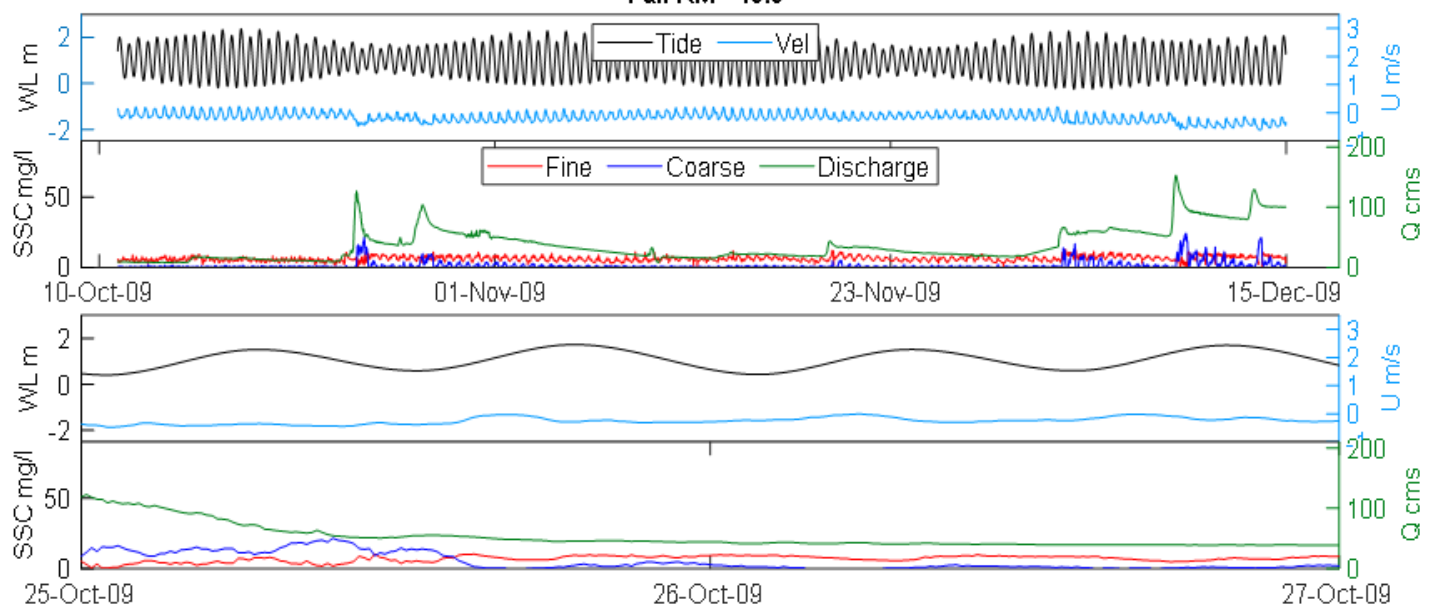


Spring RM - 1.4
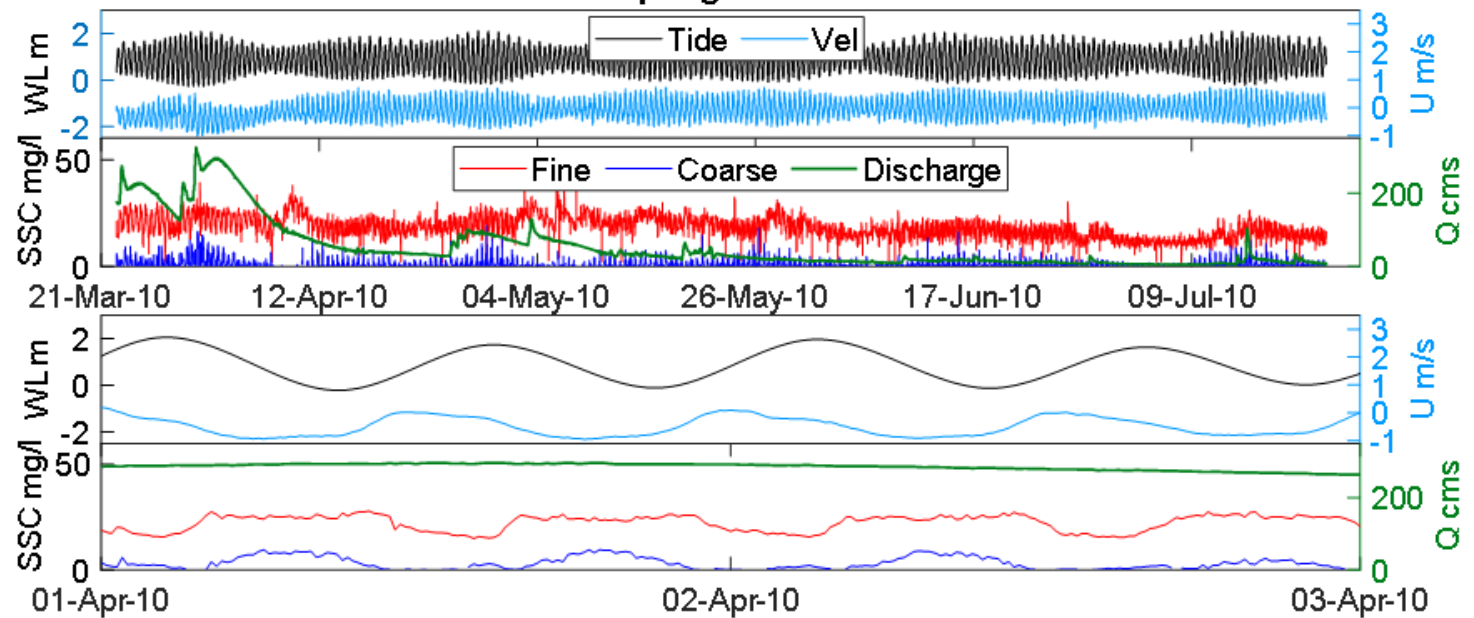

Spring RM - 4.2
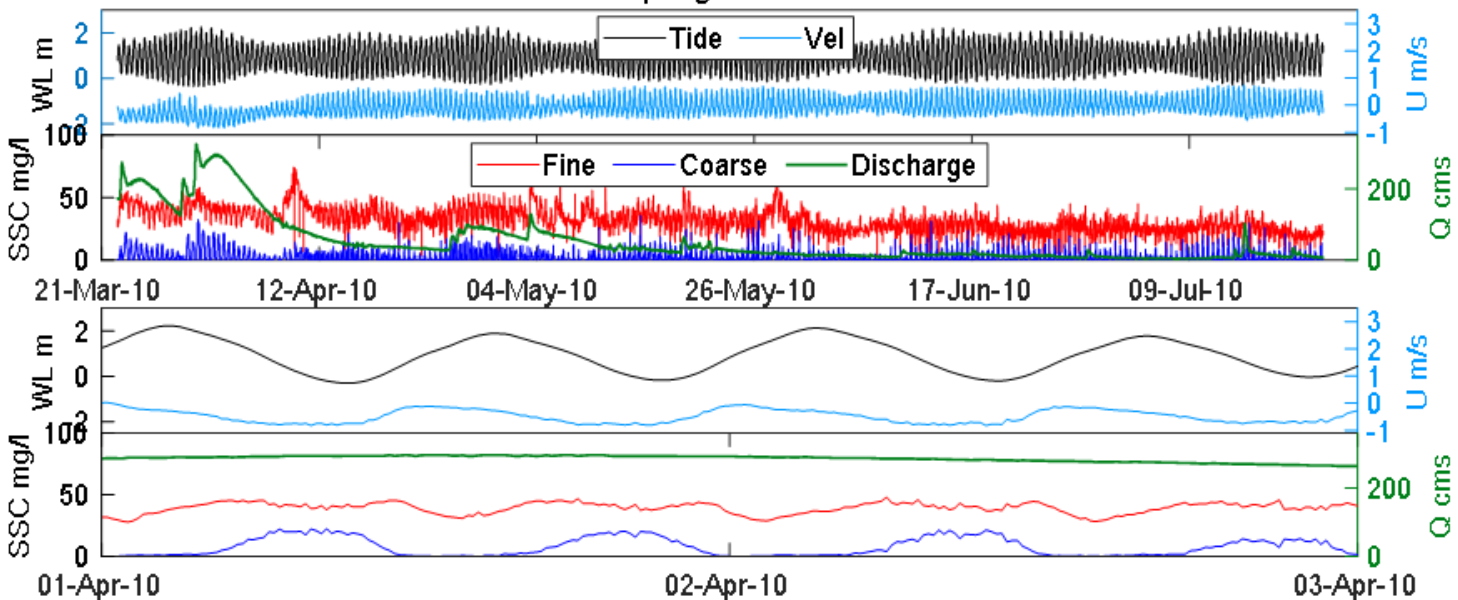

Spring RM - 6.7
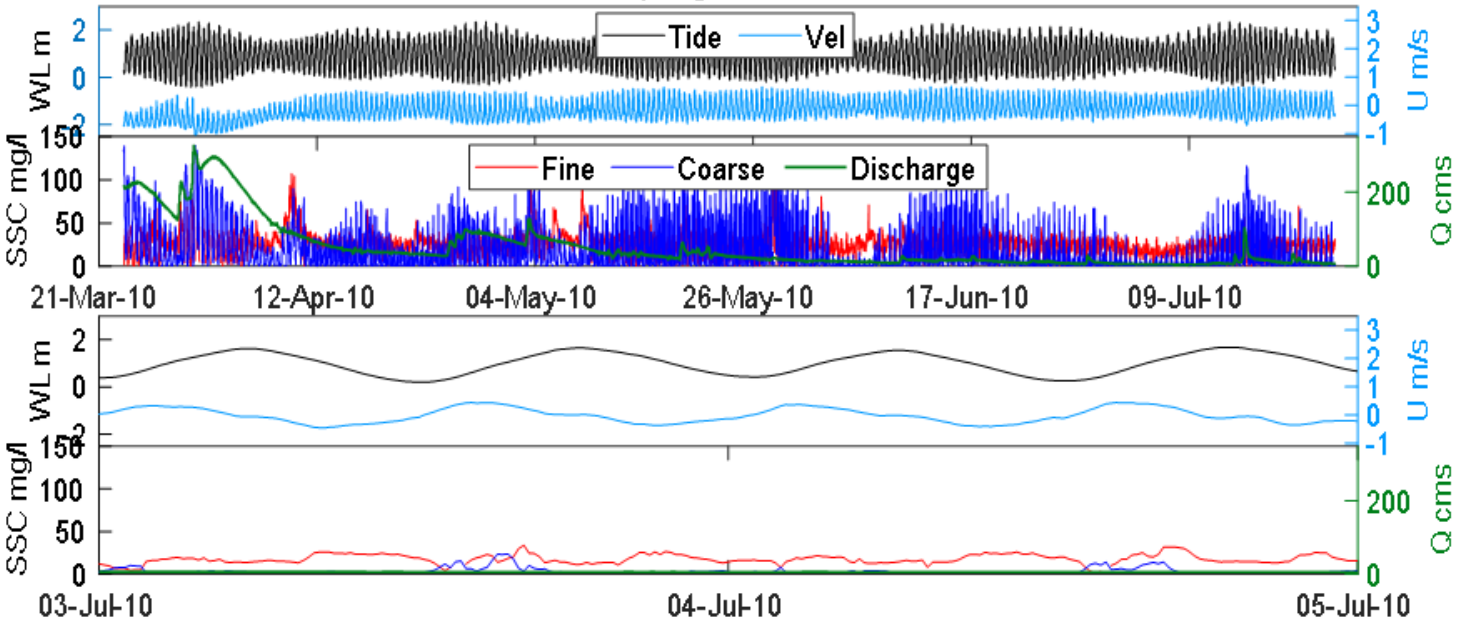
Spring RM - 10.2
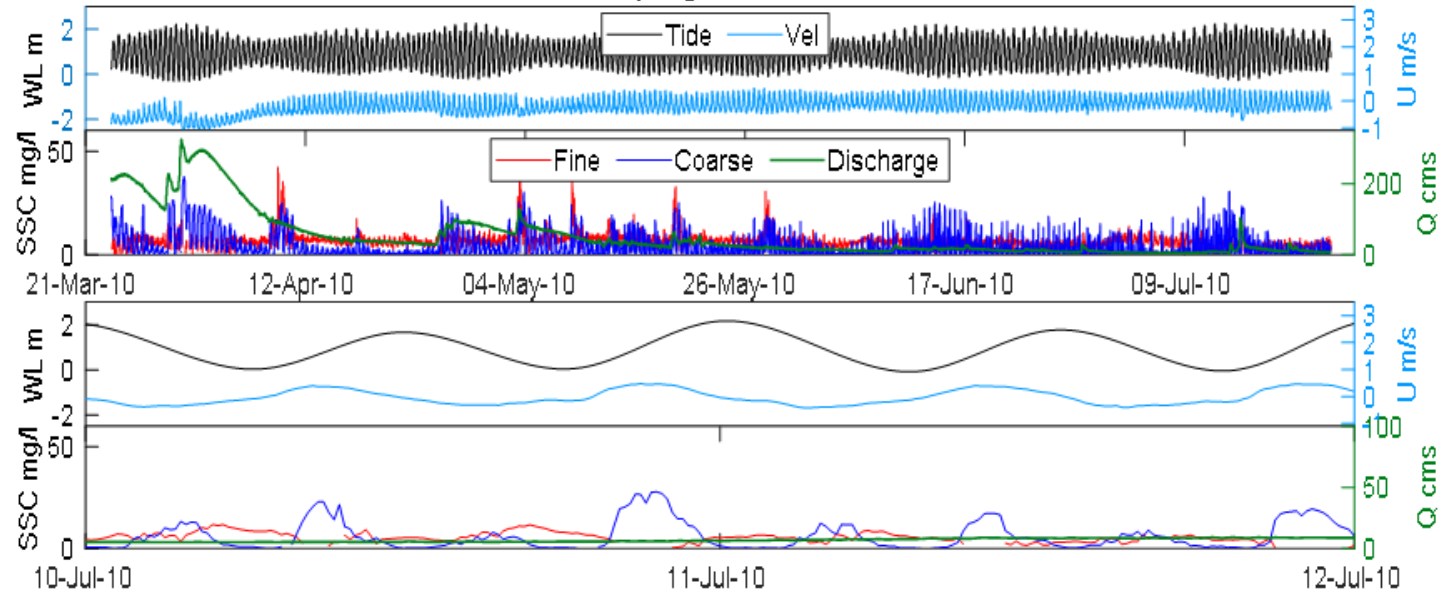

Spring RM - 13.5
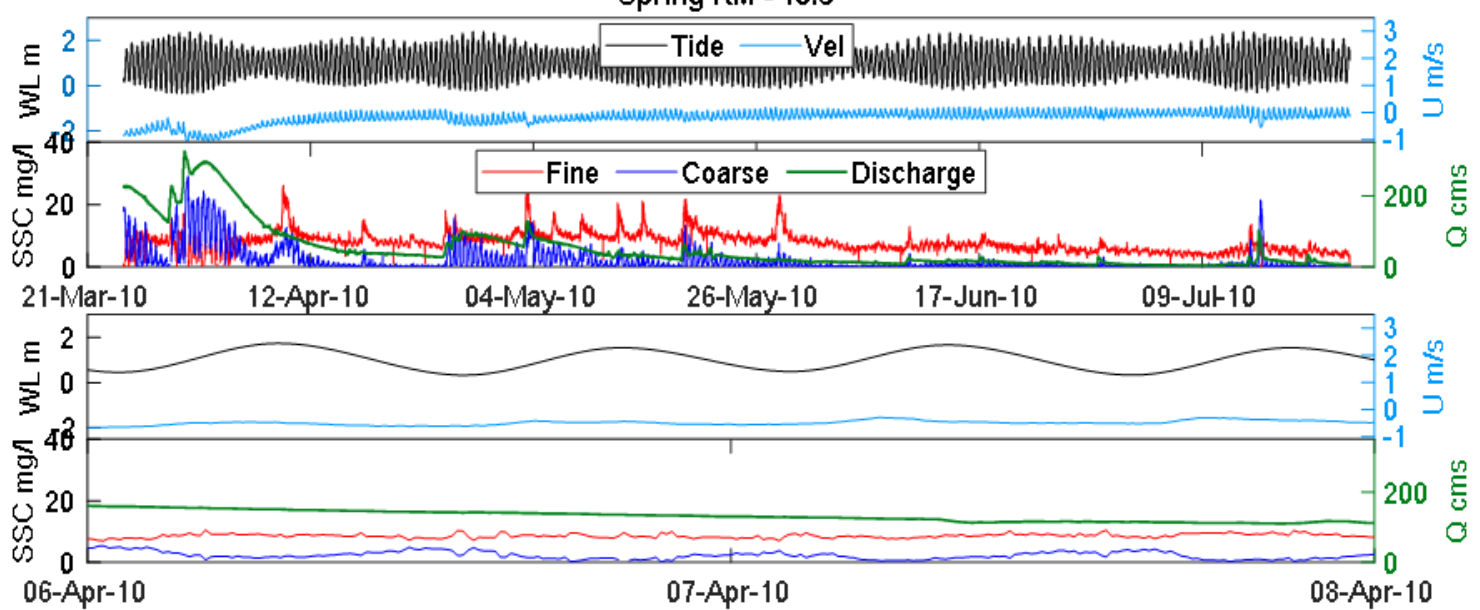